Portland State University

PDXScholar

4-30-1993

\title{
The Effects of Airline Deregulation on Airline Safety: An Econometric Analysis
}

William Charles De Jager

Portland State University

Follow this and additional works at: https://pdxscholar.library.pdx.edu/open_access_etds

Part of the Aviation Safety and Security Commons

Let us know how access to this document benefits you.

\section{Recommended Citation}

De Jager, William Charles, "The Effects of Airline Deregulation on Airline Safety: An Econometric Analysis" (1993). Dissertations and Theses. Paper 1297.

https://doi.org/10.15760/etd.1296

This Dissertation is brought to you for free and open access. It has been accepted for inclusion in Dissertations and Theses by an authorized administrator of PDXScholar. Please contact us if we can make this document more accessible: pdxscholar@pdx.edu. 
THE EFFECTS OF AIRLINE DEREGULATION ON AIRLINE SAFETY: AN ECONOMETRIC ANALYSIS

by

WILLIAM CHARLES DE JAGER

A dissertation submitted in partial fulfillment of the requirements for the degree of

DOCTOR OF PHILOSOPHY
in
SYSTEMS SCIENCE

Portland State University

(C) 1993 
TO THE OFFICE OF GRADUATE STUDIES:

The members of the committee approve the dissertation of William Charles De Jager presented April 30, 1993.
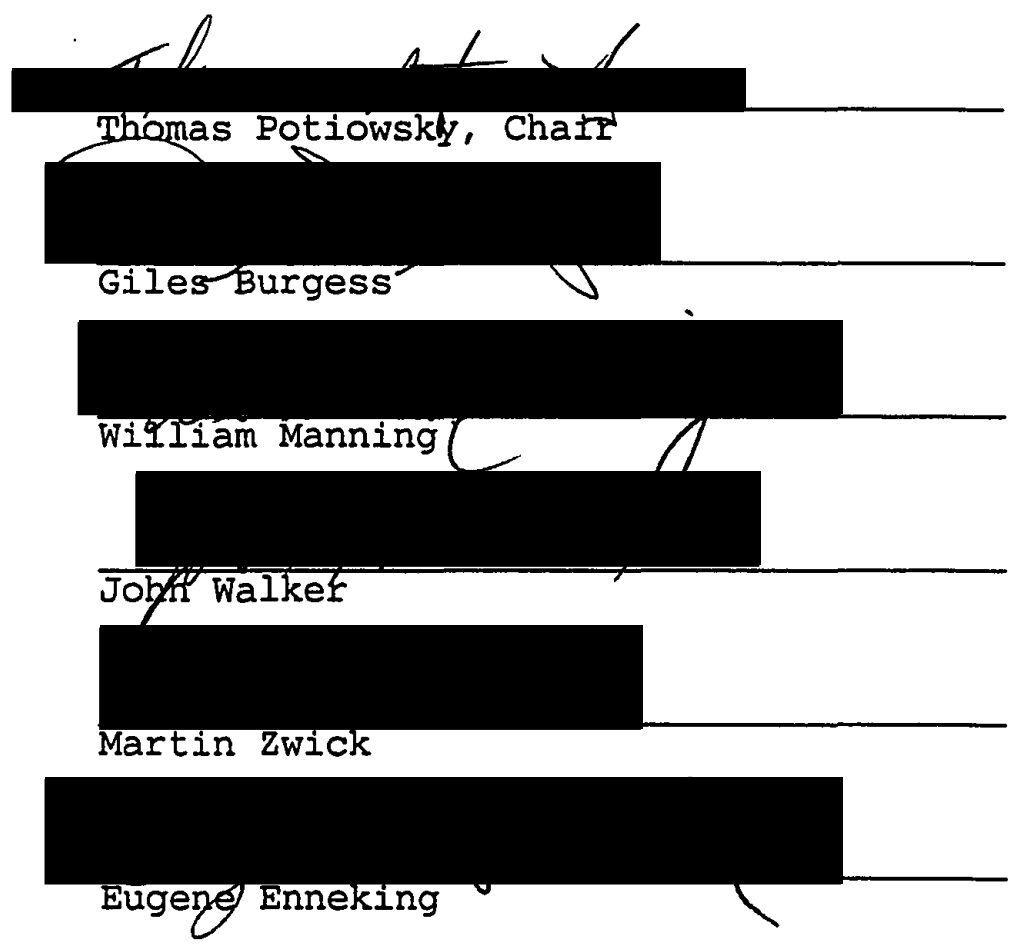

APPROVED:

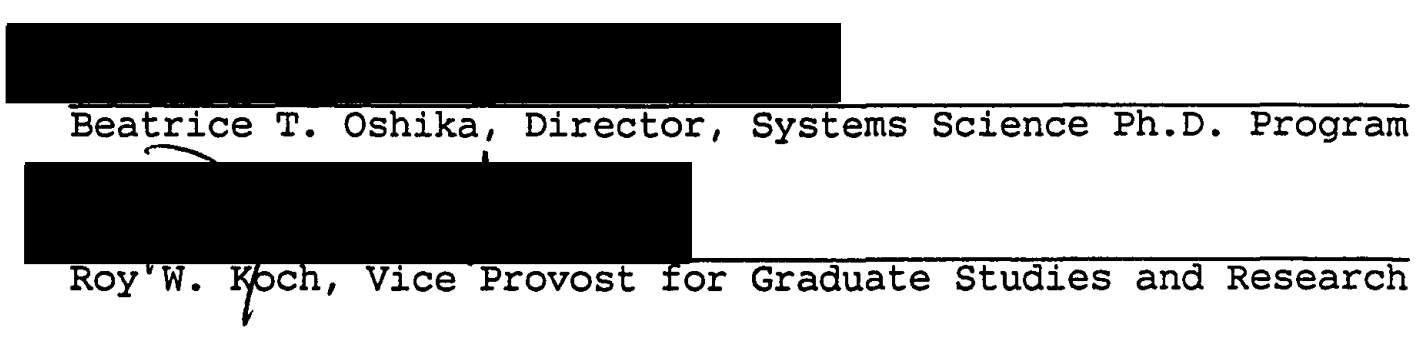


AN ABSTRACT OF THE DISSERTATION OF William Charles De Jager for the Doctor of Philosophy in Systems Science presented April 30, 1993.

Title: The Effects of Airline Deregulation on Airline Safety: an Econometric Analysis.

APPROVED BY THE MEMBERS OF THE DISSERTATION COMMITTEE:
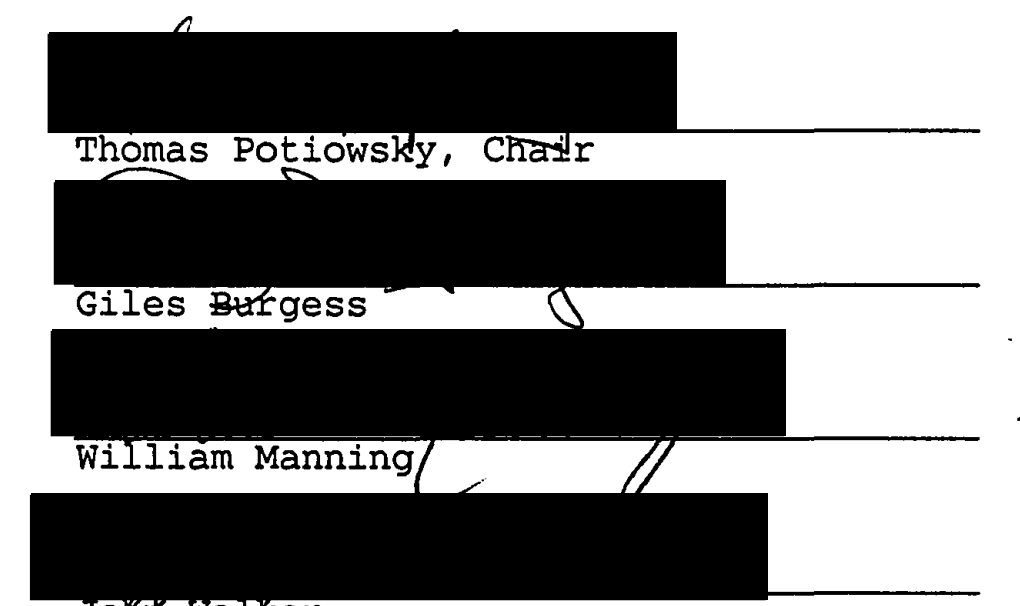

Jokn walker

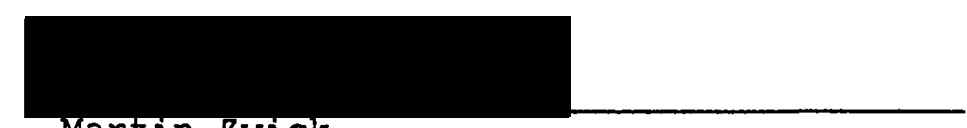
Martin 2wick

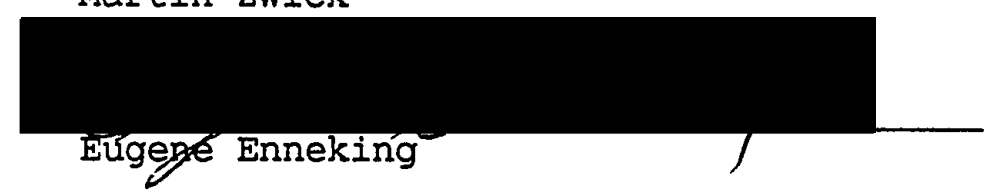

After an unfortunate series of accidents in the mid 1930 's the Air Transport Association (ATA) lobbied Congress for regulation of the industry. The ATA claimed that unfair 
competition was endangering the public safety. The Civil Aeronautics Act of 1938 created the Civil Aeronautics Board ( $C A B)$ and gave the $C A B$ the authority to regulate the industry. During the regulation era airline ridership increased and safety improved.

During the regulation period, opportunity for comparing the safety record of the regulated industry with the record of the unregulated portions of the industry was limited. The few attempts made rendered inconclusive results.

During a period of high inflation and high interest rates in the 1970 's interest in deregulating the airlines arose. With passage of the Airline Deregulation Act of 1978, interest in the effects of regulation on airline safety was renewed. More than a decade has passed since deregulation. The industry has continued to improve its safety record during the deregulation period. The question remains: "How has deregulation affected airline safety?".

In this study records of airline accidents and incidents investigated by the National Transportation Safety Board are examined. The occurrences are divided into those with causes that are under the airlines control and those that are not under their control. Those under the airlines control are regressed against time and a dummy variable for deregulation. The possible effects of airline profitability on the results, are also explored. 
The results indicate that deregulation had an adverse effect on airline safety. The effects of alternative formulations are also examined. The effect though statistically significant is small. It does not suggest the need to return to a regulated airline industry. But, it does suggest the need for additional research into the connection between airline safety and competition. 
TABLE OF CONTENTS

PAGE

IIST OF TABLES...........................

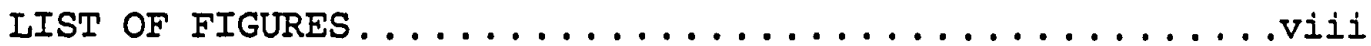

CHAPTER

I INTRODUCTION $\ldots \ldots \ldots \ldots \ldots \ldots \ldots \ldots \ldots \ldots$

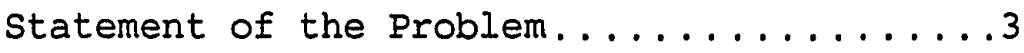

The Null Hypothesis

Significance of the study...........

II THE LITERATURE...................

The History of Regulation...........

Early History

The Regulation

Competition

Domestic Passenger Fare Investigation

The Move to Deregulation

Chairman Kahn

Deregulation. . . . . . . . . . . . . .12

Service Levels

The Market and Hub and Spoke Systems

Fares at Hubs

More on Contestability

Summary of History Section

Safety........................ 20

Airline Safety Under Regulation Non-regulatory Incentives for Safe Operation

The FAA and other Safety Considerations 
Safety in the Deregulation Era.........28

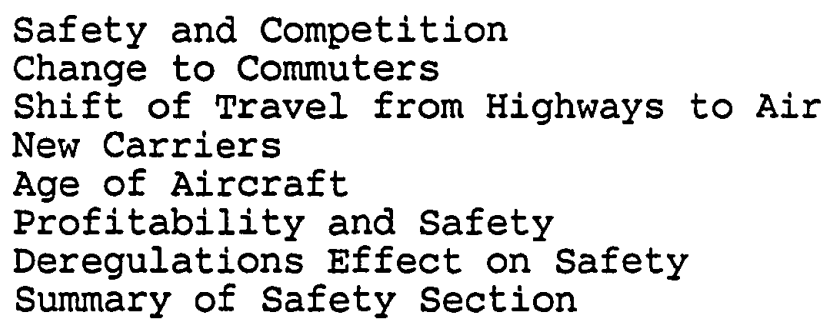

III THE MODELS AND METHODOLOGY .............36

Measuring Safety.................. 36

Government Statistics and Definitions

Safety as Measured in the Literature

Divisor

Rates Used in this Study

Time Series Models................43

Deregulation Timing

Deregulation Timing in the Literature

Time Series Model

Box-Cox Transformation

Instability in the Time Series Model

other Model Considerations

Controllable occurrences............50

Cause and Other Researchers

Criteria Used in this Analysis

Economic Health and Safety...........56

Economic Health and Safety in the Literature

Measures of Economic Well-being

Model

ANALYSIS . . . . . . . . . . . . . . . . .660

Regression Results................60

Data

Ordinary Least Squares Results 
Difficulties with the OLS Model........74

Poisson Distribution and Maximum Likelihood Regressions

The Box-Cox Model

The Cross-sectional Model

Operating Ratio.................82

Other Tests...................85

CUSUM Test

Coincidence of the Structural Change and the Date of Deregulation

Uncontrolable Occurrences............991

v CONCLUSIONS .................... 94

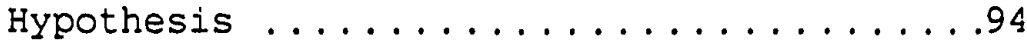

Null Hypothesis

Regression Issues

Formulation Issues

Data Problems

Other Factors and Timing

Conclusions ....................102

Other Concerns

Recommendations

SELECTED BIBLIOGRAPHY . . . . . . . . . . . . . . . . . 107

APPENDICES

A CONTROLLABLE - UNCONTROLLABLE . . . . . . . . . 117

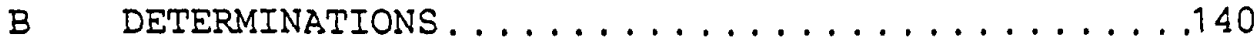

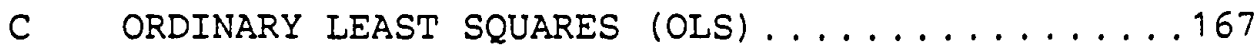

D MAXIMUM LIKELIHOOD (USING SHAZAM NON-IINEAR) . .177

E OLS USING THE SQUARE ROOT OF RATE ........187

F BOX COX PROCEDURE ............... 196 
G POOLED CROSS-SECTIONALLY HETEROSKEDASTIC AND

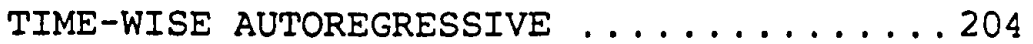

H POOLED CROSS-SECTIONALIY HETEROSKEDASTIC AND TIME-WISE AUTOREGRESSIVE WITH ZERO DUMMY .212

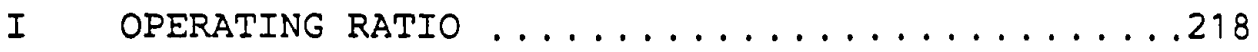

$\mathrm{J}$ OPERATING RATIO WITH ZERO DUMMY .........230

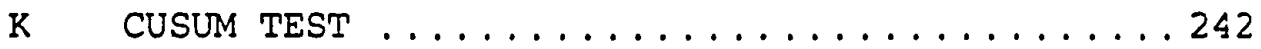

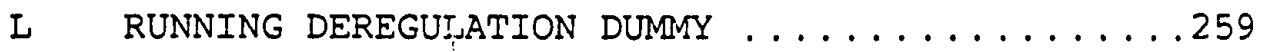

M NOT CONTROLLABLE . . . . . . . . . . . . . . . . 291

$\mathrm{N}$ POOLED CROSS-SECTIONALLY HETEROSKEDASTIC AND TIME-WISE AUTOREGRESSIVE USING REVENUE

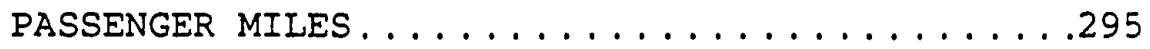




\section{LIST OF TABLES}

TABLE

PAGE

I Fatal Accidents and Total Accidents .........61

II Accidents and Incidents for Eight Airlines....662

III oLs Results........................

IV Poisson Models.....................77

v Box-Cox Results.....................79

VI Cross-sectional Results...............81

VII Operating Ratio Results................84

VIII CUSUM Results................... 86

IX Controllable Occurrences with Various Dummy Years ..........................90

$\mathrm{X}$ Occurrences Not Under the Airlines Control . . .992

XI Comparison of Regression Results........... 97 


\section{LIST OF FIGURES}

FIGURE

PAGE

1 CUSUM of squared Residuals.............88

2 Uncontrollable Occurence Rate..............93 
CHAPTER I

\section{INTRODUCTION}

Since the beginning of the history of flight, air safety has been a concern. We are told that Daedalus briefed Icarus on flight safety as part of the preflight preparation before aviation's "first" fatal accident (Bulfinch, 1947: 156).

This concern for aviation safety was part of the impetus for the regulation of the airline industry in the 1930 's. The Civil Aeronautics Act was passed in 1938 after an unfortunate series of accidents and allegations of impropriety in the airmail and airline industry. Senator Bronson cutting and four others died in the crash of a TWA Skychief in Missouri in May 1935. Wiley Post and Will Rogers died just three months later. These accidents damaged public faith in the industry and demonstrated the limitations present in aviation (Whitnah, 1966: 116).

Providing a safe airline is an expensive proposition. Preventative maintenance; redundancy of important instruments and controls; and training of aircrews, maintenance personnel, and cabin attendants are all expensive. Established airlines were right to fear price 
competition from new entries that might not be as conscious of safety. They also were right to fear the adverse public perception of the airline industry caused by aircraft accidents.

The airlines formed the Air Transport Association of America in 1936 to lobby Congress for regulation. The 1938 Act created the independent regulatory agency, the Civil Aeronautics Board $(C A B)$. The Act gave the $C A B$ authority to control entry into and exit from markets (routes). The $C A B$ was also authorized to regulate fares, to award subsidies, to control mergers and to regulate safety.

Economic regulation and the resultant limits to competition are generally viewed as advantageous by the industry being regulated. As Jordan shows in Airline Regulation in America: Effects and Imperfections, regulation protects producers by helping them form a cartel to obtain monopoly benefits. These benefits include limiting entry so that relatively fewer firms exist. Exit would also be controlled so that the market share of an exiting firm would accrue to one or more of the remaining firms. Higher price levels would be expected. The U.S. airline industry fit this description during the regulation era (Jordan, 1970: 49).

Economic regulation provided an environment that fostered growth and high safety levels in the U.S. airline industry. The domestic trunks flew 3.3 million revenue 
passenger miles (RPM) in 1945. By 1975 this had increased to 119 million RPM (Bailey, Graham and Kaplan, 1985: 204,5). This increase was accompanied by a corresponding decrease in accident rates.

During the seventies, the political climate turned in favor of deregulation of the transportation industry. Inflation was a major impetus in airline deregulation. The prevailing economic theory indicated that deregulation should have a positive effect. Deregulation was expected to result in lower fares and increases in passenger travel.

\section{STATEMENT OF THE PROBLEM}

The problem addressed by this study concerns the relationship between economic regulation of the airline industry and air safety. Specifically the study will address the effect on air safety of the Airline Deregulation Act of 1978 .

It is certain that safety has continued to improve since the beginning of the deregulation era. However, the question is, has safety improved as much as it would have if the industry were still regulated?

Note also that safety may have been over-provided during the regulation era. The appropriate economic goal for regulators is optimum safety not maximum safety. The optimum level of safety is reached when an additional increment of safety would cost more than the resulting 
benefit to society in decreased risk. This level might be different for different consumers. Given the opportunity, more risk-adverse consumers might opt for higher levels of safety than their less risk-adverse counterparts.

Transportation consumers might not be willing to pay for the "optimum" level of safety. There may be third party who are affected by the transportation consumers' decisions. Air travel consumers may not be willing to pay for these third parties' needs.

The possibility that safety was over-provided will not be addressed in this study. Nor will I try to establish what the optimum level of safety might be.

A safe airline operation is in everyone's best interest, but safety has a concomitant cost. An airline's profitability might affect its ability to cover this cost. To the extent that this is true, deregulation may have had a positive effect on airline safety. This would be the case if deregulation had a positive effect on airline profitability, and this positive effect on airline profitability had, in turn, a positive effect on safety expenditures.

The Null Hypothesis

The Null Hypothesis will be that "Economic deregulation of the airlines has had no effect on airline safety." 
SIGNIFICANCE OF THE STUDY

The cost to society of even one major aircraft accident is tremendous. Modern airliners, in addition to being very expensive, are capable of carrying several hundred passengers. The potential loss of even one aircraft with its passengers and crew is terrible. Under regulation the airline industry's safety record was a very good and improving one. There is no clear evidence that the airlines' safety record has deteriorated greatly under deregulation. There is, however, no clear, quantifiable basis for decision making concerning economic regulation and air safety. Comparing the safety record of the airline industry prior to, and since deregulation could establish this basis. The results of such an analysis could significantly enhance the knowledge of the relationship between economic regulation and safety. This would thus advance the economic theory of regulation and provide information needed to make regulatory decisions.

It should be noted here that finding a mathematical correlation between regulation/deregulation and airline safety does not establish a causal relationship. Finding a significant correlation between deregulation and safety merely establishes the possibility of a relationship. The nature of the relationship must be determined by the use of some other theoretical construct. Some possible mechanisms whereby the economic impact of deregulation might affect 
safety will be explored in this project; the main thrust is still to determine if such a correlation exists. Establishing a correlation between deregulation and safety is an important first step in establishing a relationship. If no significant correlation is found, any relationship that exists must be very slight assuming that the model is properly formulated. That is, such a relationship could be masked by factors that were not considered or it could be too small to be detected. Every effort will be made to eliminate the effects of other variables so that negative findings will indicate that any relationship remaining to be found is too small to be significant. 


\section{CHAPTER II}

THE LITERATURE

THE HISTORY OF REGULATION

\section{Early History}

The airlines formed the Air Transport Association of America in 1936 to lobby Congress for regulation. The 1938 Act created the independent regulatory agency, the Civil Aeronautics Board ( $C A B)$, with authority to regulate market entry, fares, subsidies, mergers and safety. In 1958 Congress passed the Federal Aviation Act of 1958. This act left the economic regulation of the airlines intact, and transferred safety regulation to the Federal Aviation Administration (FAA) (Bailey, Graham and Kaplan, 1985: 11).

\section{The Regulation}

The Civil Aeronautics Board's economic regulation of the industry was imposed, in the main, through its authority to regulate entry and exit and its authority to regulate fares.

The Board during the period from its formation until the deregulation act of 1978 did not award a single major 
route to a new industry entrant (Bailey, Graham and Kaplan, 1985: 13).

The only way to exit from the industry was through merger with an existing airline. Merger with a struggling line was a way for a healthy airline to expand into new markets (Bailey, Graham and Kaplan, 1985: 13).

In addition to controlling the entry of new airlines into the industry, the Board controlled entry and exit from specific markets by existing airlines. The Board limited service to markets to limit competition.

The Board also, in many cases, prohibited nonstop service by local service airlines. In the sixties and later, it sometimes relaxed these prohibitions where the competition with the trunk was deemed not to be excessive. This was done to improve the financial position of the local service airlines and hence to control subsidy costs (Bailey, Graham and Kaplan, 1985: 13).

The Board also regulated exit from markets and required airlines to provide adequate service to cities on their certificates.

The Board regulated air fares with respect to average cost of the airlines. An airline with high costs would drive up the average cost for the industry, and hence the fares. In this way the high-cost airline would be able to recapture some of the additional cost. This was most important for large airlines. The incentive was especially 
small to control labor costs. A new union contract would likely establish an industry standard that set costs for all airlines and resulted in increased fares to cover the cost. A strike, however, would mean losses that could not be recovered and might even entail a long-term loss of market share.

The Board's route entry policy had the effect of protecting the airlines from efficient, new entries into a market (Bailey, Graham and Kaplan, 1985: 96). In addition, the $C A B$ used its route authority to aid those airlines which were fiscally the weakest. The Board often awarded lucrative new routes to those lines most in need of financial help (Bailey, Graham and Kaplan, 1985: 13).

\section{Competition}

The Board did not regulate airline schedules. Nor did it regulate the type or size of aircraft used. This meant that the main way to compete was through service. Airlines were free to decide when and how to serve a city pair. An airline could serve a route with a nonstop, connecting or through flight. The type of aircraft used proved to be an important way to differentiate product. As the technology improved, airlines improved their equipment, first with pressurized cabins, then with jet service and later with wide-body service. 
Domestic Passenger Fare Investigation

In January of 1970, the CAB began the Domestic

Passenger Fare Investigation. During the course of the investigation, the $\mathrm{CAB}$ found that higher fares encouraged higher capacity on a route. The higher capacity resulted in lower load factors and increased costs (Load factor, as used here, is the ratio of paying passengers to seats available. It is generally expressed as a percent.) At the same time, lower fares caused lower capacity and higher load factors. The Board's response was to establish standard seating densities and to encourage the airlines to reduce capacity on routes with excess capacity.

In addition, the $C A B$ found a number of discount fares to be discriminatory and required them to be eliminated. In this climate of increasingly pervasive regulation and concern over inflation the time seemed right to consider regulatory reform (Oster et al., 1981: 41).

The differential pricing that the Board found discriminatory, Frank calls efficient (Frank, 1983: 238). The airlines enjoy important economies of scale. The marginal cost of adding another passenger to a partially loaded aircraft is much below the average cost per passenger. To price at the average price denies the pricesensitive passenger the flight and the airline the revenue. If the airline can differentiate between the price-sensitive 
and non-price-sensitive passengers and charge accordingly, they increase market efficiency (Frank, 1983: 238).

\section{The Move to Deregulation}

By 1975, President Ford's administration proposed legislation to remove rate control from the CAB. At the same time Senator Kennedy's Senate Judiciary Subcommittee on the $C A B$ was gaining a great deal of publicity claiming that $C A B$ regulation of the airline industry had resulted in much higher fares than would otherwise be the case.

In March of 1975, Board Chairman Robert Timm, a proponent of regulation and capacity limitations, was replaced by John Robson. The Board soon began to liberalize the rules governing charter flights and ended the route moratorium in effect since 1969. Airline officials opposed deregulation, though most believed that a gradual reduction in price controls would not be harmful. The industry seemed to most fear the loss of route-entry regulation.

The industry stance was not united, however. Antideregulation forces took another blow in late 1975 when United Airlines stated that it would not oppose deregulation.

\section{Chairman Kahn}

In 1977, President Carter appointed Alfred Kahn as chairman of the CAB. Kahn was the first chairman to come out in favor of deregulation prior to his appointment. By 
the time of his appointment, reform had gained considerable momentum. Outgoing chairman Robson came out in favor of deregulation. Continental and Airwest joined United in favor of deregulation and several diverse political groups also supported regulatory reform or deregulation (Oster et al., 1981: 47).

Under Chairman Kahn air fare restrictions were reduced. By April 1978 approval was not required for up to 50 percent fare reductions. Route authority was also liberalized. By 1978, opponents of a route authorization needed to show cause why a new route authorization should not be granted. The fact that a competitor was already established on the route and objected to the entry of another airline was not sufficient to prevent the authorization as in the past.

In October 1978, President Carter signed the Airline Deregulation Act into law. The act provided for a phaseout of airline regulation over a five-year period beginning in January 1979. The $C A B$ was to be reguired to approve some new routes each year. It lost all route authority after 1981 and rate authority after January 1983. In fact, deregulation began almost immediately with the CAB granting approval to all requested route and fare changes.

\section{DEREGULATION}

The prospect of deregulation was greeted by predictions of bankruptcies, of decreased fares, of increased demand, of 
increased profitability (for at least the largest lines) and of declining service, especially in the smaller cities. Some observers also predicted a decrease in safety. Not all of these predictions have been shown to be accurate. While the darkest predictions of widespread bankruptcies proved to be too gloomy, there have been bankruptcies. Under the $C A B^{\prime}$ 's regulation there were no bankruptcies. Exit from the industry was by merger only.

Increased competition has caused decreases in air fares. The decreases in air fares resulted in remarkable increases in both traffic and load factors. Additionally, the deregulated airlines were able to structure fares to target price sensitive portions of the market. Since deregulation, an incremental decrease in average fare causes a larger increase in traffic volume (Meyer, 1980: 71). Therefore, the airlines' profitability has increased as well.

In their study "Assessment of Efficiency Effects of Airline Deregulation" Caves, et al. compared U.S. air carriers with non-U.S. airlines that had not been deregulated. They concluded that U.S. airlines improved their relative position in growth of total factor productivity versus the regulated non-U.S. carriers (Caves, Christensen, Tretheway and Windle, 1987: 304).

There were some losers in the deregulation aftermath. Labor lost its ability to command premium wages. The loss 
was not complete in that increased demand for air travel increased the demand for airline pilots. This did leave a somewhat odd legacy, in that demand for pilots was going up at the same time that wages for pilots were going down. Under economic regulation airline labor unions were strong and wages were relatively high. The time period since deregulation has been characterized by wage and work rules concessions, new non-union carriers and "B scales." "B scales" were instituted so that newly hired employees are hired under a different, less lucrative wage structure than previously hired employees. This is consistent with the increased level of competition under deregulation.

Since deregulation there has been an increase in the number of mergers and also in the number of new airlines being formed. The previously unregulated intrastate airlines have taken advantage of their new mandate to enter interstate service. In the two years after deregulation Air Florida, Pacific Southwest Airlines, Southwest Airlines and Air California, all former intrastate lines, entered the interstate market.

New commuter lines have also sprung up to offer service in smaller markets, many of which were abandoned by the trunk lines. Many of these commuter lines eventually formed marketing alliances with the major airlines. Most of the larger commuters now belong to such an alliance (Oster and Zorn, 1989: 132). 
People Express was an airline that demonstrated the changes brought by deregulation. People Express inaugurated no frills, low cost trans-Atlantic flights and then faded from the scene when other airlines began to compete.

\section{Service Levels}

The service to some smaller communities has declined, but the picture is not all bleak. There were more non-hub locales where the total number of flights increased than locales where the number declined, in the period May 1978 to June 1979. (Non-hubs are the smallest airports in the FAA's airport classification system, i.e. those that enplane fewer than 115,000 passengers per year.) However, this increase of flights to non-hubs was small and not evenly distributed. Some non-hub airports lost all of their service while others gained (Meyer, 1980: 27).

The nature of flights into and out of non-hubs changed, also. There were substantial increases in flights from nonhubs to hubs and decreases in flights from non-hubs to other non-hubs. Both Oster and Meyer argue that this change in the nature of the service to small cities has made it more useful to the consumer. They argue that flights to a hub where one will likely find connections to many other places are more useful than flights to another non-hub where air service is also poor. The result is much better service 
than indicated by the small growth in flights into and out from non-hubs (Oster, 1980: 109) (Meyer, 1980: 76).

Huston and Butler examined service levels before and after the Ozark-TWA and the Northwest-Republic mergers. For their analysis they first compared the number of flights per day to cities served from three major hubs. These hubs were St. Louis in the case of TWA-Ozark, and Detroit and Minneapolis in the case of Northwest-Republic. They also looked at the number of cities served from the major hubs. They found that the number of flights from each served city to the hub decreased. This decrease averaged one flight per day. They also found that a total of 25 more cities were served from these hubs, after the mergers (Huston and Butler, 1988: 205).

However, Huston and Butler also argued that the number of flights into a city is not the proper measure of service level since the advent of hub and spoke routing. They argued that the proper measure was the number of cities that can be reached in a day, by traveling through the hub. The loss of a flight into a hub does not decrease the public welfare as much as additional destinations increases the public welfare (Huston and Butler, 1988: 207).

The Market and Hub and Spoke Systems

Hub and spoke systems allows carriers to fill a higher proportion of their seats. It also allows them to increase 
the number of nonstop routes between their hubs and other destinations. This has decreased the competition at hub airports (Borenstein, 1992: 49).

Hub and spoke operations do require that passengers change planes more often than traditional routing systems. The increased flights into hubs do, however, allow more flights to be completed without a change of airline (Borenstein, 1992: 49).

Fares at Hubs

Huston and Butler compared fares at St. Louis before and after the TWA-Ozark merger. That merger gave TWA an 82 percent share of the traffic at st. Louis. Huston and Butler refer to hub airports that are dominated by a single carrier like this, fortress hubs (Huston and Butler, 1988: 203). They found an average increase in fares of 21 percent at St. Louis compared to a 3.9 percent change in the average airline fares for the same period (Huston and Butler, 1988: 210).

Borenstein found that the dominant airline at an airport attracts a disproportionate share of the passengers who originate there. He also found that prices at Minneapolis increased faster than the national average after the Northwest-Republic merger as did the prices at St. Louis after the TWA-Ozark merger (Borenstein, 1992: 56). 
First Huston and Butler, and later, Borenstein argued that fortress hubs provide the dominant airline a stronger position there that makes competition from other airlines ineffective (Huston and Butler, 1988: 211) (Borenstein, 1992: 54). Certainly most flights by one airline into another's fortress hub are direct flights from its own hubs.

More on Contestability

Bailey and Panzer argued that airline markets were contestable*. They held that there were few barriers to entry into a new market. Capital costs are not sunk costs because they are mobile and can be applied to other markets if conditions change. Further, they argued that a carrier that served both ends of a city pair could readily respond to an opportunity in such a market (Bailey and Panzer, 1981: 128). More recent experience indicates that hub markets are not as contestable as Bailey and Panzer thought.

Morrison and Winston conclude that airline markets are not perfectly contestable, but that they are imperfectly contestable. They regressed the price per seat mile on the number of competitors in a market. They found significant differences in the price per seat mile when there were several competitors as compared to only one or two airlines

* I use contestable in the broader sense here. I use contestable to describe a market where the threat of competition has some effect on market behavior. Perfectly contestable is used to describe a market where a single potential competitor is sufficient threat to prevent the taking of monopoly rents. 
flying the route (Morrison and winston, 1987: 61). In a perfectly contestable market, where there were no entry costs, additional competitors should make no difference in the price of the service. The presence of potential competitors would be sufficient to keep the prices down. That a market is not perfectly contestable does not mean that potential competitors don't have an effect. Morrison and Winston also found that potential competitors could substitute for competitors, if imperfectly. They found that it took approximately three potential competitors to have the effect of one actual competitor. They defined potential competitors as airlines that served at least one end of a city pair market. Because potential competitors did increase travelers' welfare, albeit not as much as actual competitors, they concluded that airline markets were imperfectly contestable (Morrison and Winston, 1987: 59).

Summary of History Section

The nature of the economic pressures on the airlines changed with deregulation. These changes in economic pressures caused changes in the way the airline industry operates. Some of these changes were not universally expected. Others, like the hub and spoke routing system were not mentioned in the economic literature at all prior to deregulation. 
The question remains: "How have these changes in economics and the changes in operating procedures affected airline safety?"

\section{SAFETY}

Concern for airline safety was a major cause of airline regulation in 1938. After the war years, the fifties and sixties were characterized by expansion of the air travel industry and by increased levels of safety. Very little was published about airline safety in the economic literature during this period.

Airline safety has become a hot topic since airline deregulation. When it became clear that airline regulation would change, there were a number of monographs published expressing concern over the likely state of airline safety under deregulation. As the data on airline safety under deregulation became available, several empirical studies were published.

\section{Airline Safety under Regulation}

During the regulation era, there were ways to compare the effects of regulation on airline safety. One could compare the safety record of the major airlines with the intrastate carriers. One could also compare the majors with the commuter airlines. 
In his book Airline Regulation in America; Effects and Imperfections, Jordan compares passenger fatality rates of the California intrastate carriers and the rates of the larger trunk and local service airlines, over the same routes (Jordan, 1970: 50). The low-cost intrastate carriers were not subject to economic regulation by the civil Aeronautics Board. They were subject, only, to the much less restrictive California state regulations. All carriers operated under essentially the identical safety regulations of the FAA (CAA prior to 1958).

During the period 1949 to 1965 the accident rate for the California intrastate carriers was 2.67 per 100 million Revenue Passenger Miles (RPM) compared to 0.45 and 0.92 per 100 million RPM for the trunk and local service carriers respectively (Jordan, 1970: 49). (Revenue passenger miles are the number of paying passengers times the number of miles flown and are related to seat miles by load factor.) Jordan points out a difficulty interpreting these figures. The intrastate carrier accident rate reflects only two fatal accidents by the California intrastate carriers during this period. He further notes that one of these accidents was an accident by Paradise Airlines, an airline that accounted for 93 percent of the California intrastate carriers' fatalities while accounting for less than one half of one percent of all RPM carried by California intrastate carriers. If this airline is left out of the statistics, the fatalities per 
100 million RPM of the remaining carriers is 0.19 , which is lower than either the trunk or local service carriers. If one eliminates the least successful carrier from the group of trunks or local carriers, neither of those fatality rates would be reduced as low as 0.19 (Jordan, 1970: 51). Jordan's analysis emphasizes the difficulty of "measuring" safety by comparing accident or fatality rates, due to the paucity of occurrences.

Comparing accident rates of the certified carriers with the accident rates of the air taxi services or commuter lines might seem like a good way to assess the effects of regulation on air safety. And, indeed, the regulated airlines have a much better safety record. However, the comparison is one of apples to oranges. First, air taxi and commuter services fly much shorter distances increasing the number of takeoffs and landings per revenue mile. As accidents are much more apt to happen in the takeoff and landing phase than while cruising at altitude, this comparison is inherently unfair (Oster and zorn, 1983: 7). Additionally, comparisons of accidents per RPM are unfair because the smaller size of the aircraft flown by the commuters biases that calculation. If we look at accidents per operation we find that the accident rate for commuter lines is very near that of the major airlines, but it is still significantly higher (Oster and Zorn, 1983: 7). Even this comparison is not conclusive because of the different 
types of equipment used by the different operations. The jet powered aircraft used by all the regulated airlines are simply more reliable than the smaller reciprocating engine aircraft used by some commuters. Jet engines themselves are inherently more reliable than reciprocating engines. Also jet powered aircraft because of their higher cruise altitudes and increased rates of climb spend less time exposed to severe weather and mid-air collision potential than their reciprocating engine counterparts.

Also the type of operation itself affects the safety record. Because the commuters by their very nature use smaller, less used airports they do not have the benefits of the best facilities. At these smaller airports the runways are shorter and the ground-based navigation and approach facilities are not as good. Often the weather information is poorer and radar approach control facilities may be poorer or lacking altogether. However, weather and approach minimums are higher for these poorer equipped airports and should compensate for the lack of technical equipment, at least from a safety, if not from a convenience, standpoint. Oster and zorn did a study of commuter safety during the seventies. In this study they stated that carrier size was an important determinant in commuter airline safety. In the study they found that commuters above a certain minimum size had a better safety record than smaller lines. The safety record for the larger commuter lines was comparable 
to the majors when measured in terms of accidents per operation. (Oster and Zorn, 1983: 8).

\section{Non-regulatory Incentives for Safe Operation}

Regulatory forces are not the only forces that push for safe operation of an airline. Most airline employees could be expected to have a personal stake in the safe operation of the airline. Pilots have an especially strong incentive as their own safety is directly affected by their actions to maintain a safe operation. Besides the personal incentives of the employees there are also possible market incentives to run a safe airline operation.

Paul Biederman in his book, The U.S. Airline Industry: End of an Era, calls safety a largely discounted but potential source of product differentiation for the airlines. However, while consumers are concerned over airline safety, they generally fail to see differences in safety among the certified carriers. He further states that while the $C A B$ certified carriers have shown a better safety record than the charter operators, the gap is reduced as the supplemental airlines obtain newer equipment (Biederman, 1982: 53).

Andrew Chalk likens the market forces on aircraft manufacturers to classic lemon equilibrium, where the consumer is unable to determine which aircraft are good or bad (Chalk, 1986: 44). While the consumer is unable to 
enforce airline safety standards through purchase decisions, Chalk demonstrates that at least in the case of the DC-10 crash on May 25, 1979 the capital market did provide a market incentive to invest in safety.

Chalk studied the stock market's response to McDonnell Douglas at the time of the accident, by correlating newspaper accounts of the accident with McDonnell Douglas stock price movements. He found a $\$ 200$ million decline in McDonnell Douglas shareholder wealth associated with the accident (Chalk, 1986: 44).

Karels criticizes Chalk's study. Since the accident was blamed on faulty maintenance practices by American Airlines, Karels argues that there should have been no effect on MCDonnell Douglas stock. Further, he states that by extension of Chalk's argument, American Airlines should have been affected by a loss of shareholder wealth. Karels finds no such loss for American and in fact the losses he finds for McDonnell Douglas are much smaller than those Chalk finds and are not significant (Karels, 1989: 353). I find Karels' arguments weak. At the time of the accident and for most of the period of Chalk's study, most observers expected McDonnell Douglas to be blamed for the accident. The newspapers explained in great detail all of the difficulties that McDonnell Douglas had with the DC-10. They hardly mentioned the issue of American's maintenance practices. They even implied, in some cases, that McDonnell 
Douglas's concern about American's maintenance practices was simple misdirection on their part.

Barnett and Lo Faso performed another study of the aftermath of the 1979 DC-10 crash. They looked for passenger avoidance of the DC-10. They found no evidence of avoidance (Barnett and Lo Faso, 1983: 1225).

After the 1989 crash of a DC-10, Barnett et al. found some resistance to the $\mathrm{DC}-10$. The effect was short-lived and began to fade within one month (Barnett, Menighetti and Prete, 1992: 46).

Borenstein and zimmerman looked for market incentives for the safe operation of commercial airlines. For their study they used accidents with at least one on-board fatality. They found little or no effect on consumer response prior to deregulation and only weak response after deregulation. They also looked for changes in airline equity associated with accidents. They concluded that overall the changes in equity value were lower than the social costs of the accidents. For their sample they found an average equity loss of $\$ 4.5$ million associated with an average of over forty fatalities. In addition to the loss of life, most accidents involved the total destruction of the aircraft (Borenstein and Zimmerman, 1988: 933). 
The FAA and Other Safety Considerations

Economic and safety regulation of the airlines were separated by the Federal Aviation Act of 1958. The Airline Deregulation Act of 1978 did not change the FAA's role in regulating airline safety.

Some observers like John Godson, who has written a number of books condemning the airlines' safety record, maintain that the industry has a history of under-regulating safety. Godson in his books (Unsafe at any Height, Runway, The Rise and Fall of the DC- 10, etc.) is especially hard on the FAA and claims that the agency has neither the will nor the expertise to regulate airline safety. He is especially incensed at what he considers the FAA's unwillingness to make the tough decisions required to ensure airline passenger safety (Godson, 1973: 135).

Captain " $\mathrm{X}$," the author of the book Unfriendly Skies: Revelations of a Deregulated Airline Pilot, maintains that increased competitive pressure brought on by deregulation has adversely affected safety ("X" and Dodson, 1989: 171).

Safety is determined not only by the economic environment, i.e. competition, regulation, etc., but also by the level of government expenditure on safety enforcement and infrastructure (airports, air traffic control, weather forecasting service, etc.). The optimum level of expenditure on safety enforcement and infrastructure may be 
different post deregulation compared to during regulation (Moses and Savage, 1989: 315).

To the extent that economic deregulation is the cause of increased airline traffic it should be accompanied by increased expenditures on surveillance and infrastructure. Decreases in safety level that are attributable to a failure to make these expenditures are different than decreases that are attributable to changes in economic regulation (Moses and Savage, 1989: 313). The decreases due to a lack of expenditures on surveillance and infrastructure are not the primary concern of this study.

The volume of air traffic has increased tremendously since the onset of deregulation. While traffic volume has gone up, the number of airports available to the airlines has remained static. The last new airport constructed was the Dallas-Ft. Worth airport in 1973 (Bailey 89). When the new Denver airport is completed it will have been over twenty years since the last new airport was completed. Deregulation occurred in the first decade of this hiatus. Deregulation caused a large increase in traffic that was not compensated for by an increase in infrastructure.

\section{SAFETY IN THE DEREGULATION ERA}

Deregulation has caused a number of changes in the airline industry. It is responsible for increased levels of competition, changes in the route structure, and shifts in 
travel patterns. Deregulation is also at least partly responsible for large increases in air travel in the past decade. It is the cause of changes in the profitability of airlines and is credited with causing a number of airline bankruptcies. Each of these changes has had a potential impact on safety.

\section{Safety and Competition}

Safety is expensive. It costs money to train aircrews, to inspect aircraft, and to perform preventative maintenance. There is an optimum amount of safety for the airlines to provide. This optimum amount is something less than absolute safety. If additional safety expenditures will not result in savings from losses to society at least equal to the expenditures, the expenditures should not be made.

According to Moses and Savage, there is every reason to believe that the airlines provided more than the optimal amount of safety under regulation. The airlines competed in the area of service because they could not compete on the basis of price. They therefore provided too much service. For instance, load factors before deregulation were lower than after because they provided too many flights. They probably also provided too much of the service called safety (Moses and Savage, 1989: 309). 


\section{Change to Commuters}

The commuter and local service airline's safety record improved significantly in the post deregulation era (Oster and Zorn, 1989: 139). Safety regulations for commuter operations were changed in 1978. Other changes in market structure make the commuter airlines, as a group, look more like the safest commuters in the earlier Oster and zorn analysis (Oster and Zorn, 1983: 6).

The commuter airlines serve many communities that were served by the majors prior to deregulation. The transition from jet service to commuter service could be expected to adversely affect airline safety for these markets.

Deregulation may also have caused an increase in the average number of stops one makes per trip. This increase of operations per trip increases the travelers' exposure. The overall effect on air safety is probably quite small (Rose, 1992: 80).

\section{Shift of Travel from Highways to Air}

The commuters have increased the number of flights into the smaller markets as they have taken these markets over (Rose, 1992: 79). Service has changed to a hub and spoke which would make the flights from these smaller markets more attractive. These factors combined to induce a shift from automobile to air travel. To the extent that travelers 
shift from highway to air travel, the total transportation system's safety is improved.

Accident rates for the air transportation system are quite low. Conversely the accident rates for automobiles are relatively high. Therefore, it would seem that any change from highway to air travel would have a very positive effect. However, there are some statistical caveats that need to be addressed.

Rural interstates are the safest of our highways. They are also the roads that compete most with air travel. Highway travel incurs nearly the same risk per mile on long or short trips. Air travel incurs almost all of its risk on the takeoff and landing phases of flight. Consequently, the risk per mile is much higher for short trips (Evans, Frick and Schwing, 1990: 239).

The accident rates for highway travel vary considerably for different profile drivers. This difference in profile does not bear on air travel accident rates. Further, the average air passenger's profile is different from that of the average driver. A belted, low risk driver, driving on a rural interstate on a short inter-city trip, during daylight hours, enjoys approximately the same low risk of fatality as an air passenger making the same inter-city connection (Evans, Frick and Schwing, 1990: 239). Still the shift from highway to air travel has had a positive effect. Rose 
calculates the figure at 90 to 140 lives per year (Rose, 1992: 82).

\section{New Carriers}

Deregulation spawned a number of new air carriers. According to Barnett and Higgins the safety record of these new entrants is not enviable. As a group they averaged twelve times as many fatalities per flight as the established majors during the period 1979-1986 (Barnett and Higgins, 1989: 1).

The risk is sensitive to the measure of safety performance, however. Using accidents per departure, the new entrants appear to perform at least as well as the established carriers (Rose, 1992: 86).

\section{Age of Aircraft}

Competition levels have increased since deregulation. Traffic levels have also increased. This has caused airlines to postpone retiring aging aircraft from the fleet. Fleet age has been widely viewed with concern. The Aloha Airlines accident in April 1988 highlighted this concern. Morrison and Winston looked at aircraft age and accidents. They compared the age (in flying hours) of aircraft involved in accidents pre and post deregulation. They found that the age of aircraft involved in accidents had increased during deregulation but not as fast as the average age of the fleet (Morrison and Winston, 1988: 12). 
Profitability and Safety

Increased competition, leading to reduced profitability, leading to shortcuts in training or maintenance is touted as a mechanism by which deregulation could lead to reduced safety. Some observers suggest that if deregulation increased profitability, as seems likely, that deregulation may then have improved safety (Rose, 1989: 93).

In a study of airline safety during the regulation era, Golbe found no relationship between safety and profitability (Golbe, 1986: 317). In a more recent study, Rose looked for a relationship between profitability and safety. She found that higher operating profits are associated with lower accident rates the following year (Rose, 1989: 97).

\section{Deregulations Effect on Safety}

There have been a number of recent studies that addressed the question, "How has deregulation affected airline safety?" The answers have varied from researcher to researcher.

Morrison and Winston looked for a deregulation effect on insurance expenses for the airlines. They found no correlation between deregulation and safety (Morrison and Winston, 1988: 10).

Barnett and Higgins looked at fatalities per departure to measure airline safety. Fatality rates have decreased 
dramatically for the U.S. domestic trunks since deregulation. They conclude that the established carriers were not affected by deregulation. However, the new jet entrants that arose since deregulation did not enjoy the same low fatality rates. Had deregulation not occurred, these new entrants would not have existed. Therefore, the airlines' safety record would have improved even more if deregulation had not occurred (Barnett and Higgins, 1989: 17).

Rose looked for and found no deregulation effect on safety (Rose, 1992: 89). Morrison and Winston looked to see if pilot experience was a factor since deregulation. They found that the average age and flying experience of pilots involved in accidents is higher since deregulation. They conclude that deregulation has not caused the airlines to hire less experienced pilots (Morrison and Winston, 1988: 11).

\section{Summary of Safety Section}

Many researchers have addressed the question "How has deregulation affected airline safety?" The answer is muddled by continued changes in the industry. It is, however, safe to draw some conclusions from the work already done.

First, the safety record of the airlines has continued to improve during the deregulation era. Profitability 
appears to be positively linked with safety in the case of the smaller airlines. The change in travel patterns from highway travel to air travel has a positive effect on overall transportation safety. Older, well established airlines, as a group, are safer than the new entrants, as a group.

There remains the question of the safety performance of those airlines most directly affected by the deregulation act. The large trunk lines that carry the bulk of the country's air passengers have an improving safety record during the deregulation era, but is it as good as it would have been under regulation? 
CHAPTER III

THE MODELS AND METHODOLOGY

MEASURING SAFETY

Government statistics and Definitions

To determine if deregulation affected airline safety, one must first decide how to measure safety. Even defining something so seemingly simple as a "fatal accident" can be surprisingly complex. The FAA reports a number of different statistics indicative of safety levels. These included accidents, fatal accidents, various accident rates, and service difficulty reports.

Accidents. Accidents are the most commonly used indicator of safety. The National Transportation Safety Board defines an aircraft accident as follows:

An occurrence associated with the operation of an aircraft which takes place between the time any person boards the aircraft with intention of flight until such time as all such persons have disembarked, and in which any person suffers death or serious injury as a result of being in or upon the aircraft or by direct contact with the aircraft or anything attached thereto, or in which the aircraft receives substantial damage.

and fatal injury as:

Any injury which results in death within 30 days of the accident. (NTSB, various) 
The NTSB reports accidents and fatal accidents for air carriers. From the definitions given above it is easy to see that accidents caused by hijackings or sabotage should be included, and when the NTSB reports fatal accidents it reports those resulting from these causes. Yet when it reports fatal accident rates it often leaves out fatalities that result from hijackings (NTSB, various).

The NTSB similarly reports as fatal, those accidents where a collision between a general aviation aircraft and an airliner results in the death of a general aviation passenger. Again when calculating rates, these accidents are not included.

Other Measures. The FAA is not just interested in accidents. Some events that are indicative of safety levels are not serious enough to be categorized as accidents. These events are called incidents. The FAA also records and reports these incidents. According to the Department of Transportation an incident is:

An occurrence involving the operation of one or more aircraft in which a hazard or potential hazard to safety is involved but which is not classified as an accident due to degree of injury and/or extent of damage. (U.S. DOT, 1986: 6)

Another category of events that the FAA tracks are called Service Difficulty Reports or SDR's. SDR's are reported for a variety of problems including in-flight fires, false fire warnings and certain in-flight engine shutdowns. Unfortunately, the criteria for reporting SDR's 
is vague enough to render them inappropriate for this type of analysis.*

The Part $121^{\star *}$ airlines report accidents and incidents per the U.S. Department of Transportation's Order 8020.11, Aircraft Accident and Incident Notification, Investigation and Reporting. The NTSB investigates all airline accidents and selected incidents involving Part 121 carriers.

\section{Safety as Measured in the Literature}

Some researchers use fatal accidents as the appropriate measure of airline safety. Some go further and differentiate between those accidents that are fatal to only a small percentage of the passengers and those airline disasters that kill nearly everyone on board (Barnett and Higgins, 1989: 5).

* The worst of the criteria is the last which reads: Any other failure, malfunction or defect in an aircraft that occurs or is detected at any time if, in the airline's opinion, that failure, malfunction or defect has endangered or may endanger the safe operation of an aircraft used by it.

In addition to the vague definitions the numbers are staggering and they make analysis a daunting task. For instance, in the two-year period January 1987 to January 1989, over 24,000 SDR's were filed with the FAA by the U.S. air carriers (Seattle Times, 1989: E1).

** The scheduled airlines, the subject of this study, are those airlines operating under Part 121 of the Federal Aviation Regulations (FARs). Those eight major airlines that operated for the full period of the study were selected. They were American, Continental, Delta, Eastern, NorthWest, PanAm, TWA, and United. 
Chance and Ferris looked for stock market changes caused by airline disasters. For their analysis they used only accidents that resulted in more than ten fatalities (Chance and Ferris, 1987: 154).

While these disasters make headlines and are the sort of thing most of us associate with the term airline accident they are not suited to measuring the effect of deregulation on airline safety. These kinds of disasters are simply too rare*.

Oster and Zorn, also argue that accidents are rare enough events that further limiting one's analysis should be avoided (Oster and Zorn, 1989: 135).

Rose argues that FAA inspection results and fines are inappropriate measures of safety. These are more measures of safety inputs than outputs. She argues that how these inputs might translate to safety outputs is not well understood (Rose, 1989: 95).

Rose further argues that incidents are not appropriate measures to use because the definition of an incident is not as objective as that of an accident. She also argues that incidents are more likely to include a higher proportion of events attributable to air traffic control errors (Rose, 1989: 96).

* Thin statistics do not result in biased estimates of regression coefficients, but rather inefficient estimates (Rose, 1989: 97). 
Divisor

To change the raw numbers of accidents or incidents to a rate, one must divide by a suitable factor representing exposure. There are several measures of accident rates in use for the airlines. These include accidents per revenue passenger mile (RPM), fatalities per RPM, and accidents per flying hour.

Revenue Passenger Miles. Revenue passenger miles is the most common measure of air transportation use. Fatalities per RPM is probably the best available measure of the public's risk. It is not necessarily the best measure of the airlines' efforts to maintain a safe operation. The airline accident rate measured in accidents per RPM is biased downward as equipment gets larger. The accident rate as measured in fatalities per RPM is biased upward as load factors increase. These biases are due to changes in Revenue Passenger Miles that don't have a direct bearing on the airlines safety practices.

Operations. Oster and Zorn make a strong argument for using accidents per operation (one takeoff and landing) as a measure of safety when comparing one airline to another. This is especially important when comparing short haul lines to trunks. The takeoff and landing phases of flight are the most dangerous portions of any flight. Short haul and commuter airlines make many more takeoffs and landings per 
million revenue passenger miles than do trunk airlines

(Oster and Zorn, 1983: 7).

Hours. For the purposes of this study accidents and incidents per 100,000 flying hours will be used. In this study, each airline's safety record will be compared only to itself. Also the airlines used in the study have been chosen so that the nature of their operations has not changed a great deal over the time frame in question. Therefore, the advantage of accidents per operation over accidents per flying hour does not accrue in this case*.

Rates Used in this Study

The Airlines. The airlines I selected for this study are American, Continental, Delta, Eastern, Northwest, Pan American, Trans World and United. Of the eleven trunk** airlines that entered the deregulation era in 1979 these eight airlines are the only ones that remained in business

\footnotetext{
* The most obvious way the nature of operations could change and affect exposure as measured by hours of flying time would be to change the average stage length or the length of the flights. To confirm the hypothesis of no advantage using operations, I compared regressions for three OLS models. The results are shown in the appendix. I compared the results from the model using hours as the measure of exposure with two other models. The first uses operations as the measure and the second uses operations and stage length as measures of exposure. These are the measures used by Oster and Zorn, and by Rose, respectively. The results are similar to the results obtained by the oLs model using hours as the measure of exposure. * Trunk was the term used to designate the large long haul airlines operating under Part 121 of the FARs. The locals were the smaller, short haul carriers that also operated under Part 121.
} 
for the duration of the study. The other trunks were Western, National, and Braniff. Their dispositions were: Western was purchased by Delta, National was purchased by Pan Am and, Braniff entered bankruptcy. Since the end of the study period Eastern and Pan American have also ceased to operate.

Commuters and Intrastate carriers did not come under the same $\mathrm{CAB}$ regulations as the trunk and local airlines. The local and regional airlines have for the most part undergone a great deal of change during the time since deregulation. These changes include mergers and changes in route structure that make comparisons very difficult. Those regionals that have undergone the least change tend to be rather small so that there are few data points to work with, making analysis difficult.

Exclusions. Oster and zorn omit intra-Alaska, intraHawaii, international, Caribbean and charter operations from their analysis (Oster and Zorn, 1989: 136). Other researchers have excluded international and/or charter operations from their analysis (Barnett and Higgins, 1989: 5) (Rose, 1989: 97). I have included all operations for each of the selected airlines. The purpose of this research was to determine how deregulation affected the individual airline's operations. There is no reason to believe that deregulations effects will be different on different segments of a major airlines operations. 
In this analysis, I have used incident and accident statistics as a measure of safety levels rather than accident statistics alone. The advantage to using incident statistics is that accidents are rare resulting in small sample problems, while incidents are common enough to be useful in most statistical analyses. One of the disadvantages of using incident statistics is the possibility suggested by Rose that incidents data might contain more occurrences caused by agents other than airlines or airline employees. She is concerned specifically by the possibility that incidents are more often caused by air traffic control. This and other issues relating to the use of incidents as a measure of safety will be addressed later.

\section{TIME SERIES MODEIS}

\section{Deregulation Timing}

Having determined how to measure safety, the next step is to determine exactly when deregulation took place. Again this is more complex than one might hope.

The airline deregulation act was signed into law in october 1978. The act called for the CAB to begin granting new routes by January 1980 . In fact the CAB began granting new routes immediately. This was a drastic change from the policies of the early 1970's. 
After the Domestic Passenger Fare Investigation of 1970, the Board reduced the capacity of the airlines to compete. It established standard seating densities to discourage excess capacity on highly competitive routes. It also ruled certain discount fares were discriminatory.

By the mid 1970's the political climate was such that this kind of strict economic regulation was much out of favor. By 1978, prior to the deregulation act, the restrictions on fare reductions were largely eliminated. Route authorizations had also been liberalized somewhat, by 1978.

\section{Deregulation Timing in the Literature}

The literature contains a number of empirical studies where the regulation era was compared and contrasted with the post-regulation period. A sampling of these studies demonstrates the difficulties one encounters in establishing a date for the end of regulation. Oster and zorn use 1978 as the date of deregulation. For their analysis they compared the period 1970-78 with the post-deregulation period of 1979-85 (Oster and Zorn, 1989: 139). Moore also uses 1979 as the first year of the deregulation era (Moore, 1989: 13).

Morrison and Winston claim that certain economic effects of deregulation stabilized, after a transition period ending in 1982 (Morrison and Winston, 1990: 390). 
Bailey and Panzar comment that the Civil Aeronautics Board's policies on entry changed in early 1978. Yet, they maintain that entry barriers did not really topple until after the Airline Deregulation Act passed in October of that year. They point to January 1979 as the date when the new policies were in full effect (Bailey and Panzar, 1981: 130).

Morrison and Winston use 1976 as the first year of the deregulation era in their analysis of air safety and deregulation. They provide no explanation for their use of such an early date (Morrison and Winston, 1988: 11).

The literature provides one other helpful note. Rose looked for and found a relationship between the economic well-being* of an airline and its safety record the following year (Rose, 1992: 111). It is not likely that economic deregulation's effects would show up more quickly than the effects of economic well-being.

Bailey's contention that deregulation was in full effect in January 1979 and Rose's findings of a one-year lag from economic changes in well-being to changes in safety performance are the criteria I considered most important in making my decision on the timing for the dummy variable (Bailey and Panzar, 1981: 130) (Rose, 1992: 111). I am using 1980 as the year of my dummy variable for

\footnotetext{
* Rose used operating margin as her measure of economic well-being. She defines operating margin as one minus the operating expense divided by the operating revenue (Rose, 1992: 100).
} 
deregulation. I did not end my analysis of the timing issue here. Morrison and Winston's point that certain effects stabilized after 1982 is important too (Morrison and Winston, 1990: 390). That the effects of deregulation might take a number of years to come to fruition is entirely credible. I will address this issue later in this section.

\section{Time Series Model}

Since the beginning of the Jet Age, airline accident rates have continued a downward trend. This is true for the period since deregulation too. The Null Hypothesis for the study will be that "Economic deregulation of the airlines has had no effect on airline safety." To test this hypothesis I have run a time series regression analysis of accident and incident rates using a dummy variable for pre and post deregulation. Since accidents per hour has trended lower approaching zero asymptotically, a regression equation using the $\log$ form is suggested.

$$
\text { In }(\text { Rate })=\beta_{0}+\beta_{1} \text { Time }
$$

To Test for a deregulation effect I add a dummy variable for deregulation. The equation can then take two forms.

$$
\begin{gathered}
\operatorname{In}(\text { Rate })=\beta_{0}+\beta_{1} \text { Time }+\beta_{2} \text { Dummy } \\
\ln (\text { Rate })=\beta_{0}+\beta_{1} \text { Time }+\beta_{3} \text { Dummy * Time }
\end{gathered}
$$

The form in equation (2) assumes that the effects of deregulation change the intercept term. This might be the 
case if deregulation induced airlines to make a one-time change in inspection cycles. If lengthening an inspection cycle caused a incremental decrease in safety, we would then expect that $\beta_{2}$, the regression coefficient for the dummy variable, would be positive and significant.

Equation (3) assumes that the effects of deregulation change the rate at which safety improves over time. This might be the result if deregulation induced the airlines to reduce spending on training. Assume that a certain portion of the training dollars an airline spends are effective in improving safety performance. This seems reasonable given that a great deal of the training effort is focused on analyzing past accidents and how to avoid repeating them. Then if spending on such training was reduced we could expect that the rate at which safety performance improved would be reduced.

It is possible that both of the foregoing effects will be found hence equation (4)*

$$
\ln (\text { Rate })=\beta_{0}+\beta_{1} \text { Time }+\beta_{2} \text { Dummy }+\beta_{3} \text { Dummy * Time }
$$

Note that for periods before deregulation the dummy is equal to zero and equation (4) reduces to equation (1). For periods after regulation, where the dummy is equal to one, equation (4) can be rearranged to:

$$
\ln (\text { Rate })=\left(\beta_{0}+\beta_{2}\right)+\left(\beta_{1}+\beta_{3}\right) * \text { Time }
$$


Box-Cox Transformation

The log form for measuring safety performance is not the only form the equation could take. An inverse time function would also approach a zero accident rate asymptotically. In cases where the exact form is not known the use of a Box-Cox transformation is appropriate. G. E. P. Box and D. R. Cox suggest a transformation of the form:

$$
\left(Y^{\lambda}-1\right) / \lambda
$$

where: $0<\lambda<1$. Note that here $\lim \lambda \rightarrow 0\left[\left(Y^{\lambda}-1\right) / \lambda\right]=$ In $Y$ For this formulation $\lambda$ is estimated along with the other regression coefficients (Box and Cox, 1964: 214). Then:

$$
\begin{gathered}
\text { Rate }=\beta_{0}+\beta_{1} \text { Transformed Time }+\beta_{2} \text { Dummy } \\
\text { Rate }=\beta_{0}+\beta_{1} \text { Transformed Time }+\beta_{3} \text { Dummy } * \text { Transfomed Time } \\
\text { Rate }=\beta_{0}+\beta_{1} \text { Transformed Time }+\beta_{2} \text { Dummy }+\beta_{3} \text { Dummy } * \text { Transformed Time }
\end{gathered}
$$

Instability in the Time Series Model

In the previous models I have looked for instability in the time series model caused by deregulation. Specifically, I used a dummy variable that is zero before 1980 and one beginning in 1980, to test for instability in the time coefficient at that point. As I mentioned earlier the first quarter of 1980 is not the only point that could be chosen to represent the beginning of deregulation. Nor is 
deregulation the only shock that could cause instability in the coefficient.

There are several techniques that can be used to test for instability of the slope coefficient. Quandt's log likelihood Ratio Technique tests to determine for an abrupt change in the regression relationship at some unknown time. Comparison of the recursive residuals and their standardized sum or sum of squares to approximate confidence bounds, called CUSUM or CUSUM of squares tests, can be used to test for instability and its location. Another method to investigate time variation is to calculate the regression over a short segment of successive observations and move the segment along the series. Comparisons of the coefficients so calculated are then used to test for instability and its location (Brown, Durbin and Evans, 1975: 151).

I have used the CUSUM and CUSUM of squares tests to seek instabilities in the time series model.

\section{Other Model Considerations}

The airline fleet age has gone up since the advent of deregulation. This has caused some observers to question the effect this might have on airline safety. An increasing fleet age can affect safety in two ways. First, it is possible that airliners could simply wear out. This would not apply to components like engines or avionics that are replaced several times during the lifetime of an aircraft, 
but would apply to the airframe itself. While accidents of this sort are extremely rare, they do happen. The most spectacular recent example is the Aloha accident in 1988. In that accident the airframe failed and a portion of it separated. One life was lost.

There is another way that an increase in fleet age could affect safety performance. An increase in fleet age is an indication that the airlines are not replacing older aircraft with newer presumedly safer models as quickly as in the past.

Morrison and Winston looked at aircraft age and accidents. They compared the age (in flying hours) of aircraft involved in accidents pre and post deregulation. They found that the age of aircraft involved in accidents had increased during deregulation but not as fast as the average age of the fleet (Morrison and Winston, 1988: 12). Given these results and the difficulty obtaining detailed fleet age data I have not pursued this issue further.

\section{CONTROLLABLE OCCURRENCES}

Certain types of incidents are more apt to be under an airline's control than are others. Incidents that are aircraft maintenance related and those related to aircrew training are examples of incidents over which airlines have control. 
It was the airlines who were deregulated by the Airline Deregulation Act of 1978, not the National Weather Service, the FAA, or the aircraft manufacturers. It is appropriate then, to use those accidents and incidents that are under the control of the airlines in determining if deregulation had an effect on airline safety.

Using only those accidents and incidents that are under the control of the airlines will have an additional benefit. Rose claims accidents are most often attributable to factors under the airlines' control. Such things as pilot or crew error, maintenance, or lack of training are the usual causes. Conversely incidents are likely to have a higher proportion of events attributable to air traffic control errors. Therefore, incident rates might be more sensitive to the air traffic controllers strike of 1981 than accident statistics (Rose, 1989: 96). By focusing on accidents and incidents under the airlines' control we can eliminate any problems caused by this supposed bias in incident statistics.

Having decided to use only those occurrences that are under the airlines' control, it remains to make the appropriate separation. But first let us see how others have addressed the problem. 
Cause and Other Researchers

Other researchers have separated accidents into those under the airlines' control and those not under their control. It is instructive to look at these earlier efforts.

oster and Zorn compared pre and post deregulation accident rates for the major airlines and the commuters. For their analysis they assigned accidents to one of eight categories according to "primary contributing factor" (Oster and Zorn, 1989: 142). Their assignments differ significantly from the type of assignments I have made.

Oster and zorn minimize the number of occurrences assigned to the pilot error category. They assign weather as the "primary contributing factor" in some cases where the pilot flew into known inclement weather. They call the distinction between pilot error and weather their most subjective (Oster and Zorn, 1989: 143).

They also list general aviation as the "primary contributing factor" for any accident where a general aviation aircraft was involved! This is true even for accidents like the PSA crash in San Diego (Oster and Zorn, 1989: 144). In this accident the PSA 727 ran a general aviation aircraft down from behind. The general aviation aircraft was where it was told to be by Air Traffic control (ATC). ATC pointed the aircraft out to the PSA crew and instructed them to remain clear of it. 
Oster and zorn found that commuter carrier accidents caused by weather (their cause listing) happened at half the former rate after deregulation. As the weather certainly wasn't that much better we can only assume that the real cause of these accidents was pilot error. Pilot error accident rates also improved over this period according to their figures (Oster and Zorn, 1989: 145).

Mitchell and Maloney looked for a brand name effect for airline accidents that were under an airline's control. For their analysis, they used pilot error as the criterion to determine that the airline was at fault. They did not use accidents caused by other factors like maintenance. They grouped maintenance-related accidents with those like air traffic control mistakes that are outside the airlines' control (Mitchell and Maloney, 1989: 334).

\section{Criteria Used in this Analysis}

For my analysis I have used the accidents and incidents that the National Transportation Safety Board investigated. To accommodate data availability, I have limited the analysis to the period 1964 through 1988. I obtained from the NTSB computer listings of all the Part 121 accidents and incidents for that period. These listings include cause codes and narrative descriptions of the occurrences. Dividing accidents and incidents into those under the direct control of the airline and those not under their 
direct control requires using some subjective standards. It is easy to assign most maintenance-related incidents to the group under the airlines' control. Maintenance-related incidents list a system failure or malfunction code from the Air Transport Association Aircraft Component Code Table as the primary cause. Most also list a secondary cause.

It is also easy to assign incidents caused by air traffic control errors and those caused by unruly passengers to groups beyond the airlines' control. But others are not so easy to assign.

The primary cause listed for an incident where a flight attendant was injured when the aircraft encountered clear air turbulence (CAT) is "continued flight into area of severe turbulence." The implication is that the aircrew was responsible. The trouble with this is that if the CAT was not forecast, and if the crew was not warned by a previous flight that the turbulence was there, they would have no way of knowing it.

Some occurrences have both a primary and a secondary cause and one is under the airline's control and the other is not. In general, the primary cause will be used as the determining factor. Therefore, the incident with "continued flight into area of severe turbulence" listed as the primary cause is under airline control even though the turbulence is not. 
An exception is the case where aircrew error is listed as the primary cause and improper or conflicting instructions from air traffic control (ATC) is listed as the secondary cause. An example of this is incidents when two aircraft respond to the same clearance and ATC doesn't catch the discrepancy (There is no way for the aircrew to know that this has happened, since they can't receive and transmit at the same time.)

Another example is an incident where an aircrew aborted a takeoff on ATC instructions issued late in the takeoff roll. The late abort caused two blown tires. The primary cause is listed as aircrew error i.e. aborted the takeoff late, resulting in two blown tires. The secondary cause is ATC issued improper instructions i.e. called for an aborted takeoff late in the takeoff roll. (The Traffic sector had become overloaded.) It is clear that safety is not enhanced by encouraging the crew to avoid blown tires by continuing the takeoff roll in the face of ATC instructions to the contrary.

It should be noted, that by not listing these incidents as under the airlines' control, the implication is not that they are the fault of the air traffic controllers. Rather it is simply that the airline cannot control these incidents by providing the aircrew with more or better training.

A small number of occurrences could not be classified. These included accidents that occurred under the 
jurisdiction of a foreign power where the NTSB did not have the results of the accident investigation. They also included a very small number of accidents, where the investigation was closed with the cause listed as undetermined. *

After separating the occurrences into those under the control of the airlines and those not under their control, I was able to recalculate rates using only those occurrences under the control of the airlines. I then ran the regressions suggested by the models in equations (2), (3), $(4),(6),(7)$, and (8).

\section{ECONOMIC HEALTH AND SAFETY}

One way in which deregulation might affect safety performance is through changes in economic well-being. If the additional competitive pressure caused by deregulation squeezed an airline's profit margin, the airline might scrimp on safety inputs to recover some of the lost profit. This raises the question of a possible relationship between economic well-being and safety performance. Other researchers have looked for such a relationship.

* Of the 1,118 occurrences investigated, a total of fiftysix had causes that could not be determined. These fiftysix occurrences were left out of the analysis. 
Economic Health and Safety in the Literature

Golbe looked for and found no relationship between economic well-being and safety. She regressed the square root of accidents on average current profits, departures and stage length. Using aggregate data she found no significant relationship between profits and safety (Golbe, 1986:100).

Rose confirms Golbe's results using non-lagged aggregate data. However, she goes on to show that using pooled data masks the true relationship. Using crosssectional data and regressing accident rates on lagged operating margin she found a correlation between profit and safety. Specifically she found a significant correlation between higher operating margins and lower accident rates in the following year (Rose, 1989: 111).

In view of these findings it is important to control for profitability in the earlier models.

Measures of Economic Well-being

The usual measure of economic well-being is Return on Investment (ROI). However ROI is affected by historical costs and accounting methods. A statistic that reflects current operating health might be more useful.

Other researchers also found ROI less than satisfactory. Golbe used both ROI and net income. She cited the link between capital expenditures and safety improvements as her difficulty with ROI (Golbe, 1986: 312). 
Gomez-Ibanez, Oster and Pickrell use operating ratio as the appropriate measure. They looked for the effects of deregulation on profitability. For the operating ratio they used operating expenses divided by operating revenues (Gomez-Ibanez, Oster and Pickrell, 1983: 81).

Rose uses operating margin as a measure of economic well-being. She defines operating margin as one minus the operating ratio (Rose, 1989: 100).

I have selected operating ratio as the measure of profitability to use for this analysis. Such a statistic can be calculated from data available from Data Base Products, Inc. Data Base Products extracts the data from Form 41 Data reported by the airlines to the FAA and CAB.

Model

To control for profitability I have used the following models.

$$
\begin{gathered}
\ln \text { (Rate) }=\beta_{0}+\beta_{1} \text { Time }+\beta_{2} \text { Dummy }+\beta_{4} \text { Opratio } \\
\ln (\text { Rate })=\beta_{0}+\beta_{1} \text { Time }+\beta_{3} \text { Dumny } * \text { Time }+\beta_{4} \text { opratio } \\
\text { In (Rate) }=\beta_{0}+\beta_{1} \text { Time }+\beta_{2} \text { Dummy }+\beta_{3} \text { Dummy } * \text { Time }+\beta_{4} \text { opratio } \\
\text { These are simple modifications of the models shown in }
\end{gathered}
$$$$
\text { equations (2) and (3)* . Here Opratio is used to indicate }
$$$$
\text { the operating ratio lagged one year. There is an advantage }
$$$$
\text { to these new formulations. With these models, if the }
$$

\footnotetext{
* Note here the use of time as the measure of technological progress. As noted earlier time turns out to be a better measure than uncontrollable occurrences.
} 
regression coefficient for the dummy term is significant, we can be assured that it is not due to changes in profitability following deregulation. 
CHAPTER IV

ANALYSIS

REGRESSION RESULTS

\section{Data}

The data for this study is taken from published National Transportation Safety Board (NTSB) statistics and from computer tape data supplied by the NTSB. The published data includes listings of fatal accidents and total accidents and flying hours. The tape data included listings of incidents and accidents that the NTSB has investigated. The listings are for Part 121 carriers, and occurrences from 1964 through 1988.

Table I shows fatal accidents and total accidents for the years 1961 through 1987. Table II shows the tabulated results of sorting the accidents and incidents into those under the airlines' control and those not under their control. (The appendix has a more complete listing and includes the results from each individual occurrence.)

The column also lists, under the heading "other occurrences," the number of occurrences that could not be assigned to one category or other. This was most often due 
to the incident or accident occurring outside U.S.

jurisdiction. More rarely, it was because the investigation

was closed without a cause being determined. Fifty-six

(approximately 5\%) of the occurrences were classified as

"other."

TABLE I

FATAL ACCIDENTS AND TOTAL ACCIDENTS

\begin{tabular}{cccc} 
Year & $\begin{array}{c}\text { Fatal } \\
\text { Accidents }\end{array}$ & $\begin{array}{c}\text { All } \\
\text { Accidents }\end{array}$ & $\begin{array}{c}\text { Flying } \\
\text { Hours }\end{array}$ \\
\hline 1961 & 6 & 66 & 3654503 \\
1962 & 6 & 47 & 3491174 \\
1963 & 6 & 54 & 3604228 \\
1964 & 11 & 59 & 3774771 \\
1965 & 8 & 65 & 4071987 \\
1966 & 5 & 56 & 4232982 \\
1967 & 8 & 54 & 4924080 \\
1968 & 13 & 56 & 5521931 \\
1969 & 8 & 51 & 5892254 \\
1970 & 4 & 43 & 5780503 \\
1971 & 7 & 43 & 5706270 \\
1972 & 7 & 46 & 5659485 \\
1973 & 8 & 36 & 5898575 \\
1974 & 7 & 43 & 5474495 \\
1975 & 2 & 30 & 5422665 \\
1976 & 2 & 22 & 5587601 \\
1977 & 3 & 20 & 5800843 \\
1978 & 3 & 20 & 6031743 \\
1979 & 4 & 23 & 6700322 \\
1980 & 5 & 15 & 6797578 \\
1981 & 0 & 25 & 6571288 \\
1982 & 4 & 15 & 6440163 \\
1983 & 4 & 22 & 6649009 \\
1984 & 3 & 12 & 7438497 \\
1985 & 4 & 17 & 7947435 \\
1986 & 1 & 20 & 9356906 \\
1987 & 4 & 30 & 9711000 \\
198 & 1 & &
\end{tabular}




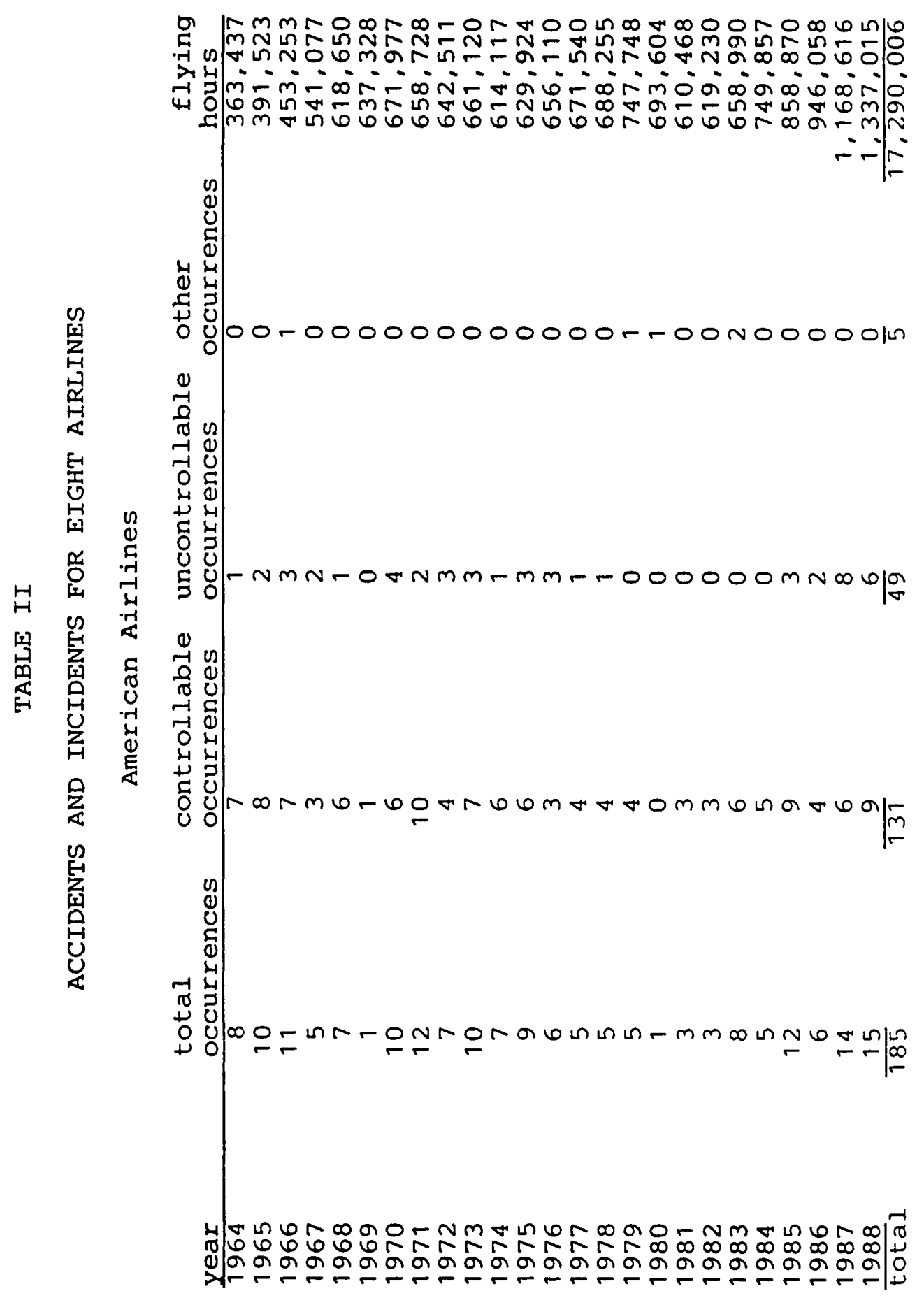




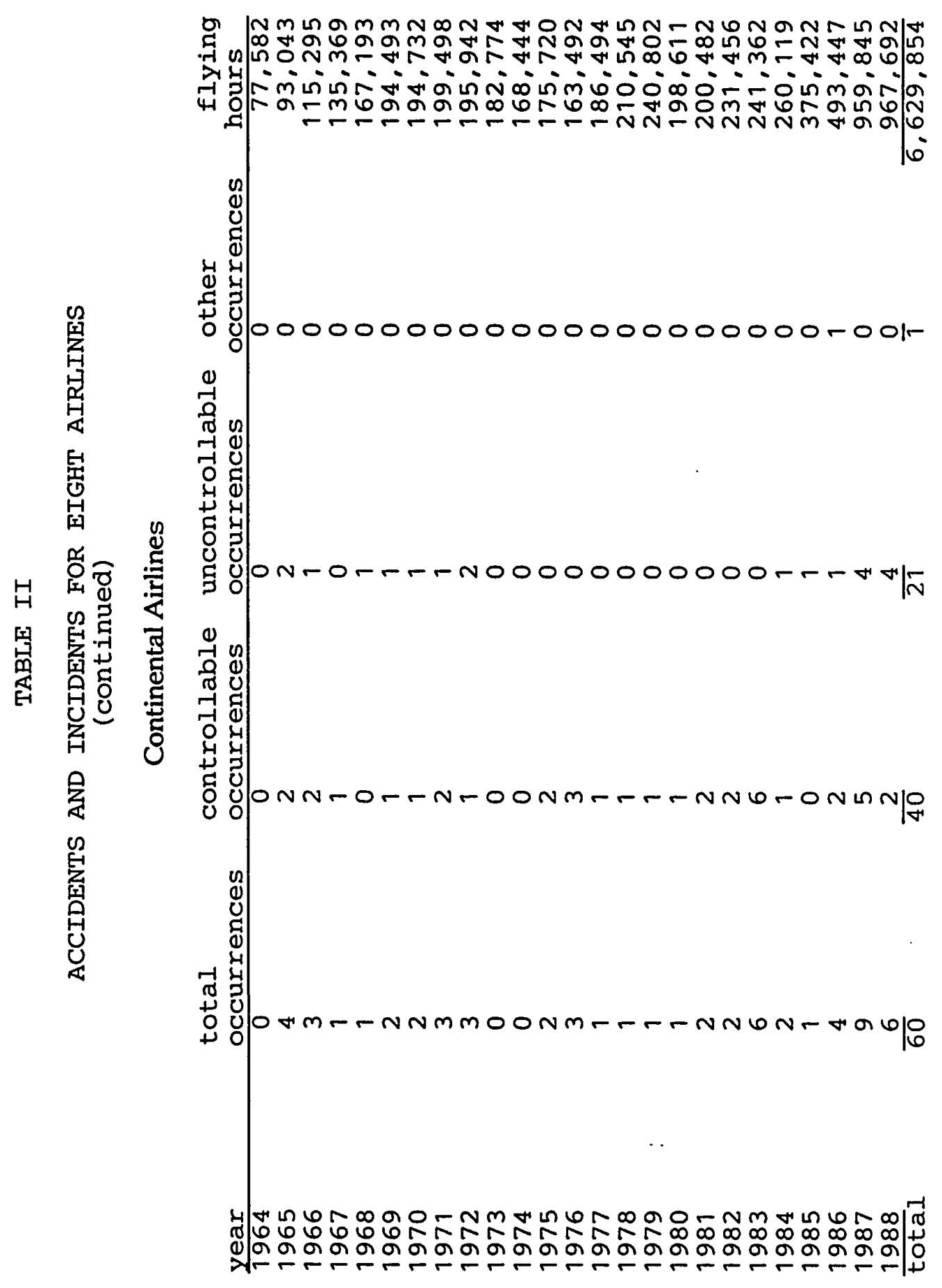




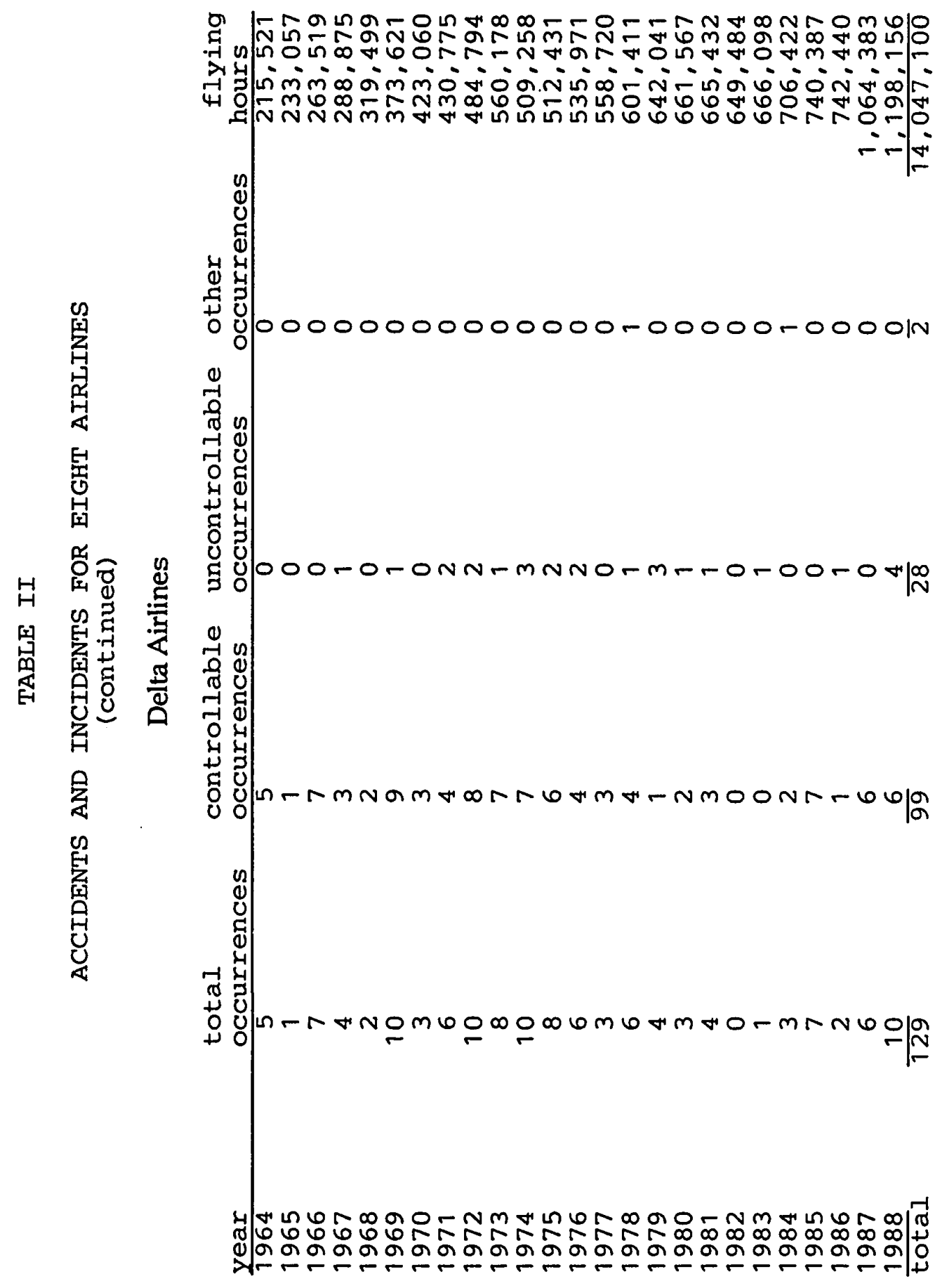




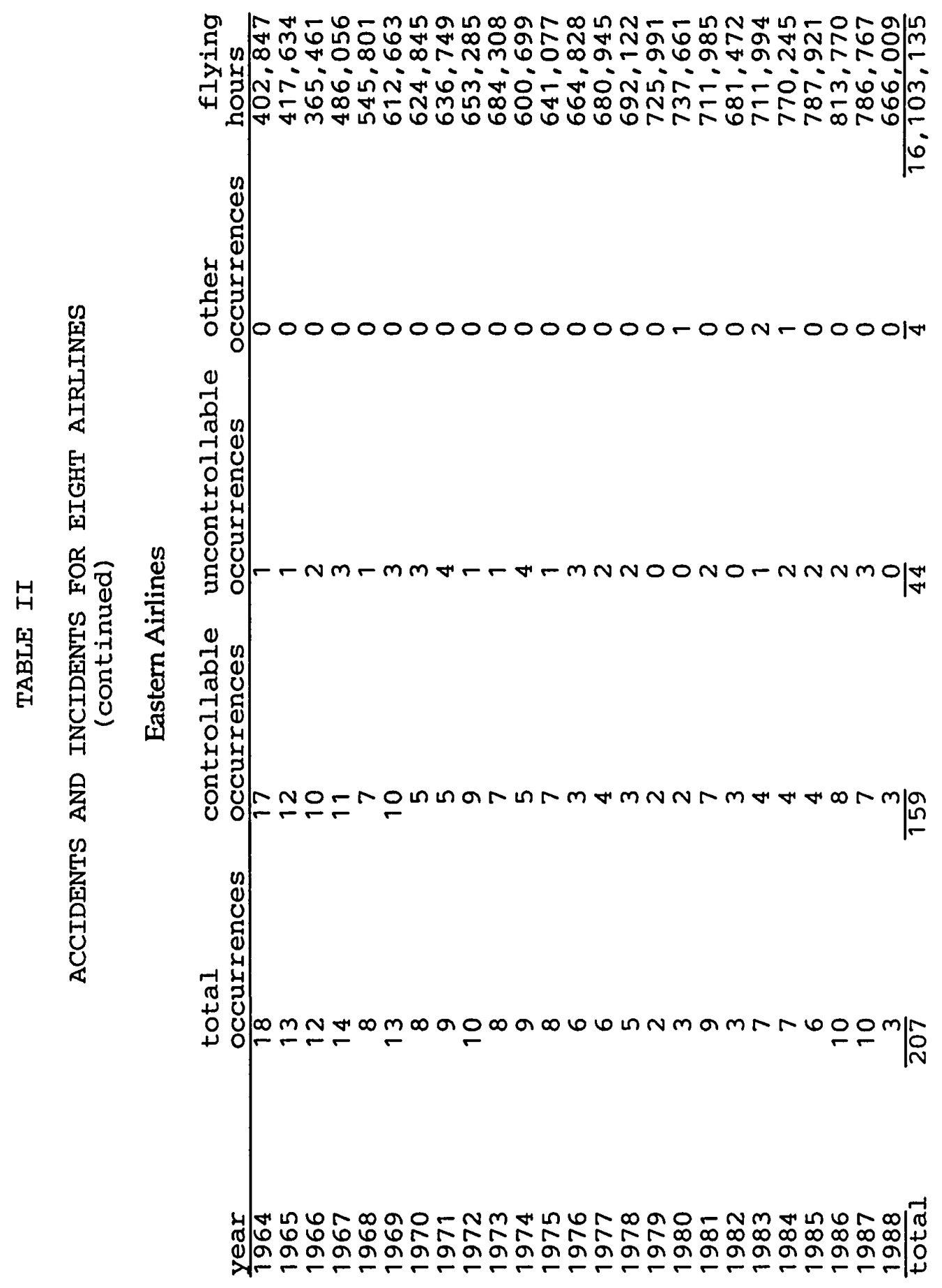




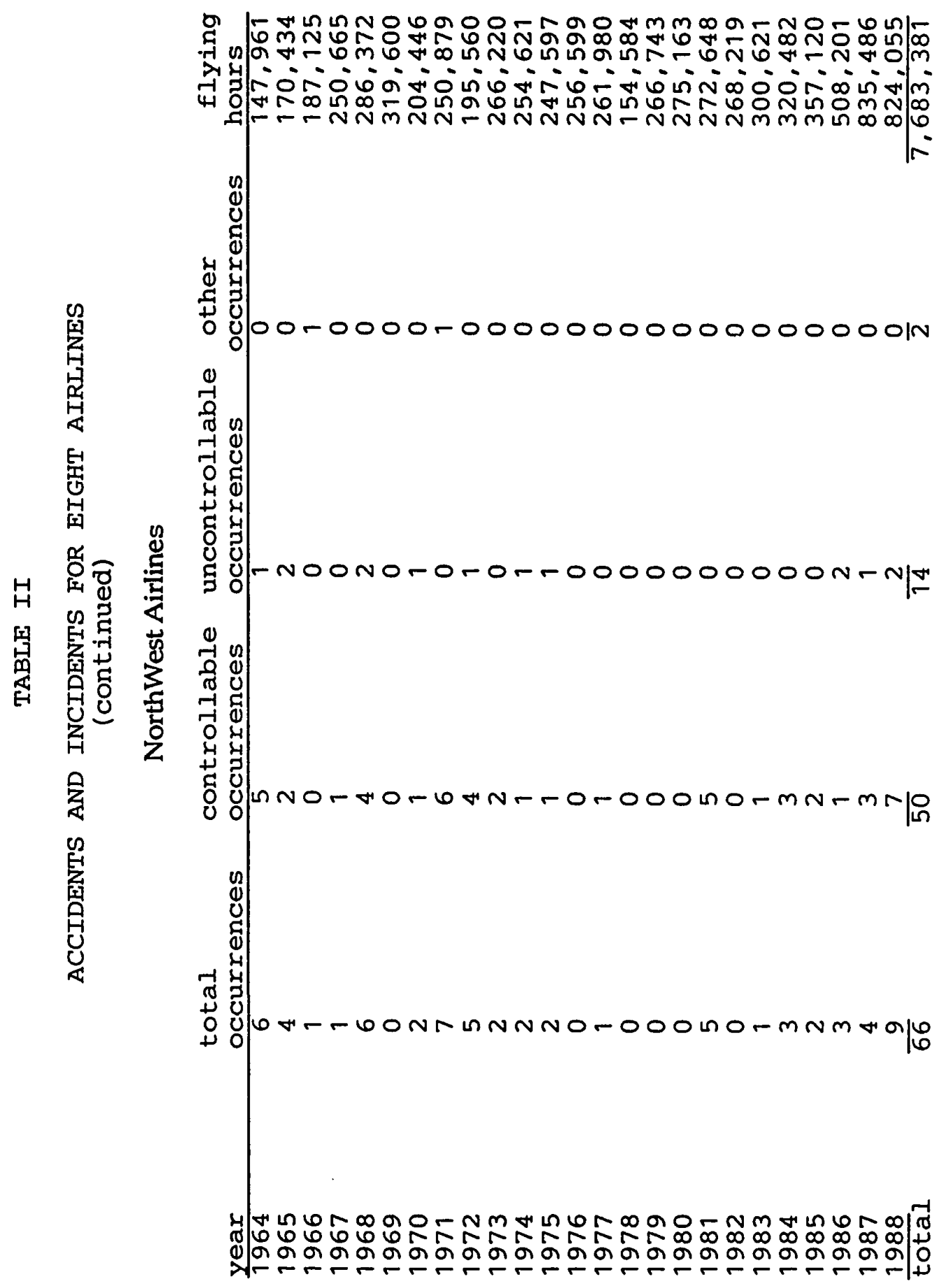




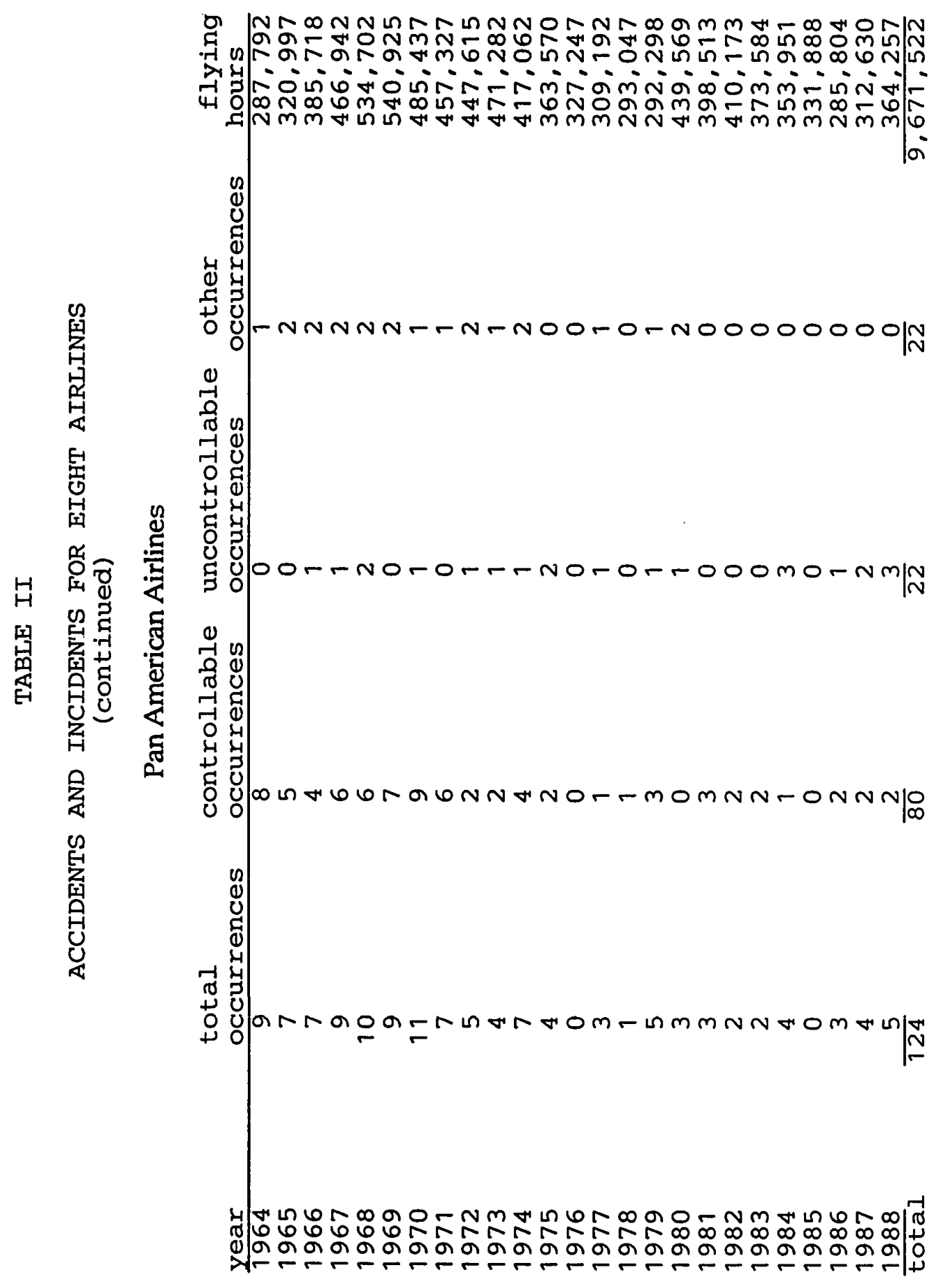




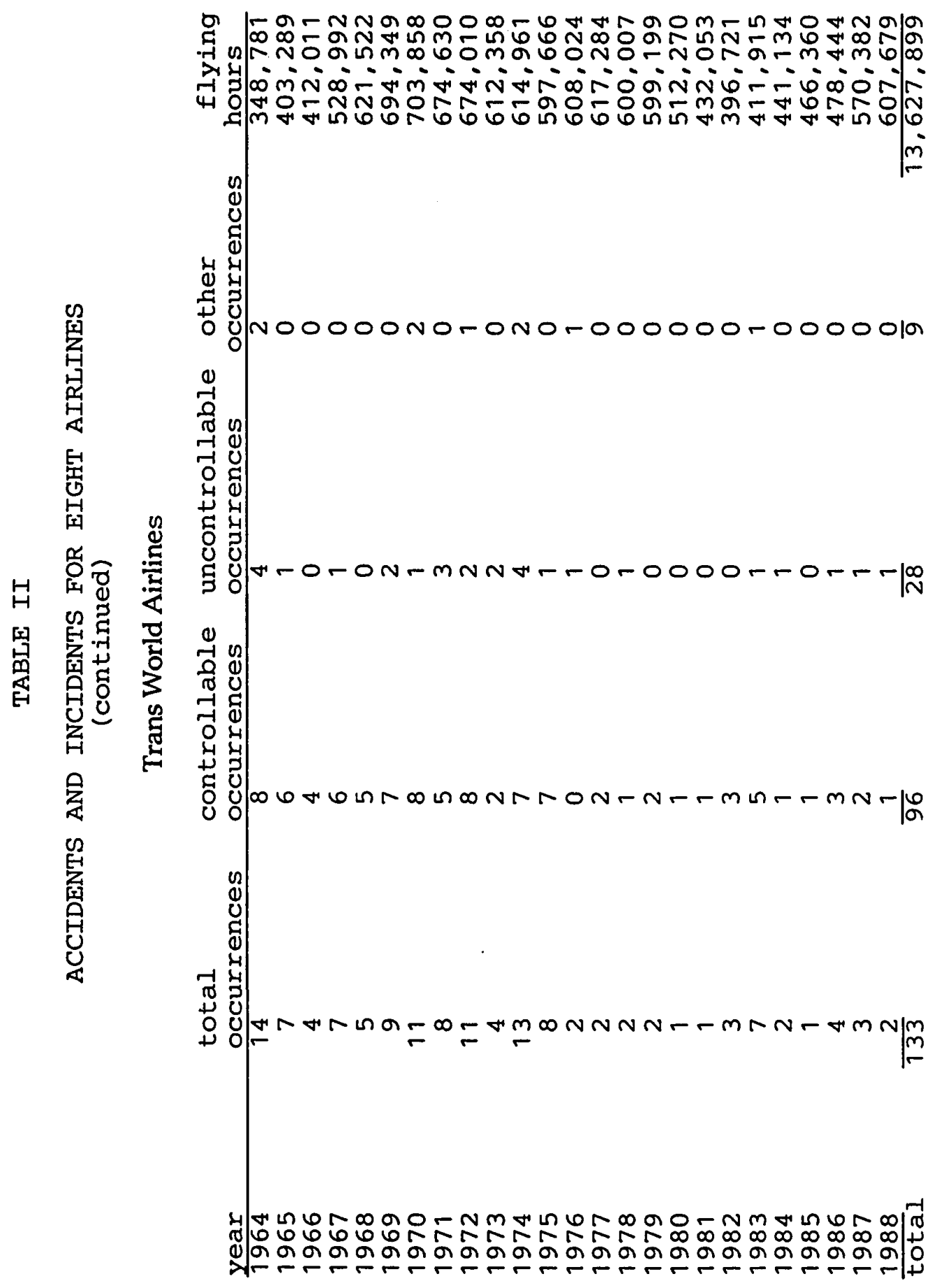




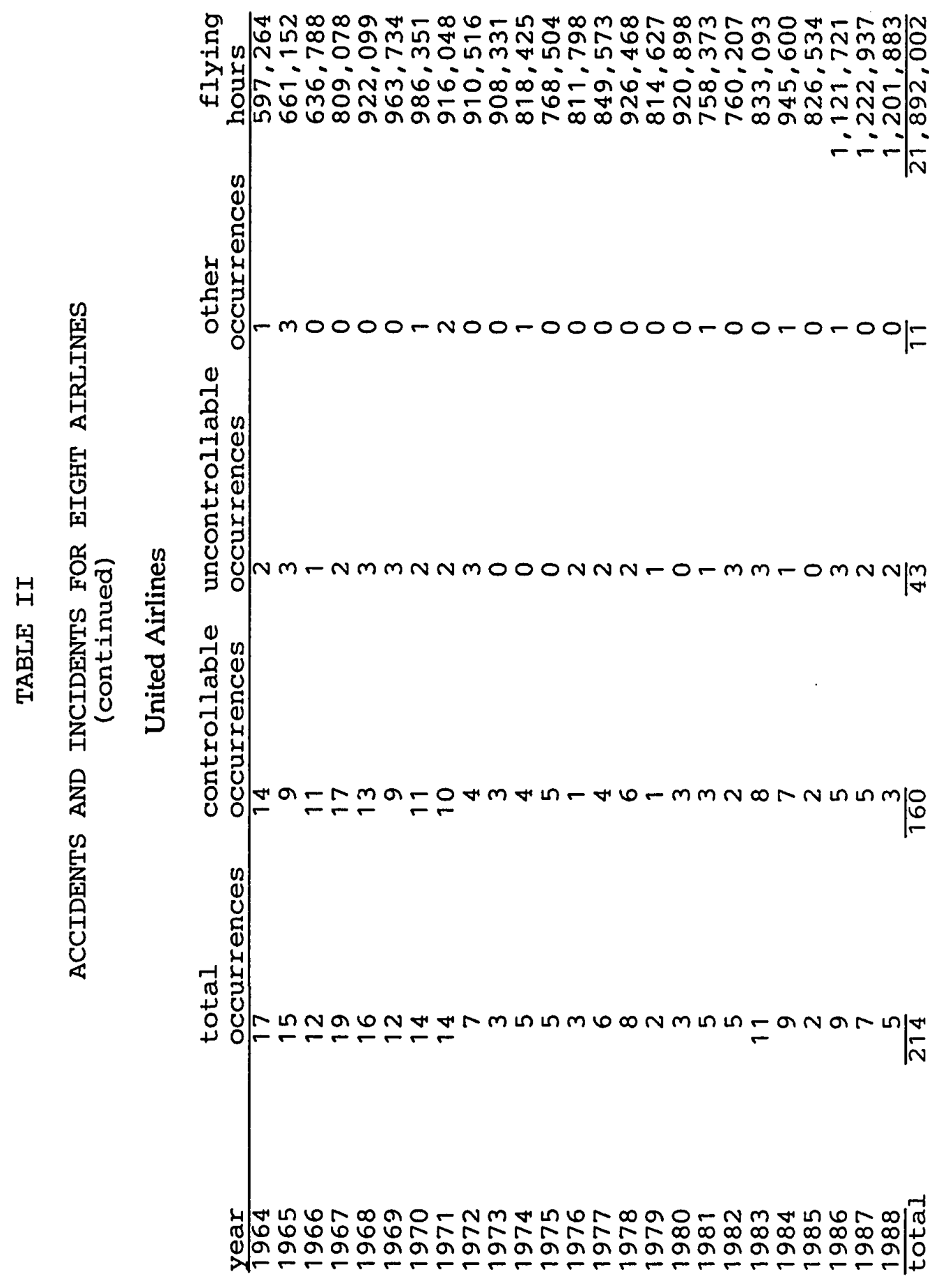




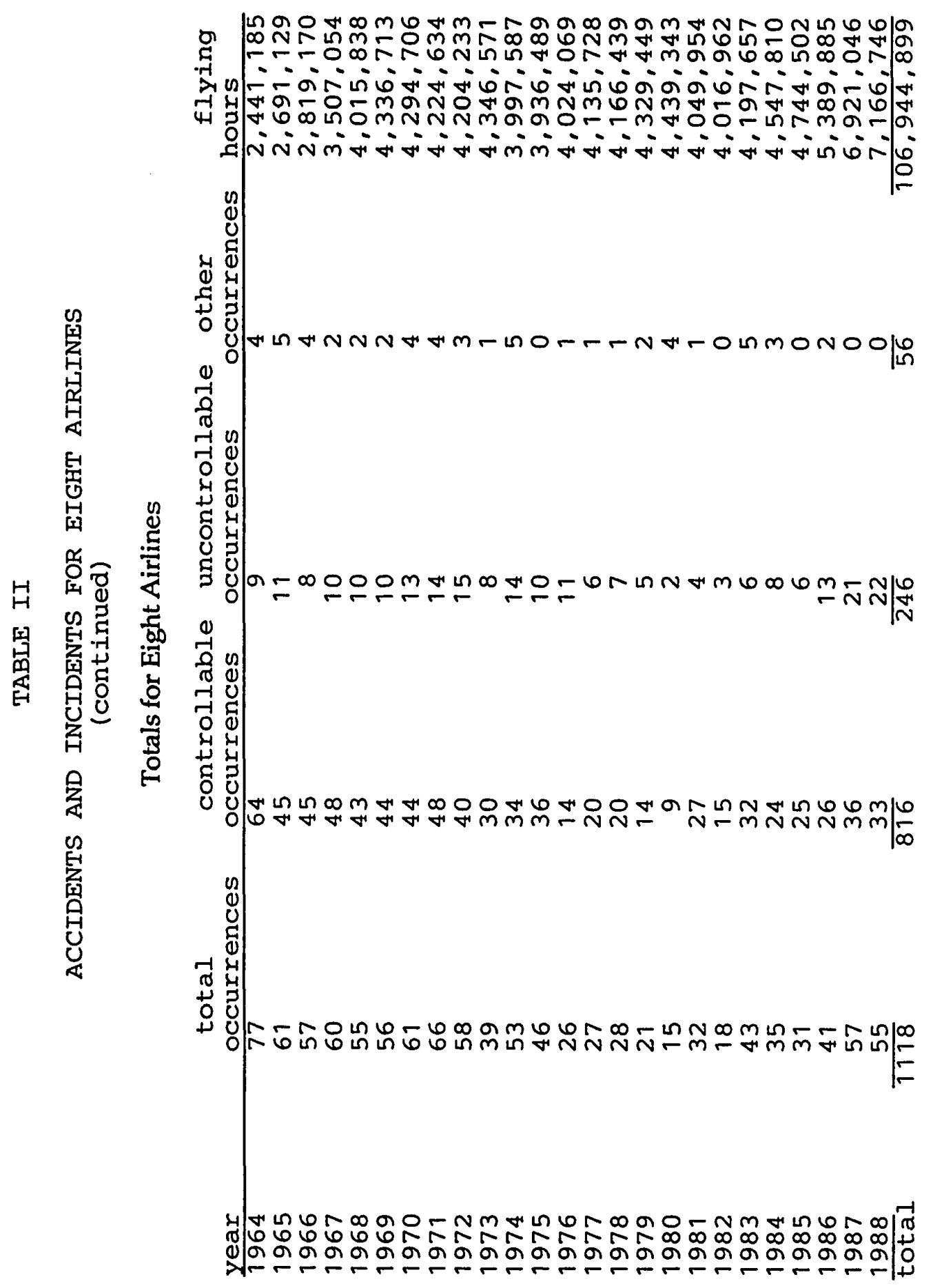




\section{Ordinary Least Squares Results}

The first regression results are ordinary least squares (OLS) regressions. The regressions have been run using three data sets. The first two sets use fatal accident and all accident rates for all part 121 carriers. Also shown are regressions using controllable occurrences for the eight airlines (American, Continental, Delta, Eastern, Northwest, Pan Am, TWA, and United). Controllable occurrences are those accidents and incidents with causes that are under the airlines' control. The models are equations (2), (3), and (4) from the previous chapter and are repeated below for reader convenience. These and all subsequent regression results are obtained using the SHAZAM, econometrics computer program, DOS extended memory version 6.2 .

$$
\begin{gathered}
\ln \text { (Rate) }=\beta_{0}+\beta_{1} \text { Time }+\beta_{2} \text { Dummy } \\
\ln (\text { Rate })=\beta_{0}+\beta_{1} \text { Time }+\beta_{3} \text { Dummy * Time } \\
\ln \text { (Rate) }=\beta_{0}+\beta_{1} \text { Time }+\beta_{2} \text { Dummy }+\beta_{3} \text { Dummy * Time }
\end{gathered}
$$

The models are generic. The rate could be all fatal accidents for all Part 121 carriers divided by total hours flown by those carriers. Or, depending on the data set being used, the rate might be the number of occurrences with cause factors that are under the airlines' control divided by hours flown.

Regression Results The coefficients for time in the fatal accident models have the expected sign and are significantly different from zero. See Table III. The 
coefficients for the dummy variables are not significant. This is not unexpected given the thinness of the fatal accident statistics and it is consistent with the findings of other researchers (Rose, 1989: 100). Note the use of a zero dummy in the fatal accident model. This is used as an alternative formulation where a regression formula leads to a In (0) problem. (There were no fatal accidents by Part 121 carriers in 1980.) This formulation was pioneered by Pakes and Griliches and by Hausman, Hall and Griliches. It will be discussed in later sections (Pakes and Griliches, 1980: 378) (Hausman, Hall and Griliches, 1984: 910).

The results from the controllable occurrence models and the models using all accidents are more instructive.

These results differ from Rose's 1989 results. She did not have data for 1987 and 1988 for her calculations. Also Rose tested the dummy variable for significance using 1978 as the year when deregulation began. As discussed in the last chapter I believe 1980 to be more appropriate. Rose did not use a dummy variable for time since deregulation, in her 1989 study (Rose, 1989: 99).

In the models using all accidents the coefficient for time is significant. The coefficient for the deregulation dummy has the expected sign, but is not significant. In the model using time since deregulation, the coefficient is significant at the five per cent level. 
TABLE III

\section{OLS RESULTS}

Fatal Accidents

Dependent Variable $=$ In Fatal accident rate

$\begin{array}{llccc} & \beta_{0} & \beta_{1} & \beta_{2} & \beta_{3} \\ \text { coefficient } & 5.95 & -0.0832 & -0.0408 & \\ \text { t-ratio } & 4.30+\dagger & -4.22+\dagger & -0.117 & \\ \text { R-square adjusted }=0.6943 & \text { Sum of square Errors }=5.3371 \\ \text { coefficient } & 5.47 & -0.0762 & & -0.0367 \\ \text { t-ratio } & 4.11+\dagger & -4.04+\dagger & & -0.608 \\ \text { R-square adjusted }=0.6990 & \text { Sum of Square Errors }=5.2558 \\ & & -0.0797 & 0.279 & 0.0736 \\ \text { coefficient } & 5.70 & -3.92+\dagger & 0.517 & 0.783 \\ \text { t-ratio } & 3.99+\dagger & \text { Sum of Square Errors }=5.1925 & \end{array}$

All Accidents

Dependent variable $=$ In All accidents rate

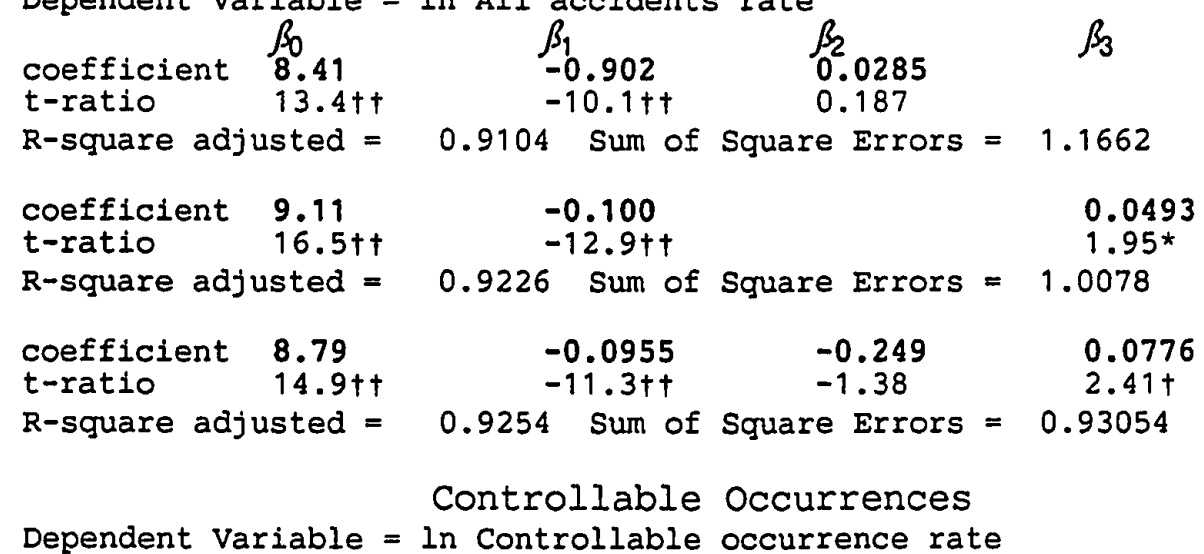

$\begin{array}{lllll} & \beta_{0} & \beta_{1} & \beta_{2} & \beta_{3} \\ \text { coefficient } & 8.54 & -0.0888 & 0.480 & \\ \text { t-ratio } & 6.51 \dagger \dagger & -4.85 \dagger \dagger & 1.75^{*} & \end{array}$

$\mathrm{R}$-square adjusted $=0.6165 \quad$ Sum of Square Errors $=2.9506$

$\begin{array}{llll}\text { coefficient } & 10.2 & -0.113 & 0.156 \\ \text { t-ratio } & 10.6 \dagger \dagger & -8.48 \dagger \dagger & 4.65+\dagger \\ \text { R-square adjusted }=0.7800 & \text { Sum of Square Errors }=1.6928\end{array}$

$\begin{array}{lllll}\text { coefficient } & 10.2 & -0.112 & -0.1039 & 0.157\end{array}$

t-ratio $\quad 9.27+t \quad-7.30+t \quad-0.421 \quad 3.95+t$

R-square adjusted $=0.7695$ Sum of Square Errors $=1.69287$

$\beta_{0} \leftrightarrow$ constant
$\beta_{2} \leftrightarrow$ deregulation dummy $\beta_{3} \leftrightarrow$ time since deregulation

* significant at the 108 level +58 level $+\dagger 18$ level 
In the regressions using controllable occurrences the coefficients all have the expected sign and all are significantly different from zero. The deregulation dummy in equation (2) is significant at the 108 level conetailed), while all others including the time since deregulation dummy are significant at the $1 \%$ level.

These results provide evidence that airline safety was affected by economic deregulation. Airline safety improved over time during the regulation era. Deregulation did not reverse that trend. However, the results of the OLS regressions indicate that the trend has slowed in the period since deregulation. This preliminary evidence is reason enough to look closer at the relationship between deregulation and airline safety.

DIFFICULTIES WITH THE OLS MODEL

Before the results of the OLS are accepted, there are some difficulties that need to be addressed. For the results of an OLS regression to be valid some assumptions need to be made about the data. The data presented here violate some of those assumptions. Specifically, the error terms are assumed to be normally distributed. Accident data, however, is ordinarily thought to follow a Poisson distribution. Also, the error terms are assumed to be uncorrelated. In this case, several firms react to the same economic conditions, in the same time periods. Under these 
circumstances, cross-sectional correlation of the error terms is a more reasonable assumption than uncorrelated error terms.

In addition to concerns about the error terms, there are the specification concerns discussed in the previous chapter. These include the possibility that the log form does not best model the safety to time relationship. There is also the concern that the true relationship includes a term that measures economic well-being of the airlines.

One last concern needs to be addressed before we can accept the oLS results. That is the problem raised by the model specification and the resulting need to substitute for the $\log (0)$. Each of these concerns will be addressed in subsequent sections.

\section{Poisson Distribution and Maximum Likelihood Regressions}

The Poisson distribution is characterized by discreet events occurring at random intervals. In a Poisson distribution, the number of events that occur in one time period is independent of the number of events occurring in other periods. The number of accidents in a certain period is a typical example of this distribution (McClave and Dietrich, 1982: 154). A number of researchers have applied this model to accident research (Rose, 1990: 950).

The appropriate regression technique for a Poisson distribution is a maximum likelihood technique like that 
used by the SHAZAM non-linear command (Hausman, Hall and Griliches, 1984: 912). Alternatively, the Poisson distributed variable could be transformed so that it assumes a normal distribution. Both techniques have been used in the literature. Rose used a maximum likelihood technique when she looked for a relationship between accident rates and economic well-being (Rose, 1990: 50).

Golbe took the square root of accidents to transform the distribution to a normal one. Golbe also sought a relationship between accident rates and economic well-being (Golbe, 1986: 312).

Results from both the maximum likelihood regression and OLS regressions using the square root of accident rates are shown below. They are similar to the results from the oLs regressions. See Table IV.

The maximum likelihood regression is the appropriate technique to use for the Poisson distribution. These regression results indicate that using the simpler oLS form does not overstate the case for a relationship between deregulation and airline safety. 
TABLE IV

POISSON MODELS

Maximum Likelihood Results

Dependent Variable in Fatal accident rate

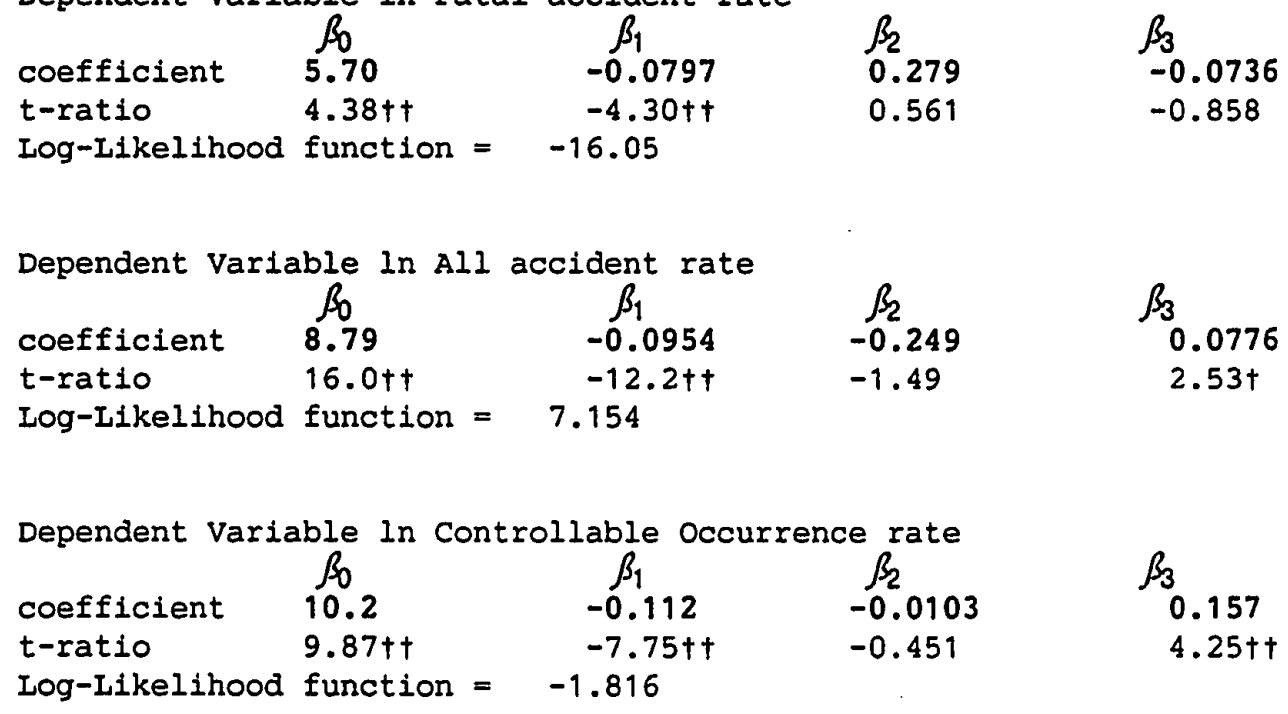

Square Root Results

Dependent Variable square root Fatal accident rate

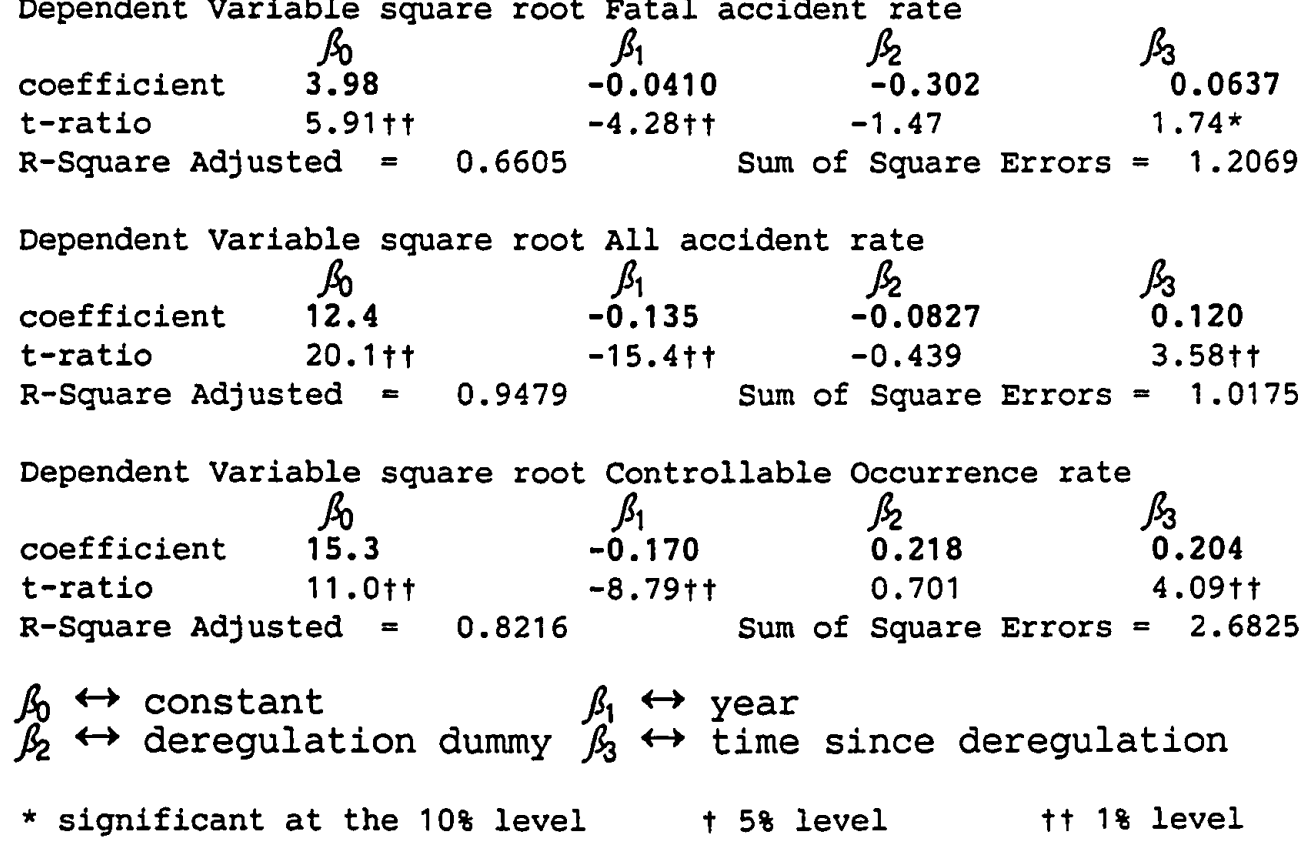


The Box-Cox Model

Accident rates have declined throughout aviation history. The data indicates a decaying function that approaches zero asymptotically. It is usual to assume the form is a log decay function. However there is no requirement that accidents should decay logarithmically. The formulation suggested by Box and Cox is appropriate when the exact form is not known.

The Box-Cox models from Chapter III are shown below. The results of the regressions for these models are shown in Table V.

$$
\begin{aligned}
& \text { Rate }=\beta_{0}+\beta_{1} \text { Transformed Time }+\beta_{2} \text { Dummy } \\
& \text { Rate }=\beta_{0}+\beta_{1} \text { Transformed Time }+\beta_{3} \text { Dummy * Transfomed Time } \\
& \text { Rate }=\beta_{0}+\beta_{1} \text { Transfomed Time }+\beta_{2} \text { Dummy }+\beta_{3} \text { Dummy * Transfomed Time } \\
& \text { The Box-Cox results are similar to the results obtained } \\
& \text { using the log form. This similarity indicates that the log } \\
& \text { form is an adequate representation of the true relationship } \\
& \text { between safety and time. }
\end{aligned}
$$

The Cross-sectional Model

The data fits the form of a cross-sectionally correlated and time-wise auto-regressive model described by Kmenta (Kmenta, 1986: 622). There is a difficulty using the $\log$ form of the equation, however. 
TABLE V

BOX-COX RESULTS

Dependent Variable in Fatal accident rate

$\begin{array}{lllll} & \beta_{0} & \beta_{1} & \beta_{2} & \beta_{3} \\ \text { coefficient } & 6.14 & -0.0832 & -0.3 .12 & 0.0852 \\ \text { t-ratio } & 5.51+\dagger & -5.25+\dagger & -0.907 & 1.39 \\ \text { R-square adjusted }=0.6987 & & \text { sum of Square Errors }= & 3.6999\end{array}$

Dependent Variable ln All accident rate

$\begin{array}{lllll} & \beta_{0} & \beta_{1} & \beta_{2} & \beta_{3} \\ \text { coefficient } & 21.6 & -0.254 & -0.161 & 0.221 \\ \text { t-ratio } & 19.0+\dagger & -15.8+\dagger & -0.462 & 3.57 \dagger \dagger \\ \text { R-square adjusted }= & 0.9474 & & \text { sum of } & \text { Square Errors }= \\ & 3.6556\end{array}$

Dependent Variable in Controllable Occurrences rate

\begin{tabular}{lllll} 
& $\beta_{0}$ & $\beta_{1}$ & $\beta_{2}$ & $\beta_{3}$ \\
coefficient & 20.3 & -0.236 & 0.293 & 0.288 \\
t-ratio & $12.5+\dagger$ & $-10.5+t$ & 0.787 & $4.90+\dagger$ \\
R-square adjusted $=$ & 0.8238 & \multicolumn{2}{c}{ sum of square Errors } & 5.2791
\end{tabular}

$\beta_{0} \leftrightarrow$ constant $\quad \beta_{1} \leftrightarrow$ year
$\beta_{2} \leftrightarrow$ deregulation dummy $\beta_{3} \leftrightarrow$ time since deregulation

t† significant at the 18 level

The data is such that when one separates the accidents/incidents out by airline the occurrence rate is often zero for a given year. Rose addresses this problem and suggests the form used by Griliches et al. (Rose, 1989: 99) (Pakes and Griliches, 1980: 378) (Hausman, HaIl and Griliches, 1984: 910).

This method requires using a zero dummy. This dummy is set to ' 1 ' where the rate is zero and ' $O$ ' where the rate is non-zero. A transformed rate is then calculated. This transformed rate does not have zeroes. The transformed rate 
is equal to the original rate plus the zero dummy* (Hausman, Hall and Griliches, 1984: 910).

Griliches suggests selecting the data set to reduce the number of occurrences of zeroes, to preferably less than ten percent (Hausman, Hall and Griliches, 1984: 910). The data set in use here does not fit that description. It is, however, possible to select airlines for which the data does fit that criteria. By eliminating Continental, Northwest, and Pan Am from the data sample we are left with only the five largest airlines. The resulting data set fits the criteria. In this truncated data set, zero occurs in only three per cent of the data points.

The regression results of a pooled cross-sectionally correlated and time-wise auto-regressive model are shown in Table VI.

It is also possible to transform the rate to eliminate the $\log (0)$ problem. This creates a new problem, in that there is no theoretical basis for the form of the transformation. One can make some pertinent observations though.

If the rate is transformed by adding a very small number, $\left(10^{-6}\right)$ the log can be taken. This seems at first to be a good transformation in that it requires little change to the data. However, this creates another problem. The not preserve the ordering of the data. 


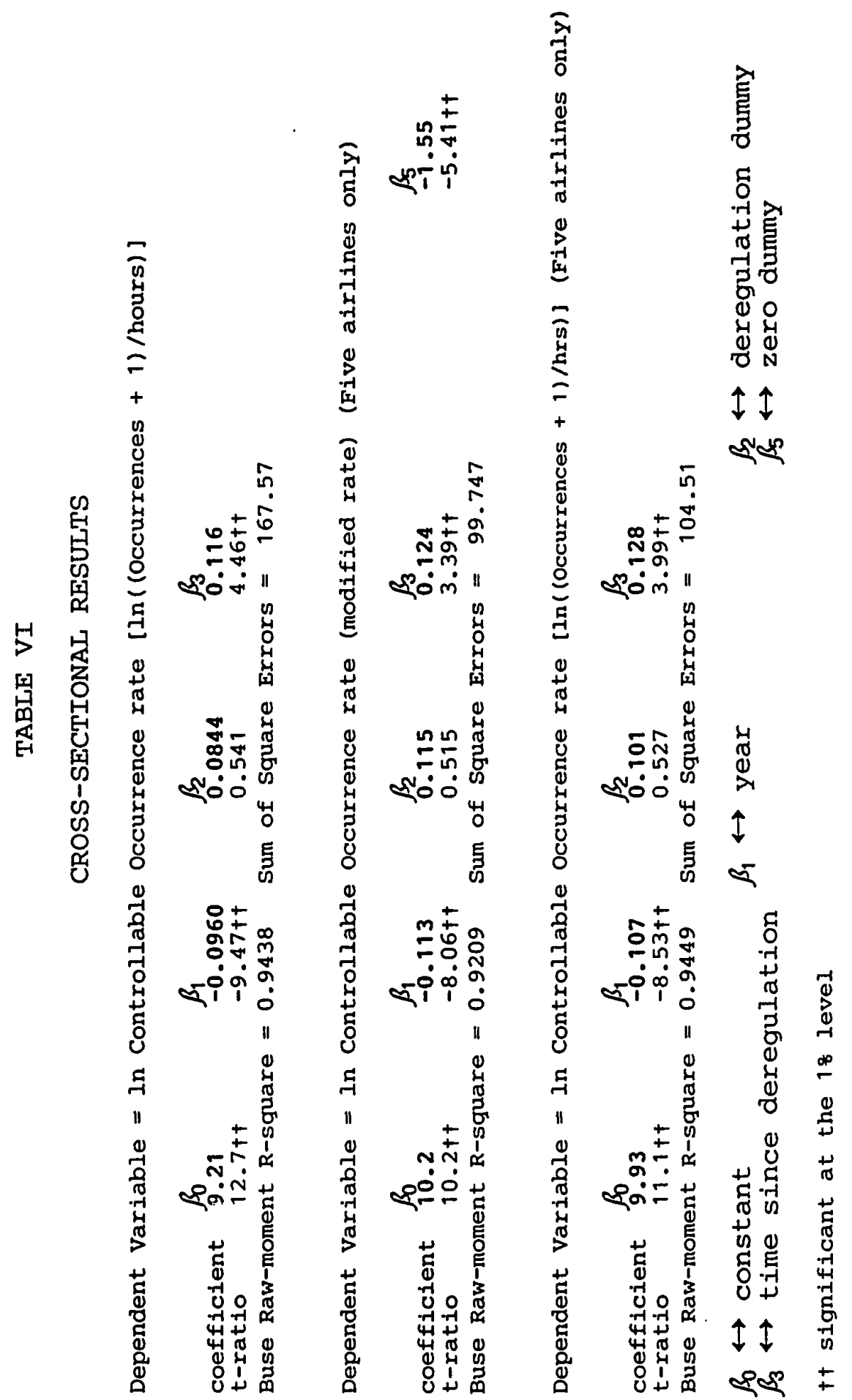


"zero points" become outliers. In fact, regressions run using this kind of transformation give coefficients and tratios for time that are much different from those expected.

By adding a larger number to the number of occurrences, one for instance, the data remains smooth and the regression coefficients have the expected signs and t-ratios. While this is not particularly satisfying from a theoretical standpoint, it does have the advantage of making the pooled cross-sectional analysis possible. Also the results are similar to those obtained using the Box-Cox transformation.*

\section{OPERATING RATIO}

If the airlines' economic health is a determinant in airline safety, some measure of economic health should be included in the formulation. Omitting variables from regression models can make the remaining variables appear to be more significant than they really are. Many observers suggested that deregulation would adversely affect the airlines' economic health. Some researchers have found links between airline economic well-being and safety (Rose, 1990: 953). In that case, omitting economic well-being could easily make the dummy for deregulation appear significant when it really is not.

\footnotetext{
* This transformation preserves the data ordering and does not introduce any obvious problems with respect to the residuals. Plots of the residuals are shown in Appendix $\mathrm{H}$.
} 
To test this hypothesis the regressions from equations

(9) and (10) were run. The equations are shown below.

$$
\begin{gathered}
\ln \text { (Rate) }=\beta_{0}+\beta_{1} \text { Time }+\beta_{2} \text { Dummy }+\beta_{4} \text { Opratio } \\
\ln \text { (Rate) }=\beta_{0}+\beta_{1} \text { Time }+\beta_{3} \text { Dummy * Time }+\beta_{4} \text { Opratio } \\
\text { In (Rate) }=\beta_{0}+\beta_{1} \text { Time }+\beta_{2} \text { Dummy }+\beta_{3} \text { Dummy * Time }+\beta_{4} \text { Opratio }
\end{gathered}
$$

The variable "opratio" is the ratio of operating expenses divided by operating revenue and is lagged one period.* Operating ratio is used to measure economic wellbeing. To the extent that safety improvements require capitalization, the use of return on investment could obscure the profitability-safety relationship. Operating ratio also has the advantage that it does not include the non-airline business of the airline holding companies. The other variables are as before.

The results of these regressions are shown in Table VII. The operating ratio is not significant in either form. the deregulation dummy is significant in both forms. The operating ratio results confirm Rose's results. She found that economic well-being was not a significant factor in determining safety for larger airlines. She obtained these results using data from all Part 121 carriers. However, she found that the effects varied for different carrier groups.

* Operating ratio is used as the measure of economic wellbeing to avoid problems with other measures. Return on investment can obscure the safety-profit relationship where safety improvements are imbedded in capital (Golbe, 1986: 312). Operating ratio as used here has the additional value of focusing on the airline operation and not on other activities of the airline holding companies. 


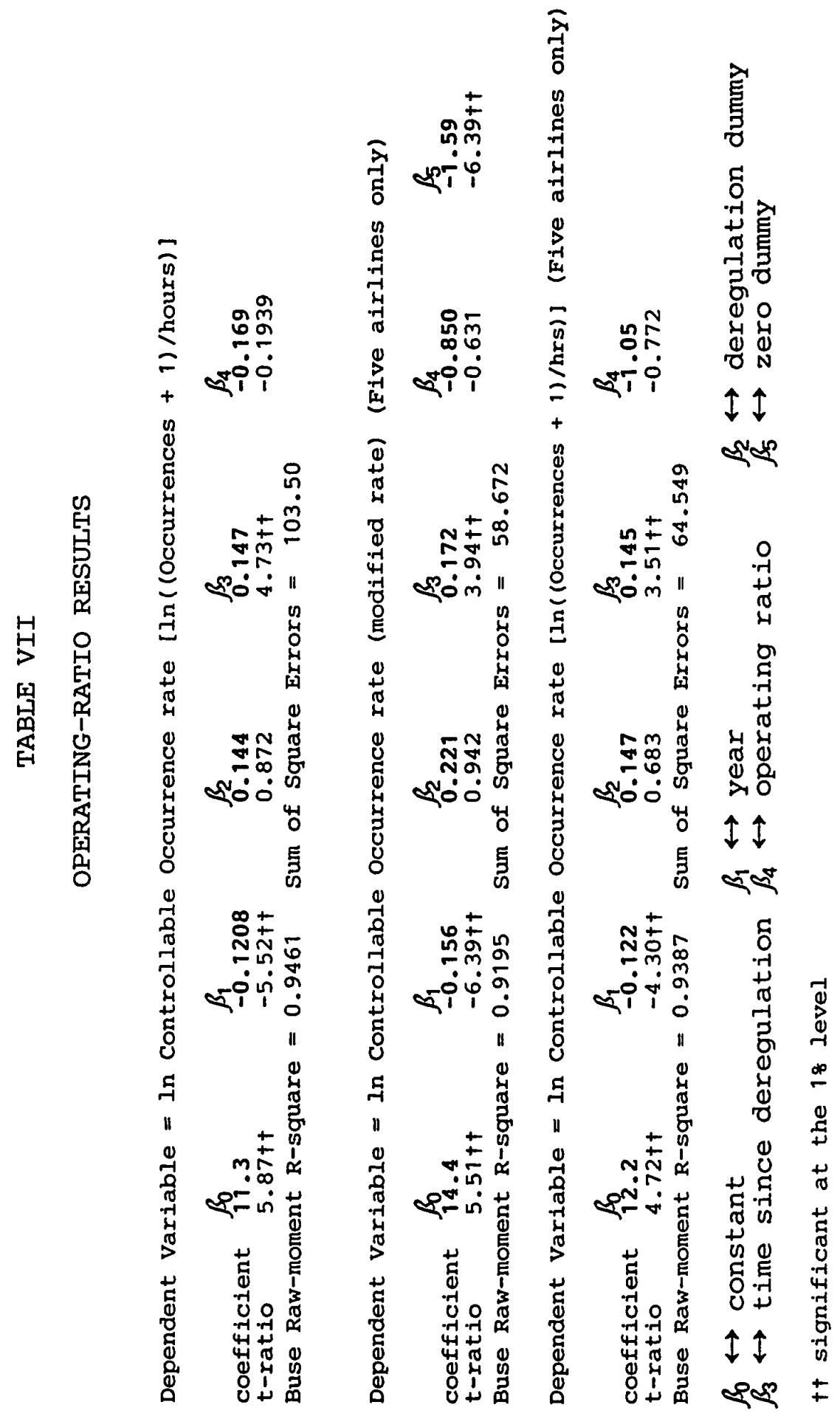


For the largest airlines operating ratio did not have a clear effect on safety, while for the smaller airlines there was a profitability effect. For the smaller airlines high profitability had a favorable effect on safety (Rose, 1990: 955).

The regressions were also run using an un-lagged form. (See the appendix.) The results were similar. The operating ratio results confirm earlier work by Golbe (Golbe, 1986: 314).

These results indicate that the original formulation was not harmed by the omission of the operating ratio.

OTHER TESTS

\section{CUSUM Test}

Another test for structural changes in regression models is the CUSUM or cumulative sum of residuals test. The output from this test is shown in Table VIII. The test was performed three times, using fatal accidents, all accidents, and accidents and incidents that were under the airlines' control.

The fatal accident and all accident models showed no indication of structural change. The model, using occurrences under the airlines' control, goes outside the 108 significance bounds in the last year. A plot of the recursive residuals is shown in Figure 1. 


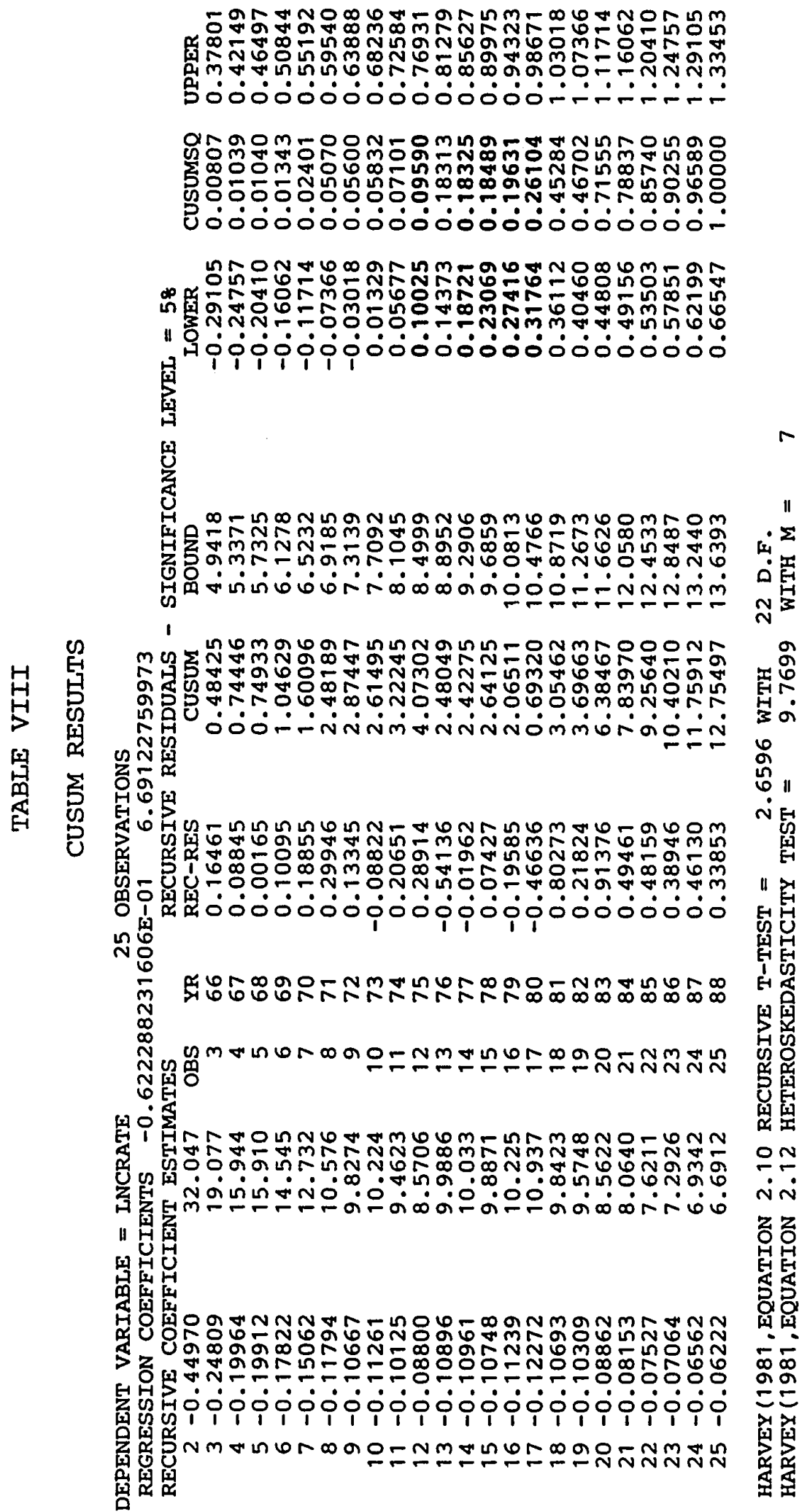




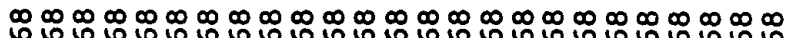
m m m m m m m m ష

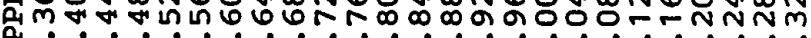

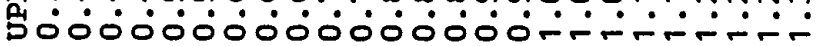

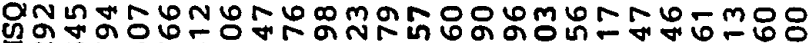

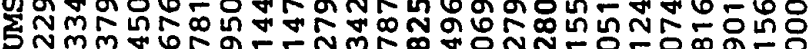

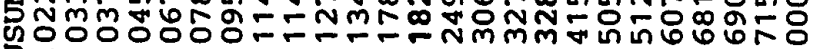

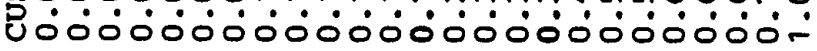

我里号

$\infty \infty \infty \infty \infty \infty \infty \infty N N N N N N N N N N N N N N N N N$ 论

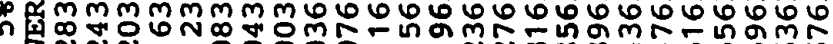
ริำกㄴ. H 空

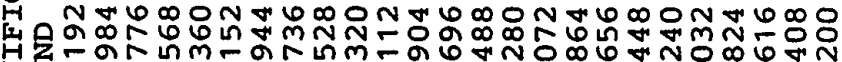

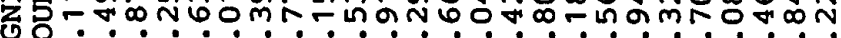
H

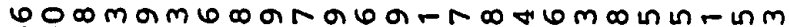

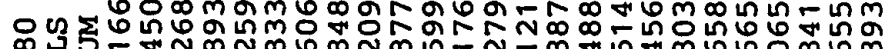

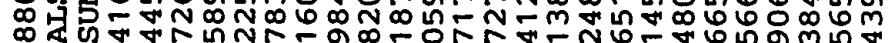

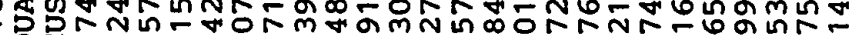
हु$$
\text { y }
$$

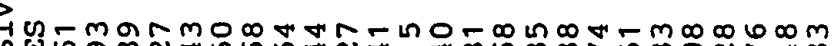

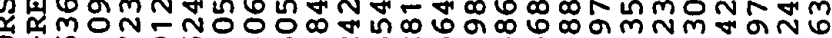
T⿱宀 N

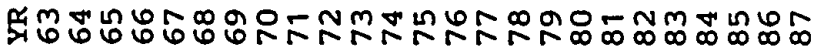

แூmm $\infty$<smiles>C=CCCC</smiles>

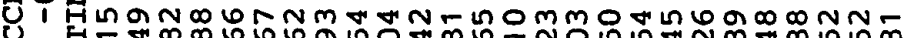

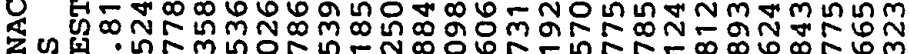

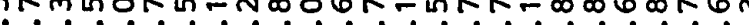
II

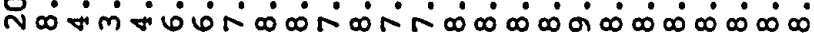

$\infty$

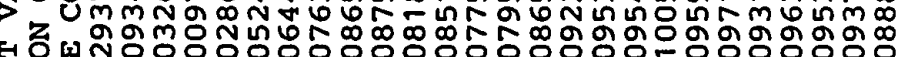

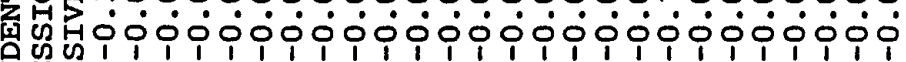
Nm in

. 


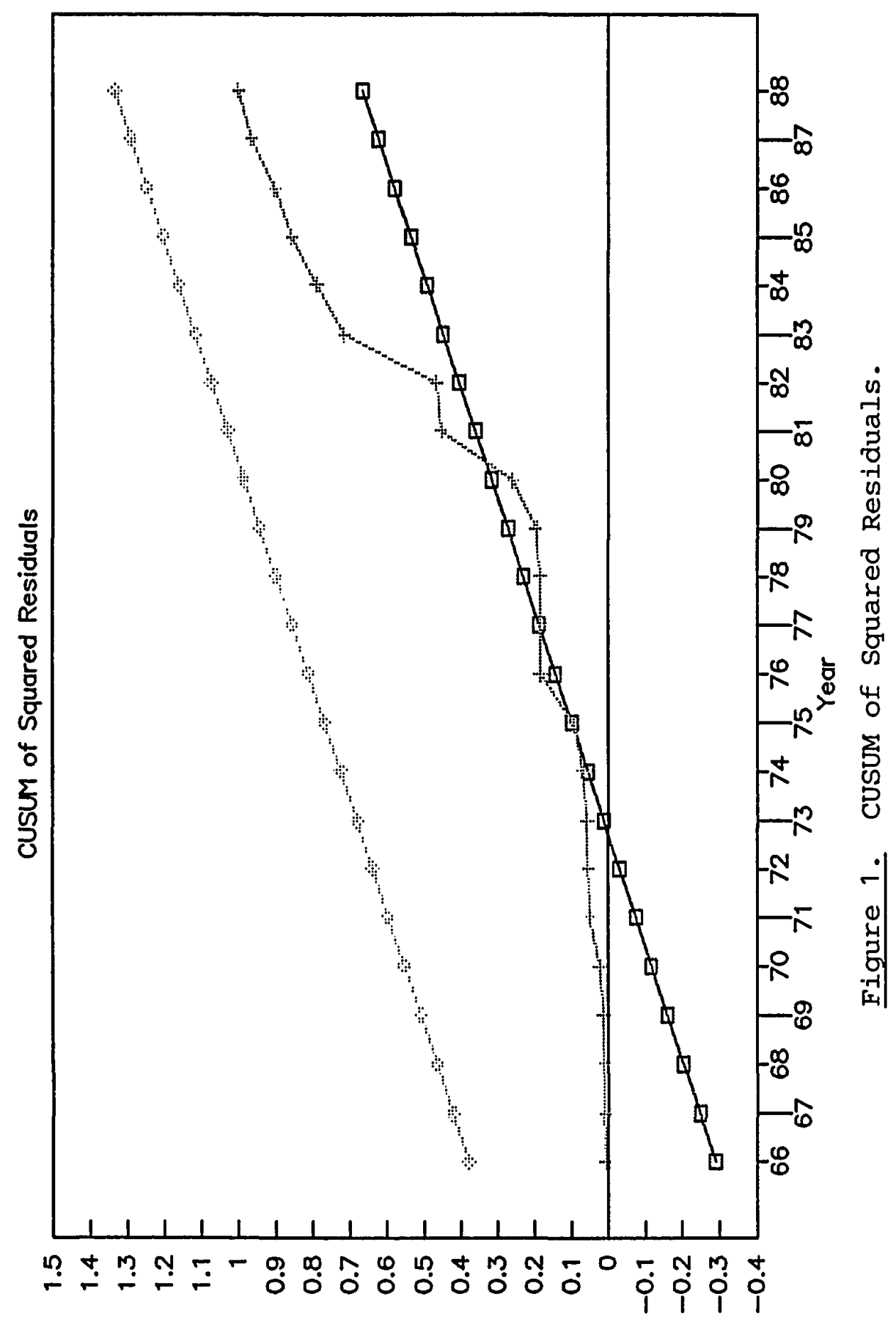

jonp!say 
These results are not conclusive. However, they are not inconsistent with the results of the oLs regressions.

Coincidence of the Structural Change and the Date of Deregulation

We have seen that there is an apparent structural change in the model near the time of deregulation. The question remains then, is 1980 the date of this apparent change? One obvious way to test this is to simply run the regressions using different dates for the dummy variable.

Results of such an exercise are shown below in Table IX. From the table one can see that any of the years 1978 through 1980 appear to fit the data quite well.

The time frame 1978 through 1980 fits the date of deregulation well. $C A B$ chairman, John Robson began to relax some of the regulatory restrictions as early as 1976 . Alfred Kahn, his successor, continued the process. The airlines could not be fully deregulated without legislation, however. The legislation was passed and signed into law in october 1978. The law provided for a seven-year phase in period. The CAB, however, had completely deregulated the industry by the end of 1979 ( Caves, Christensen, Tretheway and windle, 1987: 286).

1980 then was the first full year after deregulation was complete. Some of the early changes in regulatory posture certainly affected the industry as early as 1978 . 


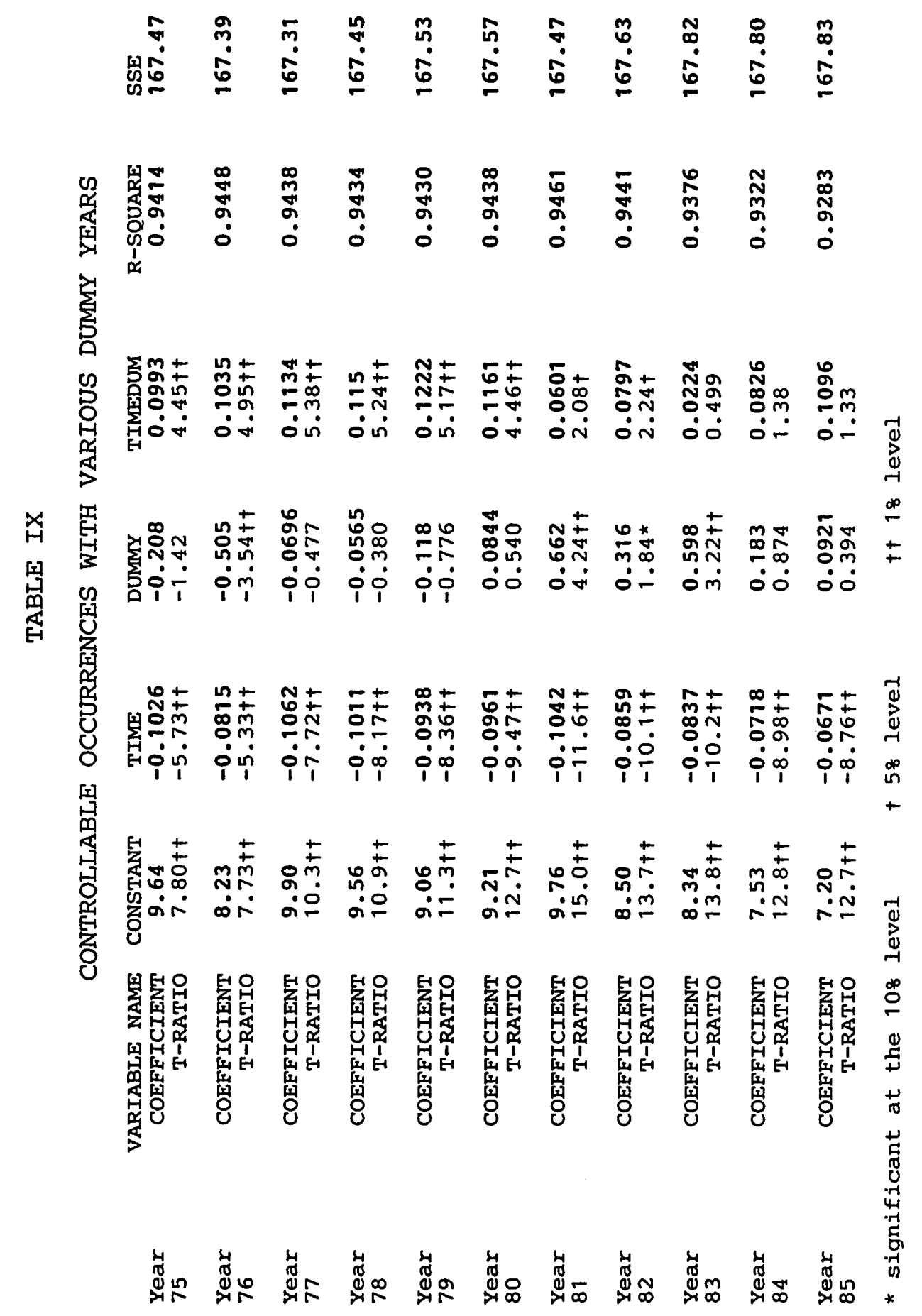


UNCONTROLLABLE OCCURRENCES

As a final exercise I have regressed the occurrences that are not under the airlines' control on time and the dummy for deregulation. I used equation (4), shown below.

$$
\ln (\text { Rate })=\beta_{0}+\beta_{1} \text { Time }+\beta_{2} \text { Dummy }+\beta_{3} \text { Dummy * Time }
$$

This equation reduces to equation (1) for time periods prior to deregulation. It can also be rearranged as follows for periods after deregulation.

$$
\ln (\text { Rate })=\left(\beta_{0}+\beta_{2}\right)+\left(\beta_{1}+\beta_{3}\right) \star \text { Time }
$$

The regression results are shown in Table $\mathrm{x}$. Looking at the table, one can see that the dummy coefficient is small compared to the constant term. While the coefficient for the term for time times dummy, (TIMEDUM), is large compared to the coefficient for the time variable, (YEAR). This can also be seen, graphically in Figure 2 . The results are disturbing. As we have seen from earlier regressions, the rate of improvement in airline safety slowed during the period since deregulation. The large positive coefficient on the variable TIMEDUM implies that the occurrences not under the airlines' control have fared even worse.

Economic deregulation cannot explain these results. Moses and Savage suggest that the infrastructure is an important factor that can affect airline safety. The increases in flying activity brought on by deregulation require additional investment in the infrastructure. They suggest that the government might not have invested enough 
TABLE X

OCCURRENCES NOT UNDER THE AIRLINES' CONTROL

Dependent Variable in uncontrollable occurrence rate $\begin{array}{lllll} & \beta_{0} & \beta_{1} & \beta_{2} & \beta_{3} \\ \text { coefficient } & 4.71 & -0.0528 & -1.299 & 0.274\end{array}$ $\begin{array}{lllll}\text { t-ratio } & 4.65+t & -3.74 t \dagger & -.570 & 7.50 \dagger t\end{array}$

R-Square Adjusted $\quad=0.7756$

Sum of Squared Errors $=1.4275$

$\beta_{0} \leftrightarrow$ constant $\quad \beta_{1} \leftrightarrow$ year $\quad \beta_{2} \leftrightarrow$ deregulation dummy

$\beta_{3} \leftrightarrow$ time since deregulation

* significant at the 108 level $t 58$ level $+\dagger 18$ level

to meet this increased need for infrastructure. Without this investment, the aviation industry cannot achieve the optimum level of safety (Moses and Savage, 1990: 174).

Appropriate investment in the infrastructure is needed to obtain the high levels of safety we expect. The regression results suggest that this level of investment is not being provided. 
93

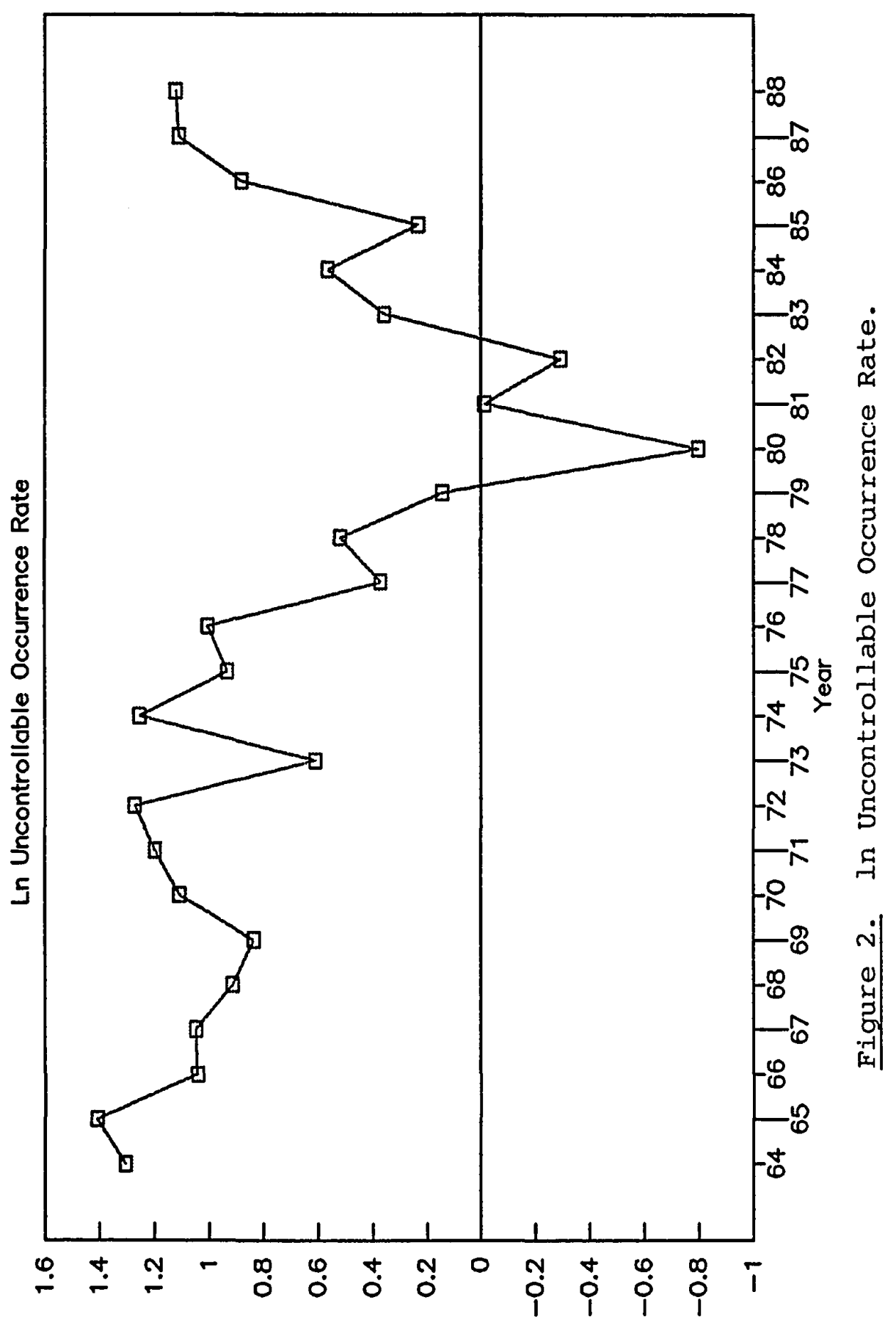

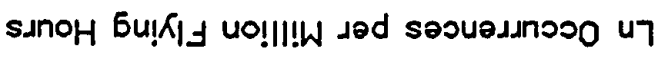




\section{CHAPTER V}

\section{CONCLUSIONS}

There has not been a decrease in safety levels since deregulation. Safety levels have continued to improve since then. The question, however, is "Are safety levels as high as they would be if the industry were still regulated?"

\section{HYPOTHESIS}

\section{Null Hypothesis}

The original question to be answered with this study concerned the effect of deregulation on airline safety. The Null Hypothesis was "Economic deregulation of the airlines has had no effect on airline safety." To test this hypothesis I focused primarily on the safety records of those eight trunk airlines that existed throughout the test period.

Other researchers have looked at the effect of new entrants. New entrants, as a group, are not as safe as the established airlines (Barnett and Higgins, 1989: 16). Others have also looked at the effects of expanding the commuters' share of the market. The smaller commuter lines are not as safe as the major carriers. However, the larger 
commuters have safety records approaching those of the majors (Oster and Zorn, 1983: 9).

The major trunk lines dominate the airline industry. The eight largest trunks controlled $86.5 \%$ of the market in 1987 (Borenstein, 1992: 47). Since the major trunks dominate the industry, it is important to see how deregulation affected this portion of the industry. The effect of deregulation on the trunks is the effect that has the greatest impact on the traveling public.

To answer this question I began with a simple OLS regression model of safety on time with a dummy for deregulation. The regression results indicated that safety had been adversely affected by deregulation. There were several potential problems with these first results.

\section{Regression Issues}

One of the oLS model assumptions is that the distribution of the error terms is normal. Since accidents occur with a Poisson distribution, this assumption is violated. The use of maximum likelihood techniques showed that the oIS model did not overstate the case for an adverse affect from deregulation.

The OLS assumption of no correlation of the error terms is violated by using cross-sectional data from the several firms in the study. Regression results from the pooled cross-sectionally correlated and time-wise auto-regressive 
model formulation indicate that the oLs results were not invalidated by making this assumption.

There is no theoretical reason to assume that the log form of the equation is the correct formulation. The regression results from the Box-Cox formulation show that the log form is a good approximation. These results also confirm the oLS results that indicate an adverse effect from deregulation.

The use of the log form created problems where there were no occurrences for some data points. In these cases the log formulation called for taking the log of zero. This problem was "solved" in three different ways. First, use was made of a "zero dummy." Here at each occurrence of $\log (0)$, the data point was replaced by $\log (1)$ and the "zero dummy" was set equal to one. The second "solution" involved modifying all the data points by adding a constant so that all rates were positive. The third was the use of the BoxCox formulation. Each of these approaches confirmed the initial OLS results. Table XI shows a comparison of the different formulations and techniques. 


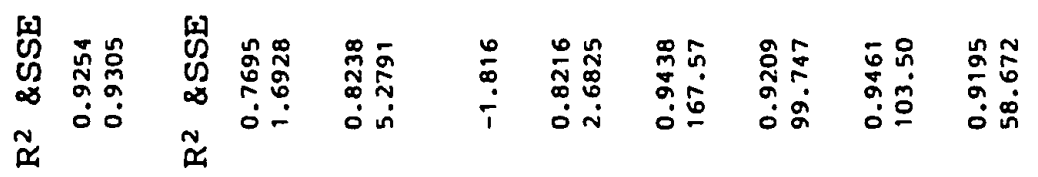

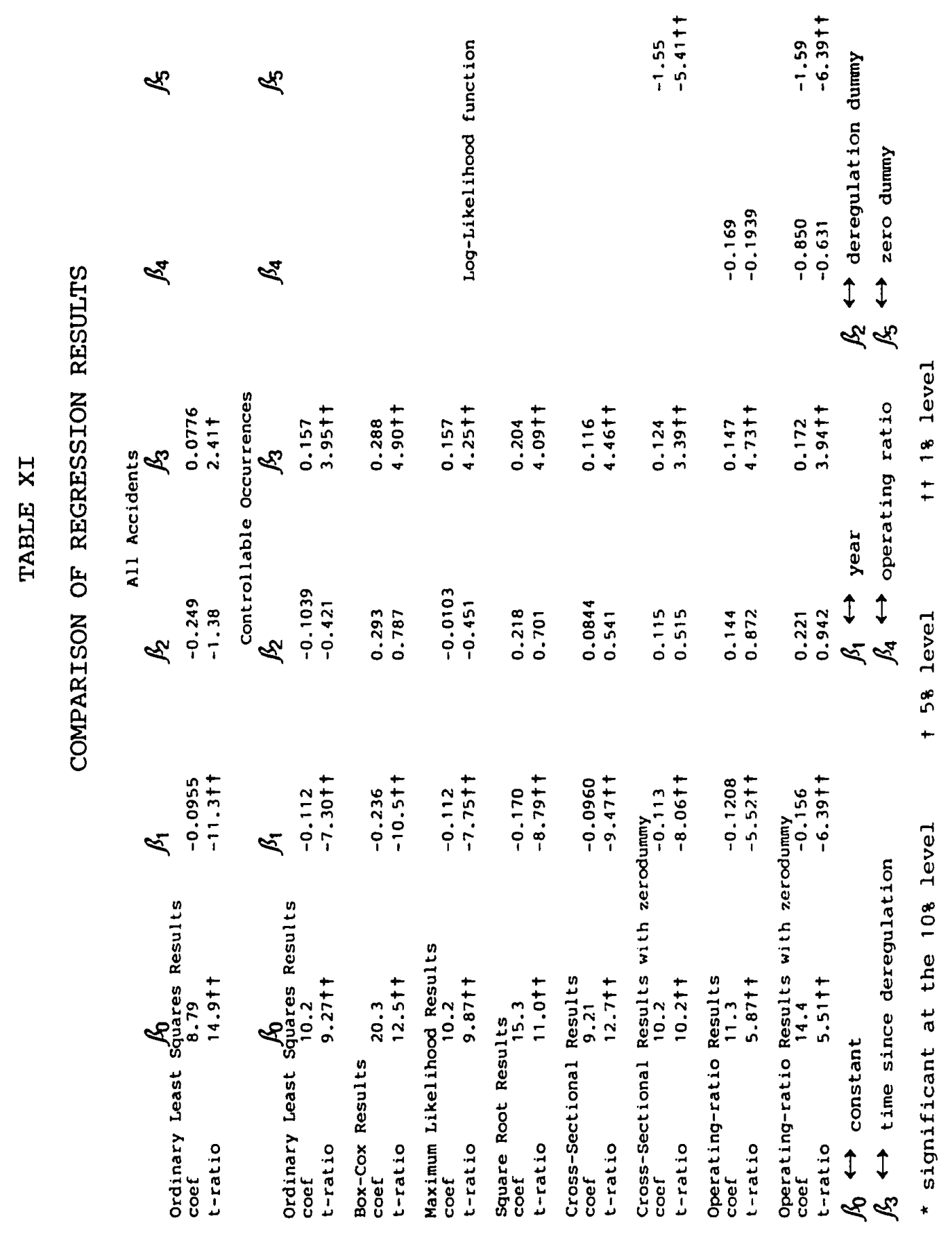




\section{Formulation Issues}

It is possible with the simple model of safety regressed on time that important independent variables might be left out of the model. One of the issues often considered as a result of deregulation is increasing fleet age. The competitive pressures of the deregulated industry have increased the age of aircraft in the fleet.

other researchers have found that the average age of aircraft involved in accidents has not gone up as fast as the average age of the fleet (Winston and Morrison, 1988: 11). This indicates that older airplanes are not causing safety problems. Therefore leaving fleet age out of the model does not change the results.

Changes in hiring practices for pilots are also cited as a factor in airline safety. How the increased age of airline new hires might affect safety is not clear. Some argue that older pilots might not retain the skills necessary to cope with emergency situations. Others argue that older pilots might be more experienced and therefore safer. Again as with fleet age the average age of pilots involved in accidents has gone up. It has not gone up as fast as the average age of all pilots, nor is the change statistically significant (Morrison and Winston, 1988: 11). Morrison and Winston also found that flying experience of pilots involved in accidents has gone up during the deregulation era. They measured experience both as total 
flying hours and as hours in aircraft type (Morrison and Winston, 1988: 11). Therefore, the results of our regressions should not be affected by leaving out pilot age as a factor.

Economic-well being of the airlines is a consideration that is often cited as a possible determinant of airline safety. Rose found that in some cases it did affect safety. Economic well-being* was included in an alternative formulation of the model. The regression results from this model indicated that in this case economic well-being was not a determinant of safety. Its inclusion or omission did not affect the results.

\section{Data Problems}

The data set is not ideal. Fatal accidents are the kinds of occurrences that concern travelers and terrorize board rooms. However, measuring safety using fatal accident statistics is difficult. Fatal accidents are simply too rare. Using all accidents as a measure of safety seems reasonable. Minor accidents have the same kinds of causes and the difference between a minor accident and tragedy often seems a matter of luck. Many other researchers have used this approach.

\footnotetext{
* Rose used operating margin which she defined as one minus the operating ratio. I used operating ratio as the measure of economic well-being.
} 
In this study, that approach was extended to include all incidents investigated by the NTSB. Rose objected to this extension. She states that most accidents are caused by pilot error, maintenance problems or training deficiencies. These cause categories are clearly factors under the airlines' control. She suspected that incidents are likely to contain a higher proportion of occurrences with cause factors like air traffic control error. Thus, a higher percentage of these occurrences would be caused by factors not under the airlines' control (Rose, 1989: 96).

In this study I have divided the occurrences into those with cause factors that are under the airlines' control and those with cause factors not under their control. This eliminates that difficulty with incident data. There is another difficulty.

Dozens of incidents are reported every year. This data is on-line for the years after 1980. For prior years it is not available on-line. Nor is the data available at all from any one source. What is available, is computer listings of those incidents investigated by the NTSB.

The NTSB investigates those incidents that are deemed to be of particular interest from a safety standpoint. To the extent that this is accomplished, this pre-sorting by the NTSB should improve the usefulness of the data set. However, there is the possibility that the NTSB has, from 
time to time, for organizational or safety or other reasons, changed the way it selects incidents to investigate.

If there was a problem with incident data, the regressions using incident data should differ from those using accident data. However, regression results for models using all accidents and models using incidents and accidents do not differ greatly. The difference of interest is in the significance of the coefficient on the deregulation dummies. The increased sample size obtained by using incidents and accidents provides more statistical power. While the dummy variables are significant at the five or ten per cent level using accident data, they are significant at the one per cent level using incidents and accidents. This additional statistical power was the reason for using incidents.

\section{Other Factors and Timing}

There is also the possibility that the change in safety levels implied by these findings was caused by some factor other than deregulation. The air traffic control strike and the controllers' subsequent dismissal is often cited as a factor that might have affected safety. Using only those occurrences that are caused by factors under the airlines' control is one technique that was used to eliminate that concern.

If the structural change in the model was caused by deregulation, the change should occur within a reasonable 
time after deregulation. Two techniques were used to test

for timing. The results of the CUSUM test were not conclusive.

The second method used was the simple expedient of checking to see if moving the dummy variables in time provided a better fit. The results of this simple experiment showed that the timeframe 1979-1980 best captured the structural change found. This fits with the 1978 passage of the airline deregulation act. All observers note that deregulation had actually begun before the bill was signed. Bailey notes that deregulation was in complete effect by January 1979 (Bailey and Panzar, 1981: 130). Again the results fit well with these observations.

\section{CONCLUSIONS}

The initial results from the simplest model using the simplest regression technique suggested that deregulation has adversely affected safety. Issues including OIS assumptions, model formulation, and data problems were raised and addressed. In every case the resulting regression model gave the same results. The coefficient for the dummy for time since deregulation is positive and significant. Only for the models using fatal accidents were the results ambiguous.

It is possible that some factor has been overlooked. It is possible some other factor is the cause of these 
statistical results. But, every effort has been made to eliminate other possibilities and I feel compelled to conclude that deregulation adversely affected airline safety. This adverse effect amounts to approximately seven or eight additional fatal accidents since deregulation.

\section{Other Concerns}

Airline safety did not improve after deregulation at the same pace as before deregulation. This was true for occurrences with cause factors under the control of the airlines. It was also true for those incidents and accidents with cause factors that were not under the airlines' control. Those occurrences not under the control of the airlines fared more poorly than those under their control.

Some of the problems that raised the rate of occurrences that were not under the airlines' control had to do with infrastructure. Airport and airway facilities and air traffic control did not fare well under deregulation. The increased traffic generated by deregulation was not matched by a corresponding increase in investment in infrastructure. The results from the model using uncontrollable occurrences indicates that the investment probably should have been made. 


\section{Recommendations}

Economics is not an interesting science, if it has no relevant input into policy making. I will, therefore, hazard some recommendations based on observations made in this study.

The benefits to the consumer of airline deregulation were calculated by Morrison and Winston to be roughly six billion dollars per year (Morrison and Winston, 1990: 390). Even if this figure is far too large, clearly, we can spend our safety dollars more effectively than by returning to a 1960's style regulation of the airline industry.

The following is sometimes suggested as a mechanism for a deregulation effect on safety. Deregulation increases competitive pressure. The increased competitiveness decreases profitability. Decreased profitability leads to cost cutting on maintenance and/or training. That leads to increased accidents or incidents. Rose's results, as confirmed here, suggest a disconnect between airline profitability and safety.

This indicates a need for further research to determine a mechanism and a solution. The results of other research suggest possible alternatives.

Market-based pricing arrangements for landing rights that place a premium on peak demand periods has been cited as a place to start (Bailey and Kirstein, 1989: 157). Worsening airport congestion is one of the results of 
deregulation. User fees that reflected the opportunity costs of the peak period landing slots would help reduce this dangerous congestion. The extra revenue could be used to upgrade facilities to reduce the problem.

The experience with air taxi operations has shown that tightening training requirements and mandating higher experience levels for pilots can have a profound effect on safety. When stricter standards were accompanied by increased surveillance and inspection emphasis, safety levels of the air taxi services improved dramatically. Deregulation did cause an increased workload in the FAA's air carrier inspection offices. This increased workload was not accompanied by increased staffing to match.

Whether stricter training requirements, congestion pricing at airports, or increased surveillance by the FAA are appropriate steps to take is not certain. Further research of this form where occurrences are separated by cause seems an appropriate place to start. In this way a mechanism for the deregulation safety connection might be ascertained.

Consumers have benefited from airline deregulation. For consumers to reap the full benefits of a competitive transportation system, policy makers need to consider the economic pressures of deregulation and their effect on the airlines. They also need to consider how the impacts of the 
expanding market for air travel affects the need for infrastructure and the need for safety surveillance and inspection. 
Andruilaitis, Robert J., David L. Frank, Tae H. Oum, Michael W. Tretheway. Deregulation and Airline Employment: Myth versus Fact. Vancouver, B.C.: The University of British Columbia Centre for Transportation Studies, 1986.

Akerlof, George A. "The Market for 'Lemons': Quality Uncertainty and the Market Mechanism." The Quarterly Journal of Economics 84, no.3 (August 1970): 488-500.

Alpert, Geraldine. "Is Market Structure Proof of Market Power." Mergers and Acquisitions (Summer 1984) 47-51.

Apcar, Leonard M. "Pilots' Bitter Strike Against Continental Changed Their Union" Wall Street Journal, 17 March 1986 .

Arnott, Richard J., and Joseph E. Stiglitz. "Congestion Pricing to Improve Air Travel Safety." in Transportation Safety in an Age of Deregulation. Leon Moses and Ian Savage. Oxford, Oxford University Press, 1989 .

Bailey, Elizabeth E., ed. Public Regulation: New Perspectives on Institutions and Policies. Cambridge, Mass.: The MIT Press, 1987.

Bailey, Elizabeth E., David R. Graham, and Daniel P. Kaplan. Deregulating the Airlines. Cambridge, Mass.: The MIT Press, 1985.

Bailey, Elizabeth E., and David M. Kirstein. "Can Truth in Airline Scheduling Alleviate the Congestion and Delay Problem?" in Transportation Safety in an Age of Deregulation. Leon Moses and Ian Savage. Oxford, Oxford University Press, 1989.

Bailey Elizabeth E., and John C. Panzar. "The Contestability of Airline Markets During the Transition to Deregulation." Law and Contemporary Problems. 44, no. 1 (Winter 1981): 125-45.

Barley, Stephen. The Final Call - Why Airline Disasters Continue to Happen. New York: Pantheon Books, 1990. 
Barone, S. S., Mansour Javidan, G. B. Reschenthaler, and Dennis J. H. Kraft. "Deregulation in the Canadian Airline Industry: Is There Room for a Large Regional Airline?

Barnett, Arnold, and Mary K. Higgins. "Airline Safety: The Last Decade." Management Science. 35, no. 1 (January 1989) : 1-21.

Barnett, Arnold, and Anthony J. LaFaso. "After the Crash: The Passenger Response to the DC-10 Disaster." Management Science. 29, no. 11 (November 1983) : 122536.

Barnett, Arnold, John Menighetti, and Matthew Prete. "The Market Response to the Sioux City DC-10 Crash." Risk Analysis. 12, no. 1 (1992): 45-52

Bauer, Paul A. "Airline Hubs: A Study of Determining Factors and Effects." Economic Review of The Federal Reserve Bank of Cleveland (Quarter 4,1987 ): 13-19.

Bauer, Paul A. "'Don't Panic': A Primer on Airline Deregulation." Economic Review of the Federal Reserve Bank of Cleveland (Quarter 4, 1986): 17-24.

Berry, Steven T., "Airport Presence as Product Differentiation." AEA Papers and Proceedings. 80, no. 2 (May 1990): 394-99.

Biederman, Paul. The U.S. Airline Industry: End of an Era. New York: Praeger, 1982.

Borenstein, Severin, "The Evolution of U.S. Airline Competition." Journal of Economic Perspectives. 6, no. 2 (Spring 1992): 45-73

Borenstein, Severin, "The Dominant-Firm Advantage in Multiproduct Industries: Evidence from the U.S. Airlines." Quarterly Journal of Economics. no. 106 (November 1991): 1237-66.

Borenstein, Severin, "Airline Mergers, Airport Dominance, and Market Power." AEA Papers and Proceedings. 80, no. 2 (May 1990): 400-04.

Borenstein, Severin, "Hubs and High Fares: Dominance and Market Power in the U.S. Airline Industry." Rand Journal of Economics. 20, no.3 (Autumn 1989): 344-65. 
Borenstein, Severin, and Martin B. Zimmerman. "Market Incentives for a Safe Commercial Airline Operation." The American Economic Review (December 1988): 913-35.

Borenstein, Severin, "Price Discrimination in Free-Entry Markets." Rand Journal of Economics. 16, no. 3 (Autumn 1985): 380-97.

Borenstein, Severin, and Martin B. Zimmerman. "Losses in Airline Demand and Value Following Accidents." in Transportation Safety in an Age of Deregulation. Leon Moses and Ian Savage. Oxford, Oxford University Press, 1989 .

Boyer, Kenneth D. The Safety Effects of Mode Switching Following Deregulation. in Transportation Safety in an Age of Deregulation. Leon Moses and Ian Savage. Oxford, Oxford University Press, 1989.

Brown, R. I., J. Durbin, and J. M. Evans. "Techniques for Testing the Constancy of Regression Relationships over Time." Journal of the Royal Statistical Society 37 , no.2 (1975): 149-92.

Breyer, Stephen. Regulation and its Reform. Cambridge, Mass.: The Harvard University Press, 1982.

Bulfinch, Thomas. Bulfinch's Mythology. New York: The Macmillan Co., 1947.

Caves, Douglas W. Air Transport and Its Regulators: An Industry Study. Cambridge, Mass.: The Harvard University Press, 1962.

Caves, D. W. . L. R. Christensen, and M. W. Thretheway. "Economics of Density versus Economies of Scale: Why Trunk and Local Service Airlines Costs Differ. Rand Journal of Economics. 15, no. 4 (Winter 1984) 471-89.

Caves, D. W., I. R. Christensen, M. W. Thretheway, and R. J. Windle. "An Assessment of the Efficiency Effects of the U.S. Airline Deregulation Via an International Comparison." from Public Regulation: New Perspectives on Institutions and Policies. Cambridge, Mass.: The MIT Press, 1987.

Chalk, Andrew J. "Comment on Karels." Economic Inquiry. 27, no. 2 (April 1989): 355-56.

Chalk, Andrew J. "Market Forces and Commercial Aircraft Safety." The Journal of Industrial Economics. 36 , no. 1 (September 1987): 61-81. 
Chalk, Andrew J. "Market Forces and Aircraft Safety: The Case of the DC-10." Economic Inquiry 24, no. 1 (January 1986): $43-60$.

Civil Aeronautics Board. Air Carrier Financial Statistics. and similar titles. (Quarterly March 1973 to June 1989).

Civil Aeronautics Board. Air Carrier Traffic Statistics. and similar titles. (Monthly March 1973 to September 1991).

Civil Aeronautics Board. Domestic Passenger Fare Investigation: January 1970 to December 1974. Washington, D.C.: GPO, 1976.

Civil Aeronautics Board. Supplement to the Handbook of Airline Statistics (various editions from 1973 to 1976).

Civil Aeronautics Board. Handbook of Airline Statistics (various editions from 1963 to 1973).

Davis, Lou, J. A. Donoghue. "Special Report on Commuter and Regional Airline Safety." Air Transport World (February 1984): 69-83.

Douglas, George W. and James C. Miller III. Economic Regulation of Domestic Air Transport: Theory and Policy. Washington D.C.: The Brookings Institution, 1974.

Eads, George $C$. The Local Service Airline Experiment. Washington, D.C.: The Brookings Institution, 1972.

Evans, Leonard, Michael C. Frick, and Richard C. Schwing. "Is it Safer to Fly or Drive?" Risk Analysis. 10, no. 2 (1990) : 239-46.

Feaver, Douglas B. "Pilots' Union, Amid Strike, Steers FAA Toward Safety Issues at Continental." Washington Post, 5 April 1984.

Frank, Robert H. "When are Price Differentials Discriminatory?" Journal of Policy Analysis and Management. 2, no.2 (1983): 238-55.

Godson, John. Runway. New York: Charles Scribner's Sons, 1973.

Godson, John. Unsafe at any Height. New York: Charles Scribner's Sons, 1970. 
Golbe, Devra L. "Safety and Profits in the Airline Industry." The Journal of Industrial Economics. 34, no. 3 (March 1986): 305-19.

Graham, D. R. D. P. Kaplan, and D. Sibley. "Efficiency and Competition in the Airline Industry." Bell Journal of Economics 14, no.1 (Spring 1983): 118-138.

Green, William H. Econometric Analysis. New York: Macmillan Publishing Co., 1992.

Gritta, Richard D. "The Significance of the Operating Ratio in Air Transportation." Proceedings of the Transportation Research Forum. 177-79.

Gujarati, Damodar N. Basic Econometrics. New York: McGrawHill Book Company, 1988.

Hausman, Jerry, Bronwyn H. Hall, and Zvi Griliches. "Econometric Models for Count Data with an Application to the Patents-R\&D Relationship." Econometrica 52, no. 4 (July 1984): 909-38.

Holmes, Thomas J. "The Effects of Third-Degree Price Discrimination in Oligopoly." The American Economic Review. 79, no. 1 (March 1989): 244-51.

Hubbard, David G. Winning Back the Sky: A Tactical Analysis of Terrorism. Dallas, Tex.: Saybrook Press, 1986.

Hurdle, Gloria J., Richard L. Johnson, Andrew S. Joskow, Gregory J. Werden, and Michael A. Williams. "Concentration, Potential Entry, and Performance in the Airline Industry." The Journal of Industrial Economics. 38, no. 2 (December 1989): 119-39.

Huston, John H. and Richard V. Butler. "The Effects of Fortress Hubs on Airline Fares and Service: The Early Returns. Logistics and Transportation Review. 24, no. 3 (September 1988): 203-15.

Johnston, J. Econometric Methods. New York: McGraw-Hill Book Company, 1984 .

Jordan, William A. Airline Regulation in America Effects and Imperfections. Baltimore, Md.: John Hopkins Press, 1970. 
Jovanis, Paul P. "A System Perspective on the Effects of Economic Deregulation on Motor Carrier Safety." in Transportation Safety in an Age of Deregulation. Leon Moses and Ian Savage. Oxford, Oxford University Press, 1989.

Judge, George G. et al., The Theory and Practice of Econometrics. New York: John Wiley and Sons, 1984.

Kahn, Alfred E. "Deregulation and Vested Interests: The Case of Airlines." in The Political Economy of Regulation R. B. Noll and B. M. Owen eds. Washington, D.C.: American Enterprise Institute, 1983.

Karels, Gordon V., "Market Forces and Aircraft Safety: An Extension." Economic Inquiry 27, no. 2 (1989): 345-354.

Keeler, Theodore E. "Airline Regulation and Market Performance." Bell Journal of Economics and Management Science 3, no. 2 (Autumn 1972): 399-424.

Keyes, Lucile S. "The Deregulation of Airline Mergers by the Department of Transportation." Journal of Air Law and Commerce. 53 (1988): 737-64.

Keyes, Lucile S. "A Preliminary Appraisal of Merger Control under the Airline Deregulation Act of 1978." Journal of Air Law and Commerce. 46 (1980): 71-100.

Keyes, Lucile S. "Notes on the history of Federal regulation of Airline Mergers." Journal of Air Law and Commerce. 37 (1971): 357-87.

Kmenta, Jan. Elements of Econometrics. New York: Macmillan Publishing Co, 1986.

Meyer, John R. "Transportation Deregulation: Possibilities and Prospects." Journal of Contemporary Business 9, no. 2 (1980): 69-85.

Meyer, John R. and Clinton V. Oster. Deregulation and the New Airline Entrepreneurs. Cambridge, Mass.: The MIT Press, 1984.

Meyer, John R, et al., Airline Deregulation: The Early Experience. Boston: Auburn House Publishing Co., 1981.

Mitchell, Mark L. and Michael T. Maloney. "Crisis in the Cockpit? The Role of Market Forces in Promoting Air Travel Safety." Journal of Law and Economics 32

(October 1989): 329-55. 
Morrison, Steven A.and Clifford Winston. "The Dynamics of Airline Pricing and Competition." AEA Papers and Proceedings (May 1990): 389-93.

Morrison, Steven A.and Clifford Winston. "Enhancing the Performance of the Deregulated Air Transportation System." Brookings Papers: Microeconomics (1989): 61112 .

Morrison, Steven A.and Clifford Winston. "Air Safety, Deregulation and Public Policy." The Brookings Review, (Winter 1988): 10-15.

Morrison, Steven A.and Clifford Winston. The Economic Effects of Airline Deregulation. Washington, D.C.: The Brookings Institute, 1986.

Moses, Leon and Ian Savage eds. Transportation Safety in an Age of Deregulation. Oxford: Oxford University Press, 1989 .

Moses, Leon and Ian Savage "Aviation Deregulation and Safety" Journal of Transport Economics and Policy 24, no. 2 (May 1990): 171-88.

Munley, Frank. Commuter Airline Safety: An Analysis of Accident Records and the Role of Federal Regulation. Washington, D.C.: Aviation Consumer Action Project, 1976.

Nance, John J. "Economic Deregulation's Unintended but Inevitable Impact on Airline Safety." in Transportation Safety in an Age of Deregulation. Leon Moses and Ian Savage. Oxford, Oxford University Press, 1989.

Oster, Clinton V. "The Impact of Deregulation On Service to Small Communities." Journal of Contemporary Business 9, no. 2 (1980) 103-121.

Oster, Clinton V., John S. Strong, C. Kurt Zorn. Why Airplanes Crash - Aviation Safety in a Changing World. New York: Oxford University Press, 1992.

Oster, Clinton V. and C. K. Zorn. "Airline Deregulation, Commuter Safety, and Regional Air Transportation." Growth and Change 14, no.3 (July 1983): 3-11.

Panzar, John C. and Ian Savage. "Regulation, Deregulation, and Safety: An Economic Analysis." in Transportation Safety in an Age of Deregulation. Leon Moses and Ian Savage. Oxford, Oxford University Press, 1989. 
Power-Waters, Brian Safety Last The Dangers of Commercial Aviation: An Indictment by an Airline Pilot. New York: Dial Press, 1972.

Reiss, Peter C. and Pablo T Spiller. "Competition and Entry in Small Airline Markets." The Journal of Law and Economics. 32 (October 1989): \$179-\$202

Rose, Nancy L. "Fear of Flying? Economic Analyses of Airline Safety." Journal of Economic Perspectives 26 , no. 2 (Spring 1992): 75-94.

Rose, Nancy I. "Profitability and Product Quality: Economic Determinants of Airline Safety and Performance." Journal of Political Economy 98, no. 5 (October 1990): 944-964

Rose, Nancy L. "Financial Influences on Airline Safety." in Transportation Safety in an Age of Deregulation Leon Moses and Ian Savage eds. Oxford: Oxford University Press, 1989.

Rosenfield, Harry N., Daniel z. Henkin, Henry A. Duffy, and Daniel T. Smith. "Special Report: Is Deregulation Good or Bad for Safety." National Safety and Health News (July 1986): 60-65.

Seattle Times, April 16, 1989

Spiller, P. T. "The Differential Impact of Airline Regulation on Individual Firms and Markets: An Empirical Analysis." Journal of Law and Economics 26, no. 3 (October 1983): 655-689.

Stanbury, W. T. and Michael W. Tretheway. "Airline Deregulation: A Bibliography." Logistics and Transportation Review 22, no. 4 (December 1988) 449-89.

Statistics Quarterly. Washington, D.C.: GPO, quarterly March 1973 to December 1988.

Stiglitz, Joseph E. "Technological Change, Sunk Costs, and Competition." Brookings Papers on Economic Activity 3, 1987

U.S. Congress. House. Sub-Committee on Aviation of the Committee on Public Works and Transportation. Hearings on HR 11145 to Amend the Federal Aviation Act of 1958 to Improve Air Service and Provide Flexibility in Air Fares. Washington, D.C.: GPO, March 6-7, 1978. 
U.S. Congress. House. Committee on Public Works and Transportation. Legislative History of the Airline Deregulation Act of 1978. Washington, D.C.: GPO, 1979.

U.S. Congress. House. Committee on Government Operations Airline Deregulation and Aviation Safety: Hearings on 95 th Congress 1 st Session. Washington, D.C.: GPO, 1977.

U.S. Department of Transportation. Air Carrier Financial

U.S. Department of Transportation. Air Traffic Monthly Washington, D.C.: GPO, monthly January 1973 to December 1988 .

U.S. Department of Transportation (DOT). Federal Aviation Administration. Aircraft Accident and Incident Notification, Investigation, and Reporting. ORDER 8020.11. Washington, D.C.: GPO, July 1986.

U.S. National Transportation Safety Board. Annual Review of Aircraft Accident Data: U.S. Air Carxier Operations. and similar titles. Washington, D.C.: GPO, annually 1972 to 1988 .

U.S. National Transportation Safety Board. A Preliminary Statistical Analysis of Aircraft Accident Data: U.S. Civil Aviation 1974. NTSB-APAP75-1. Washington, D.C.: GPO, 1975.

U.S. National Transportation Safety Board. A Study of U.S. Air Carrier Accidents 1964 - 1969. NTSB-AAS-72-5. Washington, D.C.: GPO, May 10, 1972.

U.S. National Transportation Safety Board. Briefs of Accidents: U.S. Civil Aviation. Washington, D.C.: GPO, annually 1972 to 1988 .

Wall Street Journal, March 17, 1986

Watkins, Harold D., "Non-Regulated Operation Benefits PSA." Aviation Week and Space Technology 79 (July 1, 1963): 48-49.

White, Kenneth J., S. Donna Wong, Diana Whistler, and Shirley $A$. Haun, SHAZAM User's Reference Manual ver. 6.2. New York: McGraw-Hill, 1990.

Whitnah, Donald R., Safer Skyways; Federal Control of Aviation. Ames, Iowa: Press Building, 1966.

Witkin, Richard. "Pilots Union Says F.A.A. Fails to Act on Airline's Violations." New York Times, 14 June 1984. 
Captain "X" and Reynolds Dodson. Unfriendly Skies: Revelations of a Deregulated Airline Pilot. New York: Doubleday, 1989. 
APPENDIX A

CONTROLLABLE - UNCONTROLLABLE 
APPENDIX A

$$
\text { CONTROLLABLE - UNCONTROLLABLE }
$$

THE DATA

The separation of occurrences into those under the airlines control and those not under their control is central to this work. The data is taken from NTSB computer listings. The information included in the listings and the format of the listings changed in 1982 and again in 1983. The way the data was encoded also changed with the changes in formatting.

The listings are voluminous. The data fields available vary considerably for the three formats. Therefore, the three formats will be discussed separately.

Pre 1982

The first format, which was used up through 1981, consists of about 285 data fields. Approximately sixty-five per cent of these are coded entries. There were approximately 2500 different codes used for this process (NTSB, 1981: vi). For the purpose of determining whether the occurrence was or was not under the airlines' control, many of these fields were not required. Some of the encoded information did not directly pertain to the cause of the accident/incident. Some of the information had a direct bearing for some occurrences but not others. Fortunately 
most of these contained information that is repeated in the cause or remarks sections when pertinent.

The accident/incident listing formats are the same for all types of aircraft operations. Therefore, the raw data I received from the NTSB also included a large number of fields that applied to general aviation, helicopter operations, crop dusting, etc. that had no bearing on airline operations.

The first section is identifying information. It includes the identifier code, the date, time and place and the make and model of the aircraft. The second section contains general information. This includes additional information on the aircraft and the location, and information on the operator and the type of operations. It also includes the type of accident/incident and the operational phase.

The next section concerns weather, airport facilities, and data on the type of clearance and type of approach. The next section is planned routing. That is followed by data describing the accident site and pilot data. The pilot data includes ratings and certificates, experience, and medical information.

Causes and factors is the subject of the next section. This is the largest section. Up to ten cause/factors can be shown. There are approximately 1,200 codes available to 
describe the cause or factor. There is also a provision for entering a cause directly when no appropriate code exists.

The next section is a listing of injury codes. It is followed by two short narrative sections labeled remarks and cause. The cause section can be used for additional remarks if it is not needed to list the cause. This is the use most often made of this section.

The last few sections are detailed views of particular subjects. The first of these addresses engine failures and malfunctions and the crews' corrective actions. The next section covers weather and navigational aids in more detail. The next section provides a more detailed look at the pilots' flying experience with emphasis on recent experience.

The next section contains the results of alcohol and toxicology tests on the pilot. It also includes details on impact damage with an emphasis on survivability and the possibility of post-crash egress.

The next section covers fire detection and fire extinguishing equipment and certain other aircraft safety systems. The information shown includes the availability, use and in some cases the effectiveness of the equipment. The next section is administrative data concerning the NTSB. The section following is germane to crop dusting and other aerial applications. The last two sections apply to collisions between aircraft, and ditching, respectively. 
1982 and Post 1982

The changes in format in 1982 and again in 1983 did not change the nature of the data gathered. They did change the volume. From 285 fields the number rose to approximately 700. There were similar changes in the record length and the numbers of codes available.

The change in codes available was dramatic. Prior to 1982 it was possible to enter a code indicating that the pilot suffered from a psychological condition. Beginning in 1982, one could choose from a list of more than twenty "psychological conditions" ranging from diverted attention to company induced pressure to mental performance overload. Further it was then possible to apply these codes not just to the pilot but also to any other individual deemed relevant to the investigation.

\section{Data Manipulations}

The data was received on tape. It was in IBM-style fixed-length record files with multiple records per line and undetermined-length short records that are terminated by a new line. This required that a parsing routine be written and used on the data.

After the data had been parsed, it was necessary to sort the fields into the those required for the analysis and those that were extraneous to it. 
The fields not used include those showing identifying characteristics of the aircrew members, their flying experience, and some medical information. Detailed accident location data and planned itineraries are not shown. Also left out are detailed breakouts of injury codes.

The information included is only data needed to make the determination of under the airline's control or not under the airline's control. These include causes, cause factors, person identification codes associated with the causes and factors, and a narrative description of the accident/incident.

Note that aircrew experience and medical data and detailed weather code fields are not included. The information in the cause/factor fields and the narrative are used to determine when this information is relevant.

\section{DETERMINATIONS}

The next step was to decode the data and make the appropriate determinations. Due to the huge number of possible codes and the relative paucity of occurrences, it was determined that the most expeditious way to decode was simply to reverse the coding process. This entailed simply looking up the code for each field in the record under scrutiny. Following are some examples of the determinations made for this study. The fields are decoded in the righthand column. 
The examples were chosen to illustrate the methods used. They include examples from each of the three formats. Note that the controllable/not controllable determination is a two step process. First a judgment is made as to the person or agency responsible for the occurrence. Then the determination of controllable or not is made, based on that person's relationship with the airline.

The responsible agents fell naturally into just a few groupings. The largest, of course, were pilot and maintenance. Passengers, manufacturers, and air traffic control (ATC) made up the largest groupings for those not under the airlines' control.*

* A complete list of all responsible agents includes pilot with 339 occurrences; co-pilot, 20; flight engineer, 5; maintenance, 346; ground crew, 25; flight attendant, 71 ; and company, 12. Company includes both company policies and dispatchers. This is a total of 816 occurrences under the airlines' control. (Two occurrences had both pilot and maintenance as causes.)

Responsible agents not under the airlines' control include passengers, 53 occurrences; manufacturers, 40 (includes design and quality control); ATC, 37 (includes ground control); other aircraft, 28; no one, 27 (medical problems suffered by the crew in flight); National Weather Service, 17; hijackers, 13; airport/facilities, 13 (includes runway intrusions and ground vehicle collisions with aircraft); birds, 11; cargo, 5 (cargo that was mislabeled by shippers to circumvent FAR's); stowaway, 1 ; and contaminated fuel, 1. This a total of 246 not under the control of the airlines.

There were also 54 occurrences with the responsible party unknown. Foreign object damage where the source of the foreign object could not be determined caused two more. There were a total of 1,118 occurrences during the period of the study. 


\section{Maintenance}

The first example has been extracted and decoded and is labeled Example 1. From the example we see that the nozzle retention vane failed due to metal fatigue. Further portions of the turbine assembly separated from the aircraft and caused foreign object damage to the wing. The determination is that maintenance is responsible for the occurrence.

This is a typical example. Systems or component failures are assumed to be a maintenance responsibility unless the NTSB specifically finds some other agency to be responsible. (See Example 2.) The reasoning here is that inspection and maintenance are company maintenance responsibilities. The decision to remove and replace a worn component or to wait until the next inspection cycle rest entirely with the company.

Example 2 shows how a failure might not be laid on maintenance. Here the cargo door failed and separated in flight causing an explosive decompression. The door's design is specifically listed as a cause. I made the determination that the responsible party was the manufacturer.

It is appropriate to digress here for a moment. There is a natural hierarchy when assessing responsibility for an aircraft accident. Before an aircraft is allowed to fly, the design is certified airworthy by the FAA. Maintenance 
personnel certify the aircraft ready. The pilot (or the pilot's representative) preflights the aircraft, affirming maintenance's judgment. Only then does the pilot accept responsibility and fly the airplane. It is only natural then to assume that if something goes wrong at this point that the pilot is responsible.

Maintenance would be held responsible only if the airplane was broken and that break was bad enough that the pilot could not be reasonably expected to rescue the situation. For an investigator to reach the conclusion that design was responsible was a novel idea.

\section{Weather}

The NTSB's purposes in assigning causes to these occurrences is different from that needed for this analysis. These differences show up most clearly with regard to occurrences involving adverse weather. In Example 3 the aircraft ran off the runway on landing roll-out. The weather conditions and a lack of snow removal operations are listed as the causes of the incident.

Weather does not cause accidents. Flying into adverse weather conditions that are beyond the capabilities of the aircraft or aircrew causes accidents. Rarely, misinformation concerning the nature or severity of the weather causes accidents. 
In this case, while there was not as much information available as the crew apparently desired, there was no misinformation passed on. The crew did know that it was snowing hard enough to cause a complete white-out. They were told that the field had not been plowed since the snow started. And they did know that these conditions had prevailed for several minutes. Knowing all of this the crew decided to land at the scheduled destination anyway.

The aircraft in question had more than a hundred people on board. These people all had reason to expect that they would be able to make their business meetings, start their vacations or return to their families. These expectations can bring considerable pressure on the crew to complete the flight to the scheduled destination. It is exactly these kinds of issues that this study tries to address.

There is a group of occurrences classified as in-flight encounters with weather that need to be addressed. These involve turbulence. In Example 4 we see that the aircraft encountered turbulence and that several flight attendants and passengers were injured.

This is a recurring theme and several issues need to be addressed. First, turbulence is a common occurrence. It is so common that flights that encounter some turbulence are the rule rather than the exception. Second, those who travel with their seat belt securely fastened are not often injured by turbulence. Indeed, through this whole listing 
there is not one case of a person whose seat belt is securely fastened being injured by turbulence.

Given these observations, the turbulence related occurrences were sorted using the following criteria. If the seat belt sign was illuminated, the injured party was listed as the responsible party. In those cases where both passengers and flight attendants were injured, the flight attendant was listed as the responsible party. (The flight attendant is assumed to be more culpable than passengers.) In those cases where the seat belt sign is not on, the pilot is assumed responsible. In the few instances where the turbulence was clear air turbulence (CAT), and that turbulence was not forecast, the National Weather Service is listed as the responsible party. (See Example 5.)

In Example 5 the key phrase is "unforecast severe clear air turbulence." Note that the only warning of turbulence was a pilot report (pirep) that specifically denied the presence of severe turbulence. Another important factor is that the turbulence involved is ciear air turbulence. Clear air turbulence is difficult (impossible) to foresee from the cockpit. While difficult to foresee from the cockpit, CAT is relatively easy to forecast. Therefore in this example the determination is that the National Weather Service (NWS) is responsible. 
Medical

In Example 6 we have a case where the pilot suffers a heart attack. We have no indication there were earlier problems. The determination is no one is responsible. (At least given the requirement for a physical every six months there is nothing more that the company could be expected to do to avoid similar cases.)

Not all medical problems meet the same determination. See Example 7. Here the pilot did know he had a problem. He simply failed to meet his responsibilities. The company pays pilots to sit reserve and not fly just so there will be someone available to fly, if needed in a case like this. For this system to work those who aren't well enough to fly need to make that decision for themselves.

\section{Unknown}

Examples 8 and 9 show cases where a determination could not be made. Example 9, where the investigation results are not available, is the more common case.

\section{Other Results}

The other categories are straightforward. Hijackers are responsible for hijackings. Air traffic control is responsible for issuing inappropriate instructions. Passengers are responsible for their actions, such as being drunk or failing to follow instructions or starting fires in the lavatories. 
The last category of occurrence is that caused by birds. Like all flyers, birds have a responsibility to see and avoid other flyers. This is especially true in the case of bird/aircraft collisions. The prognosis of these collisions is uniformly grave for birds; such collisions are rarely fatal to aircraft. Birds should be expected to see aircraft at greater distances than pilots can be expected to see birds. Lastly, evasive maneuvers sufficient to avoid collision are not likely to do more damage to the bird than the collision. This cannot always be said for the aircraft. Thus for all bird/aircraft collisions the bird is deemed to be the responsible party.

\section{Controllable by the Airline}

After the individual or entity responsible has been identified, the occurrences are sorted into controllable, uncontrollable or unknown. Those occurrences where the responsible individual is identified as a company employee are considered controllable. These categories include pilot, co-pilot, flight engineer, flight attendant, maintenance, company (usually taken to mean dispatchers or company policies), and ground crews.

Those listed as uncontrollable include hijacker, passenger, manufacturer, air traffic control, NWS, airport or airport facilities, other aircraft, cargo (cargo that was mislabeled and shipped contrary to FAA regulations), and 
stowaways. Also included is the category "no one." This was used most often to indicate a crewmember having an inflight medical problem, while their medical certificate was complete and up-to-date.

The third category is that of unknown. It includes those occurrences where the investigation is complete, but no cause was found and those where information is incomplete or not available. These usually are those investigations under the jurisdiction of foreign governments. The unknown category also includes the two instances of foreign object damage where the source of the foreign object cannot be determined. 


\section{Identification}

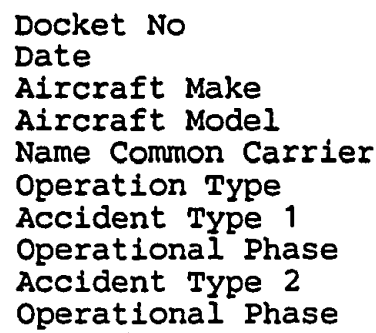

\section{Injury Codes}

Aircraft Fatal Aircraft Serious Aircraft Minor Aircraft None Aircraft Unknown Aircraft Total

Other Alrcraft Fatal Other Aircraft Serious Other Aircraft Minor Other Aircraft None Other Aircraft Unknown Other Aircraft Total

Ground Fatal

Ground Serious

Ground Minor

Ground None

Ground Unknown

Ground Total

Causes and Factors

Cause Factor $1 \mathrm{p}$
Cause 1
Cause Factor $2 \mathrm{p}$
Cause 2
Cause Factor $3 \mathrm{p}$
Cause 3
Cause Factor $4 \mathrm{p}$
Cause 4
Remarks
Cause

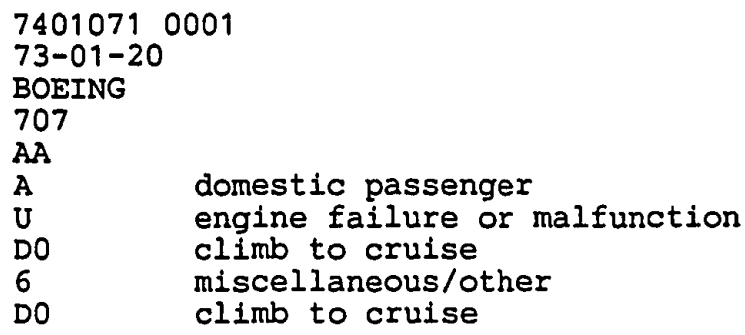

0
0
0
72
0
72

0
0
0
0
0
0

0
0
0
0
0
0 


\section{Identification}

Docket No

Date

Aircraft Make

Aircraft Model

Name Common Carrier

Operation Type

Accident type 1

operational Phase

\section{Injury Codes}

Aircraft Fatal

Aircraft Serious

Aircraft Minor

Aircraft None

Aircraft Unknown

Alrcraft Total

Other Aircraft Fatal

Other Aircraft Serious

Other Aircraft Minor

Other Aircraft None

Other Aircraft Unknown

Other Aircraft Total

\section{Causes and Factors}

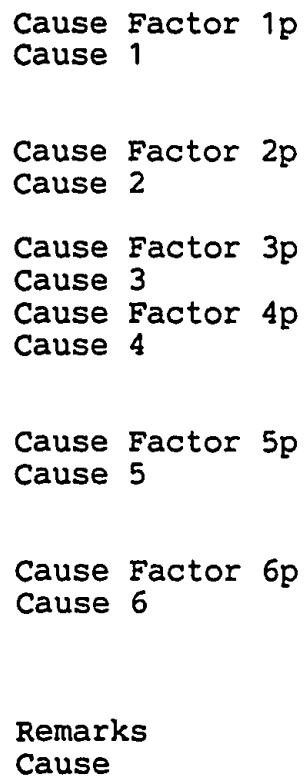

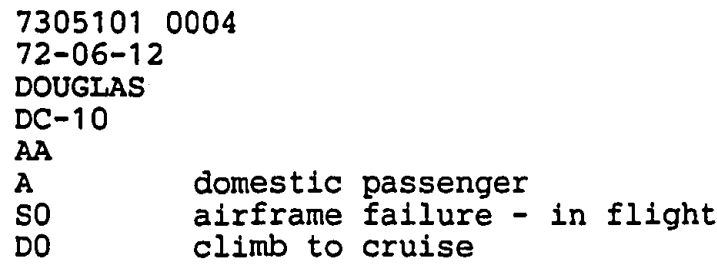

0

0

0

7

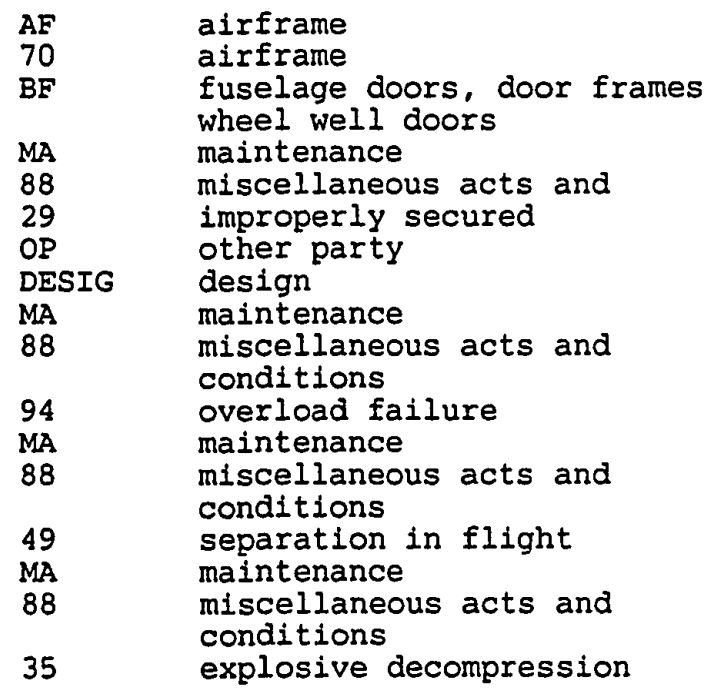

AFT BULK CARGO COMPT DOOR IMPROPERLY ENGAGED DUR ING FLT PREPARATION DUE DESIGN OF LATCH MECHANISM. 


\section{Identification}

Control Number

Occurrence Date

Accident/Incident Code

Aircraft Manufacturer

Aircraft Model and Series

Aircraft Owner
CHI82IA117

04-09-82

I

BOEING

727-200

UNITED AIRIINES

\section{Injury Codes}

Aircraft None

Aircraft Total
108

108

\section{Causes, Factors and Persons Responsible}

\begin{tabular}{lll} 
Item & Code & \multicolumn{1}{c}{ Meaning } \\
\hline Control Number & CHI82IA117 \\
Group Counter & 1 & \\
Occurrence Number & 1 & \\
Occurrence Code & 320 & on ground collision with terrain \\
Phase Code & 572 & landing roll \\
A1 Sub-code & 20000 & weather condition \\
A1 Cause/Factor & $C$ & \\
A1 Modifier Code & 2230 & whiteout \\
B1 Sub-code & 24202 & airport snow removal \\
B1 Cause/Factor & $C$ & \\
B1 Modifier Code & 3128 & not performed \\
B1 Person Code & 4124 & ground personnel \\
Direct Code & 55200 & information unavailable \\
Direct Cause/Factor & F & \\
Direct Person & 5350 & airport personnel \\
A2 Sub-code & 20000 & weather condition \\
A2 Cause Factor & $C$ & \\
A2 Modifier Code & 2220 & snow \\
A3 Sub-code & 20000 & weather condition \\
A3 Cause/Factor & $C$ & \\
A3 Modifier Code & 2218 & obscuration
\end{tabular}

\section{Narrative}

AFTER ABORTING ONE APPROACH AND HOLDING FOR SEVERAL MINUTES, THE FLIGHT WAS CLEARED FOR THE IIS APPROACH RUNWAY 32 AT 0947 EST. WHILE THE FLIGHT WAS HOLDING, THE CREW HAD SEVERAI CONVERSATIONS WITH APPROACH CONTROL AND THE COMPANY REPRESENTATIVE REGARDING RUNWAY CONDITIONS AND BRAKING ACTION. ON 2 OCCASIONS, THE UNITED CREW REQUESTED, THROUGH THE TOWER, THAT AIRPORT PERSONNEL INSPECT THE RUNWAY. THE TOWER WAS UNABLE TO CONTACT ANYONE AND STATED THAT THE LAST FIELD CONDITION REPORT WAS TAKEN AT 0815 EST. THE CREW WAS ALSO INFORMED THAT THE FIELD WAS COMPLETELY WHITED OUT AND THERE HAD BEEN NO PLOWING SINCE THE SNOW STARTED. THE APPROACH AND TOUCHDOWN WERE NORMAL WITH THE LEFT MAIN GEAR TOUCHING DOWN ABOUT 20 FT INSIDE THE IEFT EDGE OF THE RUNWAY ABOUT 1200 FT FROM THE THRESHOLD. THE LEFT MAIN GEAR LEFT THE RUNWAY APPROXIMATELY 400 FT LATER AND TRAVELED AN ADDITIONAI 750 FT BEFORE THE RIGHT GEAR RAN OFF THE RUNWAY. PRIOR TO STOPPING, THE CREW WAS ABLE TO GET THE RIGHT MAIN AND NOSE GEAR BACK ON THE RUNWAY. 
Example 4

NTSB No

ANC87FA021

Accident Incident Code

Date

Day of Week

$86-12-15$

MO

Accident Occurrence Code 0

Aircraft Manufacturer

Aircraft Series

0

BOEING

727-222

UNITED AIRIINES, INC

Operator Same

Operator Name

1

operator DBA

Operator Other

operator status

0

Injury Codes

Passenger Fatal

Passenger Serious

Passenger Minor

Passenger None

0

1

90

\section{Causes, Factors and Persons Responsible}
A1 Sub-code
20000
A1 Cause/Factor
C
2224
Weather condition
A1 Modifier Code
cause
turbulence

\section{Narrative}

ABOUT 10 MIN BEFORE ARRIVAL, THE ACFT SUDDENLY ENCOUNTERED

TURBULENCE WHICH ONE OCCUPANT DESCRIBED AS A SINGLE TREMENDOUS JOLT. THE MISHAP OCCURRED WHILE THE ACFT WAS APRX 39 MILES EAST OF ANCHORAGE INTL ARPT AND WAS DESCENDING THRU 10,000 FT. THE SEAT BELT SIGN WAS ON \& THE FLIGHT ATTENDANTS (F/A'S) WERE PREPARING THE CABIN FOR LANDING. ONE PASSENGER \& ONE F/A WERE SERIOUSLY INJURED; THE OTHER THREE F/A'S \& THREE OF THE PASSENGERS RECEIVED MINOR INJURIES. THERE WAS A SIGMET WHICH WARNED OF POSSIBLE TURBULENCE IN THE AREA. 


\section{Identification}

Control Number Occurrence Date Accident/Incident Code Aircraft Manufacturer Aircraft Model and Series Aircraft Owner

\author{
DEN82IA098 \\ 05-27-82 \\ I \\ DOUGLAS \\ DC-8-61 \\ UNITED AIRLINES INC.
}

\section{Injury Codes}

$\begin{array}{ll}\text { Aircraft Fatal } & 0 \\ \text { Aircraft Serious } & 0 \\ \text { Aircraft Minor } & 17 \\ \text { Aircraft None } & 129 \\ \text { Aircraft Unknown } & 0 \\ \text { Aircraft Total } & 146\end{array}$

Causes, Factors and Persons Responsible

\begin{tabular}{lll} 
Item & Code & \multicolumn{1}{c}{ Meaning } \\
ControI Number & DEN82IA098 \\
Group Counter & 1 & \\
Occurrence Number & 1 & \\
Occurrence Code & 240 & in-flight encounter with weather \\
Phase Code & 541 & cruise - normal \\
A1 Sub-code & 20000 & weather condition \\
A1 Cause/Factor & C & \\
A1 Modifier Code & 2205 & downdraft \\
B1 Sub-code & 24524 & descent \\
B1 Cause/Factor & 3140 & \\
B1 Modifier Code & 4001 & \\
B1 Person Code & 20000 & weather conditions \\
A2 Sub-code & C & \\
A2 Cause Factor & 2225 & turbulence, clear air \\
A2 Modifier Code & &
\end{tabular}

\section{Narrative}

THIS AIRCRAFT ENCOUNTERED UNFORECAST SEVERE CLEAR AIR TURBULANCE (CAT) WHILE IN CRUISE FLIGHT AT FL350 NEAR GOSHEN, IN. AS A RESULT OF THE ENCOUNTER, THE AIRCRAFT ENTERED AN UNCONTROLLED DESCENT WHICH WAS ARRESTED AT 31,500 FEET. A TOTAL OF SEVENTEEN PASSENGERS AND FIVE FLIGHT ATTENDANTS RECEIVED MINOR INJURIES. THE AIRCRAFT WAS INSPECTED AND FOUND AIRWORTHY. THE ONLY WARNING THAT THE CREW HAD AS TO THE POSSIBIIITY OF CAT WAS A PIREP, PASSED ON BY THE CENTER CONTROLLER, THAT REPORTED MODERATE OR LESS TURBULANCE IN THE AREA. AFTER THE ENCOUNTER THE FLIGHT CONTINUED UNEVENTFULLY TO DENVER. 
Identification

Docket No.

Date

Aircraft Make

Aircraft Model

Carrier

Operation Type

Accident Type

Operation Phase

\section{Injury Codes}

Aircraft Fatal

Aircraft Serious

Aircraft Minor

Aircraft None

Aircraft Unknown

Aircraft Total

\section{Causes and Factors}

Cause Factor 1p Cause 1

Cause Factor $2 \mathrm{p}$ Cause 2

Remarks

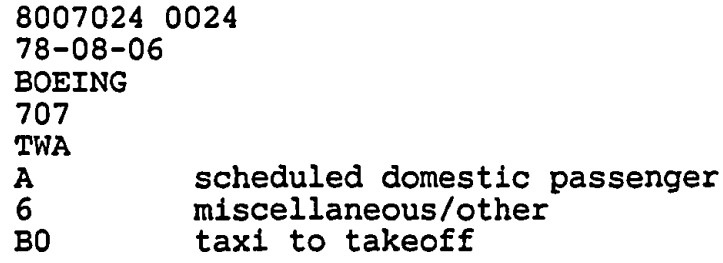

TWA

A scheduled domestic passenger

6 miscellaneous/other

BO taxi to takeoff

$\begin{array}{ll}\text { P } & \text { pilot } \\ 64 & \text { pilot } \\ 64 & \text { incapacitation } \\ & \\ \text { MA } & \text { miscellaneous acts, conditions } \\ 88 & \text { miscellaneous } \\ 65 & \text { pilot suffered heart attack }\end{array}$

MYOCARDIAL INEARCTION 


\section{Identification}

NTSB No.

Date

Day of Week

Accident Occurrence Code

Aircraft Manufacturer

Aircraft Series

Aircraft Owner

Injury Codes

Passenger Fatal

Passenger Serious

Passenger Minor

Passenger None

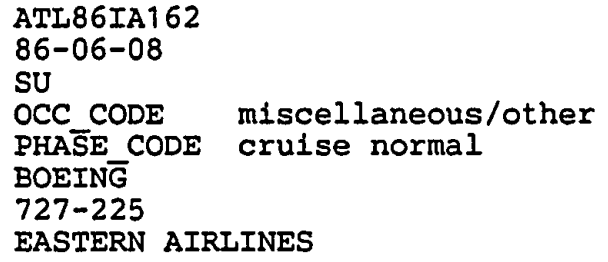

EASTERN AIRLINES

\section{Causes, Factors and Persons Responsible}

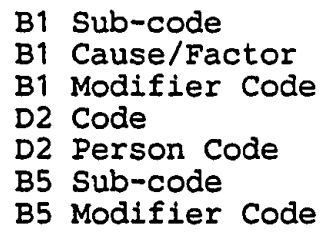

planning decision pilot in command improper incapacitation (other organic problem) pilot in command flight to alternate destination performed

\section{Narrative}

DURING A SCHEDULED AIR CARRIER FLIGHT AT NORMAL CRUISING ALTITUDE, THE CAPTAIN PASSED OUT UPON RE-ENTERING THE COCKPIT AFTER EXCUSING HIMSELF TO GO TO THE LAVATORY. THE FLIGHT CREW DIVERTED TO AN ALTERNATE DESTINATION DUE TO THE MEDICAL EMERGENCY. A REVIEW OF THE CAPTAIN'S MEDICAI HISTORY REVEALED THAT CHRONIC IYMPHATIC LUKEMIA WAS DIAGNOSED IN 1981 AND WAS FIRST REPORTED TO THE FAA IN 1985. THE CAPTAIN HAD RECEIVED SPECIAL AUTHORIZATION FROH THE FAA TO HOLD A FIRST CLASS MEDICAL CERTIFICATE IN JULY OF 1985 AND RETURNED TO FLIGHT STATUS IN FEBRUARY OF 1986 AFTER A 7 MONTH PERIOD OF SICK LEAVE. 


\section{Identification}

Docket No.

Date

Aircraft Make

Aircraft Model

Name Common Carrier

Operation Type

Accident Type 1

Operational Phase

\section{Injury Codes}

Aircraft Fatal

Aircraft Serious

Aircraft Minor

Aircraft None

Aircraft Unknown

Aircraft Total

Causes and Factors
66122110078

65-10-17

Douglas

DC-6

UAL

A domestic passenger service

F gear retracted

co takeoff run

Cause Factor 1p

Cause 1

0
0
5
11
0
16

Remarks

MS miscellaneous

84 miscellaneous

I undetermined

Remarks
Cause

AT V1 SPD AS THE CAPT STARTED TO RAISE THE NOSEW

HEEL IT RETRACTED. CAUSE OF RETRACTION NOT FOUND. 
Identification

Docket No.

Date

Aircraft Make

Alrcraft Model

Name Common Carrier

Operation Type

Accident Type 1

Operational Phase

\section{Injury Codes}

\section{Aircraft Fatal}

Aircraft Serious

Aircraft Minor

Aircraft None

Aircraft Unknown

Aircraft Total

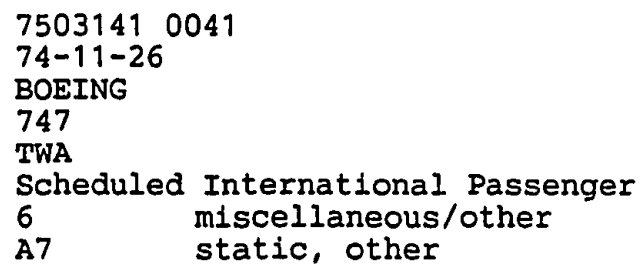

0
3
47
105
0
155

Causes and Factors

Remarks

Cause
ACFT AWAITING CLRNC.SPARKS \& SMOKE FM COVE IT.F/ A INITIATED EVAAC.INVEST JURISDCTN GOVT OF ITALY. 
APPENDIX B

DETERMINATIONS 
APPENDIX B

DETERMINATIONS

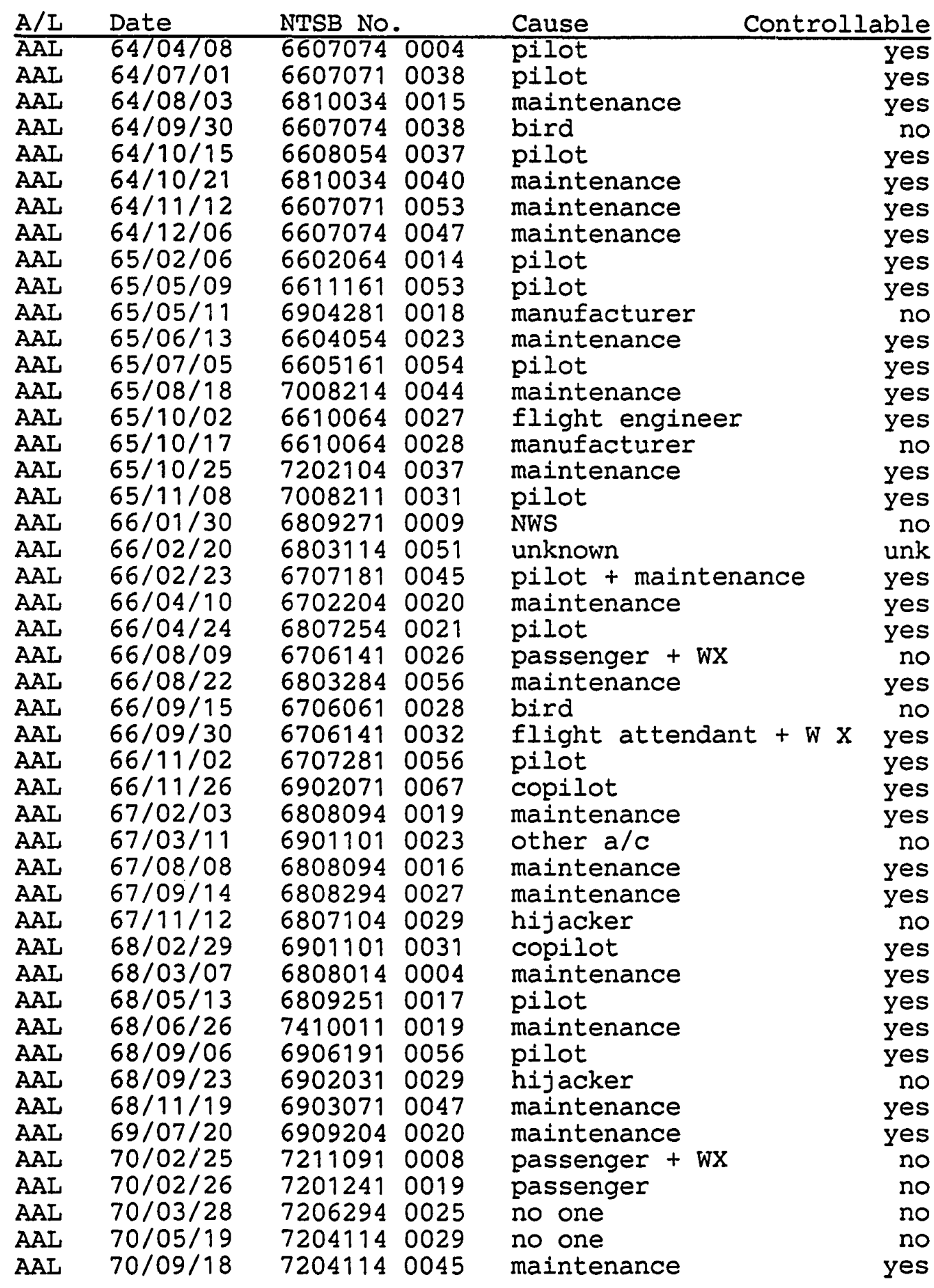




\section{APPENDIX B \\ DETERMINATIONS \\ (continued)}

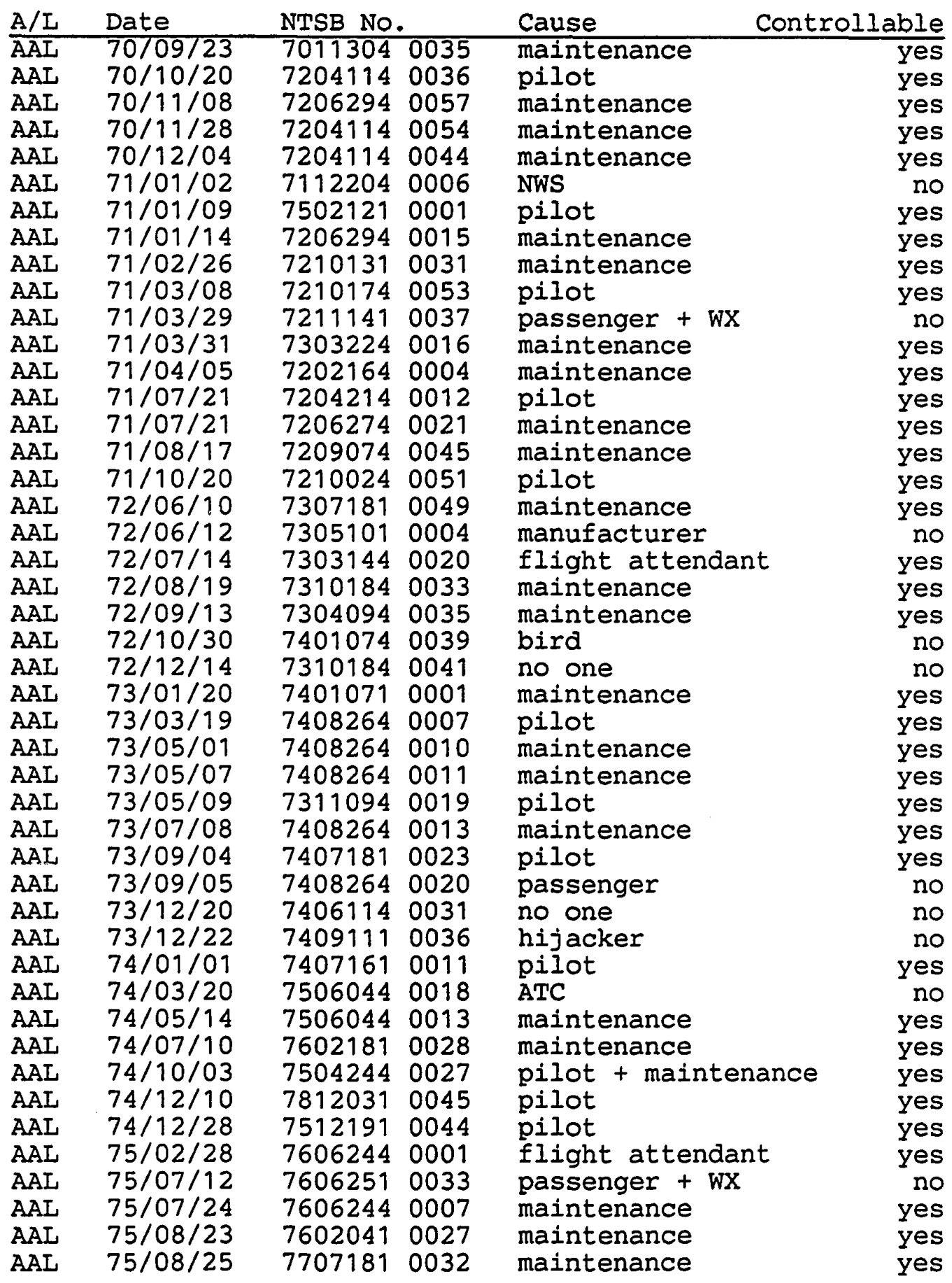




\section{APPENDIX B}

DETERMINATIONS

(continued)

\begin{tabular}{|c|c|c|c|c|c|}
\hline$A / L$ & Date & NTSB No. & & Cause & Controllable \\
\hline$\overline{\mathrm{AAL}}$ & $75 / 09 / 08$ & 7606251 & 0026 & manufacturer & $\mathrm{nc}$ \\
\hline AAL & $75 / 09 / 17$ & 7606244 & 0009 & maintenance & ye: \\
\hline AAI & $75 / 10 / 11$ & 7606254 & 0015 & maintenance & yes: \\
\hline AAL & $75 / 11 / 26$ & 7606241 & 0024 & ATC & nc \\
\hline AAL & $76 / 04 / 27$ & 7708251 & 0005 & pilot & yes \\
\hline AL & $76 / 05 / 06$ & 7702021 & 0006 & pilot & yes \\
\hline AI & $76 / 05 / 18$ & 76 & 0009 & passenger & nc \\
\hline AAL & $76 / 08 / 08$ & 7708251 & 0017 & passenger + WX & no \\
\hline $\mathrm{AL}$ & $76 / 09 / 19$ & 021 & 0018 & passenger & no \\
\hline AL & $76 / 12 / 12$ & 34 & 0018 & maintenance & ye: \\
\hline AL & $77 / 01 / 25$ & 770 & 0002 & pilot & yes: \\
\hline AI & $77 / 03 / 04$ & 7804 & 0005 & passenger + wX & nc \\
\hline AL & $77 / 04 / 05$ & 7907064 & 0008 & maintenance & yes \\
\hline AL & $77 / 06 / 22$ & 294 & 0010 & maintenance & ye: \\
\hline AL & $77 / 07 / 28$ & 780 & 0007 & maintenance & yes \\
\hline AL & $78 / 05 / 21$ & 790 & 0011 & maintenance & yes: \\
\hline AAL & $78 / 08 / 08$ & 800 & 0004 & flight attendant & yes \\
\hline AL & $78 / 09 / 20$ & 800 & 0016 & pilot & ye: \\
\hline AL & $78 / 10 / 04$ & 790 & 0022 & company & ye: \\
\hline AI & $78 / 11 / 07$ & 79 & 0021 & other a/c & ne \\
\hline AL & $79 / 04 / 10$ & 094 & 0008 & maintenance & yes \\
\hline AI & $79 / 04 / 19$ & 091 & 0032 & pilot & yes \\
\hline AI & $79 / 05 / 25$ & 81 & 0028 & maintenance & yes \\
\hline AL & $79 / 08 / 29$ & 81 & 0015 & pilot & ye: \\
\hline $\mathrm{AL}$ & $79 / 09 / 18$ & 91 & 0029 & unknown & un \\
\hline AL & $80 / 10 / 17$ & 31 & 0012 & unknown & un] \\
\hline AI & $81 / 09 / 07$ & 82 & 0013 & company & yes \\
\hline AI & $81 / 10 / 13$ & 41 & 0017 & flight attendant & yes \\
\hline Al & $81 / 12 / 18$ & 82 & 0007 & maintenance & yes \\
\hline AAL & $82 / 11 / 22$ & FTW & $44 I$ & pilot & yes \\
\hline AL & $82 / 12 / 26$ & FTW & $86 I$ & pilot & yes \\
\hline$A I$ & $82 / 12 / 30$ & FTW & $172 I$ & flight attendant & yes \\
\hline AI & $83 / 01 / 13$ & CHI8 & 972 & copilot & yes \\
\hline AAI & $83 / 09 / 07$ & CHIE & 192 & maintenance & yes: \\
\hline AAL & $83 / 09 / 23$ & FTW83IA4 & 382 & unknown & un] \\
\hline AAI & $83 / 10 / 05$ & FTW84IAO & 1072 & unknown & un? \\
\hline A. & $83 / 10 / 12$ & NYCE & 072 & pilot & yes \\
\hline AAI & $83 / 11 / 08$ & CHI84IAO & 1412 & maintenance & ye: \\
\hline AAL & $83 / 12 / 07$ & NYC84IAO & 1482 & maintenance & yes \\
\hline AAI & $83 / 12 / 29$ & LAX84IA1 & 192 & maintenance & yes \\
\hline A & $84 / 02 / 17$ & LAX84IA1 & 952 & maintenance & yes: \\
\hline$\lambda$ & $84 / 03 / 10$ & FTW84IA1 & 602 & maintenance & yes \\
\hline AAI & $84 / 07 / 03$ & DEN84IA2 & 092 & pilot & yes \\
\hline AAI & $10 / 17$ & LAX85IA0 & 1232 & maintenance & yes \\
\hline AI & $84 / 12 / 12$ & NYC85IAO & 1432 & maintenance & yes \\
\hline AAL & $85 / 03 / 24$ & CHI85IA1 & 492 & copilot & yes \\
\hline
\end{tabular}


APPENDIX B

DETERMINATIONS

(continued)

\begin{tabular}{|c|c|c|c|c|}
\hline $\mathrm{A} / \mathrm{L}$ & Date & NTSB No. & Cause & Controllable \\
\hline$\overline{\mathrm{AAL}}$ & $85 / 03 / 29$ & FTW85IA168 2 & pilot & yes \\
\hline AAI & $85 / 04 / 16$ & LAX85IA206 2 & manufacturer & no \\
\hline AAI & $85 / 04 / 23$ & CHI85FA174 1 & pilot & yes \\
\hline AAL & $85 / 05 / 27$ & CHI85IA212 2 & maintenance & yes \\
\hline AAL & $85 / 05 / 28$ & NYC85FA138 1 & maintenance & yes \\
\hline AAL & $85 / 06 / 23$ & CHI85FA249A1 & copilot & yes \\
\hline AAL & $85 / 06 / 27$ & DCA85AA027 1 & airport/facilities & \\
\hline AAL & $85 / 08 / 07$ & CHI85IA339 2 & maintenance & yes \\
\hline AAI & $85 / 09 / 03$ & FTW85IA341 2 & maintenance & yes \\
\hline AAL & $85 / 10 / 24$ & LAX86IA021 2 & ground crew & ye \\
\hline AAI & $85 / 11 / 07$ & MKC86LA025 1 & bird & \\
\hline AAL & $86 / 01 / 02$ & CHI86MA056 2 & copilot & yes \\
\hline AAL & $86 / 02 / 08$ & DCA86IA0172 & pilot & yes \\
\hline AAL & $3 / 02$ & CHI86IA099 2 & no one & no \\
\hline AAL & $1 / 12$ & ATL86LA090 1 & maintenance & $t \in$ \\
\hline AAL & $86 / 05 / 07$ & FTW86IA078 2 & pilot & \\
\hline AAL & $86 / 05 / 17$ & CHI86MA142B2 & ÄTC & no \\
\hline AAL & $1 / 06$ & 7IA068 2 & maintenance & yes \\
\hline AAL & $3 / 08$ & NYC87IA105 2 & manufacturer & $\pi$ \\
\hline AAL & $87 / 03 / 23$ & CHI87IA100 2 & manufacturer & \\
\hline AAL & $87 / 03 / 25$ & CHI87MA101 1 & maintenance & yes \\
\hline AAL & $3 / 26$ & SEA87IA068 2 & maintenance & ye \\
\hline AAL & $5 / 29$ & CHI87IA135 2 & ATC & $\mathrm{n}$ \\
\hline AAL & $87 / 06 / 06$ & LAX87IA230 2 & maintenance & ye \\
\hline AAL & $87 / 08 / 02$ & CHI87IA183A2 & other $a / c$ & \\
\hline AAL & $87 / 08 / 11$ & $\operatorname{IA} 3042$ & ATC & no \\
\hline AAL & $87 / 09 / 02$ & MIA87IA237 2 & maintenance & yes \\
\hline AAL & $87 / 10 / 09$ & LAX88IA009 2 & other $a / c$ & \\
\hline AAI & $87 / 11 / 21$ & FTW88IA029 2 & no one & \\
\hline AAL & $87 / 12 / 26$ & MIA88LA075A1 & pilot & ye \\
\hline AAL & $2 / 26$ & MIA88LA075B1 & other a/c & \\
\hline AAI & $01 / 10$ & FTW88LA050 1 & flight attendant & \\
\hline AAL & $1 / 19$ & CHI88FA048 1 & pilot & ye \\
\hline AAI & $1 / 27$ & BLA074 1 & flight attendant & ye \\
\hline AAL & $2 / 03$ & DCA88MZ002 2 & cargo & \\
\hline $\mathrm{AA}$ & $102 / 10$ & CHI88IA061 2 & airport/facilities & \\
\hline AAL & $88 / 03 / 24$ & CHI88IA081 2 & pilot & $y \in$ \\
\hline AAL & $5 / 09$ & FTW88IA097 2 & maintenance & ye \\
\hline AA & 05/21 & FTW88NA106 1 & manufacturer & \\
\hline $\mathrm{AA}$ & $88 / 05 / 23$ & MIA88IA176B2 & ATC & \\
\hline $\mathrm{AA}$ & $107 / 14$ & CHI88IA165 2 & copilot & (c \\
\hline AAL & $88 / 09 / 21$ & FTW88IA165 2 & manufacturer & $\mathrm{n}$ \\
\hline AA & $10 / 17$ & MIA89IA012 2 & pilot & \\
\hline$A A$ & $10 / 24$ & MIA89IA016 2 & maintenance & c \\
\hline AA & -1 & IAO432 2 & maintenance & $y \in$ \\
\hline $\mathrm{AA}$ & $12 / 30$ & NYC89IAO & ATC & \\
\hline
\end{tabular}


APPENDIX B

DETERMINATIONS

(continued)

\begin{tabular}{|c|c|c|c|c|c|}
\hline $\mathrm{A} / \mathrm{L}$ & Date & NTSB No. & & Control] & $a b l e$ \\
\hline CAL & $65 / 05 / 03$ & 6601041 & 0052 & manufacturer & no \\
\hline CAL & $65 / 07 / 01$ & 6704211 & 0019 & pilot & yes \\
\hline $\mathrm{AL}$ & $65 / 08 / 17$ & 6702151 & 0044 & other $a / c$ & no \\
\hline$A L$ & $65 / 10 / 17$ & 061 & 0064 & company & yes \\
\hline AL & $66 / 03 / 24$ & 061 & 0020 & pilot & yes \\
\hline AI & $66 / 05 / 14$ & 204 & 0023 & manufacturer & no \\
\hline AL & $11 / 04$ & 44 & 0038 & maintenance & yes \\
\hline $\mathrm{AL}$ & & & 0054 & flight attendant & yes \\
\hline$A T$ & $68 / 11 / 19$ & & 0016 & passenger & \\
\hline IT & $8 / 26$ & 231 & 0032 & NWS & no \\
\hline AL & & 61 & 0061 & flight attendant & yes \\
\hline AL & & & 0038 & flight attendant $+\mathrm{W} X$ & yes \\
\hline A. & $/ 16$ & & 0047 & manufacturer & $1=0$ \\
\hline$\lambda$ & $1 / 26$ & 14 & 0029 & pilot & yes \\
\hline r & 08 & & 0033 & passenger $+W X$ & no \\
\hline A. & 71 & & 0014 & pilot & yes \\
\hline & 72 & & 0025 & o one & no \\
\hline & $72 / 01 / 21$ & & 0024 & pilot & yes \\
\hline & 119 & & 0037 & passenger + WX & no \\
\hline A & 125 & & 00 & maintenance & yes \\
\hline & 75 & & 00 & pilot & ye \\
\hline & $1 / 16$ & & 001 & maintenance & yes \\
\hline & 76 & & 00 & Lot & yes \\
\hline & 76 & & 00 & ot & yes \\
\hline & 103 & & 00 & ot & ye \\
\hline & 101 & & 0001 & Lot & ye \\
\hline & 107 & & 00 & maintenance & ye \\
\hline & 80 & & 0002 & pilot & ye \\
\hline & 27 & & 0017 & copilot & ye \\
\hline & 8 & & 0023 & pilot & $y \in$ \\
\hline & & A 1 & $39 \mathrm{~A}$ & ntenance & ye \\
\hline & & $\mathrm{DE}$ & $21 \mathrm{~A}$ & maintenance & ye \\
\hline & & MF & 121 & Lot & ye \\
\hline & 104 & $\mathrm{~L} 2$ & 2621 & maintenance & ye \\
\hline & $1 / 02$ & L & 3162 & company & ye \\
\hline & 109 & & 232 & pilot & ye \\
\hline & 118 & MK & 302 & maintenance & ye \\
\hline & & & 321 & pilot & $y \in$ \\
\hline & $3 / 20$ & MKC & 1082 & airport/facilities & 2 \\
\hline & $3 / 22$ & DEN84IA1 & 162 & pilot & ye \\
\hline & $/ 17$ & DEN & 652 & airport/facilities & $\mathrm{n}$ \\
\hline & & DEN & 801 & copilot & $y \in$ \\
\hline $\mathrm{CA}$ & $05 / 25$ & FTW & 9932 & foreign object damage & un \\
\hline & 8 & MI & & passenger $+W X$ & 1. \\
\hline CA & ת & LAX & & maintenance & $y \in$ \\
\hline & $01 / 03$ & NYC & 872 & maintenance & \\
\hline
\end{tabular}


APPENDIX B

DETERMINATIONS

(continued)

\begin{tabular}{|c|c|c|c|c|}
\hline$A / L$ & Date & NTSB No. & Cause & Controllable \\
\hline$\overline{C A L}$ & $87 / 02 / 25$ & LAX87MA125A1 & ATC & no \\
\hline CAI & $87 / 08 / 02$ & CHI87IA183B2 & pilot & yes \\
\hline CAI & $87 / 08 / 03$ & DEN87IA207 2 & maintenance & yes \\
\hline CAL & $87 / 11 / 01$ & MIA88IA055A2 & ATC & no \\
\hline CAL & $87 / 11 / 01$ & MIA88IA055B2 & ATC & no \\
\hline AI & $87 / 11 / 15$ & DCA88MA004 1 & pilot & yes \\
\hline $\mathrm{CAI}$ & $87 / 12 / 03$ & FTW88IA037 2 & manufacturer & no \\
\hline CAL & $87 / 12 / 27$ & DEN88IA0432 & pilot & yes \\
\hline CAL & $88 / 03 / 10$ & ATL88IA $108 \mathrm{~A} 2$ & ATC & no \\
\hline AL & $88 / 03 / 10$ & ATL88IA108B2 & ATC & no \\
\hline CAL & $88 / 03 / 18$ & NYC8 8 IA $109 A 2$ & ATC & no \\
\hline CAL & $88 / 04 / 03$ & MIA88FA138 & pilot & yes \\
\hline CAL & $88 / 04 / 17$ & ATL88IA 1472 & manufacturer & no \\
\hline AL & $88 / 07 / 06$ & CHI88IA159 2 & maintenance & yes \\
\hline EL & 126 & 66070710030 & pilot & yes \\
\hline$\overline{E L}$ & $64 / 05 / 05$ & 66070740007 & pilot & yes \\
\hline DEL & $64 / 06 / 10$ & $6607074 \quad 0052$ & pilot & yes \\
\hline EL & $64 / 08 / 26$ & 66070740022 & pilot & yes \\
\hline EL & 124 & 66070710054 & copilot & yes \\
\hline DEL & $65 / 11 / 18$ & 66100640034 & maintenance & yes \\
\hline EL & $66 / 02 / 27$ & 67061410018 & copilot & yes \\
\hline DEL & $66 / 03 / 03$ & 70032610011 & pilot & yes \\
\hline EL & 104 & 1710012 & company & yes \\
\hline DEL & $66 / 08 / 10$ & 1440029 & maintenance & yes \\
\hline DEL & $66 / 09 / 22$ & 0610029 & pilot & yes \\
\hline DEL & $10 / 22$ & 2510055 & pilot & yes \\
\hline EL & 118 & 1440045 & maintenance & yes \\
\hline EL & $67 / 03 / 07$ & $121 \quad 0014$ & pilot & yes \\
\hline EL & $16 / 17$ & $104 \quad 0038$ & maintenance & yes \\
\hline DEL & $6 / 24$ & 710027 & maintenance & yes \\
\hline DEL & $/ 16$ & 510052 & other $a / c$ & no \\
\hline EL & 120 & 910015 & pilot & yes \\
\hline DEL & $6 / 30$ & 51910054 & maintenance & yes \\
\hline DEL & & 2310028 & manufact & no \\
\hline DEL & 107 & $14 \quad 0037$ & maintenance & yes \\
\hline DEL & 69 & 610012 & flight attendant & yes \\
\hline DEL & 108 & 3100 & pilot & yes \\
\hline DEL & 110 & 410040 & pilot & yes \\
\hline DEL & $69 / 07 / 22$ & 2310030 & pilot & yes \\
\hline DEL & $69 / 08 / 02$ & 10047 & flight attendant & yes \\
\hline DEL & 109/04 & 70012310034 & pilot & yes \\
\hline DEL & $69 / 09 / 17$ & 70052710056 & maintenance & yes \\
\hline DEL & $69 / 10 / 16$ & $7002044 \quad 0029$ & maintenance & yes \\
\hline DEL & $70 / 05 / 18$ & 72110910039 & pilot & yes \\
\hline DEL & $70 / 09 / 08$ & 011001 & pilot & yes \\
\hline DEL & $2 / 27$ & 0043 & flight attendant & yes \\
\hline
\end{tabular}




\section{APPENDIX B}

DETERMINATIONS

(continued)

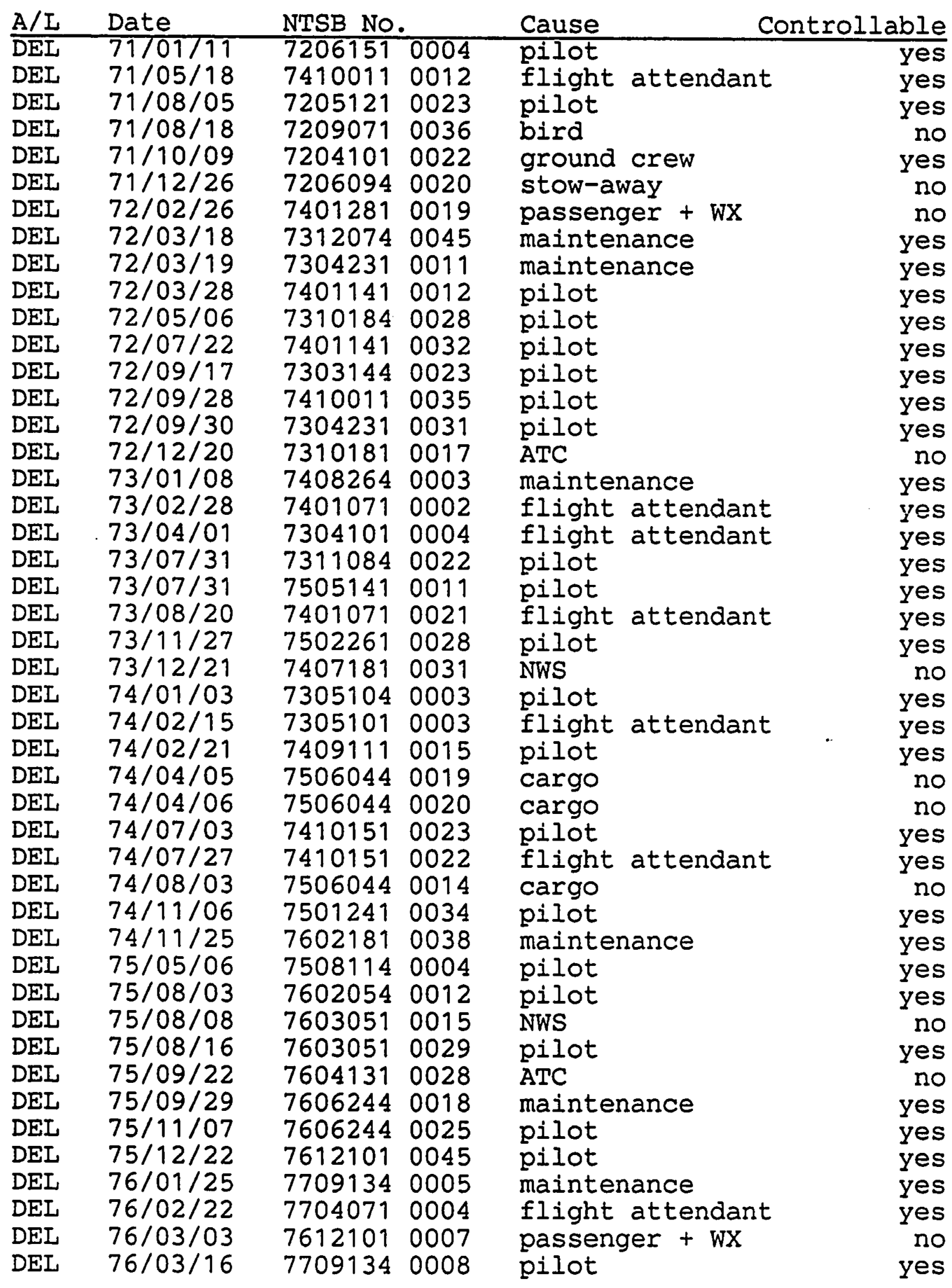


APPENDIX B

DETERMINATIONS

(continued)

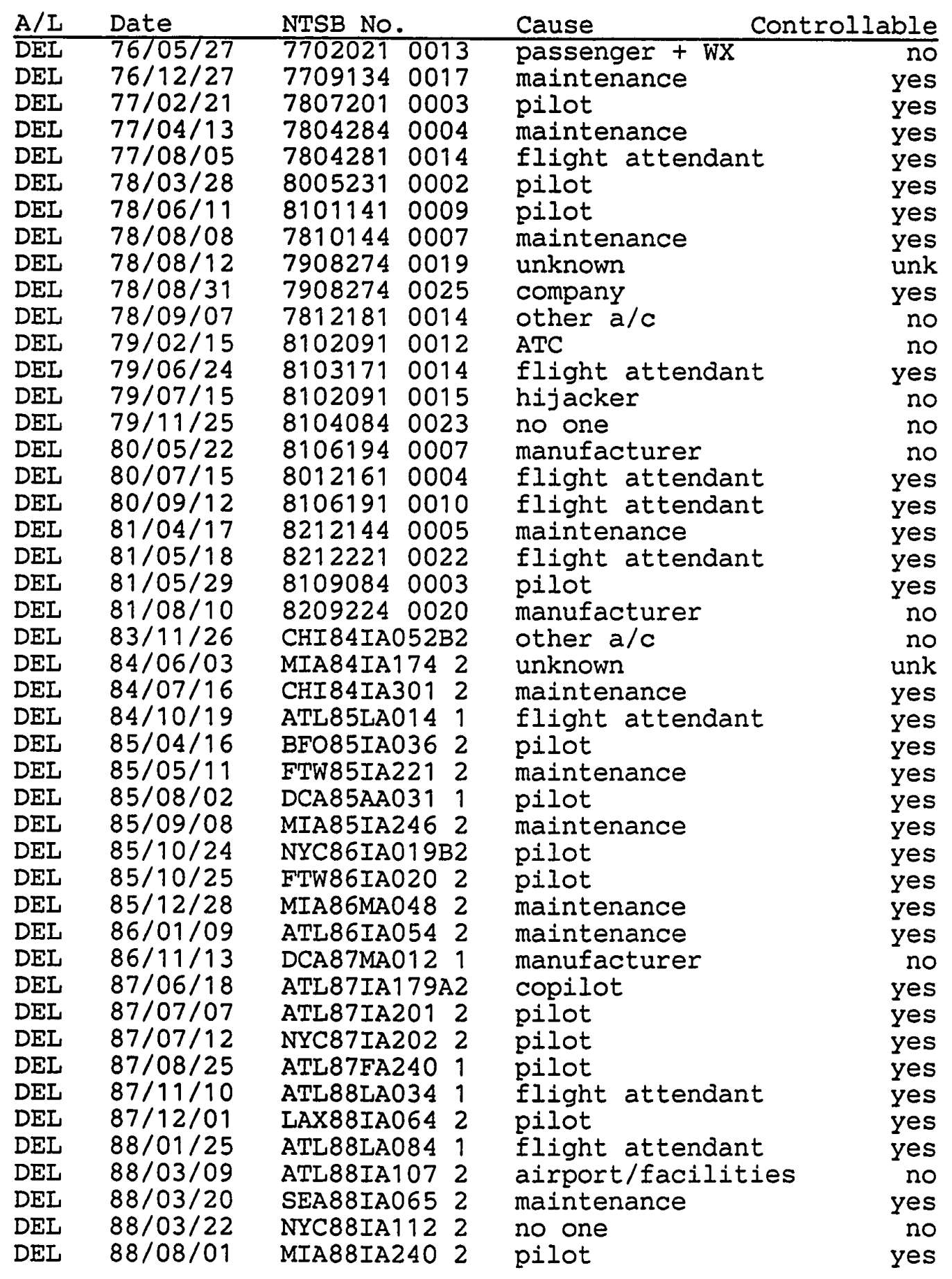




\section{APPENDIX B \\ DETERMINATIONS \\ (continued)}

\begin{tabular}{|c|c|c|c|c|}
\hline $\mathrm{A} / \mathrm{L}$ & Date & NTSB No. & Cause & Controllable \\
\hline$\overline{\mathrm{DEL}}$ & $88 / 08 / 05$ & ATL88IA226B2 & other $a / c$ & no \\
\hline DEL & $88 / 08 / 23$ & LAX88IA3112 & no one & no \\
\hline DEL & $88 / 08 / 26$ & ATL88FA239 1 & pilot & yes \\
\hline DEL & $88 / 08 / 31$ & DCA88MA072 1 & pilot & yes \\
\hline DEL & $88 / 12 / 19$ & ATL89IA057 2 & copilot & yes \\
\hline EAL & $64 / 01 / 22$ & 66070740001 & maintenance & yes \\
\hline EAL & $64 / 02 / 13$ & $6607074 \quad 0025$ & maintenance & yes \\
\hline EAL & $64 / 02 / 17$ & $6608054 \quad 0073$ & maintenance & ye \\
\hline EAL & $64 / 02 / 25$ & 71040710006 & pilot & $y \in$ \\
\hline EAL & $64 / 05 / 27$ & $6810034 \quad 0075$ & maintenance & yes \\
\hline EAL & $64 / 05 / 30$ & $6607074 \quad 0028$ & maintenance & yes \\
\hline EAL & $64 / 06 / 08$ & 66070740010 & maintenance & ye \\
\hline EAL & $64 / 06 / 18$ & $6607074 \quad 0012$ & pilot & \\
\hline EAL & $64 / 07 / 01$ & $6607074 \quad 0036$ & pilot & yes \\
\hline EAL & $64 / 07 / 15$ & 66070710049 & flight attendant & yes \\
\hline EAI & $64 / 07 / 17$ & 2510040 & pilot & yes \\
\hline EAI & $64 / 07 / 20$ & 66070710056 & copilot & yes \\
\hline EAL & $64 / 07 / 24$ & 66070710068 & passenger $+\mathrm{WX}$ & no \\
\hline EAL & $64 / 09 / 23$ & 66070710045 & ground crew & yes \\
\hline EAL & $10 / 15$ & 66070740043 & maintenance & yes \\
\hline EAL & $64 / 10 / 18$ & $6607074 \quad 0068$ & pilot & yes \\
\hline EAL & $64 / 10 / 30$ & $6602194 \quad 0041$ & ground crew & yes \\
\hline EAL & $64 / 12 / 29$ & $6607074 \quad 0066$ & maintenance & yes \\
\hline EAL & $65 / 01 / 08$ & 68042210034 & maintenance & yes \\
\hline EAI & $65 / 01 / 12$ & $6602064 \quad 0002$ & maintenance & $y$ \\
\hline EAL & $65 / 01 / 17$ & 66070740015 & maintenance & $y$ \\
\hline EAL & $65 / 02 / 08$ & 71101810001 & pilot & yes \\
\hline EAL & $65 / 03 / 05$ & 66111610035 & copilot & ye \\
\hline EAL & $65 / 04 / 19$ & 66010410074 & flight attendant & $t$ \\
\hline EAL & $65 / 04 / 26$ & 68100240036 & maintenance & ye \\
\hline EAI & $65 / 07 / 12$ & $7074 \quad 0025$ & maintenance & yes \\
\hline EAL & $65 / 07 / 16$ & 00640020 & manufacturer & no \\
\hline EAI & $65 / 09 / 28$ & 1640031 & pilot & ye \\
\hline EAL & $65 / 10 / 16$ & 1510063 & pilot & re \\
\hline EAI & $65 / 11 / 05$ & $0064 \quad 0032$ & maintenance & \\
\hline EAL & $12 / 04$ & 010033 & pilot & $y e$ \\
\hline EAL & /01/17 & $064 \quad 0004$ & maintenance & $\pi$ \\
\hline EAL & $66 / 01 / 23$ & 1210003 & pilot & \\
\hline EAL & $66 / 03 / 05$ & $6707181 \quad 0049$ & pilot & \\
\hline EAL & $66 / 03 / 15$ & $6810024 \quad 0011$ & pilot & yes \\
\hline EAI & $66 / 04 / 16$ & $6610064 \quad 0012$ & passenger & \\
\hline EAI & $66 / 04 / 17$ & 66110840016 & maintenance & \\
\hline EAL & $66 / 05 / 06$ & 66110340018 & no one & \\
\hline EAL & $66 / 05 / 20$ & $6610064 \quad 0014$ & pilot & $y$ \\
\hline EAI & $66 / 05 / 26$ & $6703214 \quad 0025$ & pilot & 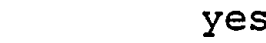 \\
\hline EAL & $66 / 06 / 18$ & 67060610040 & pilot & \\
\hline
\end{tabular}




\section{APPENDIX B \\ DETERMINATIONS \\ (continued)}

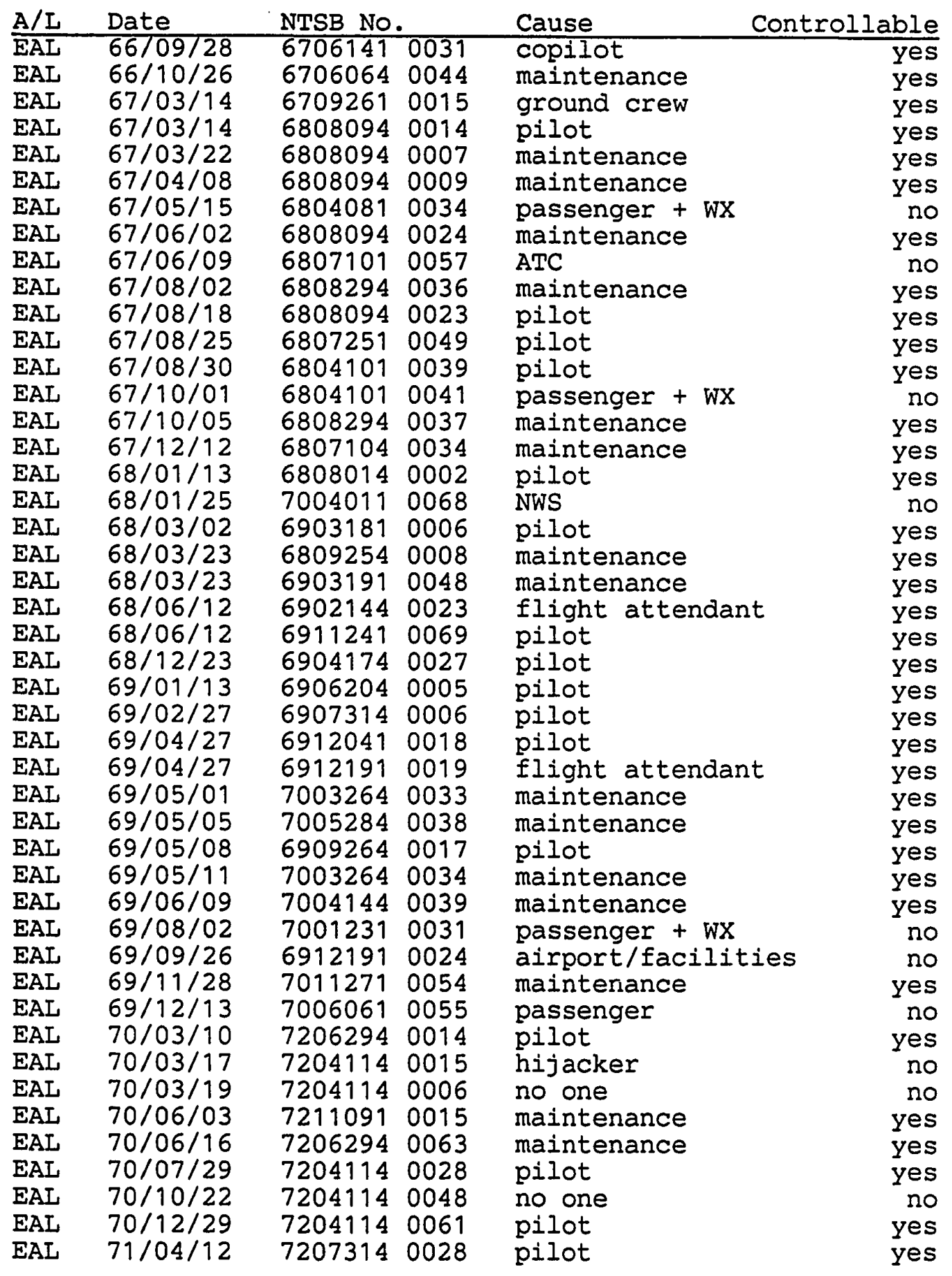




\section{APPENDIX B}

DETERMINATIONS

(continued)

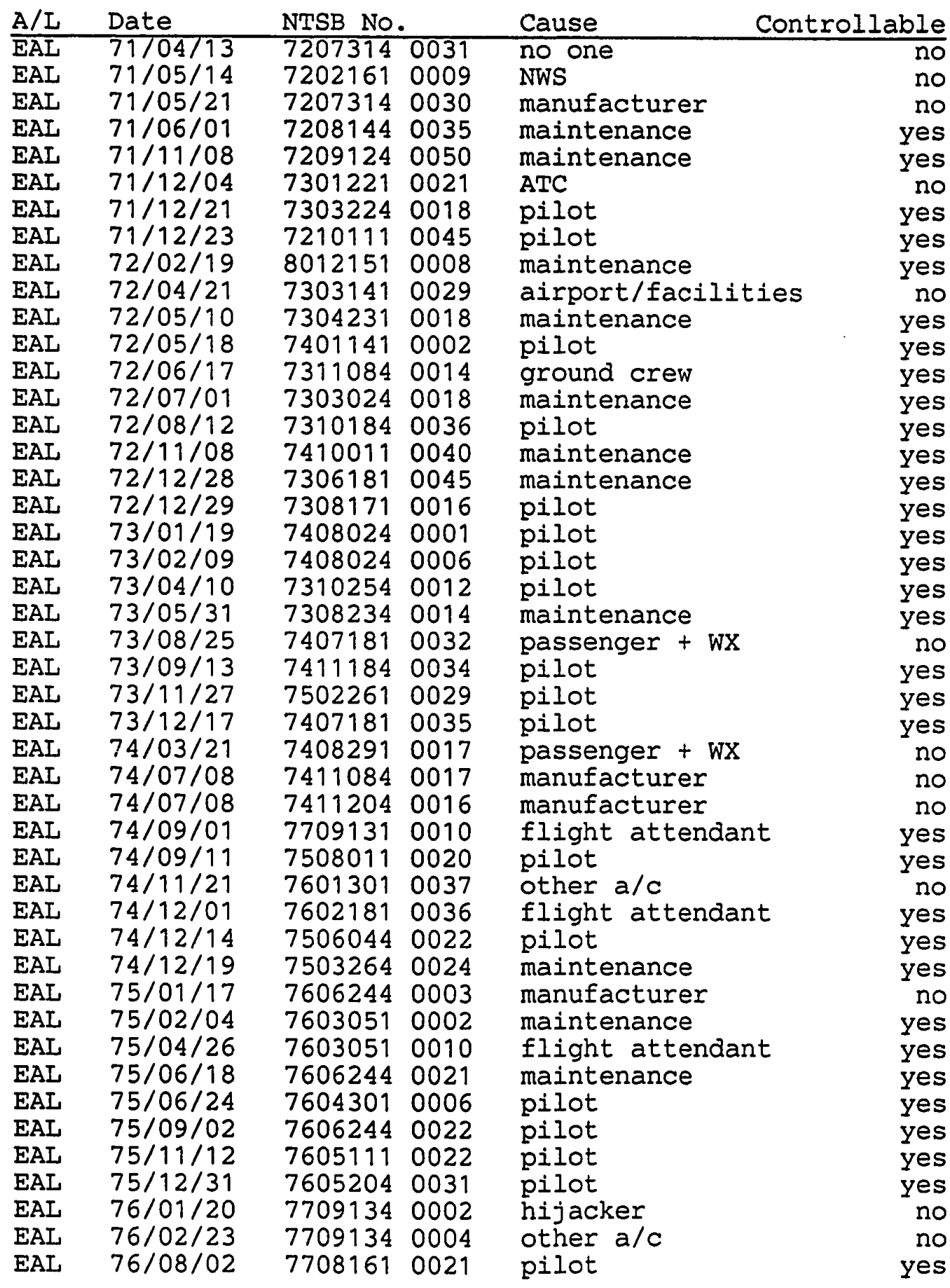




\section{APPENDIX B}

DETERMINATIONS

(continued)

\begin{tabular}{|c|c|c|c|c|c|}
\hline $\mathrm{A} / \mathrm{L}$ & Date & NTSB No. & & Cause & able \\
\hline$\overline{\text { EAL }}$ & $76 / 10 / 25$ & 7709144 & 0019 & airport/facilities & no \\
\hline EAL & $76 / 11 / 02$ & 7709134 & 0015 & maintenance & yes \\
\hline EAL & $76 / 12 / 07$ & 7709134 & 0014 & pilot & yes \\
\hline EAL & $77 / 03 / 12$ & 7803201 & 0020 & passenger + wX & no \\
\hline EAL & $77 / 05 / 25$ & 7804284 & 0014 & maintenance & yes \\
\hline EAL & $77 / 09 / 21$ & 281 & 0001 & passenger + WX & no \\
\hline EAL & $77 / 10 / 09$ & 284 & 0022 & maintenance & yes \\
\hline EAL & $77 / 12 / 31$ & 7903164 & 0028 & maintenance & $\mathrm{y}$ \\
\hline EAL & $77 / 12 / 31$ & 8001314 & 0025 & maintenance & yes \\
\hline EAI & $78 / 01 / 18$ & 7908274 & 0003 & maintenance & yes \\
\hline EAL & $78 / 02 / 10$ & 274 & 0001 & maintenance & yes \\
\hline EAL & $78 / 03 / 09$ & 7809081 & 0008 & passenger & $n$ \\
\hline EAL & $78 / 04 / 19$ & 7908271 & 0012 & flight attendant & yes \\
\hline EAI & $78 / 12 / 06$ & 061 & 0020 & passenger $+\mathrm{WX}$ & no \\
\hline EAI & $79 / 01 / 12$ & 094 & 0002 & maintenance & ye \\
\hline EAL & $79 / 03 / 22$ & 7909104 & 0001 & pilot & ye \\
\hline EAL & $80 / 04 / 04$ & 8012161 & 0003 & flight attendant & ye \\
\hline EAL & $80 / 04 / 11$ & 194 & 0002 & maintenance & yes \\
\hline$\overline{E A L}$ & $80 / 09 / 10$ & 8106194 & 0015 & unknown & un \\
\hline EAL & $81 / 01 / 31$ & 8212141 & 0011 & maintenance & ye \\
\hline EAL & $81 / 02 / 06$ & 8212141 & 0007 & maintenance & ye \\
\hline EAL & $81 / 03 / 29$ & 8212144 & 0009 & pilot & yes \\
\hline EAL & $81 / 04 / 08$ & 8212144 & 0026 & maintenance & yes \\
\hline EAL & $81 / 06 / 02$ & 8312234 & 0031 & pilot & ye \\
\hline EAL & $81 / 09 / 11$ & 8212144 & 0027 & no one & \\
\hline EAL & $81 / 09 / 22$ & 21 & 0026 & manufacturer & no \\
\hline EAL & $81 / 10 / 12$ & 8212141 & 0021 & pilot & ye \\
\hline EAL & $81 / 11 / 05$ & 8212224 & 0025 & ground crew & ye \\
\hline EAL & $82 / 04 / 20$ & MIA82IA1 & $102 I$ & maintenance & ye \\
\hline EAL & $82 / 10 / 03$ & FTW83IAO & 0052 & pilot & $\mathrm{y} \epsilon$ \\
\hline EAL & $82 / 12 / 06$ & MIA83IAO & $43 I$ & maintenance & ye \\
\hline EAL & $83 / 02 / 07$ & DCA83IAO & 0162 & pilot & ye \\
\hline EAL & $83 / 02 / 15$ & MIA83IAO & 352 & unknown & un \\
\hline EAL & $83 / 03 / 18$ & LAX83IA1 & $49 B 2$ & other $a / c$ & \\
\hline EAL & $05 / 05$ & MIA83AA1 & 1362 & maintenance & ye \\
\hline EAL & $83 / 06 / 25$ & MIA83IA1 & 1652 & unknown & un \\
\hline EAL & $83 / 11 / 06$ & MIA84 IAO & 252 & maintenance & ye \\
\hline EAL & $83 / 11 / 11$ & DCA84AAO & 5069 & maintenance & ye \\
\hline EAL & $84 / 01 / 20$ & MIA84IAO & 032 & maintenance & $y \in$ \\
\hline EAL & $84 / 01 / 21$ & MIA84IAO & 642 & maintenance & ye \\
\hline $\mathrm{EA}]$ & $84 / 02 / 16$ & ATL84 IA 1 & 1042 & maintenance & $y \in$ \\
\hline EAL & $84 / 05 / 26$ & DEN84 IA 1 & 1632 & pilot & 2 \\
\hline EAL & $84 / 07 / 16$ & DCA84 IAO & $30 A 2$ & ATC & $n$ \\
\hline EAL & $84 / 07 / 25$ & ATL84LA2 & 2351 & passenger + WX & 11 \\
\hline EAI & $08 / 25$ & MIA84IA2 & 2422 & unknown & \\
\hline EAL & & CHI85IA1 & 1012 & pilot & \\
\hline
\end{tabular}


APPENDIX B

DETERMINATIONS

(continued)

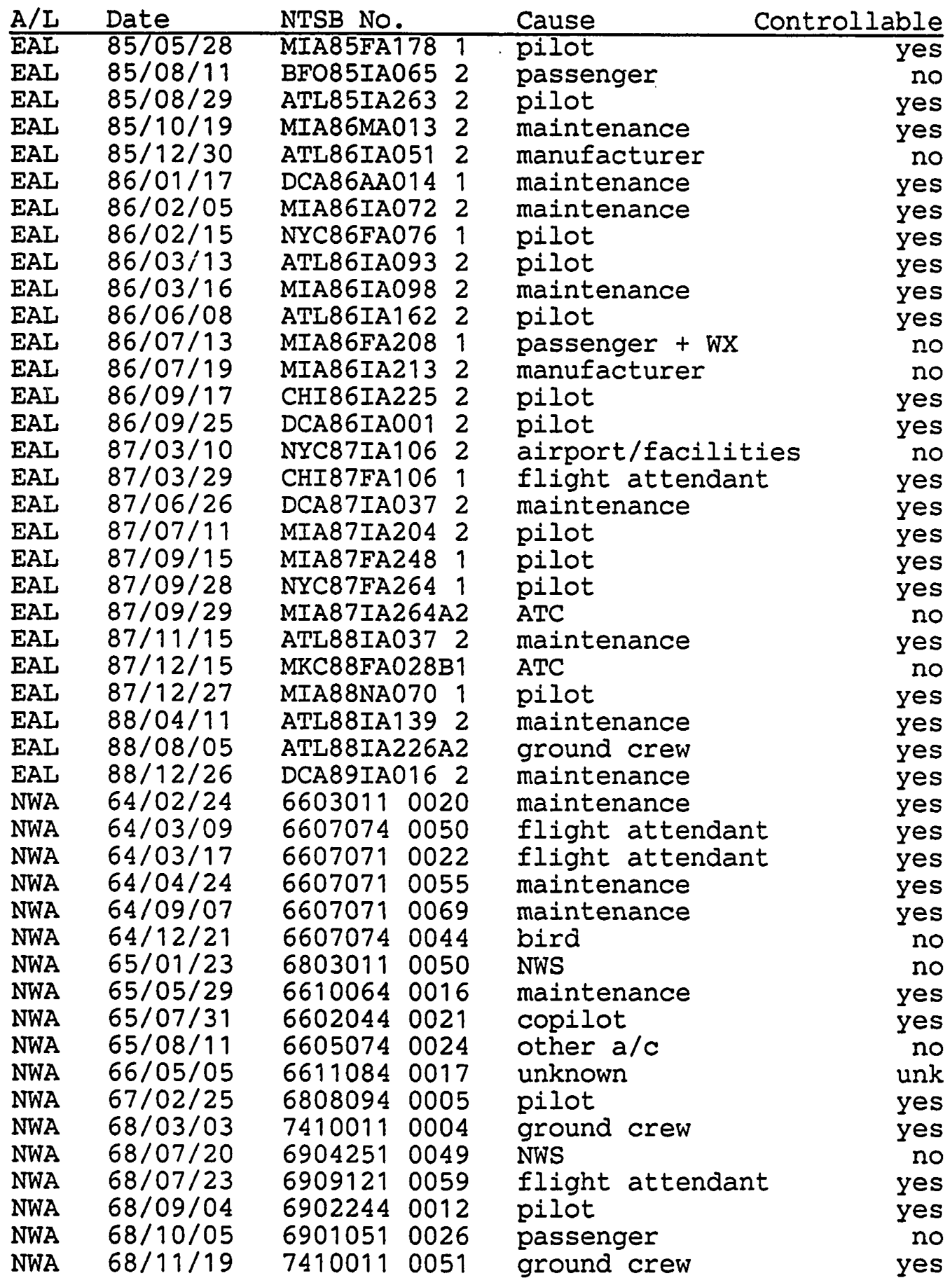




\section{APPENDIX B}

DETERMINATIONS

(continued)

\begin{tabular}{|c|c|c|c|c|c|}
\hline $\mathrm{A} / \mathrm{L}$ & Date & NTSB No. & & Cause & Controllable \\
\hline NWA & $70 / 08 / 22$ & 7204114 & 0039 & no one & no \\
\hline NWA & $70 / 12 / 18$ & 7112164 & 0081 & pilot & yes \\
\hline NWA & $71 / 03 / 13$ & 7207314 & 0025 & maintenarice & yes \\
\hline NWA & $71 / 05 / 13$ & 224 & 0005 & maintenance & yes \\
\hline NWA & $71 / 05 / 20$ & 7203234 & 0009 & maintenance & yes \\
\hline NWA & $71 / 05 / 25$ & 7207314 & 0032 & maintenance & yes \\
\hline NWA & $71 / 06 / 20$ & 7210131 & 0039 & unknown & unk \\
\hline NWA & $71 / 09 / 02$ & 304 & 0041 & maintenance & yes \\
\hline NWA & $71 / 10 / 09$ & 7209074 & 0043 & pilot & yes \\
\hline NWA & $72 / 04 / 12$ & 7304231 & 0007 & NWS & no \\
\hline NWA & $72 / 04 / 26$ & 7202094 & 0002 & pilot & yes \\
\hline NWA & $72 / 05 / 06$ & 181 & 0023 & pilot & yes \\
\hline NWA & $72 / 10 / 30$ & 7410011 & 0046 & maintenance & yes \\
\hline NWA & $72 / 12 / 15$ & 7308171 & 0037 & maintenance & yes \\
\hline NWA & $73 / 04 / 26$ & 7306071 & 0008 & pilot & yes \\
\hline NWA & $73 / 12 / 09$ & 111 & 0033 & pilot & yes \\
\hline NWA & $74 / 09 / 21$ & 7412171 & 0025 & passenger $+W X$ & no \\
\hline NWA & $74 / 11 / 21$ & 7601301 & 0037 & pilot & yes \\
\hline NWA & $75 / 03 / 13$ & 7606251 & 0043 & flight attendant & yes \\
\hline NWA & $75 / 05 / 06$ & 14 & 0004 & other $a / c$ & no \\
\hline NWA & $77 / 11 / 17$ & 7807261 & 0023 & pilot & yes \\
\hline NWA & $81 / 01 / 31$ & 8212144 & 0018 & maintenance & yes \\
\hline NWA & $81 / 02 / 11$ & 8212141 & 0020 & pilot & yes \\
\hline NWA & $81 / 04 / 09$ & 8212144 & 0001 & flight engineer & yes \\
\hline NWA & $81 / 07 / 09$ & 8110204 & 0013 & maintenance & yes \\
\hline NWA & $81 / 11 / 17$ & 8212144 & 0024 & maintenance & yes \\
\hline NWA & $83 / 05 / 26$ & CHI83IA2 & 282 & maintenance & yes \\
\hline NWA & $84 / 05 / 17$ & CHI84IA1 & 962 & maintenance & yes \\
\hline NWA & $84 / 09 / 29$ & SEA84 IA2 & 332 & maintenance & yes \\
\hline NWA & $84 / 12 / 04$ & ATL85IAC & 472 & maintenance & yes \\
\hline NWA & $85 / 01 / 26$ & CHI85IAC & 1972 & maintenance & yes \\
\hline NWA & $85 / 11 / 28$ & CHI86IAC & 342 & maintenance & yes \\
\hline NWA & $86 / 04 / 03$ & CHI86IA1 & 152 & manufacturer & no \\
\hline NWA & $86 / 11 / 05$ & CHI87IAC & 262 & manufacturer & no \\
\hline NWA & $86 / 12 / 01$ & CHI87IAC & 392 & pilot & yes \\
\hline NWA & $87 / 06 / 02$ & DEN87IA1 & $45 \mathrm{~A} 2$ & ÄTC & no \\
\hline NWA & $87 / 06 / 18$ & CHI87IA1 & 632 & pilot & yes \\
\hline NWA & $87 / 08 / 16$ & DCA87MAC & 46 & pilot & yes \\
\hline NWA & $87 / 10 / 05$ & CHI88IAC & 1032 & maintenance & yes \\
\hline NWA & $88 / 01 / 09$ & CHI88IAC & 402 & maintenance & yes \\
\hline NWA & $88 / 02 / 19$ & CHI88IAC & $73 A 2$ & ATC & no \\
\hline NWA & $88 / 03 / 27$ & CHI88IAC & 882 & maintenance & yes \\
\hline NWA & $88 / 03 / 30$ & DCA88IAC & 442 & maintenance & yes \\
\hline NWA & $88 / 07 / 11$ & CHI88FA1 & 631 & pilot & ye: \\
\hline NWA & $88 / 08 / 05$ & ATL88IR & 27 & maintenance & yes \\
\hline NWA & $88 / 09 / 09$ & CHI88F & 331 & pilot & \\
\hline
\end{tabular}




\section{APPENDIX B \\ DETERMINATIONS \\ (continued)}

\begin{tabular}{|c|c|c|c|c|c|}
\hline$A / L$ & Date & \multicolumn{2}{|c|}{ NTSB No. } & Cause & Controllable \\
\hline NWA & $88 / 10 / 24$ & CHI89IA & $\lcm{5182}$ & maintenance & yes \\
\hline NWA & $88 / 10 / 30$ & ATL89FA & 0201 & airport/facilities & no \\
\hline PAA & $64 / 03 / 05$ & 6602194 & 0072 & unknown & unk \\
\hline $\mathrm{PAA}$ & $64 / 04 / 07$ & 6607071 & 0052 & pilot & yes \\
\hline PAA & $64 / 04 / 11$ & 6710251 & 0075 & pilot & yes \\
\hline PAA & $64 / 06 / 08$ & 6607074 & 0051 & maintenance & yes \\
\hline PAA & $64 / 06 / 09$ & 6810034 & 0011 & pilot & yes \\
\hline PAA & $64 / 06 / 14$ & 6607074 & 0024 & ground crew & yes \\
\hline PAA & $64 / 09 / 25$ & 6607074 & 0029 & pilot & yes \\
\hline PAA & $64 / 11 / 10$ & 6607074 & 0064 & pilot & yes \\
\hline$P A A$ & $64 / 12 / 22$ & 6607074 & 0063 & maintenance & yes \\
\hline $\mathrm{PAA}$ & $65 / 01 / 31$ & 6601041 & 0025 & pilot & yes \\
\hline PAA & $65 / 03 / 26$ & 6711091 & 0049 & unknown & unk \\
\hline PAA & $14 / 23$ & 1091 & 0048 & pilot & yes \\
\hline $\mathrm{PAA}$ & $65 / 06 / 28$ & 211 & 0020 & maintenance & yes \\
\hline PAA & $65 / 09 / 17$ & 7110181 & 0082 & pilot & yes \\
\hline PAA & $65 / 11 / 20$ & 6610064 & 0035 & unknown & unk \\
\hline PAA & $11 / 25$ & 064 & 0029 & maintenance & yes \\
\hline PAA & $66 / 02 / 18$ & 064 & 0009 & airport/facilities & no \\
\hline PAA & $66 / 06 / 07$ & 064 & 0013 & pilot & yes \\
\hline$P A$ & $66 / 06 / 11$ & 064 & 0034 & pilot & yes \\
\hline PAA & $66 / 09 / 09$ & 061 & 0027 & pilot & yes \\
\hline PAA & $99 / 26$ & 144 & 0033 & maintenance & yes \\
\hline PAA & $66 / 09 / 30$ & 9151 & 0033 & unknown & unk \\
\hline PA & $66 / 11 / 15$ & 7111091 & 0073 & unknown & unk \\
\hline PAA & $67 / 01 / 03$ & 68 & 0001 & maintenance & yes \\
\hline PAA & $67 / 01 / 06$ & 6808094 & 0004 & passenger & no \\
\hline PAA & $67 / 01 / 19$ & 2104 & 0002 & maintenance & yes \\
\hline PAA & $67 / 03 / 06$ & 6807084 & 0032 & maintenance & yes \\
\hline PAA & 05/19 & 68 & 0013 & maintenance & yes \\
\hline PAA & $67 / 09 / 09$ & 68 & 0068 & unknown & unk \\
\hline PAA & $67 / 09 / 29$ & 69 & 0060 & unknown & unk \\
\hline PAA & $67 / 11 / 01$ & 6807104 & 0040 & pilot & yes \\
\hline $\mathrm{PA}$ & $67 / 11 / 19$ & 68 & 0030 & maintenance & yes \\
\hline PAA & $01 / 13$ & & 0007 & passenger $+\mathrm{WX}$ & no \\
\hline $\mathrm{PA}$ & $68 / 01 / 25$ & & 0065 & unknown & unk \\
\hline PAA & $68 / 01 / 28$ & & 0053 & passenger $+\mathrm{WX}$ & no \\
\hline PAA & $68 / 06 / 13$ & 71 & 0062 & pilot & yes \\
\hline PAA & $68 / 08 / 14$ & & 0022 & pilot & yes \\
\hline PAP & $68 / 09 / 14$ & & 0046 & pilot & yes \\
\hline PA & $10 / 28$ & 7001141 & 0071 & pilot & yes \\
\hline PA & $68 / 11 / 23$ & 6903141 & 0036 & unknown & unk \\
\hline PA & $68 / 12 / 12$ & 7307191 & 0063 & pilot & yes \\
\hline $\mathrm{PA}$ & $68 / 12 / 26$ & & & pilot & yes \\
\hline & $69 / 02 / 07$ & 70 & 00 & pilot & yes \\
\hline & $69 / 02 / 09$ & 7103011 & 0007 & unknown & unk \\
\hline
\end{tabular}




\section{APPENDIX B}

DETERMINATIONS

(continued)

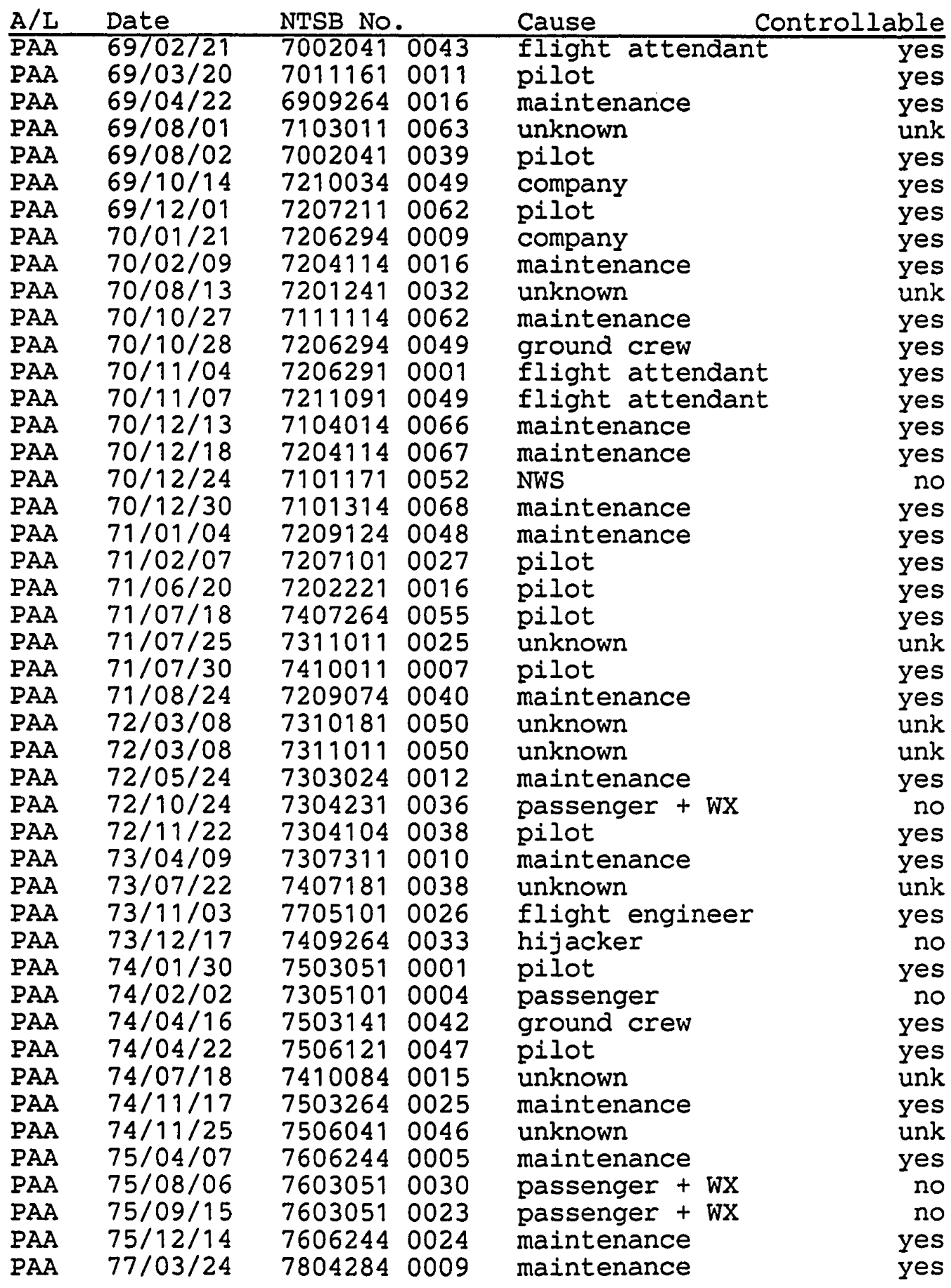




\section{APPENDIX B}

- DETERMINATIONS

(continued)

\begin{tabular}{|c|c|c|c|c|c|}
\hline $\mathrm{A} / \mathrm{L}$ & Date & NTSB NO & & Cause & Controllable \\
\hline$\overline{\mathrm{PAA}}$ & $77 / 03 / 27$ & 7910291 & 0026 & other $a / c$ & $\overline{n c}$ \\
\hline PAA & $77 / 06 / 09$ & 7806011 & 0024 & unknown & unk \\
\hline PAA & $78 / 09 / 11$ & 7908274 & 0012 & flight attendant & yes \\
\hline PAA & $79 / 04 / 21$ & 171 & 0030 & flight attendant & yes \\
\hline PAA & $79 / 06 / 01$ & 8102094 & 0014 & maintenance & \\
\hline PAA & $79 / 09 / 16$ & 8102094 & 0010 & pilot & Y \\
\hline PAA & $79 / 09 / 30$ & 8102094 & 0017 & no one & \\
\hline $\mathrm{PAA}$ & $79 / 12 / 27$ & 171 & 0004 & unknown & \\
\hline$A A$ & $80 / 09 / 03$ & 8203191 & 0017 & unknown & \\
\hline PAA & $80 / 09 / 16$ & 8203191 & 0016 & unknown & un \\
\hline AAA & $80 / 12 / 15$ & 8109294 & 0017 & bird & \\
\hline$A A$ & $81 / 02 / 12$ & & 0006 & ground crew & $e$ \\
\hline$A A$ & $81 / 05 / 20$ & 8212141 & 0009 & ground crew & \\
\hline PAA & $81 / 08 / 17$ & 8209221 & 0023 & pilot & \\
\hline PAA & $82 / 02 / 17$ & MIA82FAC & $51 \mathrm{~A}$ & maintenance & ye \\
\hline$A A$ & $82 / 07 / 09$ & DCA82AAC & $28 \mathrm{~A}$ & pilot & e \\
\hline PAA & $83 / 08 / 21$ & MIA83IA & 102 & maintenance & \\
\hline PAA & $83 / 12 / 14$ & MIA84IAC & 452 & maintenance & \\
\hline PA & $84 / 01 / 01$ & MIA84IAC & $54 A 2$ & ATC & \\
\hline PAA & $84 / 01 / 01$ & MIA84IAC & $54 B 2$ & ATC & \\
\hline $\mathrm{PAA}$ & $84 / 04 / 74$ & MIA84IA & 402 & manufacturer & \\
\hline PAA & $84 / 06 / 11$ & LAX84IA & 3492 & maintenance & \\
\hline PAA & $86 / 01 / 27$ & MIA86IAC & 662 & maintenance & $t$ \\
\hline $\mathrm{AA}$ & $86 / 11 / 06$ & DCA87MAC & $10 B 1$ & other $a / c$ & \\
\hline $\mathrm{PAA}$ & $86 / 12 / 21$ & MIA87IAC & 542 & pilot & \\
\hline PAA & $87 / 07 / 09$ & NYC87IA & $99 B 2$ & ATC & \\
\hline PAA & $87 / 08 / 09$ & NYC87IA: & $27 B 2$ & ATC & \\
\hline PAA & $87 / 10 / 27$ & MIA88IAC & $20 A 2$ & pilot & \\
\hline PAA & $87 / 11 / 11$ & MIA88FAC & 321 & pilot & \\
\hline PAA & $88 / 05 / 23$ & MIA88IA & $76 \mathrm{A2}$ & ATC & \\
\hline PAA & $88 / 07 / 24$ & MIA88IA & 312 & maintenance & \\
\hline PAA & $88 / 09 / 21$ & NYC88IA & 462 & passenger & \\
\hline PAA & $88 / 11 / 03$ & NYC89LAC & 721 & flight attendant & \\
\hline PAA & $88 / 11 / 06$ & FTW89IAC & 162 & ATC & \\
\hline TWA & $64 / 01 / 01$ & 6606081 & 0014 & pilot & \\
\hline TWA & $64 / 02 / 15$ & 6602194 & 0071 & bird & \\
\hline TWA & $64 / 03 / 09$ & 6603311 & 0021 & manufacturer & \\
\hline TWA & $64 / 05 / 29$ & 6602191 & 0034 & unknown & \\
\hline TWA & $64 / 07 / 01$ & 6607071 & 0027 & flight attendant & \\
\hline TWA & $64 / 08 / 21$ & 6607074 & 0019 & manufacturer & \\
\hline TWA & $64 / 08 / 25$ & 6607074 & 0021 & maintenance & \\
\hline TWA & $64 / 08 / 26$ & 6607071 & 0043 & pilot & \\
\hline TWA & $64 / 09 / 25$ & 6607074 & 0031 & manufacturer & \\
\hline TWA & $64 / 11 / 09$ & 6607071 & 0070 & pilot & \\
\hline TWz & $11 / 15$ & 6607071 & 0074 & maintenance & \\
\hline TWE & $11 / 23$ & 7110181 & 0080 & maintenance & \\
\hline
\end{tabular}




\section{APPENDIX B}

\section{DETERMINATIONS}

(continued)

\begin{tabular}{|c|c|c|c|c|c|}
\hline $\mathrm{A} / \mathrm{I}$ & Date & NTSB NO & & Cause & Controllable \\
\hline TWA & $64 / 12 / 03$ & 7011304 & 0077 & maintenance & yes \\
\hline TWA & $64 / 12 / 07$ & 6607074 & 0048 & unknown & unk \\
\hline IWA & $65 / 02 / 17$ & 6601041 & 0026 & pilot & yes \\
\hline TWA & $65 / 03 / 04$ & 6711094 & 0011 & pilot & yes \\
\hline IWA & $65 / 03 / 17$ & 6611231 & 0014 & pilot & yes \\
\hline WA & $65 / 05 / 04$ & 191 & 0037 & pilot & yes \\
\hline WA & $65 / 07 / 06$ & 660 & 0039 & maintenance & es \\
\hline IWA & $65 / 12 / 04$ & 6702151 & 0033 & other $\mathrm{a} / \mathrm{c}$ & \\
\hline WA & $65 / 12 / 16$ & 6610064 & 0030 & maintenance & yes \\
\hline WA & $66 / 01 / 05$ & 6609064 & 0002 & maintenance & yes \\
\hline WA & $66 / 02 / 09$ & 6610064 & 0008 & maintenance & res \\
\hline WA & $66 / 10 / 10$ & 6706064 & 0035 & maintenance & $\mathbf{s}$ \\
\hline TWA & $66 / 10 / 18$ & 6709201 & 0062 & copilot & yes \\
\hline TWA & $67 / 03 / 09$ & 6809131 & 0002 & pilot & yes \\
\hline WA & $67 / 04 / 09$ & 6808094 & 0010 & maintenance & yes \\
\hline CWA & $67 / 04 / 25$ & 7101 & 0056 & pilot & es \\
\hline TWA & $67 / 07 / 15$ & 6808094 & 0025 & pilot & yes \\
\hline TWA & $67 / 10 / 17$ & 6807084 & 0031 & pilot & yes \\
\hline WA & $67 / 11 / 06$ & 241 & 0029 & other $a / c$ & no \\
\hline WA & $67 / 11 / 20$ & 91 & 0033 & pilot & $\mathbf{s}$ \\
\hline TWA & $68 / 01 / 31$ & 7201 & 0024 & pilot & yes \\
\hline TWA & $68 / 05 / 18$ & 680 & 0007 & maintenance & yes \\
\hline WWA & $68 / 06 / 03$ & 690 & 0057 & pilot & yes \\
\hline IWA & $68 / 07 / 11$ & 69 & 0027 & flight attendant & yes \\
\hline TWA & $68 / 08 / 07$ & 34 & 0013 & maintenance & $\mathbf{S}$ \\
\hline TWA & $69 / 02 / 02$ & 7011161 & 0003 & ground crew & yes \\
\hline TWA & $69 / 04 / 08$ & 7001231 & 0029 & passenger $+W X$ & no \\
\hline WWA & $69 / 04 / 19$ & 6907294 & 0009 & maintenance & es \\
\hline TWA & $69 / 06 / 05$ & 204 & 0019 & pilot & es \\
\hline TWA & $69 / 06 / 25$ & 31 & 0014 & pilot & es \\
\hline TWA & $08 / 29$ & & 0045 & hijacker & no \\
\hline PWA & $69 / 09 / 15$ & 31 & 0036 & flight attendant & yes \\
\hline PWA & $110 / 11$ & 7002041 & 00 & flight attendant & yes \\
\hline TWA & $69 / 10 / 12$ & 7002041 & 0042 & pilot & $\mathbf{s}$ \\
\hline TWA & $70 / 03 / 19$ & 7206294 & 0022 & unknown & unk \\
\hline TWA & $70 / 04 / 22$ & 7206294 & 0024 & maintenance & yes \\
\hline TWA & $70 / 06 / 04$ & 7206294 & 0026 & pilot & yes \\
\hline TWZ & $70 / 06 / 26$ & 7206294 & 0030 & pilot & $\mathbf{s}$ \\
\hline TWA & $70 / 08 / 26$ & 7104014 & 0051 & maintenance & \\
\hline TWA & $70 / 09 / 19$ & 7206294 & 0032 & maintenance & yes \\
\hline TW. & $70 / 10 / 08$ & 7204114 & 0037 & maintenance & yes \\
\hline & & 7206304 & 0047 & maintenance & \\
\hline$I W E$ & $70 / 10 / 26$ & 7204114 & 0042 & maintenance & $\mathbf{S}$ \\
\hline$T W 2$ & $70 / 10 / 28$ & 7204114 & 0074 & no one & 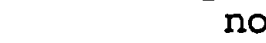 \\
\hline TWZ & $70 / 11 / 30$ & 7307091 & 0054 & unknown & $\mathrm{nk}$ \\
\hline 1. & $71 / 03 / 19$ & 7609104 & 0026 & maintenance & \\
\hline
\end{tabular}


APPENDIX B

DETERMINATIONS

(continued)

\begin{tabular}{|c|c|c|c|c|c|}
\hline$\frac{A / L}{T W A}$ & Date & & & Cause & Controllable \\
\hline TWA & $\begin{array}{l}71 / 04 / 01 \\
71 / 06 / 11\end{array}$ & $\begin{array}{l}7206011 \\
7205124\end{array}$ & $\begin{array}{l}0010 \\
0010\end{array}$ & flight attendant & yes \\
\hline SWA & $71 / 06 / 18$ & 7208144 & 0037 & no one & no \\
\hline IWA & $71 / 06 / 29$ & 7303221 & 0048 & hijacker & no \\
\hline WA & $71 / 09 / 23$ & 7311061 & 0044 & pilot & yes \\
\hline WA & $71 / 11 / 13$ & 7211141 & 0041 & pilot & yes \\
\hline TWA & $71 / 12 / 12$ & 7210021 & 0042 & pilot & yes \\
\hline WA & $72 / 04 / 18$ & 7303094 & 0006 & maintenance & yes \\
\hline WA & $72 / 05 / 23$ & 7308174 & 0013 & ground crew & yes \\
\hline WA & $72 / 06 / 26$ & 7303154 & 0017 & unknown & unk \\
\hline WA & $72 / 06 / 28$ & 7304231 & 0028 & & yes \\
\hline $\begin{array}{l}\text { IWA } \\
\text { TWA }\end{array}$ & $\begin{array}{l}72 / 07 / 18 \\
72 / 07 / 20\end{array}$ & 121 & 0027 & $\begin{array}{l}\text { manufacturer } \\
\text { ATC }\end{array}$ & no \\
\hline TWA & $72 / 09 / 01$ & 7211201 & 0013 & pilot & yes \\
\hline TWA & $72 / 09 / 13$ & 7306181 & 0022 & maintenance & yes \\
\hline IWA & $72 / 11 / 01$ & 7304101 & 0038 & maintenance & yes \\
\hline WA & $72 / 11 / 21$ & 7311014 & 0040 & maintenance & yes \\
\hline IWA & $72 / 12 / 12$ & 7307181 & 0047 & pilot & yes \\
\hline TWA & $73 / 01 / 10$ & 7406284 & 0005 & maintenance & yes \\
\hline TWA & $73 / 03 / 03$ & 7404171 & 0005 & pilot & yes \\
\hline TWA & $73 / 08 / 27$ & 7401071 & 0020 & passenger $+\mathrm{WX}$ & no \\
\hline TWA & $73 / 08 / 28$ & 7408151 & 0042 & manufacturer & no \\
\hline TWA & $74 / 01 / 16$ & 7812 & 0012 & pilot & yes \\
\hline TWA & $74 / 01 / 17$ & 7408131 & 0014 & pilot & yes \\
\hline TWA & $74 / 02 / 16$ & 7412041 & 0027 & maintenance & yes \\
\hline TWA & $74 / 03 / 17$ & 7506094 & 0005 & manufacturer & no \\
\hline TWA & $74 / 04 / 01$ & 7410251 & 0018 & passenger $+W X$ & no \\
\hline TWA & $74 / 04 / 01$ & 151 & 0009 & pilot & yes \\
\hline TWA & $74 / 04 / 19$ & 7506124 & 0010 & unknown & unk \\
\hline TWA & $74 / 05 / 04$ & 7407164 & 0009 & maintenance & yes \\
\hline TWA & $74 / 05 / 08$ & 7506044 & 0008 & maintenance & yes \\
\hline TWA & $74 / 09 / 08$ & 7506041 & 0024 & hijacker & no \\
\hline TWA & $74 / 10 / 24$ & 7506044 & 0021 & cargo & no \\
\hline TWA & $74 / 11 / 26$ & 7503141 & 0041 & unknown & unk \\
\hline TWA & $74 / 12 / 01$ & 7602111 & 0029 & pilot & yes \\
\hline TWA & $75 / 04 / 19$ & 7511174 & 0006 & pilot & yes \\
\hline TWA & $75 / 06 / 14$ & 7603051 & 0019 & maintenance & yes \\
\hline TWA & $75 / 07 / 12$ & 7603051 & 0016 & pilot & yes \\
\hline TWA & $75 / 08 / 13$ & 7606241 & 0040 & flight attendant & yes \\
\hline TWA & $75 / 09 / 11$ & 7606244 & 0029 & maintenance & yes \\
\hline TWA & $75 / 09 / 14$ & 7606254 & 0019 & maintenance & yes \\
\hline TWA & $75 / 10 / 02$ & 7606244 & 0017 & no one & no \\
\hline TWA & $75 / 12 / 22$ & 7710051 & 0044 & pilot & yes \\
\hline$T W$ & $76 / 04 / 24$ & 7711231 & 0028 & unknown & unk \\
\hline n & $76 / 11 / 17$ & 7708251 & 0027 & other a/c & $\mathrm{n}$ \\
\hline & $77 / 08 / 31$ & 14 & 0019 & maintenance & ye \\
\hline
\end{tabular}


APPENDIX B

DETERMINATIONS

(continued)

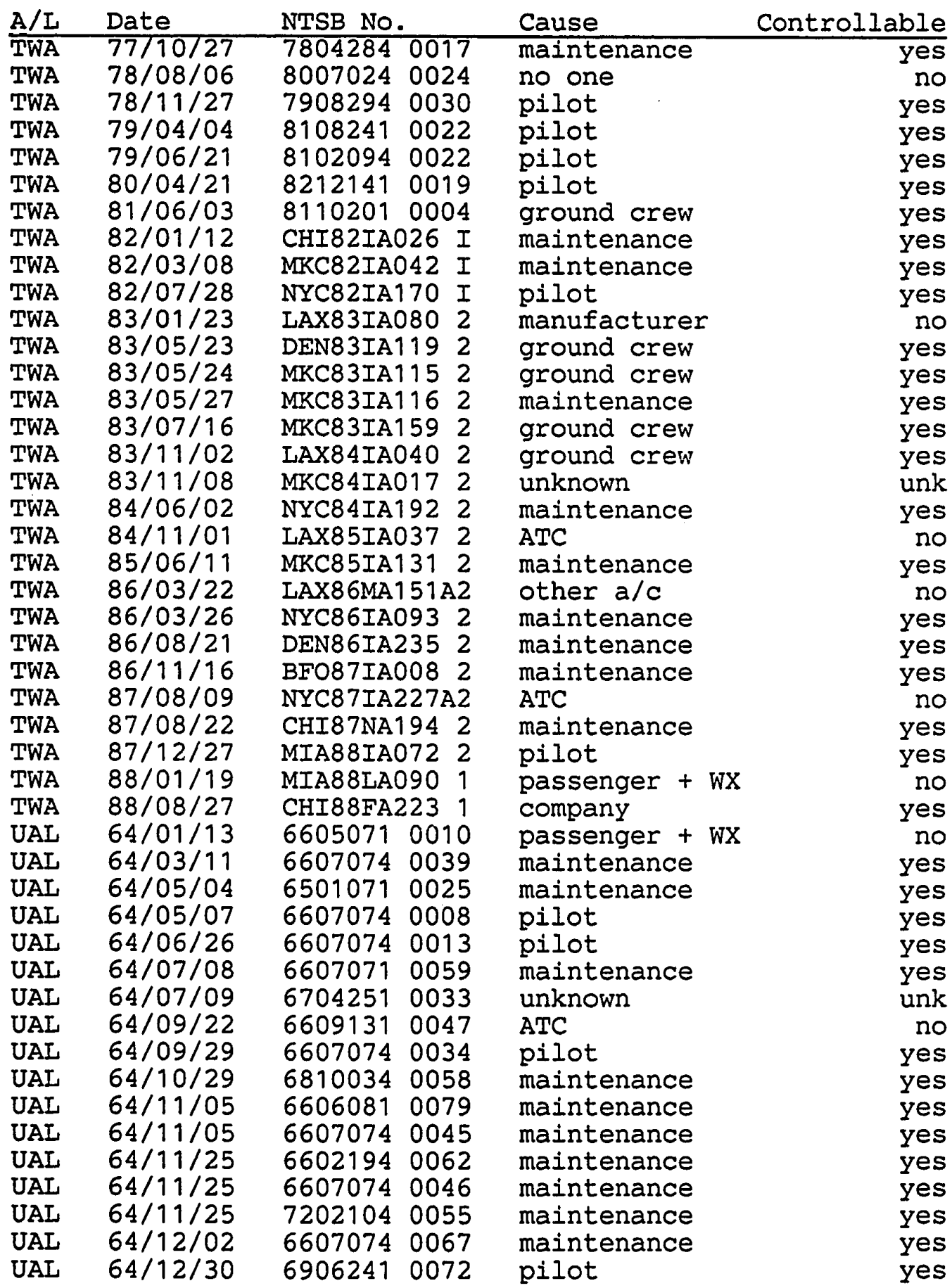


APPENDIX B

DETERMINATIONS

(continued)

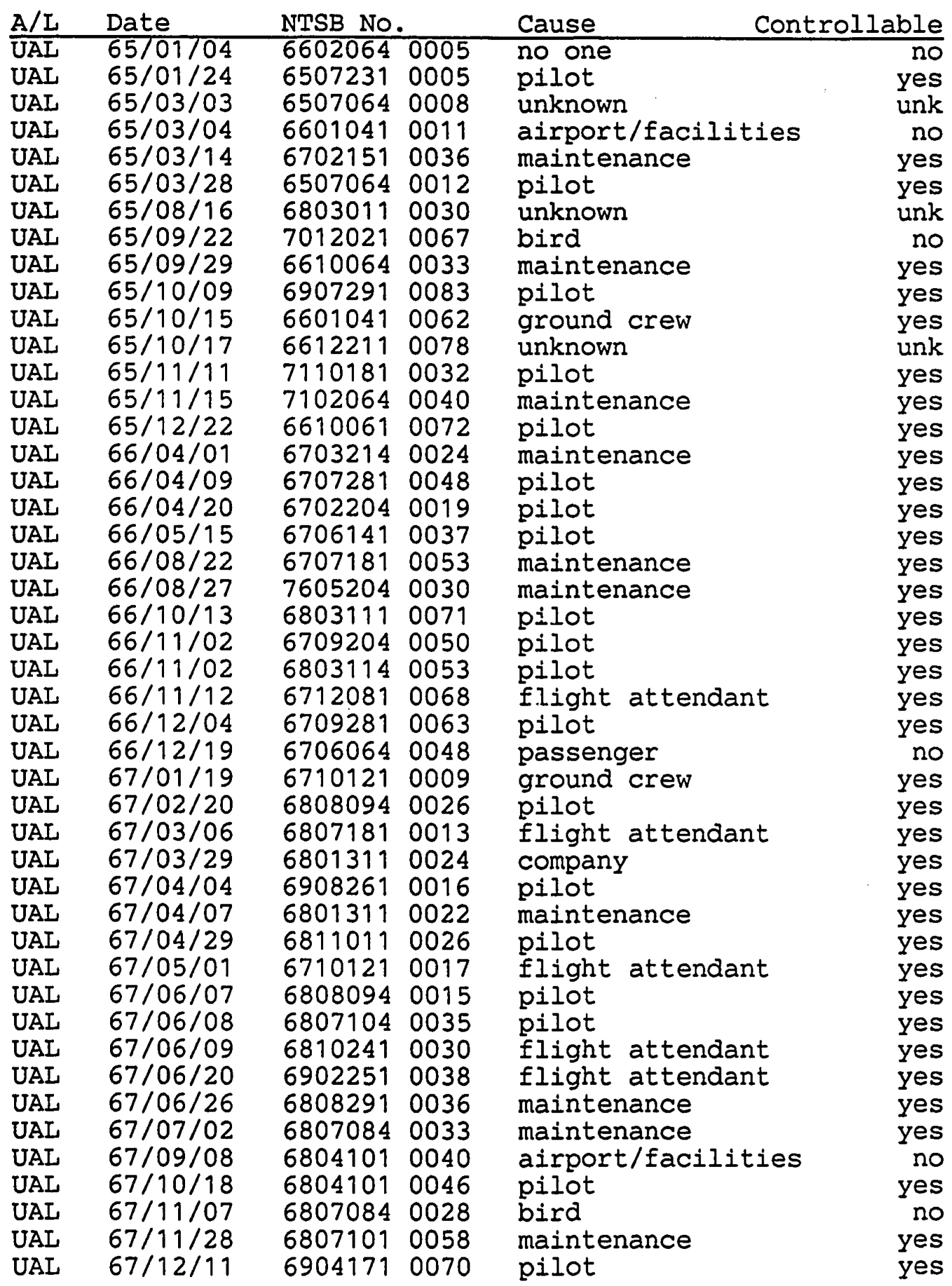


APPENDIX B

DETERMINATIONS

(continued)

\begin{tabular}{|c|c|c|c|c|c|}
\hline \\
\hline \multicolumn{6}{|c|}{$\frac{\text { NTSB No. }}{69030790023}$} \\
\hline UAL & $68 / 04 / 02$ & 6904171 & 0050 & pilot & yes \\
\hline UAL & $68 / 05 / 15$ & 680 & 0006 & flight attendant & yes \\
\hline UAL & $68 / 06 / 08$ & 6901051 & 0025 & pilot & ye \\
\hline UaI & $68 / 06 / 12$ & 6812231 & 0021 & pilot & yes \\
\hline UAL & $68 / 07 / 20$ & 6903144 & 0009 & flight attendant & yes \\
\hline UAL & $68 / 08 / 05$ & 6903071 & 0043 & pilot & $2-$ \\
\hline UAL & $68 / 08 / 06$ & 1 & 0066 & NWS & \\
\hline UAL & $68 / 08 / 07$ & 6902141 & 0037 & pilot & yes \\
\hline $\mathrm{AL}$ & $68 / 08 / 10$ & 6809251 & 0018 & passenger & no \\
\hline UAL & $68 / 09 / 06$ & 6906191 & 0056 & other $a / c$ & 10 \\
\hline UAL & $68 / 09 / 26$ & 6902014 & 0019 & pilot & \\
\hline UAL & $68 / 10 / 03$ & 7001141 & 0067 & pilot & $\boldsymbol{Y}$ \\
\hline UAL & $68 / 11 / 16$ & 6903144 & 0022 & pilot & yes \\
\hline UAL & $68 / 12 / 13$ & 6903074 & 0025 & pilot & yes \\
\hline UAL & $68 / 12 / 21$ & 690 & 0031 & pilot & e \\
\hline UAL & $69 / 01 / 07$ & 6907314 & 0002 & maintenance & \\
\hline UAL & $69 / 01 / 16$ & 6912191 & 0022 & other $a / c$ & no \\
\hline UAL & $69 / 01 / 18$ & 7103011 & 0004 & pilot & res \\
\hline UAL & $69 / 02 / 09$ & 7011161 & 0015 & passenger $+W X$ & 10 \\
\hline UAL & $69 / 04 / 12$ & 6907294 & 0008 & maintenance & \\
\hline UAI & $69 / 04 / 28$ & 6907294 & 0010 & pilot & \\
\hline UAL & $69 / 07 / 26$ & 6912191 & 0023 & company & yes \\
\hline UAL & $69 / 07 / 29$ & 174 & 0024 & pilot & \\
\hline UAL & $69 / 10 / 09$ & 7008264 & 0045 & maintenance & \\
\hline UAL & $69 / 11 / 05$ & 7004144 & 0031 & pilot & yes \\
\hline UAL & $69 / 11 / 06$ & 7101264 & 0048 & pilot & es \\
\hline JAL & $69 / 11 / 06$ & 14 & 0048 & other $a / c$ & \\
\hline UAL & $70 / 02 / 08$ & 7206294 & 0065 & pilot & \\
\hline UAL & $70 / 02 / 19$ & 7206294 & 0011 & copilot & \\
\hline UAL & $70 / 03 / 02$ & 241 & 0024 & maintenance & $y e$ \\
\hline UAL & $70 / 03 / 26$ & 14 & 0019 & maintenance & yes \\
\hline UAL & $70 / 03 / 28$ & 7206294 & 0046 & maintenance & \\
\hline UAL & $70 / 05 / 18$ & 7201241 & 0036 & maintenance & \\
\hline UAL & $70 / 05 / 27$ & 7201241 & 0022 & pilot & \\
\hline UAI & $70 / 07 / 19$ & 720 & 0012 & maintenance & \\
\hline UAI & $70 / 07 / 22$ & 7204 & 0038 & manufacturer & \\
\hline UAL & $70 / 09 / 21$ & 7211091 & 0034 & pilot & \\
\hline UAL & $70 / 10 / 01$ & 7204114 & 0072 & no one & \\
\hline UAL & $70 / 10 / 10$ & 7206294 & 0055 & flight attendan & \\
\hline UAL & $70 / 11 / 28$ & 7211091 & 0046 & pilot & \\
\hline UAI & $70 / 12 / 31$ & 7101314 & 0080 & unknown & \\
\hline UAL & $71 / 01 / 03$ & 7207121 & 0028 & pilot & \\
\hline UAL & $71 / 01 / 12$ & 7112044 & 0002 & maintenance & \\
\hline UAL & $71 / 01 / 17$ & 7303304 & 0022 & unknown & \\
\hline $\mathrm{U} 2$ & $71 / 02 / 15$ & 7211024 & 0023 & maintenance & \\
\hline
\end{tabular}




\section{APPENDIX B}

DETERMINATIONS

(continued)

\begin{tabular}{|c|c|c|c|c|c|}
\hline$A / L$ & Date & NTSB No. & & Cause & Controllable \\
\hline$\overline{\mathrm{UAL}}$ & $71 / 03 / 11$ & 7207264 & 0024 & pilot & yes \\
\hline UAL & $71 / 05 / 15$ & 7209011 & 0011 & hijacker & no \\
\hline UAL & $71 / 06 / 27$ & 7208154 & 0038 & pilot & yes \\
\hline UAL & $71 / 07 / 19$ & 7202171 & 0015 & pilot & \\
\hline UAL & $71 / 07 / 23$ & 7202221 & 0017 & pilot & yes \\
\hline UAL & $71 / 07 / 26$ & 7311011 & 0034 & pilot & yes \\
\hline AI & $71 / 08 / 14$ & 7311011 & 0043 & unknown & unk \\
\hline UAL & $71 / 08 / 21$ & 7209074 & 0046 & maintenance & ye \\
\hline UAL & $71 / 11 / 17$ & 7301111 & 0047 & maintenance & \\
\hline UAL & $71 / 12 / 04$ & 7210024 & 0052 & manufacturer & no \\
\hline UAL & $72 / 03 / 03$ & 7410011 & 0024 & flight attendant & yes \\
\hline UAL & $72 / 04 / 19$ & 7310184 & 0007 & no one & no \\
\hline UAL & $72 / 06 / 09$ & 7307314 & 0009 & hijacker & \\
\hline UAL & $72 / 07 / 21$ & 7303214 & 0021 & flight attendant & \\
\hline UAL & $72 / 08 / 04$ & 7304094 & 0034 & maintenance & yes \\
\hline UAL & $72 / 10 / 01$ & 7410011 & 0044 & manufacturer & no \\
\hline UAL & $72 / 12 / 08$ & 7402121 & 0048 & pilot & ye \\
\hline UAL & $73 / 03 / 17$ & 7401071 & 0007 & flight attendant & $t$ \\
\hline UAL & $73 / 06 / 10$ & 7409114 & 0030 & copilot & $y \in$ \\
\hline JAL & $73 / 10 / 29$ & 7401184 & 0025 & maintenance & yes \\
\hline UAL & $74 / 01 / 04$ & 7412061 & 0002 & maintenance & $y \in$ \\
\hline UAL & $74 / 01 / 24$ & 7506044 & 0002 & pilot & $y \in$ \\
\hline UAL & $74 / 05 / 05$ & 7506044 & 0011 & maintenance & $y e$ \\
\hline UAL & $74 / 09 / 21$ & 7602181 & 0039 & flight attendant & $y \in$ \\
\hline UAL & $74 / 12 / 15$ & 7506044 & 0026 & unknown & un \\
\hline UAL & $75 / 01 / 08$ & 7606244 & 0002 & pilot & $y \in$ \\
\hline UAL & $75 / 07 / 17$ & 7511174 & 0008 & maintenance & $y$ \\
\hline UAL & $75 / 08 / 24$ & 760 & 0016 & maintenance & $y \in$ \\
\hline UAL & $75 / 10 / 16$ & 091 & 0037 & maintenance & $y \in$ \\
\hline UAL & $75 / 10 / 21$ & 7606244 & 0028 & maintenance & $y \in$ \\
\hline UAL & $76 / 02 / 16$ & 7612211 & 0008 & passenger $+\mathrm{WX}$ & \\
\hline UAL & $76 / 02 / 19$ & 7709134 & 0006 & maintenance & $y \in$ \\
\hline UAL & $76 / 05 / 13$ & 770 & 0007 & no one & \\
\hline UAL & $77 / 02 / 28$ & 78 & 0012 & maintenance & ye \\
\hline UAL & $77 / 04 / 26$ & 7804284 & 0003 & pilot & \\
\hline UAL & $77 / 06 / 02$ & 78 & 0015 & maintenance & \\
\hline UAL & $77 / 08 / 01$ & 78 & 0006 & pilot & $y e$ \\
\hline UAL & $77 / 10 / 12$ & 7807264 & 0024 & ÄTC & \\
\hline UAI & $77 / 12 / 18$ & 7907061 & 0021 & ATC & \\
\hline UAL & $78 / 06 / 30$ & 7810304 & 0010 & copilot & \\
\hline UAL & $78 / 07 / 15$ & 7908274 & 0027 & no one & \\
\hline UAL & $78 / 08 / 29$ & 7908274 & 0020 & maintenance & \\
\hline UAI & $78 / 10 / 27$ & & 0031 & bird & \\
\hline UAL & $78 / 11 / 07$ & 7908274 & 0021 & pilot & \\
\hline UAL & $78 / 11 / 14$ & 7902084 & 0018 & maintenance & \\
\hline UAL & $78 / 12 / 21$ & 7908271 & 0018 & flight attendant & \\
\hline
\end{tabular}


APPENDIX B

DETERMINATIONS

(continued)

\begin{tabular}{|c|c|c|c|c|}
\hline$\frac{A / L}{U A I}$ & $\frac{\text { Date }}{78 / 12 / 28}$ & $\frac{\text { NTSB No. }}{7908291}$ & Control & Controllable \\
\hline UAL & $79 / 01 / 20$ & 81020940007 & pilot & yes \\
\hline UAL & $79 / 09 / 15$ & 81020940021 & $\begin{array}{l}\text { malntenance } \\
\text { passenger }\end{array}$ & $\begin{array}{r}\text { yes } \\
\text { no }\end{array}$ \\
\hline UAL & $80 / 06 / 25$ & 81040940013 & pilot & yes \\
\hline AL & $80 / 07 / 24$ & 82022440006 & maintenance & yes \\
\hline AL & $80 / 12 / 29$ & 81102010014 & maintenance & yes \\
\hline $\mathrm{AL}$ & $81 / 02 / 10$ & 82121410002 & flight attendant & yes \\
\hline AL & $81 / 04 / 03$ & 82121410016 & pilot & yes \\
\hline AL & 06/05 & 82121410010 & flight attendant & yes \\
\hline AL & $81 / 07 / 05$ & $8212144 \quad 0012$ & unknown & ink \\
\hline AL & $81 / 10 / 17$ & $8209024 \quad 0021$ & no one & 10 \\
\hline JAL & $82 / 02 / 23$ & DCA82AA014 A & other $a / c$ & \\
\hline ALL & $82 / 04 / 09$ & CHI82IA117 I & pilot & yes \\
\hline AL & $82 / 05 / 26$ & LAX82FA195 A & maintenance & yes \\
\hline AL & $82 / 05 / 27$ & DEN82IA098 I & NWS & 10 \\
\hline AL & $82 / 07 / 16$ & LAX82AA259 A & NWS & \\
\hline AL & $83 / 01 / 11$ & DCA83AA014 1 & pilot & yes \\
\hline $\mathrm{AI}$ & 03/11 & LAX83IA140 2 & maintenance & yes \\
\hline AI & $83 / 03 / 30$ & MKC83IA0832 & pilot & ye \\
\hline$A I$ & $83 / 04 / 10$ & CHI83IA162 2 & maintenance & $y \in$ \\
\hline UAI & $83 / 06 / 11$ & CHI83FA251 1 & maintenance & $y \in$ \\
\hline $\mathrm{AL}$ & $83 / 06 / 20$ & CHI83IA269A2 & flight engineer & yes \\
\hline AL & $83 / 07 / 05$ & CHI83IA299 2 & manufacturer & no \\
\hline AL & $83 / 07 / 20$ & CHI83IA327 2 & pilot & $y \in$ \\
\hline UAL & $83 / 08 / 19$ & DCA83IA035 2 & fuel & 10 \\
\hline $\mathrm{AL}$ & $10 / 18$ & DEN84IA007 2 & NWS & no \\
\hline AL & $2 / 09$ & DEN84IA041 2 & maintenance & yes \\
\hline AI & $84 / 01 / 23$ & CHI84IA0932 & pilot & yes \\
\hline A. & $05 / 31$ & DCA84AA025 1 & pilot & $y \in$ \\
\hline UAI & $06 / 10$ & LAX84IA351 2 & maintenance & ye \\
\hline AI & $6 / 11$ & LAX84IA350 2 & maintenance & yes \\
\hline AI & $06 / 26$ & CHI84IA254 2 & maintenance & $y \in$ \\
\hline JA. & 7/09 & SEA84IA168 2 & foreign object damage & unk \\
\hline UAI & 9/03 & BF084 IA005A2 & other $a / c$ & \\
\hline JAI & $10 / 27$ & CHI85IA032 2 & maintenance & yes \\
\hline $\mathrm{UA}$. & $1 / 16$ & DCA85AA003 1 & maintenance & yes \\
\hline UA. & 09/08 & BFO85IA074 2 & company & ve \\
\hline UAI & $11 / 26$ & DEN86IA031 2 & ground crew & $y \in$ \\
\hline UAI & 02/06 & CHI86IA083 2 & maintenance & $y \in$ \\
\hline UA. & $3 / 03$ & CHI86FA096 1 & NWS & \\
\hline UA & $3 / 31$ & LAX86MA161 2 & pilot & $y$ \\
\hline UA & $86 / 04 / 08$ & CHI86FA119 1 & maintenance & \\
\hline UAI & $86 / 06 / 24$ & LAX86MA275 2 & unknown & unk \\
\hline $\mathrm{JA}$ & $10 / 05$ & SEA87IA003 2 & maintenance & $y$ \\
\hline JA. & $10 / 29$ & LAX87IA027A2 & other $\mathrm{a} / \mathrm{c}$ & \\
\hline UA & $1 / 12$ & ATL87IA020B2 & other $a / c$ & \\
\hline
\end{tabular}


APPENDIX B

DETERMINATIONS

(continued)

$\begin{array}{llllr}\text { A/L } & \text { Date } & \text { NTSB No. } & \text { Cause } & \text { Controllable } \\ \text { UAL } & 86 / 12 / 15 & \text { ANC87FA021 } & \text { flight attendant } & \text { yes } \\ \text { UAL } & 87 / 01 / 25 & \text { CHI87IA0672 } & \text { maintenance } & \text { yes } \\ \text { UAL } & 87 / 02 / 11 & \text { CHI87FA081 } 1 & \text { hijacker } & \text { no } \\ \text { UAL } & 87 / 04 / 07 & \text { CHI87IA1092 } & \text { pilot } & \text { yes } \\ \text { UAL } & 87 / 06 / 22 & \text { LAX87LA243B1 } & \text { maintenance } & \text { yes } \\ \text { UAL } & 87 / 09 / 02 & \text { CHI87IA2012 } & \text { maintenance } & \text { yes } \\ \text { UAI } & 87 / 10 / 28 & \text { CHI88IA0112 } & \text { maintenance } & \text { yes } \\ \text { UAL } & 87 / 10 / 29 & \text { CHI88IA015A2 } & \text { ATC } & \text { no } \\ \text { UAL } & 88 / 05 / 02 & \text { DCA88IA0562 } & \text { flight engineer } & \text { yes } \\ \text { UAL } & 88 / 05 / 11 & \text { CHI88IA1112 } & \text { maintenance } & \text { yes } \\ \text { UAL } & 88 / 06 / 26 & \text { BFO88LA061 1 } & \text { passenger + WX } & \text { no } \\ \text { UAI } & 88 / 08 / 10 & \text { MKC88FA1541 } 1 & \text { maintenance } & \text { yes } \\ \text { UAL } & 88 / 12 / 23 & \text { LAX89LA0681 } & \text { NWS } & \text { no }\end{array}$




\section{APPENDIX B \\ DETERMINATIONS \\ (continued)}

\begin{tabular}{lrc} 
Cause & No. & Controllable \\
\hline Pilot & 337 & yes \\
Co-pilot & 20 & yes \\
Flight engineer & 5 & yes \\
Flight Attendant & 71 & yes \\
Company & 12 & yes \\
Maintenance & 344 & yes \\
Ground Crew & 25 & yes \\
Pilot and Maintenance & 2 & yes \\
Total Controllable & 816 & \\
& & no \\
Passenger & 53 & no \\
Manufacturer & 40 & no \\
ATC & 37 & no \\
Other Aircraft & 28 & no \\
No one & 27 & no \\
Nws & 17 & no \\
Hijacker & 13 & no \\
Airport/Facilities & 13 & no \\
Bird & 11 & no \\
Cargo & 5 & no \\
Stow-away & 1 & no \\
Fuel & 1 & \\
Total Not Controllable & 245 & unk \\
Unknown & 54 & unk \\
Foreign Object Damage & 2 & \\
Total Unknown & 56 &
\end{tabular}

Total 1,118


APPENDIX C

ORDINARY LEAST SQUARES (OLS) 


\section{APPENDIX C \\ ORDINARY LEAST SQUARES (OLS) \\ COMMAND FILE}

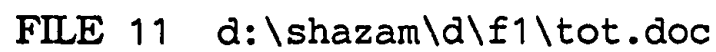

sample 125

read(11) year d totocc y $n \mathrm{u}$ hours

* generate controllable rate

genr crate $=((1000000 * y)) /$ hours

* generate log of the controllable rate genr Incrate $=\log$ (crate)

* generate time since deregulation dummy

genr timedum $=d^{*}$ (year -79 )

print $y$ hours crate lncrate year d timedum

$\begin{array}{lllll}\text { ols } & \text { Incrate year } & & \text { lexactdw } \\ \text { ols } & \text { Incrate year a } & & \text { lexactdw } \\ \text { ols } & \text { Incrate year } & & \text { timedum } & \text { lexactdw } \\ \text { ols } & \text { Incrate year d } & \text { timedum lexactdw }\end{array}$

delete / all 


\section{APPENDIX C \\ ORDINARY LEAST SQUARES (OLS) (continued]}

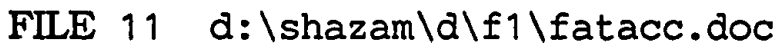
sample 127

read(11) year fatal acc hours

* generate zero dummy

genr zerodum $=\operatorname{dum}(.1$ - fatal $)$

* generate fatal accident rate genr fatrate $=(1000000 *($ fatal + zerodum $)) /$ hours

* generate $\log$ of the fatrate genr Infatrat $=\log$ (fatrate)

* generate accident rate

genr accrate $=(1000000 *$ acc $) /$ hours

* generate log of the accident rate

genr Inaccrat $=\log$ (accrate)

* generate deregulation dummy

genr $d=\operatorname{dum}($ year -79.9$)$

genr timedum $=d *($ year -79$)$

print year fatal fatrate Infatrat zerodum hours

print year acc accrate Inaccrat d timedum

ols Inaccrat year

ols lnaccrat year

ols Inaccrat year

ols Inaccrat year

ols Infatrat year zerodum

ols Infatrat year zerodum

ols Infatrat year

ols Infatrat year

delete / all

stop /exactdw

lexactdw

lexactdw

/exactdw

d timedum

lexactdw lexactdw /exactdw lexactdw 


\section{APPENDIX C \\ ORDINARY LEAST SQUARES (OLS) \\ (continued)}

\section{OUTPUT FIIE}

LOADING SHAZAM EXTENDED MEMORY Version 6.2

v2.1.06

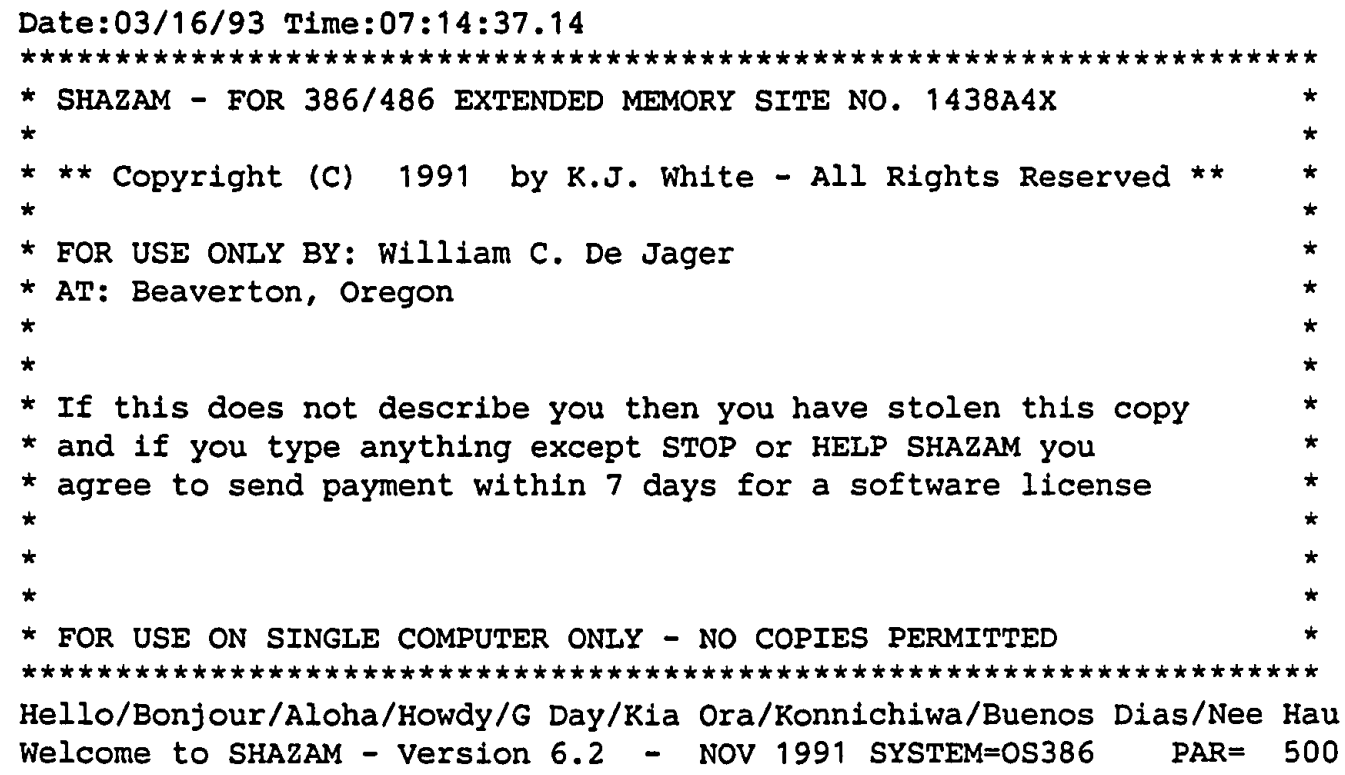




\section{APPENDIX C \\ ORDINARY LEAST SQUARES (OLS) (continued]}

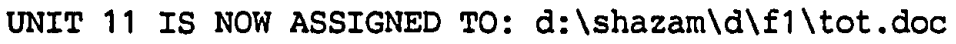

7 VARIABLES AND

25 OBSERVATIONS STARTING AT OBS

1

$\begin{array}{lllllll}\text { Y } & \text { HOURS } & \text { CRATE } & \text { LNCRATE } & \text { YR } & \text { D } & \text { TIMEDUM } \\ 64 & 2441185 . & 26.21678 & 3.266400 & 64 & 0.00 & 0.00 \\ 45 & 2691129 . & 16.72161 & 2.816702 & 65 & 0.00 & 0.00 \\ 45 & 2819170 . & 15.96214 & 2.770220 & 66 & 0.00 & 0.00 \\ 48 & 3507054 . & 13.68670 & 2.616425 & 67 & 0.00 & 0.00 \\ 43 & 4015838 . & 10.70760 & 2.370954 & 68 & 0.00 & 0.00 \\ 44 & 4336713 . & 10.14593 & 2.317073 & 69 & 0.00 & 0.00 \\ 44 & 4294706 . & 10.24517 & 2.326807 & 70 & 0.00 & 0.00 \\ 48 & 4224634 . & 11.36193 & 2.430268 & 71 & 0.00 & 0.00 \\ 40 & 4204233 . & 9.514221 & 2.252788 & 72 & 0.00 & 0.00 \\ 30 & 4346571 . & 6.901992 & 1.931810 & 73 & 0.00 & 0.00 \\ 34 & 3997587 . & 8.505131 & 2.140670 & 74 & 0.00 & 0.00 \\ 36 & 3936489 . & 9.145205 & 2.213230 & 75 & 0.00 & 0.00 \\ 14 & 4024069 . & 3.479066 & 1.246764 & 76 & 0.00 & 0.00 \\ 20 & 4135728 . & 4.835908 & 1.576069 & 77 & 0.00 & 0.00 \\ 20 & 4166439 . & 4.800262 & 1.568671 & 78 & 0.00 & 0.00 \\ 14 & 4329449 . & 3.233668 & 1.173617 & 79 & 0.00 & 0.00 \\ 9 . & 4439343 . & 2.027327 & 0.7067182 & 80 & 1.0 & 1.0 \\ 27 & 4049954 . & 6.666742 & 1.897131 & 81 & 1.0 & 2.0 \\ 15 & 4016962 . & 3.734165 & 1.317524 & 82 & 1.0 & 3.0 \\ 32 & 4197657 . & 7.623300 & 2.031209 & 83 & 1.0 & 4.0 \\ 24 & 4547810 . & 5.277265 & 1.663408 & 84 & 1.0 & 5.0 \\ 25 & 4744502 . & 5.269257 & 1.661889 & 85 & 1.0 & 6.0 \\ 26 & 5389885 . & 4.823851 & 1.573572 & 86 & 1.0 & 7.0 \\ 36 & 6921046 . & 5.201526 & 1.648952 & 87 & 1.0 & 8.0 \\ 33 & 7166746 . & 4.604600 & 1.527056 & 88 & 1.0 & 9.0\end{array}$




\section{APPENDIX C \\ ORDINARY LEAST SQUARES (OLS) (continued)}

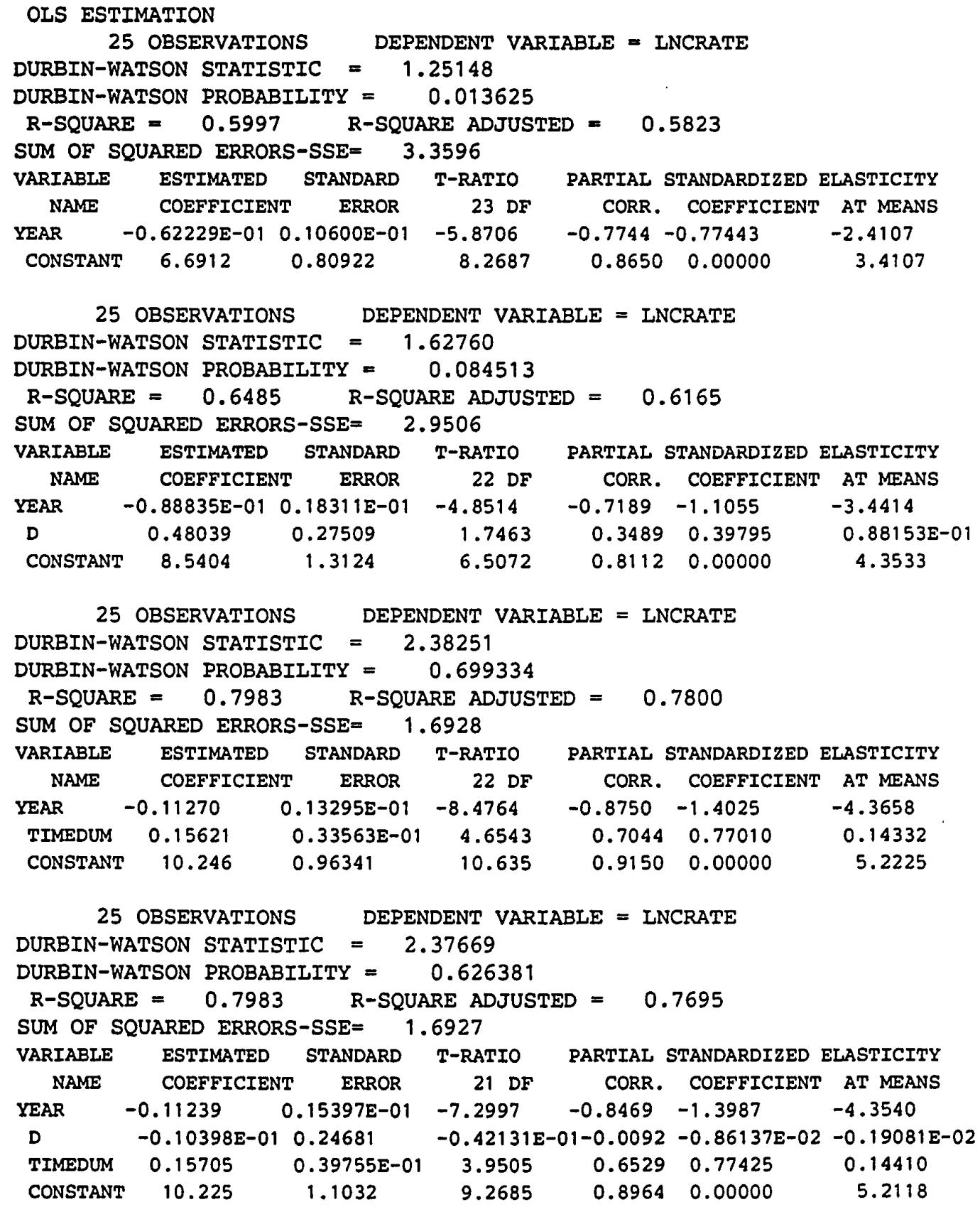




\section{APPENDIX C \\ ORDINARY LEAST SQUARES (OLS) (continued)}

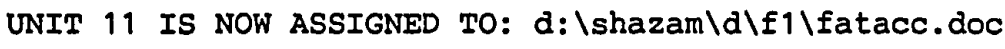

4 VARIABLES AND

27 OBSERVATIONS STARTING AT OBS

1

$\begin{array}{lcrrrr}\text { YR } & \text { FATAL } & \text { FATRATE } & \text { INFATRAT } & \text { ZERODUM } & \text { HOURS } \\ 61 & 6 . & 1.641810 & 0.4957994 & 0.00 & 3654503 . \\ 62 & 6 . & 1.718620 & 0.5415214 & 0.00 & 3491174 . \\ 63 & 6 . & 1.664712 & 0.5096519 & 0.00 & 3604228 . \\ 64 & 11 & 2.914084 & 1.069556 & 0.00 & 3774771 . \\ 65 & 8 . & 1.964643 & 0.6753105 & 0.00 & 4071987 . \\ 66 & 5 . & 1.181200 & 0.1665312 & 0.00 & 4232982 . \\ 67 & 8 . & 1.624669 & 0.4853041 & 0.00 & 4924080 . \\ 68 & 13 & 2.354249 & 0.8562217 & 0.00 & 5521931 . \\ 69 & 8 . & 1.357715 & 0.3058029 & 0.00 & 5892254 . \\ 70 & 4 . & 0.6919813 & -0.3681963 & 0.00 & 5780503 . \\ 71 & 7 . & 1.226721 & 0.2043446 & 0.00 & 5706270 . \\ 72 & 7 . & 1.236862 & 0.2125773 & 0.00 & 5659485 . \\ 73 & 8 . & 1.356260 & 0.3047307 & 0.00 & 5898575 . \\ 74 & 7 . & 1.278657 & 0.2458101 & 0.00 & 5474495 . \\ 75 & 2 . & 0.3688223 & -0.9974402 & 0.00 & 5422665 . \\ 76 & 2 . & 0.3579354 & -1.027403 & 0.00 & 5587601 . \\ 77 & 3 . & 0.5171662 & -0.6593910 & 0.00 & 5800843 . \\ 78 & 4 . & 0.6631582 & -0.4107417 & 0.00 & 6031743 . \\ 79 & 5 . & 0.7462328 & -0.2927177 & 0.00 & 6700322 . \\ 80 & 0.0 & 0.1471112 & -1.916566 & 1.0 & 6797578 . \\ 81 & 4 . & 0.6087087 & -0.4964155 & 0.00 & 6571288 . \\ 82 & 3 . & 0.4658267 & -0.7639416 & 0.00 & 6440163 . \\ 83 & 4 . & 0.6015934 & -0.5081735 & 0.00 & 6649009 . \\ 84 & 1 . & 0.1344358 & -2.006669 & 0.00 & 7438497 . \\ 85 & 4 . & 0.5033070 & -0.6865549 & 0.00 & 7947435 . \\ 86 & 1 . & 0.1068729 & -2.236115 & 0.00 & 9356906 . \\ 87 & 4 . & 0.4119040 & -0.8869649 & 0.00 & 9711000 .\end{array}$


APPENDIX C

ORDINARY LEAST SQUARES (OIS) (continued]

$\begin{array}{llllll}\text { YR } & \text { ACC } & \text { ACCRATE } & \text { LNACCRAT } & \text { D } & \text { TIMEDUM } \\ 61 . & 66 & 18.05991 & 2.893695 & 0.00 & 0.00 \\ 62 . & 47 & 13.46252 & 2.599910 & 0.00 & 0.00 \\ 63 . & 54 & 14.98240 & 2.706876 & 0.00 & 0.00 \\ 64 . & 59 & 15.63009 & 2.749198 & 0.00 & 0.00 \\ 65 . & 65 & 15.96272 & 2.770256 & 0.00 & 0.00 \\ 66 . & 56 & 13.22944 & 2.582445 & 0.00 & 0.00 \\ 67 . & 54 & 10.96652 & 2.394847 & 0.00 & 0.00 \\ 68 . & 56 & 10.14138 & 2.316624 & 0.00 & 0.00 \\ 69 . & 51 & 8.655431 & 2.158187 & 0.00 & 0.00 \\ 70 . & 43 & 7.438799 & 2.006709 & 0.00 & 0.00 \\ 71 . & 43 & 7.535571 & 2.019635 & 0.00 & 0.00 \\ 72 . & 46 & 8.127948 & 2.095308 & 0.00 & 0.00 \\ 73 . & 36 & 6.103169 & 1.808808 & 0.00 & 0.00 \\ 74 . & 43 & 7.854606 & 2.061100 & 0.00 & 0.00 \\ 75 . & 30 & 5.532335 & 1.710610 & 0.00 & 0.00 \\ 76 . & 22 & 3.937289 & 1.370492 & 0.00 & 0.00 \\ 77 . & 20 & 3.447775 & 1.237729 & 0.00 & 0.00 \\ 78 . & 20 & 3.315791 & 1.198696 & 0.00 & 0.00 \\ 79 . & 23 & 3.432671 & 1.233339 & 0.00 & 0.00 \\ 80 . & 15 & 2.206668 & 0.7914838 & 1.0 & 1.0 \\ 81 . & 25 & 3.804429 & 1.336166 & 1.0 & 2.0 \\ 82 . & 15 & 2.329134 & 0.8454964 & 1.0 & 3.0 \\ 83 . & 22 & 3.308764 & 1.196575 & 1.0 & 4.0 \\ 84 . & 12 & 1.613229 & 0.4782378 & 1.0 & 5.0 \\ 85 . & 17 & 2.139055 & 0.7603641 & 1.0 & 6.0 \\ 86 . & 20 & 2.137459 & 0.7596176 & 1.0 & 7.0 \\ 87 . & 30 & 3.089280 & 1.127938 & 1.0 & 8.0\end{array}$




\section{APPENDIX C \\ ORDINARY LEAST SQUARES (OLS) (continued]}

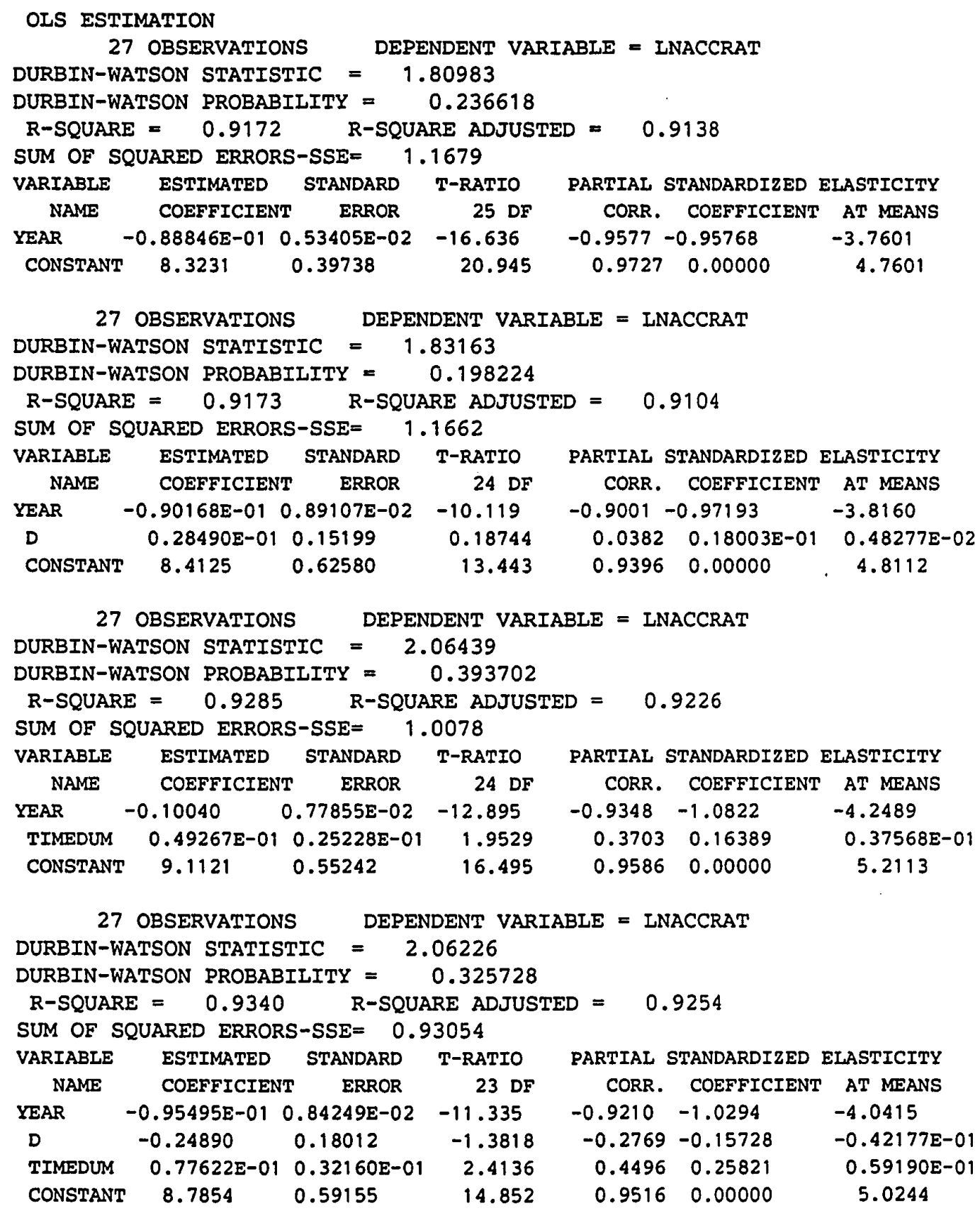




\section{APPENDIX C \\ ORDINARY LEAST SQUARES (OLS) (continued)}

\begin{tabular}{|c|c|c|c|c|c|c|}
\hline \multicolumn{2}{|c|}{27 OBSERVATIONS } & \multicolumn{5}{|c|}{ DEPENDENT VARIABLE = LNEATRAT } \\
\hline \multicolumn{7}{|c|}{ DURBIN-WATSON STATISTIC $=2.31694$} \\
\hline \multicolumn{7}{|c|}{ DURBIN-WATSON PROBABILITY $=0.736955$} \\
\hline R-SQUARE = & 0.7295 & \multicolumn{5}{|c|}{ R-SQUARE ADJUSTED $=0.7069$} \\
\hline \multicolumn{7}{|c|}{ SUM OF SQUARED ERRORS-SSE= $\quad 5.3403$} \\
\hline \multirow{2}{*}{$\begin{array}{l}\text { VARIABLE } \\
\text { NAME }\end{array}$} & ESTIMATED & STANDARD & T-RATIO & PARTIAL & STANDARDIZED E & ELASTICITY \\
\hline & COEFFICIENT & ERROR & $24 D F$ & CORR. & COEFFICIENT & AT MEANS \\
\hline YEAR & $-0.85020 \mathrm{E}-01 \mathrm{C}$ & $0.11791 \mathrm{E}-01$ & -7.2109 & -0.8272 & -0.77449 & 23.645 \\
\hline ZERODUM & -1.1842 & 0.48628 & -2.4353 & \multicolumn{2}{|c|}{$-0.4451-0.26156$} & 0.16484 \\
\hline CONSTANT & 6.0693 & 0.87468 & 6.9388 & 0.8169 & 0.00000 & -22.810 \\
\hline & OBSERVATIONS & DEPEND & DENT VARIAI & $B L E=I N$ & NFATRAT & \\
\hline DURBIN-W & IATSON STATIST & TIC & 31715 & & & \\
\hline DURBIN-W & IATSON PROBABI & ILITY $=$ & 0.662994 & & & \\
\hline R-SQUAR & $E=0.7296$ & R-SQUAI & RE ADJUSTE & $D=$ & .6943 & \\
\hline SUM OE S & QUARED ERRORS & $S-S S E=$ & 3371 & & & \\
\hline VARIABLE & ESTIMATED & STANDARD & T-RATIO & PARTIAL & STANDARDIZED E & ELASTICITY \\
\hline NAME & COEFFICIENT & ERROR & $23 \mathrm{DF}$ & CORR. & COEFFICIENT & AT MEANS \\
\hline YEAR & $-0.83196 \mathrm{E}-010$ & $0.19699 \mathrm{E}-01$ & -4.2234 & -0.6609 & -0.75787 & 23.138 \\
\hline ZERODUM & -1.1658 & 0.52097 & -2.2378 & -0.4228 & -0.25749 & 0.16227 \\
\hline D & $-0.40763 E-01$ & 0.34845 & -0.11698 & -0.0244 & $-0.21769 E-01$ & $0.45393 \mathrm{E}-0$ \\
\hline CONSTANT & 5.9457 & 1.3833 & 4.2981 & 0.6674 & 0.00000 & -22.346 \\
\hline & OBSERVATIONS & DEPENI & DENT VARIA & $B L E=L N$ & NFATRAT & \\
\hline DURBIN-W & IATSON STATIST & TIC & 33838 & & & \\
\hline DURBIN-W & IATSON PROBABI & ILITY = & 0.681875 & & & \\
\hline R-SQUAR & 0.7337 & R-SQUAI & RE ADJUSTE! & $D=$ & .6990 & \\
\hline SUM OF $S$ & SQUARED ERRORS & $S-S S E=$ & 2558 & & & \\
\hline VARIABLE & ESTIMATED & STANDARD & T-RATIO & PARTIAL & STANDARDIZED & ELASTICITY \\
\hline NAME & COEFFICIENT & ERROR & $23 \mathrm{DF}$ & CORR. & - COEFFICIENT & AT MEANS \\
\hline YEAR & $-0.76168 \mathrm{E}-010$ & $0.18831 \mathrm{E}-01$ & -4.0449 & -0.6447 & -0.69385 & 21.183 \\
\hline ZERODUM & -1.2521 & 0.50526 & -2.4781 & -0.4591 & -0.27655 & 0.17429 \\
\hline TIMEDUM & $-0.36700 \mathrm{E}-01$ & $0.60341 \mathrm{E}-01$ & -0.60822 & -0.1258 & $3-0.10317$ & 0.18391 \\
\hline CONSTANT & 5.4656 & 1.3307 & 4.1075 & 0.6505 & 0.00000 & -20.541 \\
\hline 27 & 7 OBSERVATIONS & DEPEN & IDENT VARIA & $B L E=L N$ & NFATRAT & \\
\hline DURBIN-W & VATSON STATIS? & ITIC & 36679 & & & \\
\hline DURBIN-W & VATSON PROBAB] & IIITY = & 0.636887 & & & \\
\hline R-SQUAR & 0.7369 & R-SQUA & RE ADJUSTE & $D=$ & .6891 & \\
\hline SUM OF $S$ & SQUARED ERRORS & $S-S S E=$ & 1925 & & & \\
\hline VARIABLE & ESTIMATED & STANDARD & T-RATIO & PARTIAL & STANDARDIZED & ELASTICITY \\
\hline NAME & COEFFICIENT & ERROR & $22 \mathrm{DF}$ & CORR. & COEFFICIENT & AT MEANS \\
\hline YEAR & $-0.79749 \mathrm{E}-010$ & $0.20349 \mathrm{E}-01$ & -3.9191 & -0.6412 & -0.72647 & 22.179 \\
\hline ZERODUM & -1.4465 & 0.63609 & -2.2741 & -0.4363 & $3-0.31949$ & 0.20135 \\
\hline D & 0.27908 & 0.53890 & 0.51788 & 0.1097 & $7 \quad 0.14904$ & -0.31078 \\
\hline TIMEDUM & $-0.73622 E-01$ & $0.94039 E-01$ & -0.78288 & -0.1646 & $5-0.20697$ & 0.36892 \\
\hline CONSTANT & 5.7044 & 1.4288 & 3.9925 & 0.6482 & 20.00000 & -21.439 \\
\hline
\end{tabular}


APPENDIX D

MAXIMUM LIKELIHOOD (USING SHAZAM NON-IINEAR) 


\section{APPENDIX D \\ MAXIMUM LIKELIHOOD (USING SHAZAM NON-IINEAR) \\ COMMAND FILE}

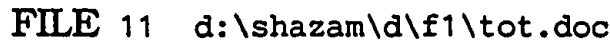

sample 125

read(11) year $d$ totocc y n $u$ hours

* generate controlable rate

genr crate $=((1000000 * y)) /$ hours

* generate $\log$ crate

genr incrate $=\log ($ crate $)$

* generate time since deregulation dummy

genr timedum $=d *($ year -79$)$

print $y$ hours crate lncrate year d timedum

nl $1 /$ ncoef $=2$

eq Incrate $=y r$ * year

coef $\quad$ yr .1

+ const

const 200

nl $1 /$ ncoef $=3$

eq Incrate $=y r$ * year + dummy * $d$

coef yr.1 dumny .1

+ const

const 200

nl $1 /$ ncoef $=3$

eq lncrate $=$ yr * year

coef $\quad y r .1$

+ toum * timedum + const

taum $.1 \quad$ const 200

nl $1 /$ ncoef $=4$

eq Incrate $=y r$ year + dummy * $d+$ tdum $*$ timedum + const

coef yr.1 dumny .1 tdum .1 const 200

delete /all 


\section{APPENDIX D \\ MAXIMUM LIKELIHOOD (USING SHAZAM NON-IINEAR) (continued)}

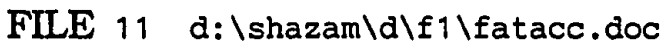

sample 127

read(11) year fat acc hours

* generate zero dumy

genr zerodum $=\operatorname{dum}(.1$ - fat $)$

* generate fatal accident rate

genr fatrate $=(1000000 *($ fat + zerodum $)) /$ hours

* generate log fatrate

genr Infatrat $=\log$ (fatrate)

* generate accident rate

genr accrate $=((1000000 * a c c)) /$ hours

* generate $\log$ accident rate

genr Inaccrat $=\log$ (accrate)

* generate deregulation dummy

genr d

$=\operatorname{dum}($ year -79.9$)$

* generate time since deregulation dummy

genr timedum $\quad=d^{*}$ (year -79$)$

print year fat fatrate d timedum zerodum

print year acc accrate d timedum hours

nl $1 /$ ncoef $=2$

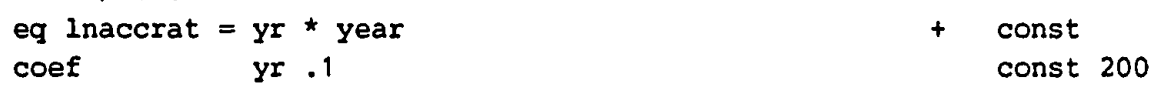

nl $1 /$ ncoef $=3$

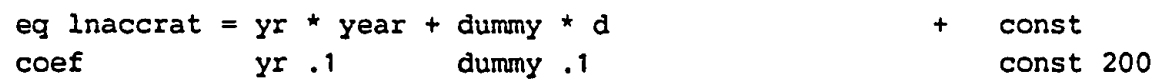

nl $1 /$ ncoef $=3$

eq Inaccrat $=$ yr $*$ year $\quad+$ tdum $*$ timedum + const

coef yr .1 tdum .1 const 200

nl $1 /$ ncoef $=4$

eq Inaccrat $=y r$ year + dumny $* d+$ tdum $*$ timedum + const

coef yr.1 dumn .1 tdum .1 const 200 


\section{APPENDIX D \\ MAXIMUM LIKELIHOOD (USING SHAZAM NON-IINEAR) (continued)}

nl / /ncoef $=3$

eq Infatrat $=y r$ * year +

coef yr.1

zd * zerodum + const

nl $1 /$ ncoef $=4$

eq Infatrat $=y r$ * year + dumny $* d$

coef yr .1 dumny .1

zd 1 const 200

nd $1 /$ ncoef $=4$

eq Infatrat $=$ yr * year

coef $y r .1$

+ tdum * timedum $+z d *$ zerodum + const

tdum 1 zd 1 const 200

nl $1 /$ ncoef $=5$

eq Infatrat $=y r$ * year + dumny * $d+$ tdum * timedum $+z d *$ zerodum + const

yr .1

dummy .1 toum .1

2d 1

const 200 
APPENDIX D

MAXIMUM LIKELIHOOD (USING SHAZAM NON-LINEAR) (continued)

OUTPUT FILE

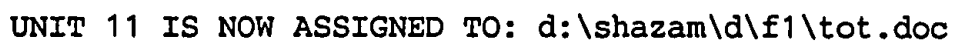

7 VARIABLES AND

25 OBSERVATIONS STARTING AT OBS

$\begin{array}{lrrrrrr}\mathbf{Y} & \text { HOURS } & \text { CRATE } & \text { LNCRATE } & \text { YR } & \text { D } & \text { TIMEDUM } \\ 64 & 2441185 & 26.21678 & 3.266400 & 64 & 0.0 & 0.00 \\ 45 & 2691129 & 16.72161 & 2.816702 & 65 & 0.0 & 0.00 \\ 45 & 2819170 & 15.96214 & 2.770220 & 66 & 0.0 & 0.00 \\ 48 & 3507054 & 13.68670 & 2.616425 & 67 & 0.0 & 0.00 \\ 43 & 4015838 & 10.70760 & 2.370954 & 68 & 0.0 & 0.00 \\ 44 & 4336713 & 10.14593 & 2.317073 & 69 & 0.0 & 0.00 \\ 44 & 4294706 & 10.24517 & 2.326807 & 70 & 0.0 & 0.00 \\ 48 & 4224634 & 11.36193 & 2.430268 & 71 & 0.0 & 0.00 \\ 40 & 4204233 & 9.514221 & 2.252788 & 72 & 0.0 & 0.00 \\ 30 & 4346571 & 6.901992 & 1.931810 & 73 & 0.0 & 0.00 \\ 34 & 3997587 & 8.505131 & 2.140670 & 74 & 0.0 & 0.00 \\ 36 & 3936489 & 9.145205 & 2.213230 & 75 & 0.0 & 0.00 \\ 14 & 4024069 & 3.479066 & 1.246764 & 76 & 0.0 & 0.00 \\ 20 & 4135728 & 4.835908 & 1.576069 & 77 & 0.0 & 0.00 \\ 20 & 4166439 & 4.800262 & 1.568671 & 78 & 0.0 & 0.00 \\ 14 & 4329449 & 3.233668 & 1.173617 & 79 & 0.0 & 0.00 \\ 9 . & 4439343 & 2.027327 & 0.7067182 & 80 & 1 . & 1.0 \\ 27 & 4049954 & 6.666742 & 1.897131 & 81 & 1 . & 2.0 \\ 15 & 4016962 & 3.734165 & 1.317524 & 82 & 1 . & 3.0 \\ 32 & 4197657 & 7.623300 & 2.031209 & 83 & 1 . & 4.0 \\ 24 & 4547810 & 5.277265 & 1.663408 & 84 & 1 . & 5.0 \\ 25 & 4744502 & 5.269257 & 1.661889 & 85 & 1 . & 6.0 \\ 26 & 5389885 & 4.823851 & 1.573572 & 86 & 1 . & 7.0 \\ 36 & 6921046 & 5.201526 & 1.648952 & 87 & 1 . & 8.0 \\ 33 & 7166746 & 4.604600 & 1.527056 & 88 & 1 . & 9.0\end{array}$


APPENDIX D

MAXIMUM LIKELIHOOD (USING SHAZAM NON-LINEAR)

(continued)

2 VARIABLES IN 1 EQUATIONS WITH 2 COEFFICIENTS

LOG-IIKELIHOOD FUNCTION $=\quad-10.38533$

MAXIMUM LIKELIHOOD ESTIMATE OF SIGMA-SQUARED $=0.13438$

COEFFICIENT ST. ERROR T-RATIO

YR $\quad-0.62229 \mathrm{E}-010.10171 \mathrm{E}-01-6.1184$
CONST
6.6912
0.77641
8.6181

3 VARIABLES IN 1 EQUATIONS WITH 3 COEFFICIENTS

LOG-IIKELIHOOD FUNCTION= $\quad-8.762643$

MAXIMUM IIKELIHOOD ESTIMATE OF SIGMA-SQUARED $=0.11802$

COEFFICIENT ST. ERROR T-RATIO

$\begin{array}{lclr}\text { YR } & -0.88835 \mathrm{E}-01 & 0.17178 \mathrm{E}-01 & -5.1716 \\ \text { DUMMY } & 0.48039 & 0.25806 & 1.8616 \\ \text { CONST } & 8.5404 & 1.2312 & 6.9367\end{array}$

3 VARIABLES IN 1 EQUATIONS WITH 3 COEFFICIENTS

LOG-LIKELIHOOD FUNCTION $=-1.817325$

MAXIMUM LIKELIHOOD ESTIMATE OF SIGMA-SQUARED $=0.67712 \mathrm{E}-01$

COEFFICIENT ST. ERROR T-RATIO

YR $\quad-0.11270 \quad 0.12754 E-01-8.8361$

TDUM $\quad 0.15621 \quad 0.31994 \mathrm{E}-01 \quad 4.8824$

$\begin{array}{llll}\text { CONST } & 10.246 & 0.92419 & 11.086\end{array}$

4 VARIABLES IN 1 EQUATIONS WITH 4 COEFFICIENTS

LOG-LIKELIHOOD FUNCTION $=-1.816268$

MAXIMUM LIKELIHOOD ESTIMATE OF SIGMA-SQUARED $=0.67706 \mathrm{E}-01$

COEFFICIENT ST. ERROR T-RATIO

YR $\quad-0.11239 \quad 0.14499 \mathrm{E}-01-7.7518$

DUMMY $\quad-0.10398 E-01 \quad 0.23029 \quad-0.45152 E-01$

TDUM $\quad 0.15705 \quad 0.36996 \mathrm{E}-01 \quad 4.2452$

$\begin{array}{llll}\text { CONST } & 10.225 & 1.0365 & 9.8651\end{array}$ 


\section{APPENDIX D \\ MAXIMUM LIKELIHOOD (USING SHAZAM NON-LINEAR) (continued)}

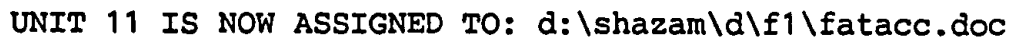

\section{VARIABLES AND}

$\begin{array}{rr}\text { YEAR } & \text { FAT } \\ 61 & 6.000000 \\ 62 & 6.000000 \\ 63 & 6.000000 \\ 64 & 11.00000 \\ 65 & 8.000000 \\ 66 & 5.000000 \\ 67 & 8.000000 \\ 68 & 13.00000 \\ 69 & 8.000000 \\ 70 & 4.000000 \\ 71 & 7.000000 \\ 72 & 7.000000 \\ 73 & 8.000000 \\ 74 & 7.000000 \\ 75 & 2.000000 \\ 76 & 2.000000 \\ 77 & 3.000000 \\ 78 & 4.000000 \\ 79 & 5.000000 \\ 80 & 0.0000000 \\ 81 & 4.000000 \\ 82 & 3.000000 \\ 83 & 4.000000 \\ 84 & 1.000000 \\ 85 & 4.000000 \\ 86 & 1.000000 \\ 87 & 4.000000\end{array}$

27 OBSERVATIONS STARTING AT OBS

1

$\begin{array}{rcrl}\text { FATRATE } & \text { D } & \text { TIMEDUM } & \text { ZERODUM } \\ 1.641810 & 0.0 & 0.00000 & 0.0 \\ 1.718620 & 0.0 & 0.00000 & 0.0 \\ 1.664712 & 0.0 & 0.00000 & 0.0 \\ 2.914084 & 0.0 & 0.00000 & 0.0 \\ 1.964643 & 0.0 & 0.00000 & 0.0 \\ 1.181200 & 0.0 & 0.00000 & 0.0 \\ 1.624669 & 0.0 & 0.00000 & 0.0 \\ 2.354249 & 0.0 & 0.00000 & 0.0 \\ 1.357715 & 0.0 & 0.00000 & 0.0 \\ 0.6919813 & 0.0 & 0.00000 & 0.0 \\ 1.226721 & 0.0 & 0.00000 & 0.0 \\ 1.236862 & 0.0 & 0.00000 & 0.0 \\ 1.356260 & 0.0 & 0.00000 & 0.0 \\ 1.278657 & 0.0 & 0.00000 & 0.0 \\ 0.3688223 & 0.0 & 0.00000 & 0.0 \\ 0.3579354 & 0.0 & 0.00000 & 0.0 \\ 0.5171662 & 0.0 & 0.00000 & 0.0 \\ 0.6631582 & 0.0 & 0.00000 & 0.0 \\ 0.7462328 & 0.0 & 0.00000 & 0.0 \\ 0.1471112 & 1 . & 1.0000 & 1 . \\ 0.6087087 & 1 . & 2.0000 & 0.0 \\ 0.4658267 & 1 . & 3.0000 & 0.0 \\ 0.6015934 & 1 . & 4.0000 & 0.0 \\ 0.1344358 & 1 . & 5.0000 & 0.0 \\ 0.5033070 & 1 . & 6.0000 & 0.0 \\ 0.1068729 & 1 . & 7.0000 & 0.0 \\ 0.4119040 & 1 . & 8.0000 & 0.0\end{array}$


APPENDIX D

MAXIMUM LIKELIHOOD (USING SHAZAM NON-IINEAR) (continued)

$\begin{array}{rrrlll}\text { YEAR } & \text { ACC } & \text { ACCRATE } & \text { D } & \text { TIMEDUM } & \text { HOURS } \\ 61 & 66 & 18.05991 & 0.00 & 0.00000 & 3654503 \\ 62 & 47 & 13.46252 & 0.00 & 0.00000 & 3491174 \\ 63 & 54 & 14.98240 & 0.00 & 0.00000 & 3604228 \\ 64 & 59 & 15.63009 & 0.00 & 0.00000 & 3774771 \\ 65 & 65 & 15.96272 & 0.00 & 0.00000 & 4071987 \\ 66 & 56 & 13.22944 & 0.00 & 0.00000 & 4232982 \\ 67 & 54 & 10.96652 & 0.00 & 0.00000 & 4924080 \\ 68 & 56 & 10.14138 & 0.00 & 0.00000 & 5521931 \\ 69 & 51 & 8.655431 & 0.00 & 0.00000 & 5892254 \\ 70 & 43 & 7.438799 & 0.00 & 0.00000 & 5780503 \\ 71 & 43 & 7.535571 & 0.00 & 0.00000 & 5706270 \\ 72 & 46 & 8.127948 & 0.00 & 0.00000 & 5659485 \\ 73 & 36 & 6.103169 & 0.00 & 0.00000 & 5898575 \\ 74 & 43 & 7.854606 & 0.00 & 0.00000 & 5474495 \\ 75 & 30 & 5.532335 & 0.00 & 0.00000 & 5422665 \\ 76 & 22 & 3.937289 & 0.00 & 0.00000 & 5587601 \\ 77 & 20 & 3.447775 & 0.00 & 0.00000 & 5800843 \\ 78 & 20 & 3.315791 & 0.00 & 0.00000 & 6031743 \\ 79 & 23 & 3.432671 & 0.00 & 0.00000 & 6700322 \\ 80 & 15 & 2.206668 & 1.0 & 1.0000 & 6797578 \\ 81 & 25 & 3.804429 & 1.0 & 2.0000 & 6571288 \\ 82 & 15 & 2.329134 & 1.0 & 3.0000 & 6440163 \\ 83 & 22 & 3.308764 & 1.0 & 4.0000 & 6649009 \\ 84 & 12 & 1.613229 & 1.0 & 5.0000 & 7438497 \\ 85 & 17 & 2.139055 & 1.0 & 6.0000 & 7947435 \\ 86 & 20 & 2.137459 & 1.0 & 7.0000 & 9356906 \\ 87 & 30 & 3.089280 & 1.0 & 8.0000 & 9711000\end{array}$


APPENDIX D

MAXIMUM IIKELIHOOD (USING SHAZAM NON-LINEAR)

(continued)

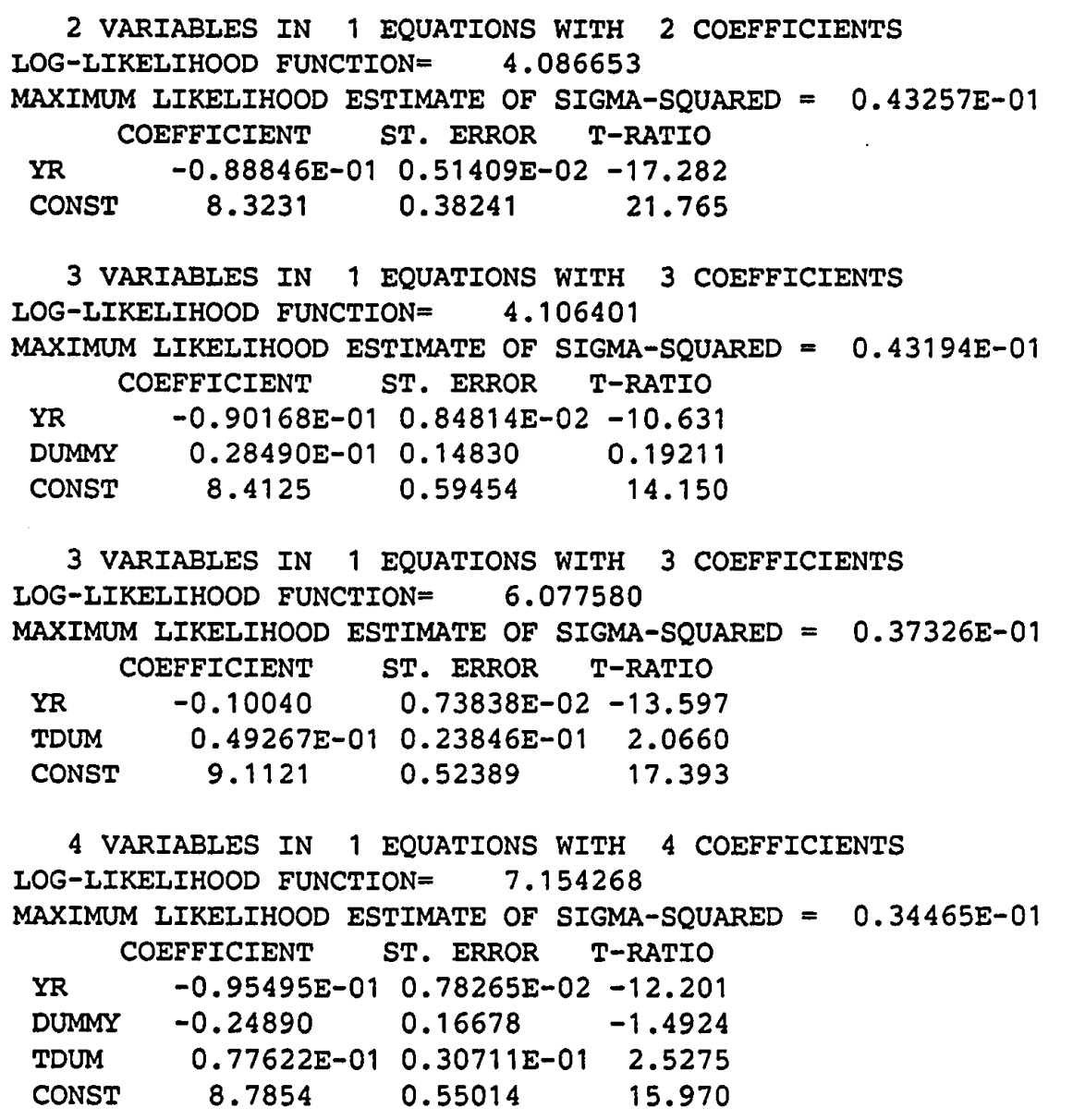




\section{APPENDIX D \\ MAXIMUM LIKELIHOOD (USING SHAZAM NON-IINEAR) (continued)}

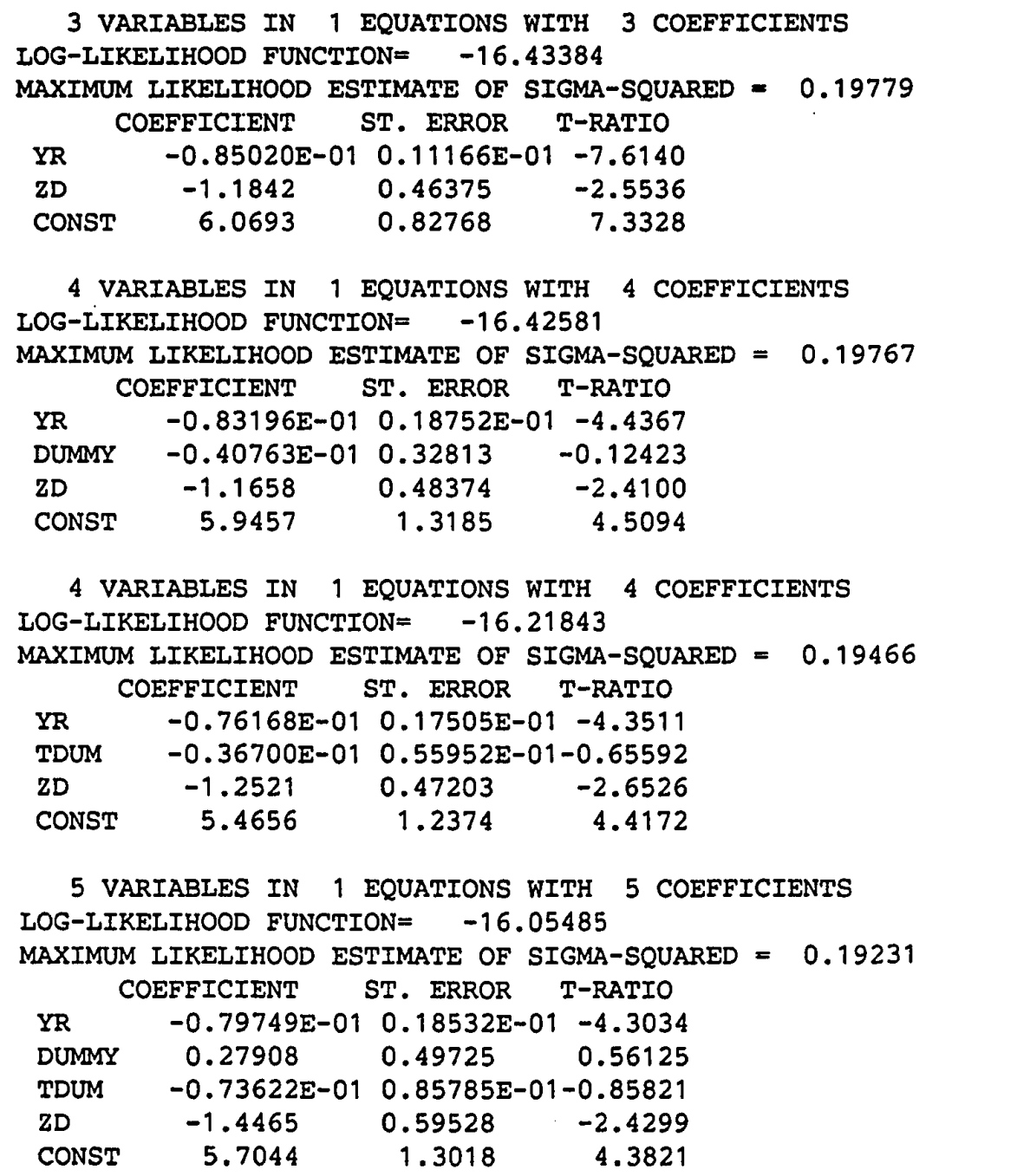




\section{APPENDIX E}

OLS USING THE SQUARE ROOT OF RATE 
APPENDIX E

OLS USING THE SQUARE ROOT OF RATE

COMMAND FILE

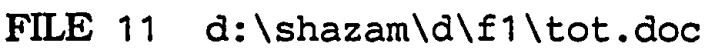

sample 125

read(11) year d totocc y $\mathrm{n} u$ hours

* generate controlable rate

genr crate $=((1000000 * y)) /$ hours

* generate square root crate

genr sqrtcrat $=$ sqrt (crate)

* generate time since deregulation dummy

genr timedum $=d^{*}($ year -79$)$

print $y$ hours crate sqrtcrat year d timedum

Ols sqrtcrat year d /exactdw

ols sqrtcrat year timedum /exactdw

ols sqrtcrat year d timedum /exactdw

delete /all 
APPENDIX E

OLS USING THE SQUARE ROOT OF RATE (continued)

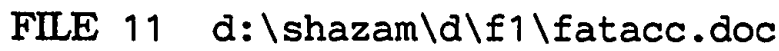
sample 127

read(11) year fat acc hours

* generate fatal accident rate

genr fatrate $=(1000000 *$ fat $) /$ hours

* generate squareroot fatrate

genr sqrtfatr = sqrt (fatrate)

* generate accident rate

genr accrate $=((1000000 * a c c)) /$ hours

* generate sqrt accident rate

genr sqrtaccr = sqrt (accrate)

* generate deregulation dummy

genr d = dum(year - 79.9)

* generate time since deregulation dummy

genr timedum $=d^{*}($ year -79$)$

print year fat fatrate d timedum

print year acc accrate d timedum hours

ols sgrtaccr year d /exactaw

ols sqrtaccr year timedum /exactdw

Ols sqrtaccr year d timedum /exactdw

ols sqrtfatr year d /exactdw

Ols sqrtfatr year timedum lexactdw

Ols sqrtfatr year d timedum /exactdw

delete /all 
APPENDIX E

OLS USING THE SQUARE ROOT OF RATE

(continued)

\section{OUTPUT FILE}

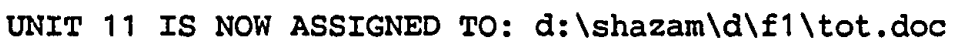

7 VARIABLES AND 25 OBSERVATIONS STARTING AT OBS

$\begin{array}{lllllll}\mathbf{Y} & \text { HOURS } & \text { CRATE } & \text { SQRTCRAT } & \text { YR } & \text { D } & \text { TIMEDUM } \\ 64 & 2441185 . & 26.21678 & 5.120232 & 64 & 0.00 & 0.00 \\ 45 & 2691129 . & 16.72161 & 4.089206 & 65 & 0.00 & 0.00 \\ 45 & 2819170 . & 15.96214 & 3.995265 & 66 & 0.00 & 0.00 \\ 48 & 3507054 . & 13.68670 & 3.699554 & 67 & 0.00 & 0.00 \\ 43 & 4015838 . & 10.70760 & 3.272247 & 68 & 0.00 & 0.00 \\ 44 & 4336713 . & 10.14593 & 3.185268 & 69 & 0.00 & 0.00 \\ 44 & 4294706 . & 10.24517 & 3.200808 & 70 & 0.00 & 0.00 \\ 48 & 4224634 . & 11.36193 & 3.370746 & 71 & 0.00 & 0.00 \\ 40 & 4204233 . & 9.514221 & 3.084513 & 72 & 0.00 & 0.00 \\ 30 & 4346571 . & 6.901992 & 2.627164 & 73 & 0.00 & 0.00 \\ 34 & 3997587 . & 8.505131 & 2.916356 & 74 & 0.00 & 0.00 \\ 36 & 3936489 . & 9.145205 & 3.024104 & 75 & 0.00 & 0.00 \\ 14 & 4024069 . & 3.479066 & 1.865225 & 76 & 0.00 & 0.00 \\ 20 & 4135728 . & 4.835908 & 2.199070 & 77 & 0.00 & 0.00 \\ 20 & 4166439 . & 4.800262 & 2.190950 & 78 & 0.00 & 0.00 \\ 14 & 4329449 . & 3.233668 & 1.798240 & 79 & 0.00 & 0.00 \\ 9 . & 4439343 . & 2.027327 & 1.423842 & 80 & 1.0 & 1.00 \\ 27 & 4049954 . & 6.666742 & 2.582004 & 81 & 1.0 & 2.00 \\ 15 & 4016962 . & 3.734165 & 1.932399 & 82 & 1.0 & 3.00 \\ 32 & 4197657 . & 7.623300 & 2.761032 & 83 & 1.0 & 4.00 \\ 24 & 4547810 . & 5.277265 & 2.297230 & 84 & 1.0 & 5.00 \\ 25 & 4744502 . & 5.269257 & 2.295486 & 85 & 1.0 & 6.00 \\ 26 & 5389885 . & 4.823851 & 2.196327 & 86 & 1.0 & 7.00 \\ 36 & 6921046 . & 5.201526 & 2.280685 & 87 & 1.0 & 8.00 \\ 33 & 7166746 . & 4.604600 & 2.145833 & 88 & 1.0 & 9.00\end{array}$




\section{APPENDIX E \\ OLS USING THE SQUARE ROOT OF RATE (continued)}

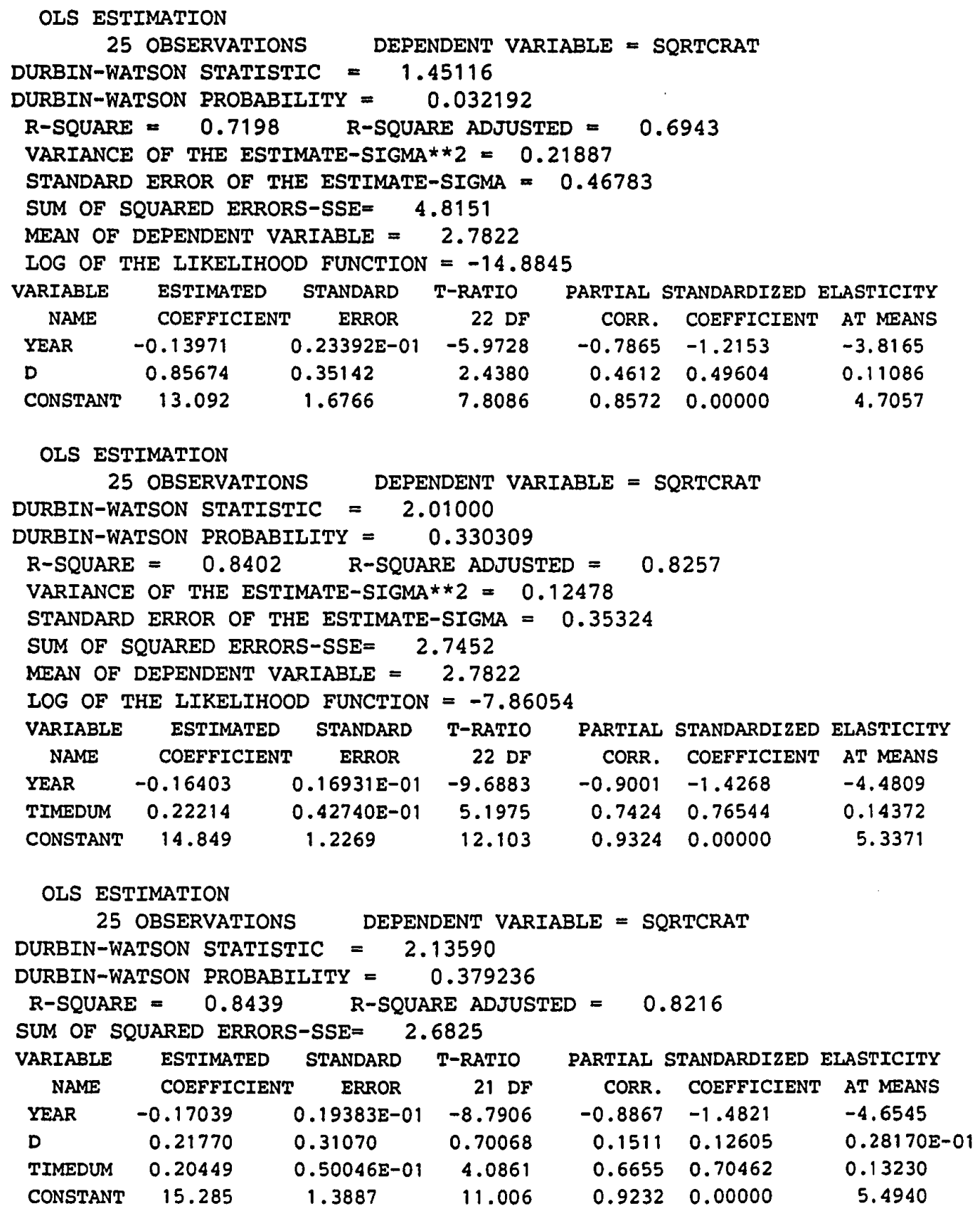




\section{APPENDIX E \\ OLS USING THE SQUARE ROOT OF RATE (continued)}

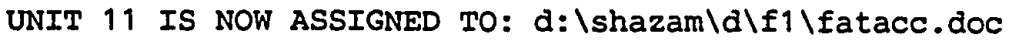

4 VARIABLES AND

$\begin{array}{ll}\text { YR } & \text { FAT } \\ 61 & 6.000000 \\ 62 & 6.000000 \\ 63 & 6.000000 \\ 64 & 11.00000 \\ 65 & 8.000000 \\ 66 & 5.000000 \\ 67 & 8.000000 \\ 68 & 13.00000 \\ 69 & 8.000000 \\ 70 & 4.000000 \\ 71 & 7.000000 \\ 72 & 7.000000 \\ 73 & 8.000000 \\ 74 & 7.000000 \\ 75 & 2.000000 \\ 76 & 2.000000 \\ 77 & 3.000000 \\ 78 & 4.000000 \\ 79 & 5.000000 \\ 80 & 0.0000000 \\ 81 & 4.000000 \\ 82 & 3.000000 \\ 83 & 4.000000 \\ 84 & 1.000000 \\ 85 & 4.000000 \\ 86 & 1.000000 \\ 87 & 4.000000\end{array}$

27 OBSERVATIONS STARTING AT OBS

$\begin{array}{ccc}\text { FATRATE } & \text { D } & \text { TIMEDUM } \\ 1.641810 & 0.0000000 & 0.0000000 \\ 1.718620 & 0.0000000 & 0.0000000 \\ 1.664712 & 0.0000000 & 0.0000000 \\ 2.914084 & 0.0000000 & 0.0000000 \\ 1.964643 & 0.0000000 & 0.0000000 \\ 1.181200 & 0.0000000 & 0.0000000 \\ 1.624669 & 0.0000000 & 0.0000000 \\ 2.354249 & 0.0000000 & 0.0000000 \\ 1.357715 & 0.0000000 & 0.0000000 \\ 0.6919813 & 0.0000000 & 0.0000000 \\ 1.226721 & 0.0000000 & 0.0000000 \\ 1.236862 & 0.0000000 & 0.0000000 \\ 1.356260 & 0.0000000 & 0.0000000 \\ 1.278657 & 0.0000000 & 0.0000000 \\ 0.3688223 & 0.0000000 & 0.0000000 \\ 0.3579354 & 0.0000000 & 0.0000000 \\ 0.5171662 & 0.0000000 & 0.0000000 \\ 0.6631582 & 0.0000000 & 0.0000000 \\ 0.7462328 & 0.0000000 & 0.0000000 \\ 0.0000000 & 1.000000 & 1.000000 \\ 0.6087087 & 1.000000 & 2.000000 \\ 0.4658267 & 1.000000 & 3.000000 \\ 0.6015934 & 1.000000 & 4.000000 \\ 0.1344358 & 1.000000 & 5.000000 \\ 0.5033070 & 1.000000 & 6.000000 \\ 0.1068729 & 1.000000 & 7.000000 \\ 0.4119040 & 1.000000 & 8.000000\end{array}$


APPENDIX E

OLS USING THE SQUARE ROOT OF RATE (continued)

$\begin{array}{lrrccr}\text { YEAR } & \text { ACC } & \text { ACCRATE } & \text { D } & \text { TIMEDUM } & \text { HOURS } \\ 61.00000 & 66 & 18.05991 & 0.00 & 0.00 & 3654503 . \\ 62.00000 & 47 & 13.46252 & 0.00 & 0.00 & 3491174 . \\ 63.00000 & 54 & 14.98240 & 0.00 & 0.00 & 3604228 . \\ 64.00000 & 59 & 15.63009 & 0.00 & 0.00 & 3774771 . \\ 65.00000 & 65 & 15.96272 & 0.00 & 0.00 & 4071987 . \\ 66.00000 & 56 & 13.22944 & 0.00 & 0.00 & 4232982 . \\ 67.00000 & 54 & 10.96652 & 0.00 & 0.00 & 4924080 . \\ 68.00000 & 56 & 10.14138 & 0.00 & 0.00 & 5521931 . \\ 69.00000 & 51 & 8.655431 & 0.00 & 0.00 & 5892254 . \\ 70.00000 & 43 & 7.438799 & 0.00 & 0.00 & 5780503 . \\ 71.00000 & 43 & 7.535571 & 0.00 & 0.00 & 5706270 . \\ 72.00000 & 46 & 8.127948 & 0.00 & 0.00 & 5659485 . \\ 73.00000 & 36 & 6.103169 & 0.00 & 0.00 & 5898575 . \\ 74.00000 & 43 & 7.854606 & 0.00 & 0.00 & 5474495 . \\ 75.00000 & 30 & 5.532335 & 0.00 & 0.00 & 5422665 . \\ 76.00000 & 22 & 3.937289 & 0.00 & 0.00 & 5587601 . \\ 77.00000 & 20 & 3.447775 & 0.00 & 0.00 & 5800843 . \\ 78.00000 & 20 & 3.315791 & 0.00 & 0.00 & 6031743 . \\ 79.00000 & 23 & 3.432671 & 0.00 & 0.00 & 6700322 . \\ 80.00000 & 15 & 2.206668 & 1.0 & 1.0 & 6797578 . \\ 81.00000 & 25 & 3.804429 & 1.0 & 2.0 & 6571288 . \\ 82.00000 & 15 & 2.329134 & 1.0 & 3.0 & 6440163 . \\ 83.00000 & 22 & 3.308764 & 1.0 & 4.0 & 6649009 . \\ 84.00000 & 12 & 1.613229 & 1.0 & 5.0 & 7438497 . \\ 85.00000 & 17 & 2.139055 & 1.0 & 6.0 & 7947435 . \\ 86.00000 & 20 & 2.137459 & 1.0 & 7.0 & 9356906 . \\ 87.00000 & 30 & 3.089280 & 1.0 & 8.0 & 9711000 .\end{array}$




\section{APPENDIX E}

\section{OLS USING THE SQUARE ROOT OF RATE} (continued)

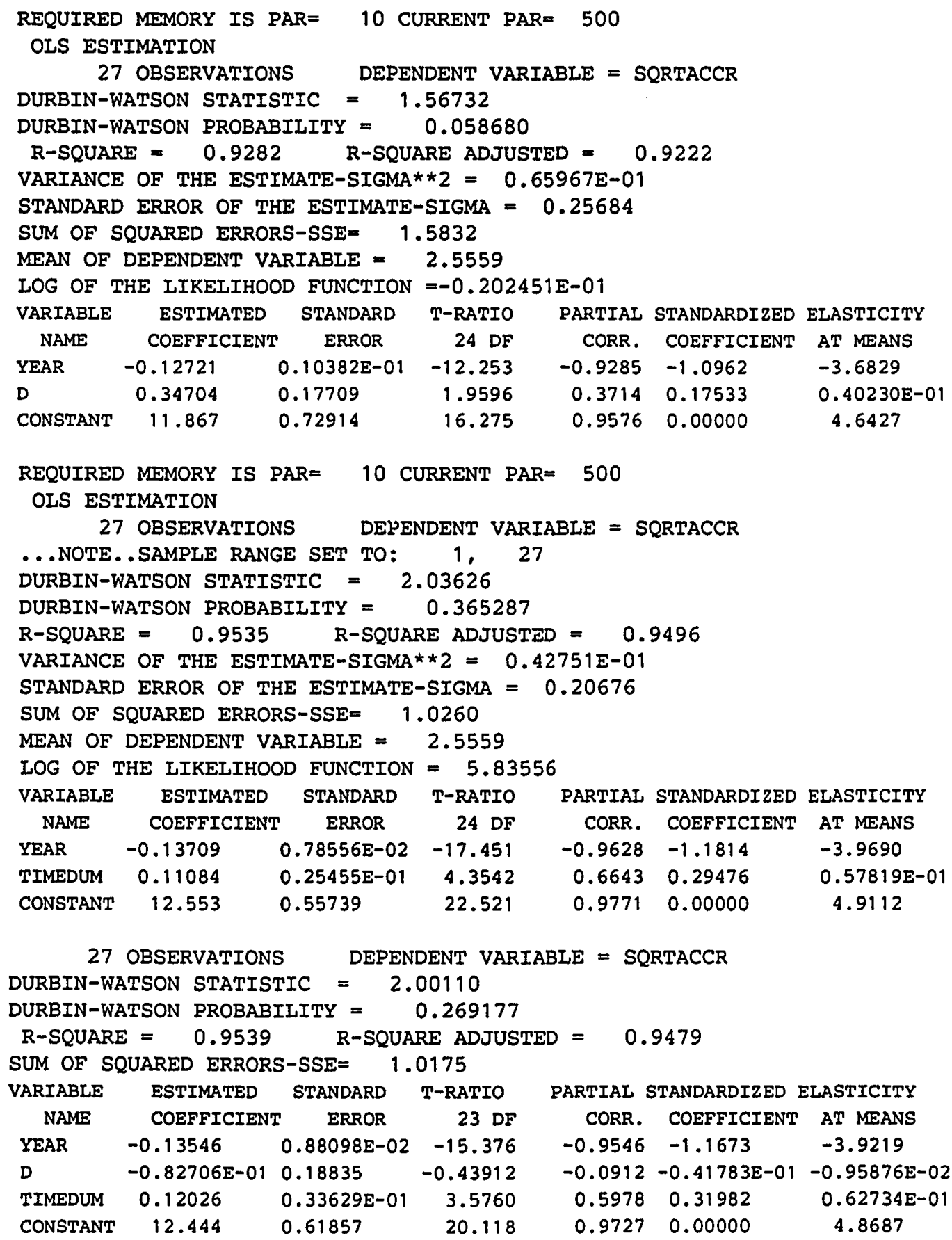




\section{APPENDIX E}

\section{OLS USING THE SQUARE ROOT OF RATE (continued)}

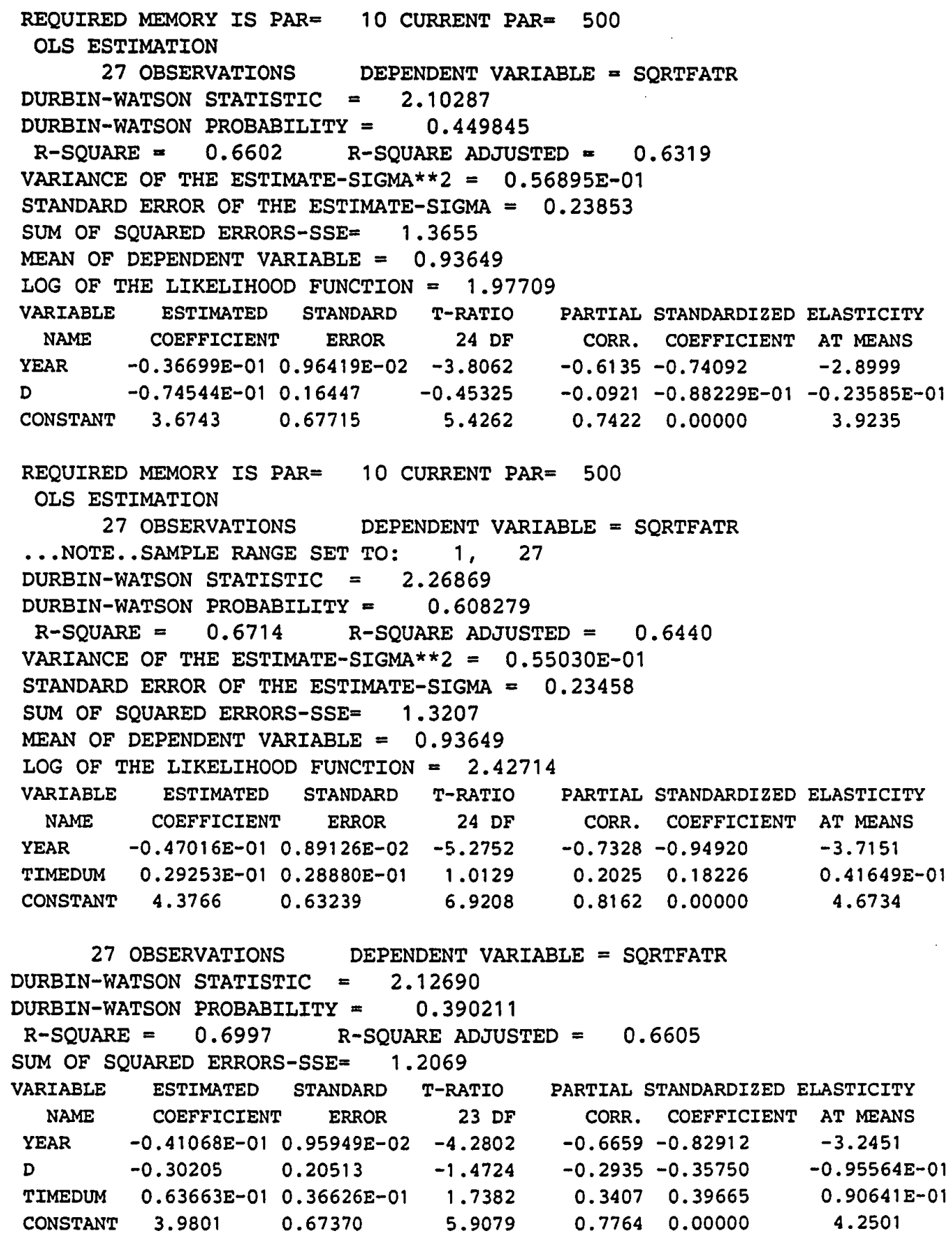


APPENDIX F

BOX COX PROCEDURE 


\section{APPENDIX F}

BOX COX PROCEDURE

COMMAND FILE

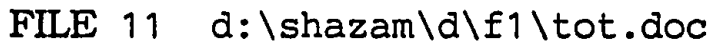

sample 125

read(11) year d totocc y $n u$ hours

* generate controlable rate genr crate $=((1000000 * y)) /$ hours

* generate time since deregulation dummy genr timedum $=d^{*}$ (year - 79)

print year $y$ hours crate d timedum

$\begin{array}{lllll}\text { box } & \text { crate year } & & \text { /auto } \\ \text { box } & \text { crate year d } & & \text { /auto } \\ \text { box } & \text { crate year } & & \text { timedum } & \text { /auto } \\ \text { box } & \text { crate year d } & \text { timedum } & \text { /auto }\end{array}$

delete / all 


\section{APPENDIX F \\ BOX COX PROCEDURE \\ (continued)}

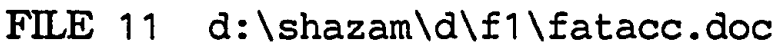

sample 127

read(11) year fatal acc hours

* generate fatal accident rate

genr fatrate $=(1000000 *($ fatal +.5$)) /$ hours

* generate accident rate

genr accrate $=(1000000 *$ acc $) /$ hours

* generate deregulation dummy

genr $d=\operatorname{dum}($ year -79.9$)$

genr timedum $=d *($ year -79$)$

print year fatal fatrate hours acc accrate d timedum

\begin{tabular}{|c|c|c|c|c|c|}
\hline box & accrate & year & & & lauto \\
\hline box & accrate & year & & & /auto \\
\hline box & accrate & year & & timedum & /auto \\
\hline box & accrate & year & $d$ & timedum & /au \\
\hline ox & fatrate & year & & & \\
\hline$x$ & fatrate & year & & & \\
\hline D & fatrate & year & & timedum & \\
\hline $\mathrm{x}$ & fatrate & year & $d$ & timedum & $/ a$ \\
\hline
\end{tabular}

delete / all 


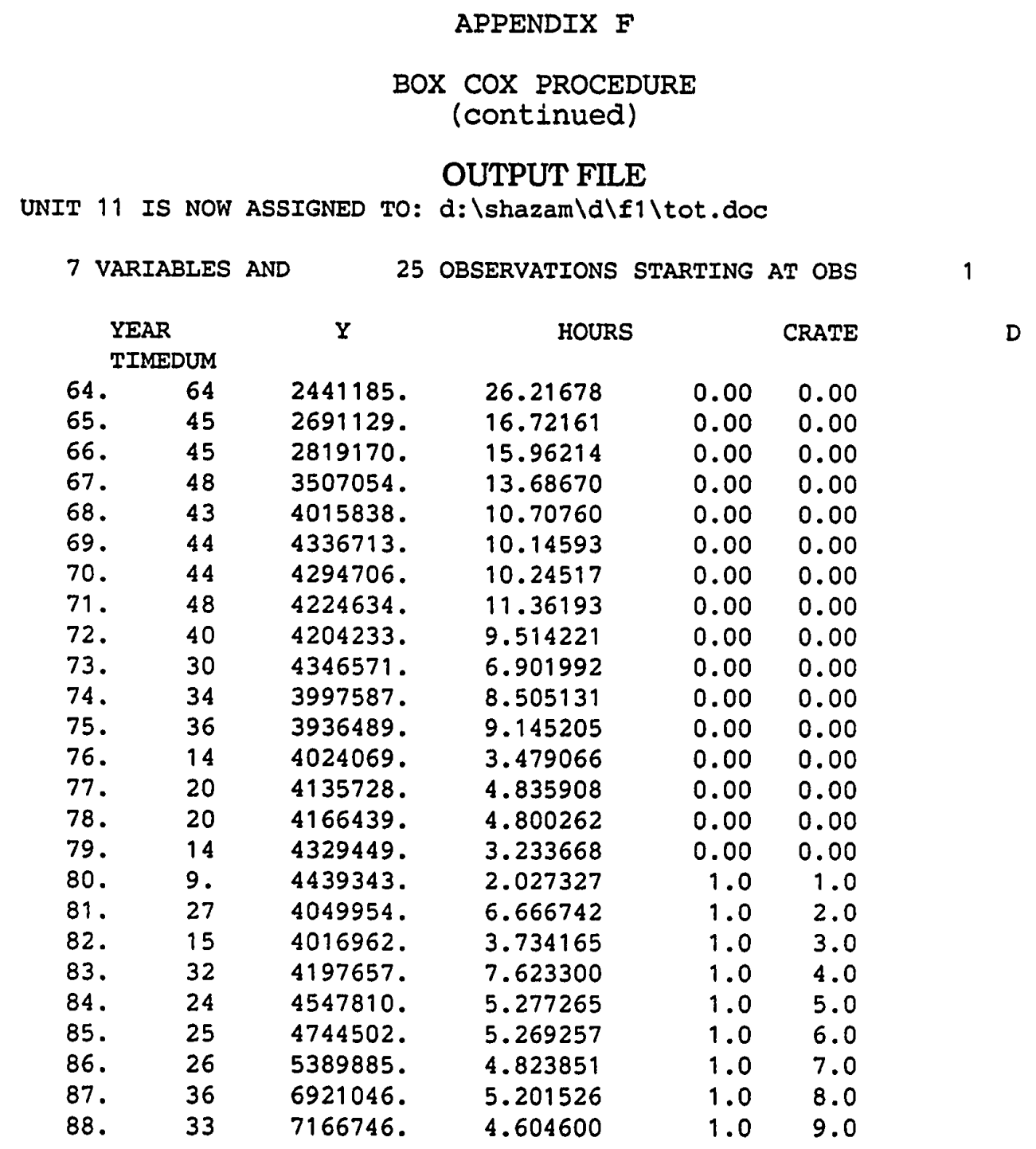




\section{APPENDIX F \\ BOX COX PROCEDURE \\ (continued)}

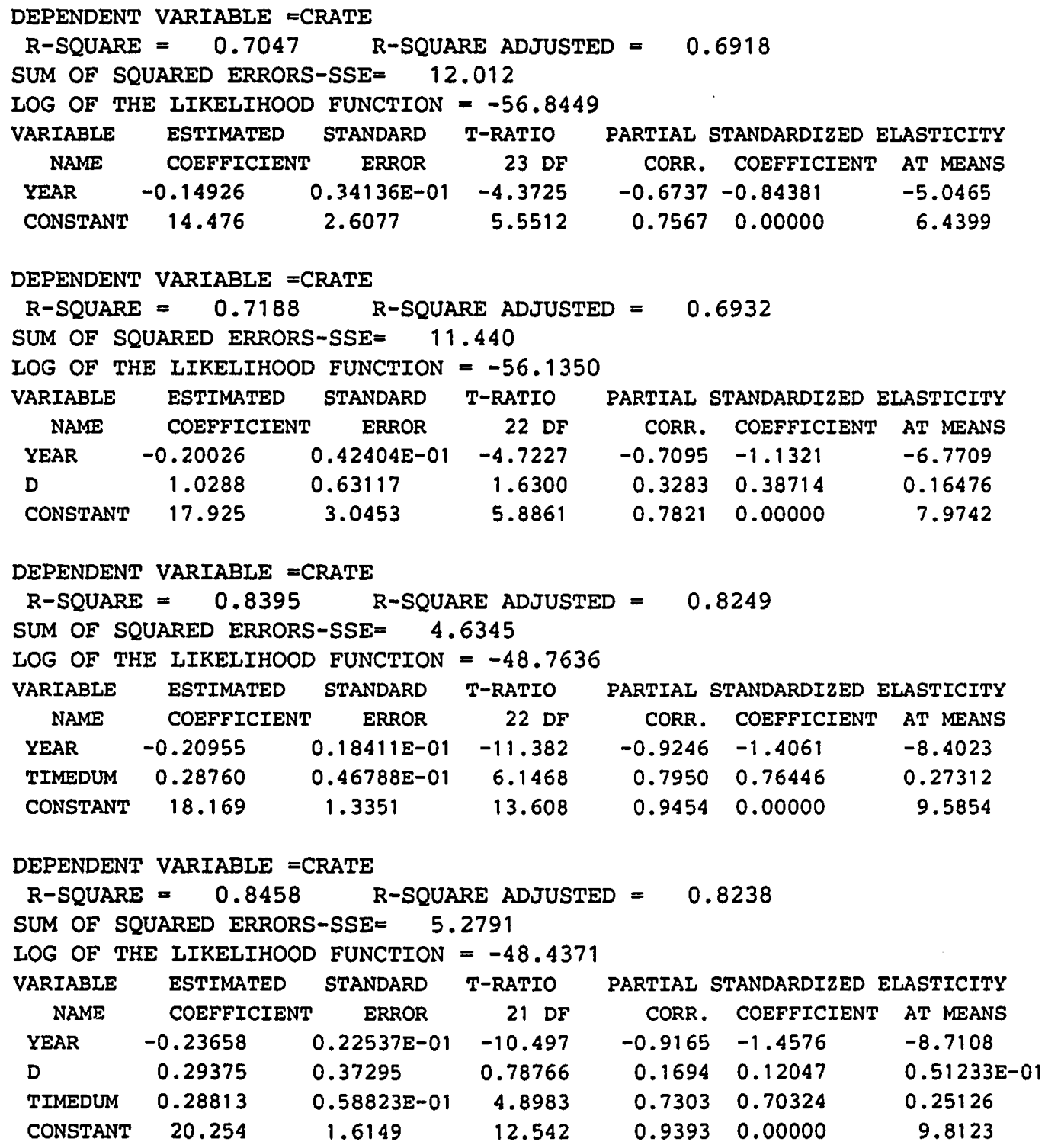


APPENDIX $\mathrm{F}$

BOX COX PROCEDURE (continued)

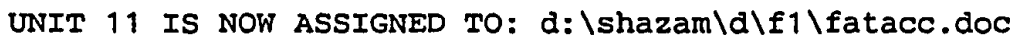

4 VARIABLES AND

$\begin{array}{rrr}\text { YR } & \text { FATAI } & \text { FATRATE } \\ 61 & 6.0 & 1.778628 \\ 62 & 6.0 & 1.861838 \\ 63 & 6.0 & 1.803438 \\ 64 & 11 . & 3.046542 \\ 65 & 8.0 & 2.087433 \\ 66 & 5.0 & 1.299320 \\ 67 & 8.0 & 1.726211 \\ 68 & 13 . & 2.444797 \\ 69 & 8.0 & 1.442572 \\ 70 & 4.0 & 0.7784790 \\ 71 & 7.0 & 1.314344 \\ 72 & 7.0 & 1.325209 \\ 73 & 8.0 & 1.441026 \\ 74 & 7.0 & 1.369989 \\ 75 & 2.0 & 0.4610279 \\ 76 & 2.0 & 0.4474192 \\ 77 & 3.0 & 0.6033606 \\ 78 & 4.0 & 0.7460530 \\ 79 & 5.0 & 0.8208561 \\ 80 & 0.00 & 0.0735556 \\ 81 & 4.0 & 0.6847973 \\ 82 & 3.0 & 0.5434645 \\ 83 & 4.0 & 0.6767926 \\ 84 & 1.0 & 0.2016536 \\ 85 & 4.0 & 0.5662204 \\ 86 & 1.0 & 0.1603094 \\ 87 & 4.0 & 0.4633920\end{array}$

27 OBSERVATIONS STARTING AT OBS

$\begin{array}{ccccc}\text { HOURS } & \text { ACC } & \text { ACCRATE } & \text { D } & \text { TIMEDUM } \\ \text { 3654503. } & 66 & 18.05991 & 0.00 & 0.00 \\ 3491174 . & 47 & 13.46252 & 0.00 & 0.00 \\ 3604228 . & 54 & 14.98240 & 0.00 & 0.00 \\ 3774771 . & 59 & 15.63009 & 0.00 & 0.00 \\ 4071987 . & 65 & 15.96272 & 0.00 & 0.00 \\ 4232982 . & 56 & 13.22944 & 0.00 & 0.00 \\ 4924080 . & 54 & 10.96652 & 0.00 & 0.00 \\ 5521931 . & 56 & 10.14138 & 0.00 & 0.00 \\ 5892254 . & 51 & 8.655431 & 0.00 & 0.00 \\ 5780503 . & 43 & 7.438799 & 0.00 & 0.00 \\ 5706270 . & 43 & 7.535571 & 0.00 & 0.00 \\ 5659485 . & 46 & 8.127948 & 0.00 & 0.00 \\ 5898575 . & 36 & 6.103169 & 0.00 & 0.00 \\ 5474495 . & 43 & 7.854606 & 0.00 & 0.00 \\ 5422665 . & 30 & 5.532335 & 0.00 & 0.00 \\ 5587601 . & 22 & 3.937289 & 0.00 & 0.00 \\ 5800843 . & 20 & 3.447775 & 0.00 & 0.00 \\ 6031743 . & 20 & 3.315791 & 0.00 & 0.00 \\ 6700322 . & 23 & 3.432671 & 0.00 & 0.00 \\ 6797578 . & 15 & 2.206668 & 1.0 & 1.00 \\ 6571288 . & 25 & 3.804429 & 1.0 & 2.00 \\ 6440163 . & 15 & 2.329134 & 1.0 & 3.00 \\ 6649009 . & 22 & 3.308764 & 1.0 & 4.00 \\ 7438497 . & 12 & 1.613229 & 1.0 & 5.00 \\ 7947435 . & 17 & 2.139055 & 1.0 & 6.00 \\ 9356906 . & 20 & 2.137459 & 1.0 & 7.00 \\ 9711000 . & 30 & 3.089280 & 1.0 & 8.00\end{array}$




\section{APPENDIX F \\ BOX COX PROCEDURE \\ (continued)}

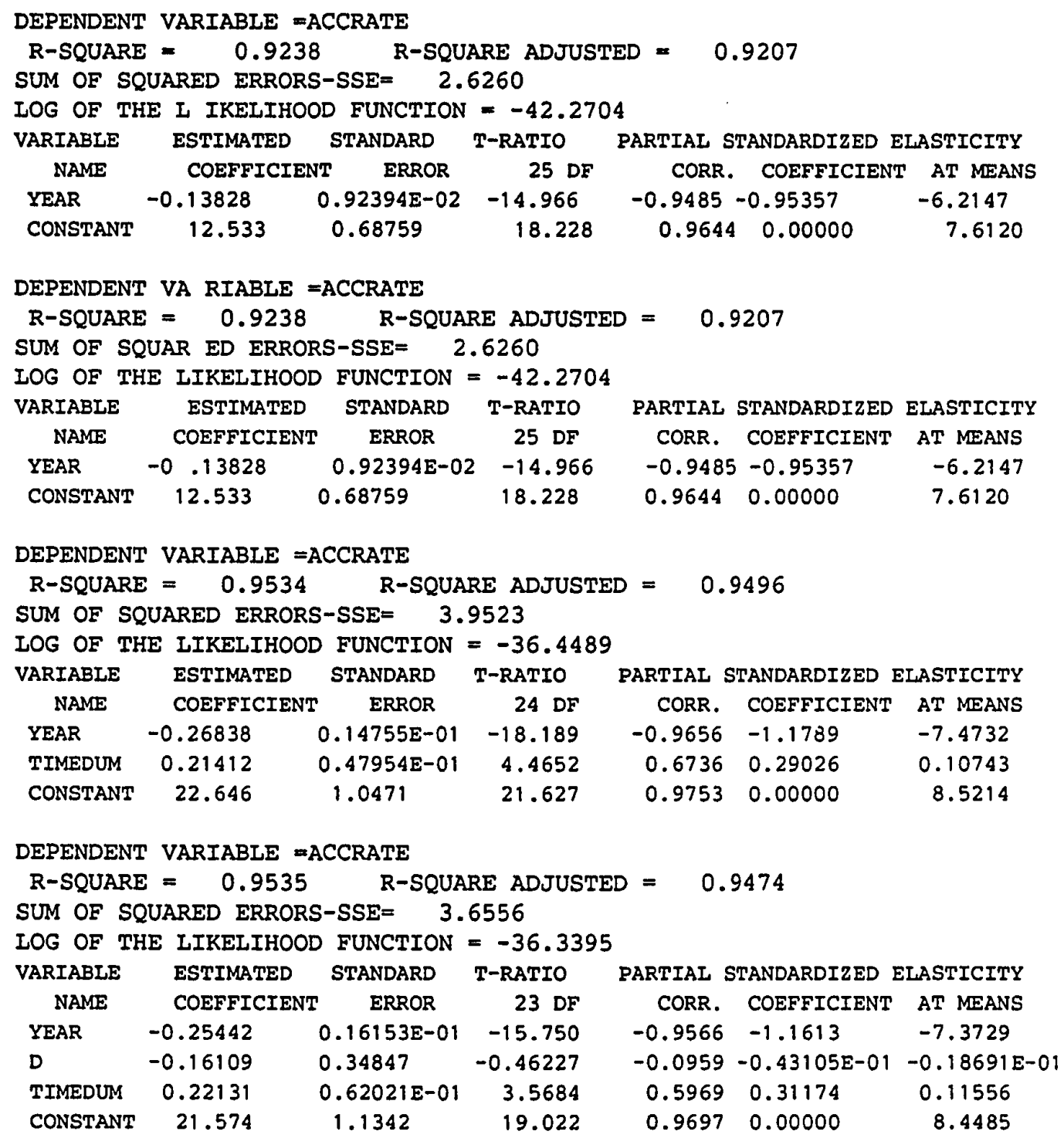




\section{APPENDIX F}

\section{BOX COX PROCEDURE \\ (continued)}

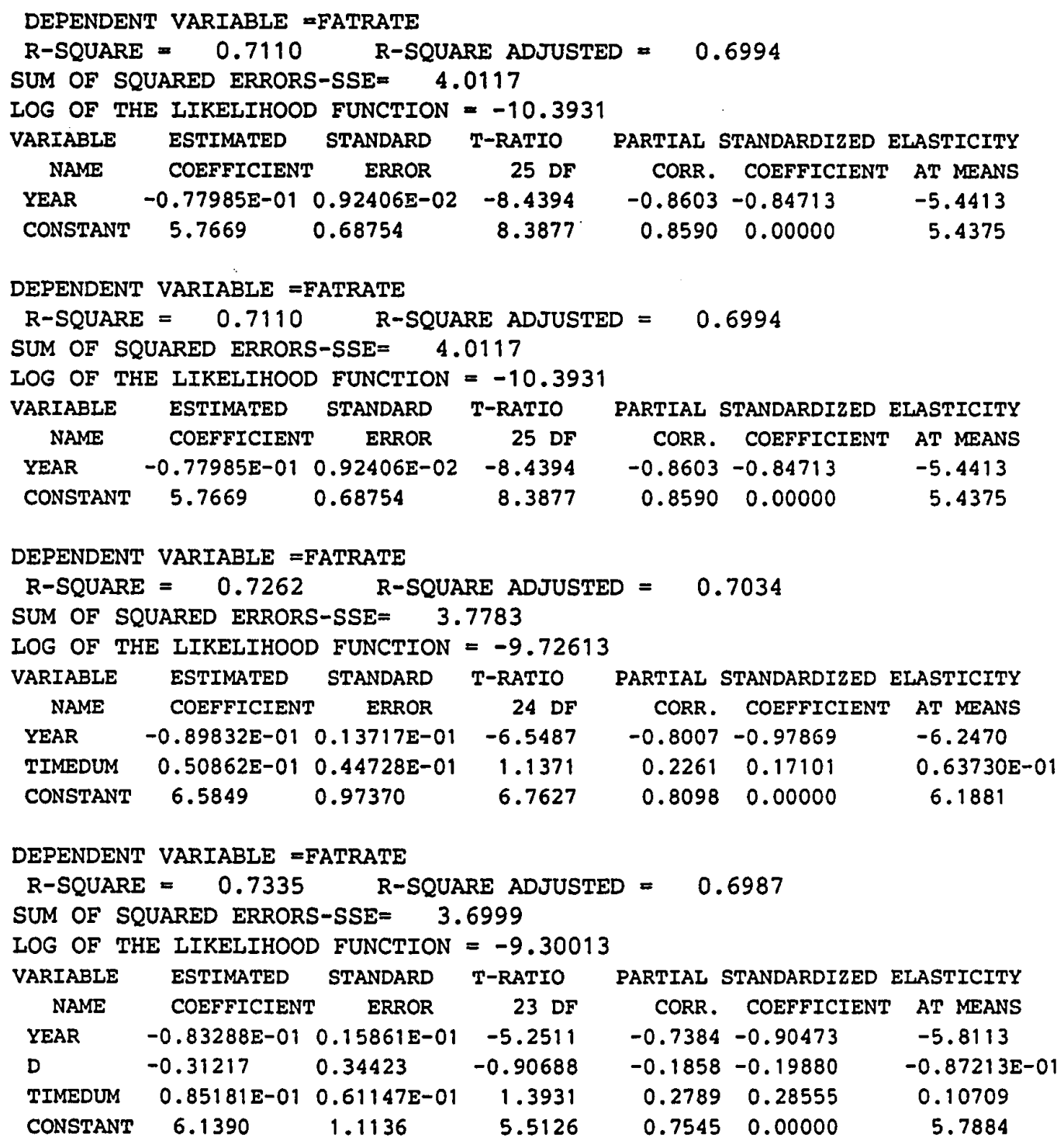




\section{APPENDIX G \\ POOLED CROSS-SECTIONALLY HETEROSKEDASTIC AND TIME-WISE AUTOREGRESSIVE}


APPENDIX G

POOLED CROSS-SECTIONALLY HETEROSKEDASTIC AND TIME-WISE

AUTOREGRESSIVE

COMMAND FILE

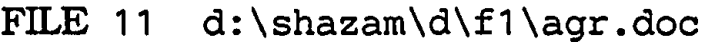

sample 1200

read(11) airline year d totocc y n u hours

* generate controllable rate

genr ocrate $=(1000000 *(y+1)) /$ hours

* generate log of the controllable rate genr Inocrate $=\log$ (ocrate)

*generate time since deregulation dummy genr timedum $=d *($ year -79$)$

print year ocrate Inocrate d timedum

pool Inocrate year /ncross $=8$

pool Inocrate year d /ncross $=8$

pool Inocrate year timedum /ncross $=8$

pool Inocrate year d timedum /ncross $=8$

delete / all 
APPENDIX G

POOLED CROSS-SECTIONALLY HETEROSKEDASTIC AND TIME-WISE

\author{
AUTOREGRESSIVE \\ (continued)
}

\title{
OUTPUT FILE
}

UNIT 11 IS NOW ASSIGNED TO: d: \shazam\d\f1\agr.doc

\begin{tabular}{lllll}
8 VARIABLES & AND & \multicolumn{5}{c}{ 200 OBSERVATIONS STARTING AT OBS } & 1 \\
YEAR & OCRATE & LNOCRATE & D & TIMEDUM \\
64.00000 & 22.01207 & 3.091591 & 0.0000000 & 0.0000000 \\
65.00000 & 22.98716 & 3.134936 & 0.0000000 & 0.0000000 \\
66.00000 & 17.65019 & 2.870746 & 0.0000000 & 0.0000000 \\
67.00000 & 7.392663 & 2.000488 & 0.0000000 & 0.0000000 \\
68.00000 & 11.31496 & 2.426126 & 0.0000000 & 0.0000000 \\
69.00000 & 3.138102 & 1.143618 & 0.0000000 & 0.0000000 \\
70.00000 & 10.41702 & 2.343441 & 0.0000000 & 0.0000000 \\
71.00000 & 16.69885 & 2.815340 & 0.0000000 & 0.0000000 \\
72.00000 & 7.781968 & 2.051809 & 0.0000000 & 0.0000000 \\
73.00000 & 12.10068 & 2.493261 & 0.0000000 & 0.0000000 \\
74.00000 & 11.39848 & 2.433480 & 0.0000000 & 0.0000000 \\
75.00000 & 11.11245 & 2.408066 & 0.0000000 & 0.0000000 \\
76.00000 & 6.096539 & 1.807721 & 0.0000000 & 0.0000000 \\
77.00000 & 7.445573 & 2.007620 & 0.0000000 & 0.0000000 \\
78.00000 & 7.264749 & 1.983034 & 0.0000000 & 0.0000000 \\
79.00000 & 6.686745 & 1.900127 & 0.0000000 & 0.0000000 \\
80.00000 & 1.441745 & 0.3658541 & 1.000000 & 1.000000 \\
81.00000 & 6.552350 & 1.879824 & 1.000000 & 2.000000 \\
82.00000 & 6.459635 & 1.865573 & 1.000000 & 3.000000 \\
83.00000 & 10.62232 & 2.362957 & 1.000000 & 4.000000 \\
84.00000 & 8.001526 & 2.079632 & 1.000000 & 5.000000 \\
85.00000 & 11.64321 & 2.454723 & 1.000000 & 6.000000 \\
86.00000 & 5.285088 & 1.664889 & 1.000000 & 7.000000 \\
87.00000 & 5.989992 & 1.790090 & 1.000000 & 8.000000 \\
88.00000 & 7.479348 & 2.012146 & 1.000000 & 9.000000 \\
64.00000 & 12.88959 & 2.556420 & 0.0000000 & 0.0000000 \\
65.00000 & 32.24316 & 3.473306 & 0.0000000 & 0.0000000 \\
66.00000 & 26.02021 & 3.258874 & 0.0000000 & 0.0000000 \\
67.00000 & 14.77443 & 2.692898 & 0.0000000 & 0.0000000 \\
68.00000 & 5.981112 & 1.788606 & 0.0000000 & 0.0000000 \\
69.00000 & 10.28315 & 2.330506 & 0.0000000 & 0.0000000 \\
70.00000 & 10.27053 & 2.329278 & 0.0000000 & 0.0000000 \\
71.00000 & 15.03774 & 2.710563 & 0.0000000 & 0.0000000 \\
72.00000 & 10.20710 & 2.323084 & 0.0000000 & 0.0000000 \\
73.00000 & 5.471238 & 1.699505 & 0.0000000 & 0.0000000 \\
74.00000 & 5.936691 & 1.781152 & 0.0000000 & 0.0000000 \\
75.00000 & 17.07262 & 2.837476 & 0.0000000 & 0.0000000 \\
76.00000 & 24.46603 & 3.197286 & 0.0000000 & 0.0000000 \\
& & & & \\
7 & & & &
\end{tabular}


APPENDIX G

POOLED CROSS-SECCTIONALLY HETEROSKEDASTIC AND TIME-WISE

\author{
AUTOREGRESSIVE \\ (continued)
}

\begin{tabular}{|c|c|c|c|c|}
\hline 77.00000 & 10.72421 & 2.372503 & 0.0000000 & 0.0000000 \\
\hline 78.00000 & 9.499157 & 2.251203 & 0.0000000 & 0.0000000 \\
\hline 79.00000 & 8.305579 & 2.116927 & 0.0000000 & 0.0000000 \\
\hline 80.00000 & 10.06994 & 2.309554 & 1.000000 & 1.000000 \\
\hline 81.00000 & 14.96394 & 2.705643 & 1.000000 & 2.000000 \\
\hline 82.00000 & 12.96143 & 2.561978 & 1.000000 & 3.000000 \\
\hline 83.00000 & 29.00208 & 3.367368 & 1.000000 & 4.000000 \\
\hline 84.00000 & 7.688789 & 2.039763 & 1.000000 & 5.000000 \\
\hline 85.00000 & 2.663669 & 0.9797046 & 1.000000 & 6.000000 \\
\hline 86.00000 & 6.079680 & 1.804952 & 1.000000 & 7.000000 \\
\hline 87.00000 & 6.251009 & 1.832743 & 1.000000 & 8.000000 \\
\hline 88.00000 & 3.100160 & 1.131454 & 1.000000 & 9.000000 \\
\hline 64.00000 & 27.83951 & 3.326456 & 0.0000000 & 0.0000000 \\
\hline 65.00000 & 8.581592 & 2.149619 & 0.0000000 & 0.0000000 \\
\hline 66.00000 & 30.35834 & 3.413071 & 0.0000000 & 0.0000000 \\
\hline 67.00000 & 13.84682 & 2.628056 & 0.0000000 & 0.0000000 \\
\hline 68.00000 & 9.389701 & 2.239613 & 0.0000000 & 0.0000000 \\
\hline 69.00000 & 26.76509 & 3.287098 & 0.0000000 & 0.0000000 \\
\hline 70.00000 & 9.454924 & 2.246536 & 0.0000000 & 0.0000000 \\
\hline 71.00000 & 11.60699 & 2.451607 & 0.0000000 & 0.0000000 \\
\hline 72.00000 & 18.56459 & 2.921256 & 0.0000000 & 0.0000000 \\
\hline 73.00000 & 14.28117 & 2.658942 & 0.0000000 & 0.0000000 \\
\hline 74.00000 & 15.70913 & 2.754242 & 0.0000000 & 0.0000000 \\
\hline 75.00000 & 13.66038 & 2.614499 & 0.0000000 & 0.0000000 \\
\hline 76.00000 & 9.328863 & 2.233113 & 0.0000000 & 0.0000000 \\
\hline 77.00000 & 7.159221 & 1.968401 & 0.0000000 & 0.0000000 \\
\hline 78.00000 & 8.313782 & 2.117915 & 0.0000000 & 0.0000000 \\
\hline 79.00000 & 3.115066 & 1.136250 & 0.0000000 & 0.0000000 \\
\hline 80.00000 & 4.534688 & 1.511756 & 1.000000 & 1.000000 \\
\hline 81.00000 & 6.011133 & 1.793613 & 1.000000 & 2.000000 \\
\hline 82.00000 & 1.539684 & 0.4315771 & 1.000000 & 3.000000 \\
\hline 83.00000 & 1.501281 & 0.4063185 & 1.000000 & 4.000000 \\
\hline 84.00000 & 4.246753 & 1.446155 & 1.000000 & 5.000000 \\
\hline 85.00000 & 10.80516 & 2.380024 & 1.000000 & 6.000000 \\
\hline 86.00000 & 2.693820 & 0.9909604 & 1.000000 & 7.000000 \\
\hline 87.00000 & 6.576580 & 1.883515 & 1.000000 & 8.000000 \\
\hline 88.00000 & 5.842311 & 1.765126 & 1.000000 & 9.000000 \\
\hline 64.00000 & 44.68198 & 3.799570 & 0.0000000 & 0.0000000 \\
\hline 65.00000 & 31.12773 & 3.438099 & 0.0000000 & 0.0000000 \\
\hline 66.00000 & 30.09897 & 3.404491 & 0.0000000 & 0.0000000 \\
\hline 67.00000 & 24.68851 & 3.206338 & 0.0000000 & 0.0000000 \\
\hline 68.00000 & 14.65736 & 2.684942 & 0.0000000 & 0.0000000 \\
\hline 69.00000 & 17.95441 & 2.887836 & 0.0000000 & 0.0000000 \\
\hline 70.00000 & 9.602381 & 2.262011 & 0.0000000 & 0.0000000 \\
\hline 71.00000 & 9.422865 & 2.243139 & 0.0000000 & 0.0000000 \\
\hline
\end{tabular}


APPENDIX G

POOLED CROSS-SECTIONALLY HETEROSKEDASTIC AND TIME-WISE

AUTOREGRESSIVE

(continued)

\begin{tabular}{|c|c|c|c|c|}
\hline 72.00000 & 15.30725 & 2.728327 & 0.0000000 & 0.0000000 \\
\hline 73.00000 & 11.69064 & 2.458789 & 0.0000000 & 0.0000000 \\
\hline 74.00000 & 9.988364 & 2.301421 & 0.0000000 & 0.0000000 \\
\hline 75.00000 & 12.47900 & 2.524047 & 0.0000000 & 0.0000000 \\
\hline 76.00000 & 6.016594 & 1.794521 & 0.0000000 & 0.0000000 \\
\hline 77.00000 & 7.342737 & 1.993712 & 0.0000000 & 0.0000000 \\
\hline 78.00000 & 5.779328 & 1.754287 & 0.0000000 & 0.0000000 \\
\hline 79.00000 & 4.132283 & 1.418830 & 0.0000000 & 0.0000000 \\
\hline 80.00000 & 4.066909 & 1.402883 & 1.000000 & 1.000000 \\
\hline 81.00000 & 11.23619 & 2.419140 & 1.000000 & 2.000000 \\
\hline 82.00000 & 5.869647 & 1.769794 & 1.000000 & 3.000000 \\
\hline 83.00000 & 7.022531 & 1.949124 & 1.000000 & 4.000000 \\
\hline 84.00000 & 6.491441 & 1.870485 & 1.000000 & 5.000000 \\
\hline 85.00000 & 6.345814 & 1.847795 & 1.000000 & 6.000000 \\
\hline 86.00000 & 11.05964 & 2.403302 & 1.000000 & 7.000000 \\
\hline 87.00000 & 10.16819 & 2.319265 & 1.000000 & 8.000000 \\
\hline 88.00000 & 6.005925 & 1.792746 & 1.000000 & 9.000000 \\
\hline 64.00000 & 40.55123 & 3.702566 & 0.0000000 & 0.0000000 \\
\hline 65.00000 & 17.60212 & 2.868019 & 0.0000000 & 0.0000000 \\
\hline 66.00000 & 5.344021 & 1.675978 & 0.0000000 & 0.0000000 \\
\hline 67.00000 & 7.978776 & 2.076785 & 0.0000000 & 0.0000000 \\
\hline 68.00000 & 17.45981 & 2.859902 & 0.0000000 & 0.0000000 \\
\hline 69.00000 & 3.128911 & 1.140685 & 0.0000000 & 0.0000000 \\
\hline 70.00000 & 9.782534 & 2.280599 & 0.0000000 & 0.0000000 \\
\hline 71.00000 & 27.90190 & 3.328695 & 0.0000000 & 0.0000000 \\
\hline 72.00000 & 25.56760 & 3.241326 & 0.0000000 & 0.0000000 \\
\hline 73.00000 & 11.26888 & 2.422045 & 0.0000000 & 0.0000000 \\
\hline 74.00000 & 7.854812 & 2.061126 & 0.0000000 & 0.0000000 \\
\hline 75.00000 & 8.077642 & 2.089100 & 0.0000000 & 0.0000000 \\
\hline 76.00000 & 3.897131 & 1.360241 & 0.0000000 & 0.0000000 \\
\hline 77.00000 & 7.634171 & 2.032634 & 0.0000000 & 0.0000000 \\
\hline 78.00000 & 6.468975 & 1.867018 & 0.0000000 & 0.0000000 \\
\hline 79.00000 & 3.748927 & 1.321470 & 0.0000000 & 0.0000000 \\
\hline 80.00000 & 3.634210 & 1.290392 & 1.000000 & 1.000000 \\
\hline 81.00000 & 22.00640 & 3.091333 & 1.000000 & 2.000000 \\
\hline 82.00000 & 3.728297 & 1.315951 & 1.000000 & 3.000000 \\
\hline 83.00000 & 6.652895 & 1.895052 & 1.000000 & 4.000000 \\
\hline 84.00000 & 12.48120 & 2.524224 & 1.000000 & 5.000000 \\
\hline 85.00000 & 8.400538 & 2.128296 & 1.000000 & 6.000000 \\
\hline 86.00000 & 3.935451 & 1.370025 & 1.000000 & 7.000000 \\
\hline 87.00000 & 4.787633 & 1.566036 & 1.000000 & 8.000000 \\
\hline 88.00000 & 9.708090 & 2.272960 & 1.000000 & 9.000000 \\
\hline 64.00000 & 31.27259 & 3.442742 & 0.0000000 & 0.0000000 \\
\hline 65.00000 & 18.69176 & 2.928083 & 0.0000000 & 0.0000000 \\
\hline 66.00000 & 12.96284 & 2.562087 & 0.0000000 & 0.0000000 \\
\hline
\end{tabular}


APPENDIX G

POOLED CROSS-SECTIONALIY HETEROSKEDASTIC AND TIME-WISE

AUTOREGRESSIVE

(continued)
14.99116

13.09140

14.78948

20.60000

15.30633

6.702188

6.365615

11.98863

8.251506

3.055796

6.468473

6.824844

13.68466

2.274956

10.03731

7.313987

8.030322

5.650500

3.013065

10.49670

9.596008

8.235943

25.80416

17.35728

12.13560

13.23271

9.653721

11.52158

12.78667

8.893764

13.35292

4.899095

13.00896

13.38540

1.644672

4.860000

3.333294

5.006684

3.904191

4.629062

10.08265

14.56611

4.533770

4.288532

8.360435
2.707460

2.571956

2.693916

3.025291

2.728267

1.902434

1.850911

2.483958

2.110396

1.117040

1.866940

1.920569

2.616276

0.8219606

2.306310

1.989789

2.083225

1.731744

1.102958

2. 351061

2. 261347

2. 108508

3.250536

2.854012

2.496143

2.582692

2.267343

2.444222

2.548403

2.185350

2.591735

1.589050

2.565638

2.594165

0.4975409

1.581038

1.203961

1.610774

1.362051

1.532354

2.310816

2.678698

1.511554

1.455945

2.123510
0.0000000

0.0000000

0.0000000

0.0000000

0.0000000

0.0000000

0.0000000

0.0000000

0.0000000

0.0000000

0.0000000

0.0000000

0.0000000

1.000000

1.000000

1.000000

1.000000

1.000000

1.000000

1.000000

1.000000

1.000000

0.0000000

0.0000000

0.0000000

0.0000000

0.0000000

0.0000000

0.0000000

0.0000000

0.0000000

0.0000000

0.0000000

0.0000000

0.0000000

0.0000000

0.0000000

0.0000000

1.000000

1.000000

1.000000

1.000000

1.000000

1.000000

1.000000
0.0000000

0.0000000

0.0000000

0.0000000

0.0000000

0.0000000

0.0000000

0.0000000

0.0000000

0.0000000

0.0000000

0.0000000

0.0000000

1.000000

2.000000

3.000000

4.000000

5.000000

6.000000

7.000000

8.000000

9.000000

0.0000000

0.0000000

0.0000000

0.0000000

0.0000000

0.0000000

0.0000000

0.0000000

0.0000000

0.0000000

0.0000000

0.0000000

0.0000000

0.0000000

0.0000000

0.0000000

1.000000

2.000000

3.000000

4.000000

5.000000

6.000000

7.000000 
APPENDIX G

POOLED CROSS-SECTIONALLY HETEROSKEDASTIC AND TIME-WISE

AUTOREGRESSIVE

(continued)

$\begin{array}{lrrrr}87.00000 & 5.259633 & 1.660061 & 1.000000 & 8.000000 \\ 88.00000 & 3.291211 & 1.191256 & 1.000000 & 9.000000 \\ 64.00000 & 25.11452 & 3.223446 & 0.0000000 & 0.0000000 \\ 65.00000 & 15.12511 & 2.716357 & 0.0000000 & 0.0000000 \\ 66.00000 & 18.84458 & 2.936225 & 0.0000000 & 0.0000000 \\ 67.00000 & 22.24755 & 3.102232 & 0.0000000 & 0.0000000 \\ 68.00000 & 15.18275 & 2.720160 & 0.0000000 & 0.0000000 \\ 69.00000 & 10.37631 & 2.339525 & 0.0000000 & 0.0000000 \\ 70.00000 & 12.16605 & 2.498650 & 0.0000000 & 0.0000000 \\ 71.00000 & 12.00810 & 2.485582 & 0.0000000 & 0.0000000 \\ 72.00000 & 5.491392 & 1.703182 & 0.0000000 & 0.0000000 \\ 73.00000 & 4.403681 & 1.482441 & 0.0000000 & 0.0000000 \\ 74.00000 & 6.109295 & 1.809811 & 0.0000000 & 0.0000000 \\ 75.00000 & 7.807376 & 2.055069 & 0.0000000 & 0.0000000 \\ 76.00000 & 2.463667 & 0.9016509 & 0.0000000 & 0.0000000 \\ 77.00000 & 5.885309 & 1.772459 & 0.0000000 & 0.0000000 \\ 78.00000 & 7.555577 & 2.022286 & 0.0000000 & 0.0000000 \\ 79.00000 & 2.455111 & 0.8981721 & 0.0000000 & 0.0000000 \\ 80.00000 & 4.343586 & 1.468700 & 1.000000 & 1.000000 \\ 81.00000 & 5.274449 & 1.662874 & 1.000000 & 2.000000 \\ 82.00000 & 3.946294 & 1.372777 & 1.000000 & 3.000000 \\ 83.00000 & 10.80312 & 2.379835 & 1.000000 & 4.000000 \\ 84.00000 & 8.460237 & 2.135377 & 1.000000 & 5.000000 \\ 85.00000 & 3.629615 & 1.289127 & 1.000000 & 6.000000 \\ 86.00000 & 5.348924 & 1.676895 & 1.000000 & 7.0000000 \\ 87.00000 & 4.906222 & 1.590504 & 1.000000 & 8.000000 \\ 88.00000 & 3.328111 & 1.202405 & 1.000000 & 9.000000\end{array}$


APPENDIX G

POOLED CROSS-SECTIONALLY HETEROSKEDASTIC AND TIME-WISE

AUTOREGRESSIVE

(continued)

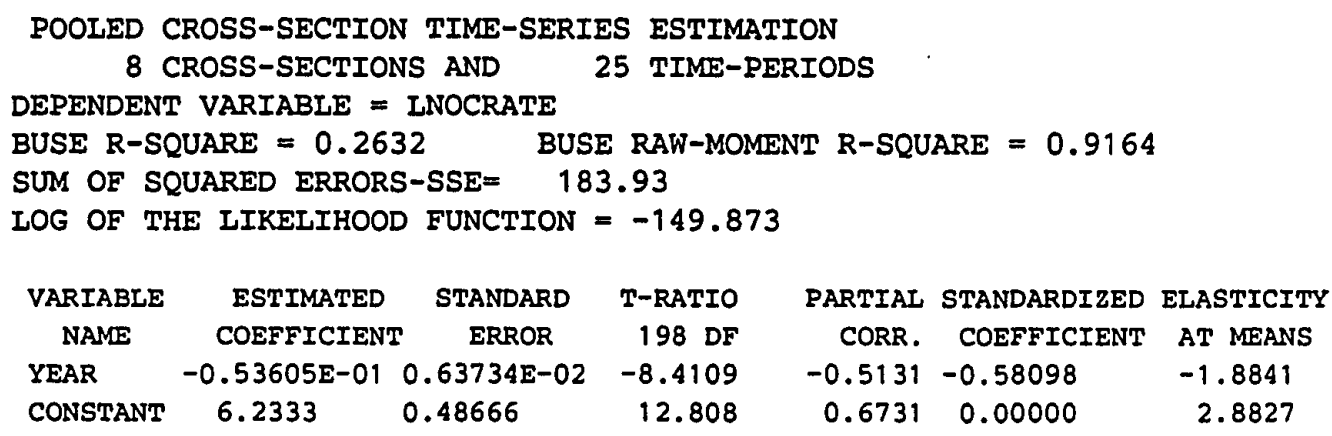

DEPENDENT VARIABLE = LNOCRATE

BUSE R-SQUARE $=0.3046 \quad$ BUSE RAW-MOMENT $R$-SQUARE $=0.9277$

SUM OF SQUARED ERRORS-SSE= 175.84

LOG OF THE LIKELIHOOD FUNCTION $=-147.425$

\begin{tabular}{lllrrrr} 
VARIABLE & \multicolumn{2}{c}{ ESTIMATED } & STANDARD & T-RATIO & \multicolumn{2}{c}{ PARTIAL STANDARDIZED EIASTICITY } \\
\multicolumn{1}{c}{ NAME } & \multicolumn{1}{c}{ COEFFICIENT } & ERROR & $197 \mathrm{DF}$ & CORR. & COEFFICIENT & AT MEANS \\
YEAR & $-0.74237 \mathrm{E}-01$ & $0.10138 \mathrm{E}-01$ & -7.3227 & -0.4626 & -0.80459 & -2.6092 \\
D & 0.38916 & 0.15032 & 2.5889 & 0.1814 & 0.28075 & $0.64789 \mathrm{E}-01$ \\
CONSTANT & 7.6548 & 0.72833 & 10.510 & 0.5994 & 0.00000 & 3.5400
\end{tabular}

DEPENDENT VARIABLE = INOCRATE

BUSE R-SQUARE $=0.4021 \quad$ BUSE RAW-MOMENT R-SQUARE $=0.9431$

SUM OF SQUARED ERRORS-SSE= 175.58

LOG OF THE IIKELIHOOD FUNCTION $=-139.342$

\begin{tabular}{lccrrrr} 
VARIABLE & \multicolumn{2}{c}{ ESTIMATED } & \multicolumn{1}{c}{ STANDARD } & \multicolumn{2}{c}{ T-RATIO } & \multicolumn{2}{c}{ PARTIAL STANDARDIZED ELASTICITY } \\
$\quad$ NAME & \multicolumn{1}{c}{ COEFFICIENT } & \multicolumn{1}{c}{ ERROR } & 197 DF & CORR. & COEFFICIENT & AT MEANS \\
YEAR & $-0.93619 \mathrm{E}-01$ & $0.91204 \mathrm{E}-02$ & -10.265 & -0.5903 & -1.0147 & -3.2904 \\
TIMEDUM & 0.12246 & $0.22893 \mathrm{E}-01$ & 5.3490 & 0.3561 & 0.52575 & 0.10194 \\
CONSTANT & 9.0477 & 0.66061 & 13.696 & 0.6984 & 0.00000 & 4.1842
\end{tabular}

DEPENDENT VARIABLE = INOCRATE

BUSE R-SQUARE $=0.4054 \quad$ BUSE RAW-MOMENT $R$-SQUARE $=0.9438$

SUM OF SQUARED ERRORS-SSE $=167.57$

LOG OF THE IIKELIHOOD FUNCTION $=-139.202$

\begin{tabular}{|c|c|c|c|c|c|c|}
\hline $\begin{array}{l}\text { VARIABLE } \\
\text { NAME }\end{array}$ & $\begin{array}{l}\text { ESTIMATED } \\
\text { COEFFICIEN }\end{array}$ & $\begin{array}{l}\text { STANDARD } \\
\text { ERROR }\end{array}$ & $\begin{array}{r}\text { T-RATIO } \\
196 \text { DF }\end{array}$ & $\begin{array}{l}\text { PARTIAL } \\
\text { CORR. }\end{array}$ & $\begin{array}{l}\text { STANDARDIZED } \\
\text { COEFFICIENT }\end{array}$ & $\begin{array}{c}\text { ELASTICITY } \\
\text { AT MEANS }\end{array}$ \\
\hline YEAR & $-0.96067 E-01$ & $0.10142 E-01$ & -9.4726 & -0.5604 & -1.0412 & -3.3764 \\
\hline D & $0.84415 E-01$ & 0.15607 & 0.54089 & 0.0386 & $0.60900 \mathrm{E}-01$ & $0.14054 \mathrm{E}-01$ \\
\hline T & 0.11606 & $0.26028 \mathrm{E}-$ & 4.4589 & 0.3035 & 0.49828 & $0.96609 \mathrm{E}-01$ \\
\hline CONS & 9.2142 & 0.72703 & 12.674 & 0.6711 & 0.00000 & 4.2612 \\
\hline
\end{tabular}




\section{APPENDIX H \\ POOLED CROSS-SECTIONALLY HETEROSKEDASTIC AND TIME-WISE AUTOREGRESSIVE WITH ZERO DUMMY}


APPENDIX H

POOLED CROSS-SECTIONALLY HETEROSKEDASTIC AND TIME-WISE

\section{AUTOREGRESSIVE WITH ZERO DUMMY}

COMMAND FILE

FIIE 11 d: \shazam\d\f1 \agrzd.doc

sample 1125

read(11) airline year d totocc y $n$ u hours

* generate controlable rate

genr crate $=((1000000 * y)) /$ hours

* generate zero dummy for crate $=0$

genr zerodum $=\operatorname{dum}(.001$ - crate $)$

* generate modified rate with ones where there were zeroes

genr modcrate $=$ crate + zerodum

* generate log of the modified rate

genr Inmodrat $=\log$ (modcrate)

* generate time since deregulation dummy

genr timedum $=d *($ year -79$)$

print year crate zerodum modcrate Inmodrat d

pool Inmodrat year zerodum pool Inmodrat year zerodum pool Inmodrat year zerodum pool Inmodrat year zerodum /ncross $=5$

/ncross $=5$

a timedum $/$ ncross $=5$

delete / all 
APPENDIX H

POOLED CROSS-SECTIONALLY HETEROSKEDASTIC AND TIME-WISE

AUTOREGRESSIVE WITH ZERO DUMMY

(continued)

\section{OUTPUT FILE}

UNIT 11 IS NOW ASSIGNED TO: d: IShazam\d\f1 lagrzd.doc

8 VARIABLES AND

125 OBSERVATIONS STARTING AT OBS

$\begin{array}{llllll}\text { YR } & \text { CRATE } & \text { ZERODUM } & \text { MODCRATE } & \text { INMODRAT } & \text { D } \\ 64 & 19.26056 & 0.00 & 19.26056 & 2.958059 & 0.00 \\ 65 & 20.43303 & 0.00 & 20.43303 & 3.017153 & 0.00 \\ 66 & 15.44391 & 0.00 & 15.44391 & 2.737215 & 0.00 \\ 67 & 5.544497 & 0.00 & 5.544497 & 1.712806 & 0.00 \\ 68 & 9.698537 & 0.00 & 9.698537 & 2.271975 & 0.00 \\ 69 & 1.569051 & 0.00 & 1.569051 & 0.4504708 & 0.00 \\ 70 & 8.928877 & 0.00 & 8.928877 & 2.189291 & 0.00 \\ 71 & 15.18077 & 0.00 & 15.18077 & 2.720030 & 0.00 \\ 72 & 6.225574 & 0.00 & 6.225574 & 1.828666 & 0.00 \\ 73 & 10.58809 & 0.00 & 10.58809 & 2.359730 & 0.00 \\ 74 & 9.770125 & 0.00 & 9.770125 & 2.279329 & 0.00 \\ 75 & 9.524959 & 0.00 & 9.524959 & 2.253916 & 0.00 \\ 76 & 4.572404 & 0.00 & 4.572404 & 1.520039 & 0.00 \\ 77 & 5.956458 & 0.00 & 5.956458 & 1.784476 & 0.00 \\ 78 & 5.811799 & 0.00 & 5.811799 & 1.759890 & 0.00 \\ 79 & 5.349396 & 0.00 & 5.349396 & 1.676984 & 0.00 \\ 80 & 0.0000000 & 1.0 & 1.000000 & 0.0000000 & 1.0 \\ 81 & 4.914263 & 0.00 & 4.914263 & 1.592142 & 1.0 \\ 82 & 4.844727 & 0.00 & 4.844727 & 1.577891 & 1.0 \\ 83 & 9.104842 & 0.00 & 9.104842 & 2.208806 & 1.0 \\ 84 & 6.667938 & 0.00 & 6.667938 & 1.897311 & 1.0 \\ 85 & 10.47889 & 0.00 & 10.47889 & 2.349362 & 1.0 \\ 86 & 4.228071 & 0.00 & 4.228071 & 1.441746 & 1.0 \\ 87 & 5.134278 & 0.00 & 5.134278 & 1.635939 & 1.0 \\ 88 & 6.731413 & 0.00 & 6.731413 & 1.906785 & 1.0 \\ 64 & 23.19960 & 0.00 & 23.19960 & 3.144135 & 0.00 \\ 65 & 4.290796 & 0.00 & 4.290796 & 1.456472 & 0.00 \\ 66 & 26.56355 & 0.00 & 26.56355 & 3.279540 & 0.00 \\ 67 & 10.38511 & 0.00 & 10.38511 & 2.340373 & 0.00 \\ 68 & 6.259801 & 0.00 & 6.259801 & 1.834148 & 0.00 \\ 69 & 24.08858 & 0.00 & 24.08858 & 3.181738 & 0.00 \\ 70 & 7.091193 & 0.00 & 7.091193 & 1.958854 & 0.00 \\ 71 & 9.285590 & 0.00 & 9.285590 & 2.228464 & 0.00 \\ 72 & 16.50185 & 0.00 & 16.50185 & 2.803473 & 0.00 \\ 73 & 12.49603 & 0.00 & 12.49603 & 2.525411 & 0.00 \\ 74 & 13.74549 & 0.00 & 13.74549 & 2.620711 & 0.00 \\ 75 & 11.70889 & 0.00 & 11.70889 & 2.460349 & 0.00 \\ 76 & 7.463090 & 0.00 & 7.463090 & 2.009970 & 0.00\end{array}$


APPENDIX H

POOLED CROSS-SECTIONALLY HETEROSKEDASTIC AND TIME-WISE

AUTOREGRESSIVE WITH ZERO DUMMY (continued)

$\begin{array}{lrlrrr}77 & 5.369416 & 0.00 & 5.369416 & 1.680719 & 0.00 \\ 78 & 6.651026 & 0.00 & 6.651026 & 1.894771 & 0.00 \\ 79 & 1.557533 & 0.00 & 1.557533 & 0.4431031 & 0.00 \\ 80 & 3.023125 & 0.00 & 3.023125 & 1.106291 & 1.0 \\ 81 & 4.508349 & 0.00 & 4.508349 & 1.505931 & 1.0 \\ 82 & 0.0000000 & 1.0 & 1.000000 & 0.0000000 & 1.0 \\ 83 & 0.0000000 & 1.0 & 1.000000 & 0.0000000 & 1.0 \\ 84 & 2.831169 & 0.00 & 2.831169 & 1.040690 & 1.0 \\ 85 & 9.454515 & 0.00 & 9.454515 & 2.246492 & 1.0 \\ 86 & 1.346910 & 0.00 & 1.346910 & 0.2978132 & 1.0 \\ 87 & 5.637069 & 0.00 & 5.637069 & 1.729364 & 1.0 \\ 88 & 5.007695 & 0.00 & 5.007695 & 1.610976 & 1.0 \\ 64 & 42.19964 & 0.00 & 42.19964 & 3.742412 & 0.00 \\ 65 & 28.73329 & 0.00 & 28.73329 & 3.358056 & 0.00 \\ 66 & 27.36270 & 0.00 & 27.36270 & 3.309181 & 0.00 \\ 67 & 22.63114 & 0.00 & 22.63114 & 3.119327 & 0.00 \\ 68 & 12.82519 & 0.00 & 12.82519 & 2.551411 & 0.00 \\ 69 & 16.32219 & 0.00 & 16.32219 & 2.792525 & 0.00 \\ 70 & 8.001984 & 0.00 & 8.001984 & 2.079690 & 0.00 \\ 71 & 7.852388 & 0.00 & 7.852388 & 2.060818 & 0.00 \\ 72 & 13.77653 & 0.00 & 13.77653 & 2.622966 & 0.00 \\ 73 & 10.22931 & 0.00 & 10.22931 & 2.325257 & 0.00 \\ 74 & 8.323636 & 0.00 & 8.323636 & 2.119099 & 0.00 \\ 75 & 10.91913 & 0.00 & 10.91913 & 2.390516 & 0.00 \\ 76 & 4.512445 & 0.00 & 4.512445 & 1.506839 & 0.00 \\ 77 & 5.874190 & 0.00 & 5.874190 & 1.770568 & 0.00 \\ 78 & 4.334496 & 0.00 & 4.334496 & 1.466605 & 0.00 \\ 79 & 2.754855 & 0.00 & 2.754855 & 1.013365 & 0.00 \\ 80 & 2.711273 & 0.00 & 2.711273 & 0.9974181 & 1.0 \\ 81 & 9.831668 & 0.00 & 9.831668 & 2.285609 & 1.0 \\ 82 & 4.402235 & 0.00 & 4.402235 & 1.482112 & 1.0 \\ 83 & 5.618025 & 0.00 & 5.618025 & 1.725980 & 1.0 \\ 84 & 5.193153 & 0.00 & 5.193153 & 1.647341 & 1.0 \\ 85 & 5.076651 & 0.00 & 5.076651 & 1.624652 & 1.0 \\ 86 & 9.830788 & 0.00 & 9.830788 & 2.285519 & 1.0 \\ 87 & 8.897170 & 0.00 & 8.897170 & 2.185733 & 1.0 \\ 88 & 4.504444 & 0.00 & 4.504444 & 1.505064 & 1.0 \\ 64 & 22.93703 & 0.00 & 22.93703 & 3.132753 & 0.00 \\ 65 & 14.87767 & 0.00 & 14.87767 & 2.699861 & 0.00 \\ 66 & 9.708479 & 0.00 & 9.708479 & 2.273000 & 0.00 \\ 67 & 11.34233 & 0.00 & 11.34233 & 2.428541 & 0.00 \\ 68 & 8.044768 & 0.00 & 8.044768 & 2.085022 & 0.00 \\ 69 & 10.08139 & 0.00 & 10.08139 & 2.310691 & 0.00 \\ 70 & 11.36593 & 0.00 & 11.36593 & 2.430620 & 0.00 \\ 71 & 7.411470 & 0.00 & 7.411470 & 2.003029 & 0.00\end{array}$


APPENDIX H

POOLED CROSS-SECTIONALLY HETEROSKEDASTIC AND TIME-WISE

AUTOREGRESSIVE WITH ZERO DUMMY

(continued)

$\begin{array}{lrrrrr}72 & 11.86926 & 0.000 & 11.86926 & 2.473952 & 0.00 \\ 73 & 3.266063 & 0.00 & 3.266063 & 1.183585 & 0.00 \\ 74 & 11.38284 & 0.00 & 11.38284 & 2.432107 & 0.00 \\ 75 & 11.71223 & 0.00 & 11.71223 & 2.460633 & 0.00 \\ 76 & 0.0000000 & 1.0 & 1.000000 & 0.0000000 & 0.00 \\ 77 & 3.240000 & 0.00 & 3.240000 & 1.175573 & 0.00 \\ 78 & 1.666647 & 0.00 & 1.666647 & 0.5108140 & 0.00 \\ 79 & 3.337789 & 0.00 & 3.337789 & 1.205309 & 0.00 \\ 80 & 1.952096 & 0.00 & 1.952096 & 0.6689034 & 1.0 \\ 81 & 2.314531 & 0.00 & 2.314531 & 0.8392070 & 1.0 \\ 82 & 7.561989 & 0.00 & 7.561989 & 2.023134 & 1.0 \\ 83 & 12.13843 & 0.00 & 12.13843 & 2.496376 & 1.0 \\ 84 & 2.266885 & 0.00 & 2.266885 & 0.8184066 & 1.0 \\ 85 & 2.144266 & 0.00 & 2.144266 & 0.7627974 & 1.0 \\ 86 & 6.270326 & 0.00 & 6.270326 & 1.835828 & 1.0 \\ 87 & 3.506422 & 0.00 & 3.506422 & 1.254596 & 1.0 \\ 88 & 1.645606 & 0.00 & 1.645606 & 0.4981085 & 1.0 \\ 64 & 23.44022 & 0.00 & 23.44022 & 3.154453 & 0.00 \\ 65 & 13.61260 & 0.00 & 13.61260 & 2.610996 & 0.00 \\ 66 & 17.27419 & 0.00 & 17.27419 & 2.849214 & 0.00 \\ 67 & 21.01157 & 0.00 & 21.01157 & 3.045073 & 0.00 \\ 68 & 14.09827 & 0.00 & 14.09827 & 2.646052 & 0.00 \\ 69 & 9.338676 & 0.00 & 9.338676 & 2.234165 & 0.00 \\ 70 & 11.15222 & 0.00 & 11.15222 & 2.411638 & 0.00 \\ 71 & 10.91646 & 0.00 & 10.91646 & 2.390272 & 0.00 \\ 72 & 4.393113 & 0.00 & 4.393113 & 1.480038 & 0.00 \\ 73 & 3.302761 & 0.00 & 3.302761 & 1.194759 & 0.00 \\ 74 & 4.887436 & 0.00 & 4.887436 & 1.586668 & 0.00 \\ 75 & 6.506147 & 0.00 & 6.506147 & 1.872747 & 0.00 \\ 76 & 1.231834 & 0.00 & 1.231834 & 0.2085037 & 0.00 \\ 77 & 4.708248 & 0.00 & 4.708248 & 1.549316 & 0.00 \\ 78 & 6.476209 & 0.00 & 6.476209 & 1.868135 & 0.00 \\ 79 & 1.227556 & 0.00 & 1.227556 & 0.2050249 & 0.00 \\ 80 & 3.257690 & 0.00 & 3.257690 & 1.181018 & 1.0 \\ 81 & 3.955837 & 0.00 & 3.955837 & 1.375192 & 1.0 \\ 82 & 2.630862 & 0.00 & 2.630862 & 0.9673117 & 1.0 \\ 83 & 9.602769 & 0.00 & 9.602769 & 2.262052 & 1.0 \\ 84 & 7.402707 & 0.00 & 7.402707 & 2.001846 & 1.0 \\ 85 & 2.419743 & 0.00 & 2.419743 & 0.8836614 & 1.0 \\ 86 & 4.457436 & 0.00 & 4.457436 & 1.494574 & 1.0 \\ 87 & 4.088518 & 0.00 & 4.088518 & 1.408183 & 1.0 \\ 88 & 2.496083 & 0.00 & 2.496083 & 0.9147228 & 1.0\end{array}$


APPENDIX H

POOLED CROSS-SECTIONALLY HETEROSKEDASTIC AND TIME-WISE

\section{AUTOREGRESSIVE WITH ZERO DUMMY \\ (continued)}

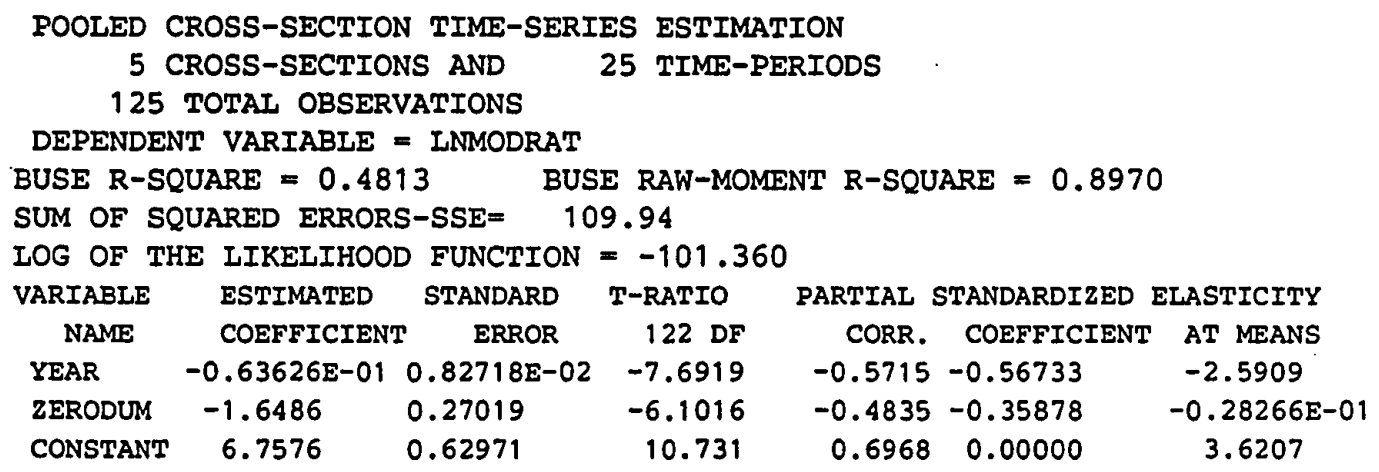


APPENDIX I

OPERATING RATIO 


\section{APPENDIX I}

OPERATING RATIO

COMMAND FILE

FILE 11 d: \shazam\d\f1\opr.doc

sample 1152

read(11) airline year d totocc y $\mathrm{n}$ u hours opratio

* generate controllable rate

genr ocrate $=(1000000 *(y+1)) /$ hours

* generate $\log$ of the controllable rate

genr Inocrate $=\log$ (ocrate)

* generate time since deregulation dummy

genr timedum $=d^{*}$ (year - 79)

print year ocrate lnocrate d timedum opratio

pool Inocrate year opratio /ncross $=8$

pool Inocrate year opratio d /ncross $=8$

pool lnocrate year opratio timedum /ncross $=8$

pool Inocrate year opratio d timedum /ncross $=8$

delete / all

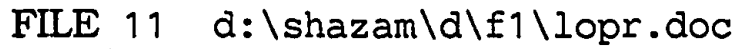

sample 1144

read (11) airline year d totocc y n u hours lagopr

* generate controllable rate

genr ocrate $=(1000000 *(y+1)) /$ hours

* generate $\log$ of the controllable rate

genr Inocrate $=\log$ (ocrate)

* generate time since deregulation dummy

genr timedum $=\mathrm{d}^{*}$ (year -79$)$

print year ocrate Inocrate d timedum lagopr

pool lnocrate year lagopr /ncross $=8$

pool Inocrate year lagopr d /ncross $=8$

pool lnocrate year lagopr timedum /ncross $=8$

pool lnocrate year lagopr a timedum /ncross $=8$ delete / all 


\section{APPENDIX I \\ OPERATING RATIO \\ (continued)}

OUTPUT FILE

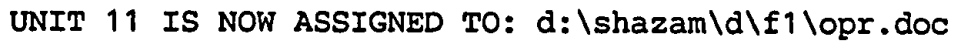

9 VARIABLES AND

152 OBSERVATIONS STARTING AT OBS

1

$\begin{array}{lccccr}\text { YR } & \text { OCRATE } & \text { LNOCRATE } & \text { D } & \text { TIMEDUM } & \text { OPRATIO } \\ 70 & 10.41702 & 2.343441 & 0.00 & 0.00 & 1.013336 \\ 71 & 16.69885 & 2.815340 & 0.00 & 0.00 & 0.9769582 \\ 72 & 7.781968 & 2.051809 & 0.00 & 0.00 & 0.9695126 \\ 73 & 12.10068 & 2.493261 & 0.00 & 0.00 & 1.024519 \\ 74 & 11.39848 & 2.433480 & 0.00 & 0.00 & 0.9761608 \\ 75 & 11.11245 & 2.408066 & 0.00 & 0.00 & 1.015878 \\ 76 & 6.096539 & 1.807721 & 0.00 & 0.00 & 0.9661233 \\ 77 & 7.445573 & 2.007620 & 0.00 & 0.00 & 0.9729827 \\ 78 & 7.264749 & 1.983034 & 0.00 & 0.00 & 0.9644798 \\ 79 & 6.686745 & 1.900127 & 0.00 & 0.00 & 0.9984729 \\ 80 & 1.441745 & 0.3658541 & 1.0 & 1.0 & 1.030660 \\ 81 & 6.552350 & 1.879824 & 1.0 & 2.0 & 0.9889147 \\ 82 & 6.459635 & 1.865573 & 1.0 & 3.0 & 1.004587 \\ 83 & 10.62232 & 2.362957 & 1.0 & 4.0 & 0.9449481 \\ 84 & 8.001526 & 2.079632 & 1.0 & 5.0 & 0.9333518 \\ 85 & 11.64321 & 2.454723 & 1.0 & 6.0 & 0.9135595 \\ 86 & 5.285088 & 1.664889 & 1.0 & 7.0 & 0.9330558 \\ 87 & 5.989992 & 1.790090 & 1.0 & 8.0 & 0.9335834 \\ 88 & 7.479348 & 2.012146 & 1.0 & 9.0 & 0.9063228 \\ 70 & 10.27053 & 2.329278 & 0.00 & 0.00 & 0.9301763 \\ 71 & 15.03774 & 2.710563 & 0.00 & 0.00 & 0.9084038 \\ 72 & 10.20710 & 2.323084 & 0.00 & 0.00 & 0.9064261 \\ 73 & 5.471238 & 1.699505 & 0.00 & 0.00 & 0.9607209 \\ 74 & 5.936691 & 1.781152 & 0.00 & 0.00 & 0.8977497 \\ 75 & 17.07262 & 2.837476 & 0.00 & 0.00 & 0.9343404 \\ 76 & 24.46603 & 3.197286 & 0.00 & 0.00 & 0.9318145 \\ 77 & 10.72421 & 2.372503 & 0.00 & 0.00 & 0.9319356 \\ 78 & 9.499157 & 2.251203 & 0.00 & 0.00 & 0.9446996 \\ 79 & 8.305579 & 2.116927 & 0.00 & 0.00 & 1.022308 \\ 80 & 10.06994 & 2.309554 & 1.0 & 1.0 & 1.062655 \\ 81 & 14.96394 & 2.705643 & 1.0 & 2.0 & 1.055547 \\ 82 & 12.96143 & 2.561978 & 1.0 & 3.0 & 1.050567 \\ 83 & 29.00208 & 3.367368 & 1.0 & 4.0 & 1.132921 \\ 84 & 7.688789 & 2.039763 & 1.0 & 5.0 & 0.9101411 \\ 85 & 2.663669 & 0.9797046 & 1.0 & 6.0 & 0.9101889 \\ 86 & 6.079680 & 1.804952 & 1.0 & 7.0 & 0.9302108 \\ 87 & 6.251009 & 1.832743 & 1.0 & 8.0 & 0.9932102 \\ 88 & 3.100160 & 1.131454 & .1 .0 & 9.0 & 0.9827683 \\ 70 & 9.454924 & 2.246536 & 0.00 & 0.00 & 0.8780282 \\ 71 & 11.60699 & 2.451607 & 0.00 & 0.00 & 0.9103325\end{array}$


APPENDIX I

OPERATING RATIO

(continued)

$\begin{array}{llllll}72 & 18.56459 & 2.921256 & 0.00 & 0.00 & 0.8855433 \\ 73 & 14.28117 & 2.658942 & 0.00 & 0.00 & 0.8898662 \\ 74 & 15.70913 & 2.754242 & 0.00 & 0.00 & 0.8797147 \\ 75 & 13.66038 & 2.614499 & 0.00 & 0.00 & 0.9504106 \\ 76 & 9.328863 & 2.233113 & 0.00 & 0.00 & 0.9215828 \\ 77 & 7.159221 & 1.968401 & 0.00 & 0.00 & 0.9069057 \\ 78 & 8.313782 & 2.117915 & 0.00 & 0.00 & 0.9035657 \\ 79 & 3.115066 & 1.136250 & 0.00 & 0.00 & 0.9537052 \\ 80 & 4.534688 & 1.511756 & 1.0 & 1.0 & 0.9502776 \\ 81 & 6.011133 & 1.793613 & 1.0 & 2.0 & 0.9762623 \\ 82 & 1.539684 & 0.4315771 & 1.0 & 3.0 & 1.023665 \\ 83 & 1.501281 & 0.4063185 & 1.0 & 4.0 & 1.014649 \\ 84 & 4.246753 & 1.446155 & 1.0 & 5.0 & 0.9360994 \\ 85 & 10.80516 & 2.380024 & 1.0 & 6.0 & 0.9512033 \\ 86 & 2.693820 & 0.9909604 & 1.0 & 7.0 & 0.9499553 \\ 87 & 6.576580 & 1.883515 & 1.0 & 8.0 & 0.9287347 \\ 88 & 5.842311 & 1.765126 & 1.0 & 9.0 & 0.9290386 \\ 70 & 9.602381 & 2.262011 & 0.00 & 0.00 & 0.9548052 \\ 71 & 9.422865 & 2.243139 & 0.00 & 0.00 & 0.9659982 \\ 72 & 15.30725 & 2.728327 & 0.00 & 0.00 & 0.9542277 \\ 73 & 11.69064 & 2.458789 & 0.00 & 0.00 & 1.015489 \\ 74 & 9.988364 & 2.301421 & 0.00 & 0.00 & 0.9537769 \\ 75 & 12.47900 & 2.524047 & 0.00 & 0.00 & 0.9960571 \\ 76 & 6.016594 & 1.794521 & 0.00 & 0.00 & 0.9565586 \\ 77 & 7.342737 & 1.993712 & 0.00 & 0.00 & 0.9830934 \\ 78 & 5.779328 & 1.754287 & 0.00 & 0.00 & 0.9593276 \\ 79 & 4.132283 & 1.418830 & 0.00 & 0.00 & 0.9614558 \\ 80 & 4.066909 & 1.402883 & 1.0 & 1.0 & 0.9994623 \\ 81 & 11.23619 & 2.419140 & 1.0 & 2.0 & 1.013401 \\ 82 & 5.869647 & 1.769794 & 1.0 & 3.0 & 1.004983 \\ 83 & 7.022531 & 1.949124 & 1.0 & 4.0 & 1.025394 \\ 84 & 6.491441 & 1.870485 & 1.0 & 5.0 & 0.9565456 \\ 85 & 6.345814 & 1.847795 & 1.0 & 6.0 & 0.9539746 \\ 86 & 11.05964 & 2.403302 & 1.0 & 7.0 & 0.9856234 \\ 87 & 10.16819 & 2.319265 & 1.0 & 8.0 & 0.9869959 \\ 88 & 6.005925 & 1.792746 & 1.0 & 9.0 & 1.053866 \\ 70 & 9.782534 & 2.280599 & 0.00 & 0.00 & 0.8650809 \\ 71 & 27.90190 & 3.328695 & 0.00 & 0.00 & 0.9570119 \\ 72 & 25.56760 & 3.241326 & 0.00 & 0.00 & 0.9611554 \\ 73 & 11.26888 & 2.422045 & 0.00 & 0.00 & 0.9115769 \\ 74 & 7.854812 & 2.061126 & 0.00 & 0.00 & 0.8982241 \\ 75 & 8.077642 & 2.089100 & 0.00 & 0.00 & 0.9387390 \\ 76 & 3.897131 & 1.360241 & 0.00 & 0.00 & 0.8935346 \\ 77 & 7.634171 & 2.032634 & 0.00 & 0.00 & 0.8998075 \\ 78 & 6.468975 & 1.867018 & 0.00 & 0.00 & 0.9144751 \\ 79 & 3.748927 & 1.321470 & 0.00 & 0.00 & 0.9567365 \\ 80 & 3.634210 & 1.290392 & 1.0 & 1.0 & 1.014600\end{array}$


APPENDIX I

OPERATING RATIO

(continued)

$\begin{array}{llllll}81 & 22.00640 & 3.091333 & 1.0 & 2.0 & 0.9988829 \\ 82 & 3.728297 & 1.315951 & 1.0 & 3.0 & 1.004236 \\ 83 & 6.652895 & 1.895052 & 1.0 & 4.0 & 0.9686219 \\ 84 & 12.48120 & 2.524224 & 1.0 & 5.0 & 0.9606870 \\ 85 & 8.400538 & 2.128296 & 1.0 & 6.0 & 0.9712254 \\ 86 & 3.935451 & 1.370025 & 1.0 & 7.0 & 0.9583825 \\ 87 & 4.787633 & 1.566036 & 1.0 & 8.0 & 0.9595731 \\ 88 & 9.708090 & 2.272960 & 1.0 & 9.0 & 0.9649883 \\ 70 & 20.60000 & 3.025291 & 0.00 & 0.00 & 1.026581 \\ 71 & 15.30633 & 2.728267 & 0.00 & 0.00 & 1.013768 \\ 72 & 6.702188 & 1.902434 & 0.00 & 0.00 & 1.001487 \\ 73 & 6.365615 & 1.850911 & 0.00 & 0.00 & 1.001192 \\ 74 & 11.98863 & 2.483958 & 0.00 & 0.00 & 1.062088 \\ 75 & 8.251506 & 2.110396 & 0.00 & 0.00 & 1.020982 \\ 76 & 3.055796 & 1.117040 & 0.00 & 0.00 & 0.9917985 \\ 77 & 6.468473 & 1.866940 & 0.00 & 0.00 & 0.9542797 \\ 78 & 6.824844 & 1.920569 & 0.00 & 0.00 & 0.9370113 \\ 79 & 13.68466 & 2.616276 & 0.00 & 0.00 & 0.9720072 \\ 80 & 2.274956 & 0.8219606 & 1.0 & 1.0 & 1.035619 \\ 81 & 10.03731 & 2.306310 & 1.0 & 2.0 & 1.105263 \\ 82 & 7.313987 & 1.989789 & 1.0 & 3.0 & 1.107374 \\ 83 & 8.030322 & 2.083225 & 1.0 & 4.0 & 0.9962797 \\ 84 & 5.650500 & 1.731744 & 1.0 & 5.0 & 1.039986 \\ 85 & 3.013065 & 1.102958 & 1.0 & 6.0 & 1.065752 \\ 86 & 10.49670 & 2.351061 & 1.0 & 7.0 & 1.136255 \\ 87 & 9.596008 & 2.261347 & 1.0 & 8.0 & 1.054600 \\ 88 & 8.235943 & 2.108508 & 1.0 & 9.0 & 1.029308 \\ 70 & 12.78667 & 2.548403 & 0.00 & 0.00 & 1.073206 \\ 71 & 8.893764 & 2.185350 & 0.00 & 0.00 & 0.9880938 \\ 72 & 13.35292 & 2.591735 & 0.00 & 0.00 & 0.9470673 \\ 73 & 4.899095 & 1.589050 & 0.00 & 0.00 & 0.9522793 \\ 74 & 13.00896 & 2.565638 & 0.00 & 0.00 & 1.010386 \\ 75 & 13.38540 & 2.594165 & 0.00 & 0.00 & 1.045252 \\ 76 & 1.644672 & 0.4975409 & 0.00 & 0.00 & 0.9738675 \\ 77 & 4.860000 & 1.581038 & 0.00 & 0.00 & 0.9816897 \\ 78 & 3.333294 & 1.203961 & 0.00 & 0.00 & 0.9801738 \\ 79 & 5.006684 & 1.610774 & 0.00 & 0.00 & 1.015234 \\ 80 & 3.904191 & 1.362051 & 1.0 & 1.0 & 1.010865 \\ 81 & 4.629062 & 1.532354 & 1.0 & 2.0 & 0.9988842 \\ 82 & 10.08265 & 2.310816 & 1.0 & 3.0 & 1.032190 \\ 83 & 14.56611 & 2.678698 & 1.0 & 4.0 & 1.019582 \\ 84 & 4.533770 & 1.511554 & 1.0 & 5.0 & 0.9793932 \\ 85 & 4.288532 & 1.455945 & 1.0 & 6.0 & 1.016468 \\ 86 & 8.360435 & 2.123510 & 1.0 & 7.0 & 1.023801 \\ 87 & 5.259633 & 1.660061 & 1.0 & 8.0 & 0.9407275 \\ 88 & 3.291211 & 1.191256 & 1.0 & 9.0 & 0.9405159 \\ 70 & 12.16605 & 2.498650 & 0.00 & 0.00 & 1.013977\end{array}$


APPENDIX I

OPERATING RATIO

(continued)

$\begin{array}{llrlll}71 & 12.00810 & 2.485582 & 0.00 & 0.00 & 0.9772700 \\ 72 & 5.491392 & 1.703182 & 0.00 & 0.00 & 0.9560165 \\ 73 & 4.403681 & 1.482441 & 0.00 & 0.00 & 0.9226813 \\ 74 & 6.109295 & 1.809811 & 0.00 & 0.00 & 0.9204581 \\ 75 & 7.807376 & 2.055069 & 0.00 & 0.00 & 1.002413 \\ 76 & 2.463667 & 0.9016509 & 0.00 & 0.00 & 0.9870916 \\ 77 & 5.885309 & 1.772459 & 0.00 & 0.00 & 0.9728370 \\ 78 & 7.555577 & 2.022286 & 0.00 & 0.00 & 0.9178491 \\ 79 & 2.455111 & 0.8981721 & 0.00 & 0.00 & 1.073398 \\ 80 & 4.343586 & 1.468700 & 1.0 & 1.0 & 1.015533 \\ 81 & 5.274449 & 1.662874 & 1.0 & 2.0 & 1.032823 \\ 82 & 3.946294 & 1.372777 & 1.0 & 3.0 & 1.014857 \\ 83 & 10.80312 & 2.379835 & 1.0 & 4.0 & 0.9711791 \\ 84 & 8.460237 & 2.135377 & 1.0 & 5.0 & 0.9097885 \\ 85 & 3.629615 & 1.289127 & 1.0 & 6.0 & 1.066666 \\ 86 & 5.348924 & 1.676895 & 1.0 & 7.0 & 1.001496 \\ 87 & 4.906222 & 1.590504 & 1.0 & 8.0 & 0.9807680 \\ 88 & 3.328111 & 1.202405 & 1.0 & 9.0 & 0.9239948\end{array}$




\section{APPENDIX I}

\section{OPERATING RATIO \\ (continued)}

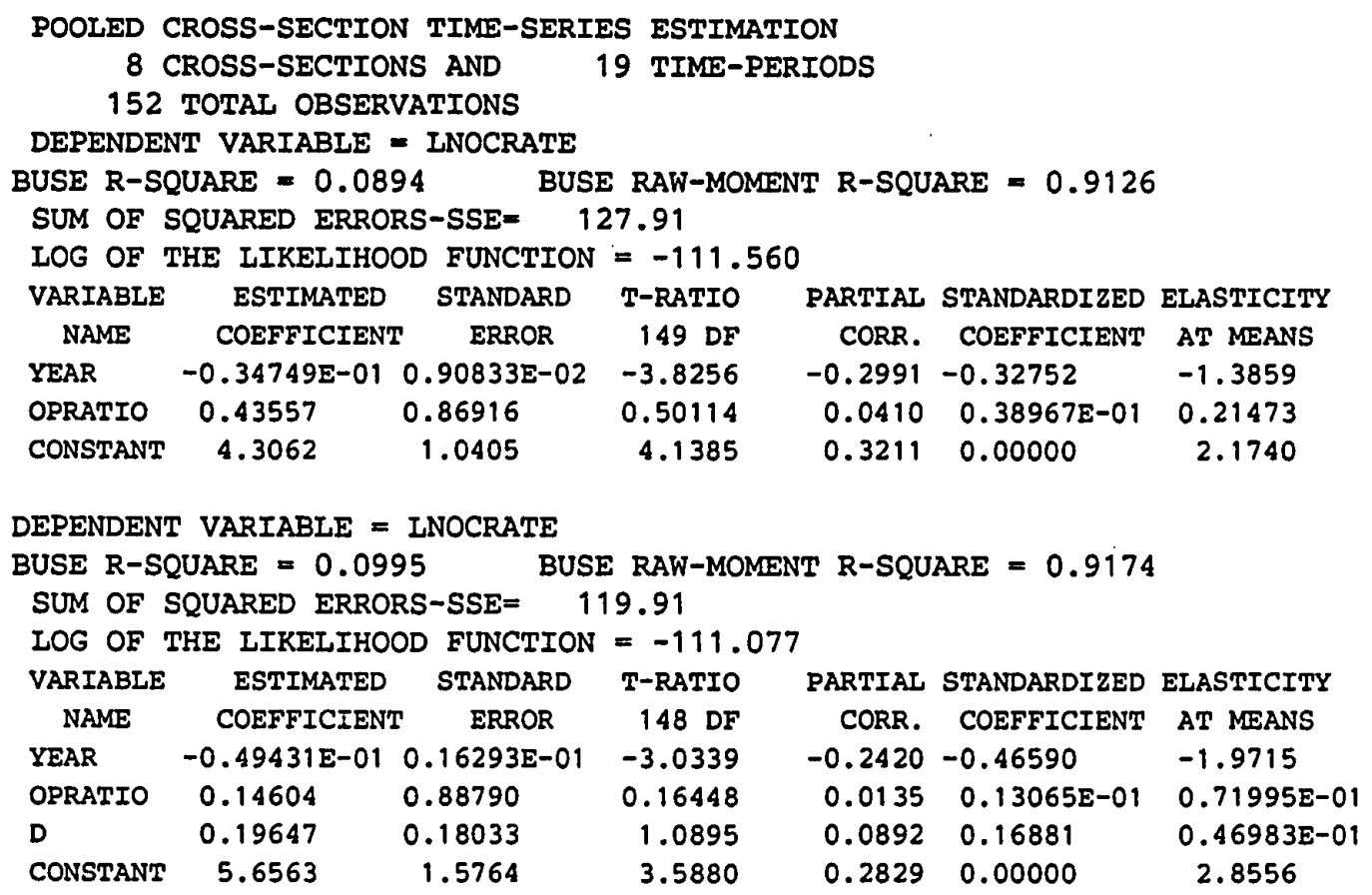




\section{APPENDIX I \\ OPERATING RATIO \\ (continued)}

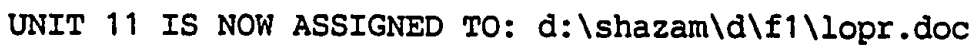

9 VARIABLES AND

$\begin{array}{cc}\text { YEAR } & \text { OCRATE } \\ 71 & 16.69885 \\ 72 & 7.781968 \\ 73 & 12.10068 \\ 74 & 11.39848 \\ 75 & 11.11245 \\ 76 & 6.096539 \\ 77 & 7.445573 \\ 78 & 7.264749 \\ 79 & 6.686745 \\ 80 & 1.441745 \\ 81 & 6.552350 \\ 82 & 6.459635 \\ 83 & 10.62232 \\ 84 & 8.001526 \\ 85 & 11.64321 \\ 86 & 5.285088 \\ 87 & 5.989992 \\ 88 & 7.479348 \\ 71 & 15.03774 \\ 72 & 10.20710 \\ 73 & 5.471238 \\ 74 & 5.936691 \\ 75 & 17.07262 \\ 76 & 24.46603 \\ 77 & 10.72421 \\ 78 & 9.499157 \\ 79 & 8.305579 \\ 80 & 10.06994 \\ 81 & 14.96394 \\ 82 & 12.96143 \\ 83 & 29.00208 \\ 84 & 7.688789 \\ 85 & 2.663669 \\ 86 & 6.079680 \\ 87 & 6.251009 \\ 88 & 3.100160 \\ 71 & 11.60699 \\ 72 & 18.56459 \\ 73 & 14.28117 \\ 74 & 15.70913 \\ 75 & 13.66038 \\ 76 & 9.328863\end{array}$

144 OBSERVATIONS STARTING AT OBS

1

$\begin{array}{cccc}\text { LNOCRATE } & \text { D } & \text { TIMEDUM } & \text { LAGOPR } \\ 2.815340 & 0.00 & 0 . & 1.013336 \\ 2.051809 & 0.00 & 0 . & 0.9769582 \\ 2.493261 & 0.00 & 0 . & 0.9695126 \\ 2.433480 & 0.00 & 0 . & 1.024519 \\ 2.408066 & 0.00 & 0 . & 0.9761608 \\ 1.807721 & 0.00 & 0 . & 1.015878 \\ 2.007620 & 0.00 & 0 . & 0.9661233 \\ 1.983034 & 0.00 & 0 . & 0.9729827 \\ 1.900127 & 0.00 & 0 . & 0.9644798 \\ 0.3658541 & 1.0 & 1 & 0.9984729 \\ 1.879824 & 1.0 & 2 & 1.030660 \\ 1.865573 & 1.0 & 3 & 0.9889147 \\ 2.362957 & 1.0 & 4 & 1.004587 \\ 2.079632 & 1.0 & 5 & 0.9449481 \\ 2.454723 & 1.0 & 6 & 0.9333518 \\ 1.664889 & 1.0 & 7 & 0.9135595 \\ 1.790090 & 1.0 & 8 & 0.9330558 \\ 2.012146 & 1.0 & 9 & 0.9335834 \\ 2.710563 & 0.00 & 0 . & 0.9301763 \\ 2.323084 & 0.00 & 0 . & 0.9084038 \\ 1.699505 & 0.00 & 0 . & 0.9064261 \\ 1.781152 & 0.00 & 0 . & 0.9607209 \\ 2.837476 & 0.00 & 0 . & 0.8977497 \\ 3.197286 & 0.00 & 0 . & 0.9343404 \\ 2.372503 & 0.00 & 0 . & 0.9318145 \\ 2.251203 & 0.00 & 0 . & 0.9319356 \\ 2.116927 & 0.00 & 0 . & 0.9446996 \\ 2.309554 & 1.0 & 1 & 1.022308 \\ 2.705643 & 1.0 & 2 & 1.062655 \\ 2.561978 & 1.0 & 3 & 1.055547 \\ 3.367368 & 1.0 & 4 & 1.050567 \\ 2.039763 & 1.0 & 5 & 1.132921 \\ 0.9797046 & 1.0 & 6 & 0.9101411 \\ 1.804952 & 1.0 & 7 & 0.9101889 \\ 1.832743 & 1.0 & 8 & 0.9302108 \\ 1.131454 & 1.0 & 9 & 0.9932102 \\ 2.451607 & 0.00 & 0 . & 0.8780282 \\ 2.921256 & 0.00 & 0 . & 0.9103325 \\ 2.658942 & 0.00 & 0 . & 0.8855433 \\ 2.754242 & 0.00 & 0 . & 0.8898662 \\ 2.614499 & 0.00 & 0 . & 0.8797147 \\ 2.233113 & 0.00 & 0 . & 0.9504106 \\ & & & \end{array}$


APPENDIX I

OPERATING RATIO

(continued)

$\begin{array}{llllll}77 & 7.159221 & 1.968401 & 0.00 & 0 . & 0.9215828 \\ 78 & 8.313782 & 2.117915 & 0.00 & 0 . & 0.9069057 \\ 79 & 3.115066 & 1.136250 & 0.00 & 0 . & 0.9035657 \\ 80 & 4.534688 & 1.511756 & 1.0 & 1 & 0.9537052 \\ 81 & 6.011133 & 1.793613 & 1.0 & 2 & 0.9502776 \\ 82 & 1.539684 & 0.4315771 & 1.0 & 3 & 0.9762623 \\ 83 & 1.501281 & 0.4063185 & 1.0 & 4 & 1.023665 \\ 84 & 4.246753 & 1.446155 & 1.0 & 5 & 1.014649 \\ 85 & 10.80516 & 2.380024 & 1.0 & 6 & 0.9360994 \\ 86 & 2.693820 & 0.9909604 & 1.0 & 7 & 0.9512033 \\ 87 & 6.576580 & 1.883515 & 1.0 & 8 & 0.9499553 \\ 88 & 5.842311 & 1.765126 & 1.0 & 9 & 0.9287347 \\ 71 & 9.422865 & 2.243139 & 0.00 & 0 . & 0.9548052 \\ 72 & 15.30725 & 2.728327 & 0.00 & 0 . & 0.9659982 \\ 73 & 11.69064 & 2.458789 & 0.00 & 0 . & 0.9542277 \\ 74 & 9.988364 & 2.301421 & 0.00 & 0 . & 1.015489 \\ 75 & 12.47900 & 2.524047 & 0.00 & 0 . & 0.9537769 \\ 76 & 6.016594 & 1.794521 & 0.00 & 0 . & 0.9960571 \\ 77 & 7.342737 & 1.993712 & 0.00 & 0 . & 0.9565586 \\ 78 & 5.779328 & 1.754287 & 0.00 & 0 . & 0.9830934 \\ 79 & 4.132283 & 1.418830 & 0.00 & 0 . & 0.9593276 \\ 80 & 4.066909 & 1.402883 & 1.0 & 1 & 0.9614558 \\ 81 & 11.23619 & 2.419140 & 1.0 & 2 & 0.9994623 \\ 82 & 5.869647 & 1.769794 & 1.0 & 3 & 1.013401 \\ 83 & 7.022531 & 1.949124 & 1.0 & 4 & 1.004983 \\ 84 & 6.491441 & 1.870485 & 1.0 & 5 & 1.025394 \\ 85 & 6.345814 & 1.847795 & 1.0 & 6 & 0.9565456 \\ 86 & 11.05964 & 2.403302 & 1.0 & 7 & 0.9539746 \\ 87 & 10.16819 & 2.319265 & 1.0 & 8 & 0.9856234 \\ 88 & 6.005925 & 1.792746 & 1.0 & 9 & 0.9869959 \\ 71 & 27.90190 & 3.328695 & 0.00 & 0 . & 0.8650809 \\ 72 & 25.56760 & 3.241326 & 0.00 & 0 . & 0.9570119 \\ 73 & 11.26888 & 2.422045 & 0.00 & 0 . & 0.9611554 \\ 74 & 7.854812 & 2.061126 & 0.00 & 0 . & 0.9115769 \\ 75 & 8.077642 & 2.089100 & 0.00 & 0 . & 0.8982241 \\ 76 & 3.897131 & 1.360241 & 0.00 & 0 . & 0.9387390 \\ 77 & 7.634171 & 2.032634 & 0.00 & 0 . & 0.8935346 \\ 78 & 6.468975 & 1.867018 & 0.00 & 0 . & 0.8998075 \\ 79 & 3.748927 & 1.321470 & 0.00 & 0 . & 0.9144751 \\ 80 & 3.634210 & 1.290392 & 1.0 & 1 & 0.9567365 \\ 81 & 22.00640 & 3.091333 & 1.0 & 2 & 1.014600 \\ 82 & 3.728297 & 1.315951 & 1.0 & 3 & 0.9988829 \\ 83 & 6.652895 & 1.895052 & 1.0 & 4 & 1.004236 \\ 84 & 12.48120 & 2.524224 & 1.0 & 5 & 0.9686219 \\ 85 & 8.400538 & 2.128296 & 1.0 & 6 & 0.9606870 \\ 86 & 3.935451 & 1.370025 & 1.0 & 7 & 0.9712254 \\ 87 & 4.787633 & 1.566036 & 1.0 & 8 & 0.9583825\end{array}$


APPENDIX I

OPERATING RATIO

(continued)

\begin{tabular}{|c|c|c|c|c|c|}
\hline 88 & 9.708090 & 2.272960 & 1.0 & 9 & 0.9595731 \\
\hline 71 & 15.30633 & 2.728267 & 0.00 & 0. & 1.026581 \\
\hline 72 & 6.702188 & 1.902434 & 0.00 & 0. & 1.013768 \\
\hline 73 & 6.365615 & 1.850911 & 0.00 & 0. & 1.001487 \\
\hline 74 & 11.98863 & 2.483958 & 0.00 & 0. & 1.001192 \\
\hline 75 & 8.251506 & 2.110396 & 0.00 & 0. & 1.062088 \\
\hline 76 & 3.055796 & 1.117040 & 0.00 & 0. & 1.020982 \\
\hline 77 & 6.468473 & 1.866940 & 0.00 & 0. & 0.9917985 \\
\hline 78 & 6.824844 & 1.920569 & 0.00 & 0. & 0.9542797 \\
\hline 79 & 13.68466 & 2.616276 & 0.00 & 0 . & 0.9370113 \\
\hline 80 & 2.274956 & 0.8219606 & 1.0 & 1 & 0.9720072 \\
\hline 81 & 10.03731 & 2.306310 & 1.0 & 2 & 1.035619 \\
\hline 82 & 7.313987 & 1.989789 & 1.0 & 3 & 1.105263 \\
\hline 83 & 8.030322 & 2.083225 & 1.0 & 4 & 1.107374 \\
\hline 84 & 5.650500 & 1.731744 & 1.0 & 5 & 0.9962797 \\
\hline 85 & 3.013065 & 1.102958 & 1.0 & 6 & 1.039986 \\
\hline 86 & 10.49670 & 2.351061 & 1.0 & 7 & 1.065752 \\
\hline 87 & 9.596008 & 2.261347 & 1.0 & 8 & 1.136255 \\
\hline 88 & 8.235943 & 2.108508 & 1.0 & 9 & 1.054600 \\
\hline 71 & 8.893764 & 2.185350 & 0.00 & 0. & 1.073206 \\
\hline 72 & 13.35292 & 2.591735 & 0.00 & 0. & 0.9880938 \\
\hline 73 & 4.899095 & 1.589050 & 0.00 & 0. & 0.9470673 \\
\hline 74 & 13.00896 & 2.565638 & 0.00 & 0. & 0.9522793 \\
\hline 75 & 13.38540 & 2.594165 & 0.00 & 0. & 1.010386 \\
\hline 76 & 1.644672 & 0.4975409 & 0.00 & 0. & 1.045252 \\
\hline 77 & 4.860000 & 1.581038 & 0.00 & 0. & 0.9738675 \\
\hline 78 & 3.333294 & 1.203961 & 0.00 & 0. & 0.9816897 \\
\hline 79 & 5.006684 & 1.610774 & 0.00 & 0. & 0.9801738 \\
\hline 80 & 3.904191 & 1.362051 & 1.0 & 1 & 1.015234 \\
\hline 81 & 4.629062 & 1.532354 & 1.0 & 2 & 1.010865 \\
\hline 82 & 10.08265 & 2.310816 & 1.0 & 3 & 0.9988842 \\
\hline 83 & 14.56611 & 2.678698 & 1.0 & 4 & 1.032190 \\
\hline 84 & 4.533770 & 1.511554 & 1.0 & 5 & 1.019582 \\
\hline 85 & 4.288532 & 1.455945 & 1.0 & 6 & 0.9793932 \\
\hline 86 & 8.360435 & 2.123510 & 1.0 & 7 & 1.016468 \\
\hline 87 & 5.259633 & 1.660061 & 1.0 & 8 & 1.023801 \\
\hline 88 & 3.291211 & 1.191256 & 1.0 & 9 & 0.9407275 \\
\hline 71 & 12.00810 & 2.485582 & 0.00 & 0 . & 1.013977 \\
\hline 72 & 5.491392 & 1.703182 & 0.00 & 0 . & 0.9772700 \\
\hline 73 & 4.403681 & 1.482441 & 0.00 & 0 . & 0.9560165 \\
\hline 74 & 6.109295 & 1.809811 & 0.00 & 0. & 0.9226813 \\
\hline 75 & 7.807376 & 2.055069 & 0.00 & 0 . & 0.9204581 \\
\hline 76 & 2.463667 & 0.9016509 & 0.00 & 0 . & 1.002413 \\
\hline 77 & 5.885309 & 1.772459 & 0.00 & 0 . & 0.9870916 \\
\hline 78 & 7.555577 & 2.022286 & 0.00 & 0 . & 0.9728370 \\
\hline 79 & 2.455111 & 0.8981721 & 0.00 & 0. & 0.9178491 \\
\hline 80 & 4.343586 & 1.468700 & 1.0 & 1 & 1.073398 \\
\hline
\end{tabular}




\section{APPENDIX I \\ OPERATING RATIO (continued)}

$\begin{array}{lllllr}81 & 5.274449 & 1.662874 & 1.0 & 2 & 1.015533 \\ 82 & 3.946294 & 1.372777 & 1.0 & 3 & 1.032823 \\ 83 & 10.80312 & 2.379835 & 1.0 & 4 & 1.014857 \\ 84 & 8.460237 & 2.135377 & 1.0 & 5 & 0.9711791 \\ 85 & 3.629615 & 1.289127 & 1.0 & 6 & 0.9097885 \\ 86 & 5.348924 & 1.676895 & 1.0 & 7 & 1.066666 \\ 87 & 4.906222 & 1.590504 & 1.0 & 8 & 1.001496 \\ 88 & 3.328111 & 1.202405 & 1.0 & 9 & 0.9807680\end{array}$




\section{APPENDIX I \\ OPERATING RATIO \\ (continued)}

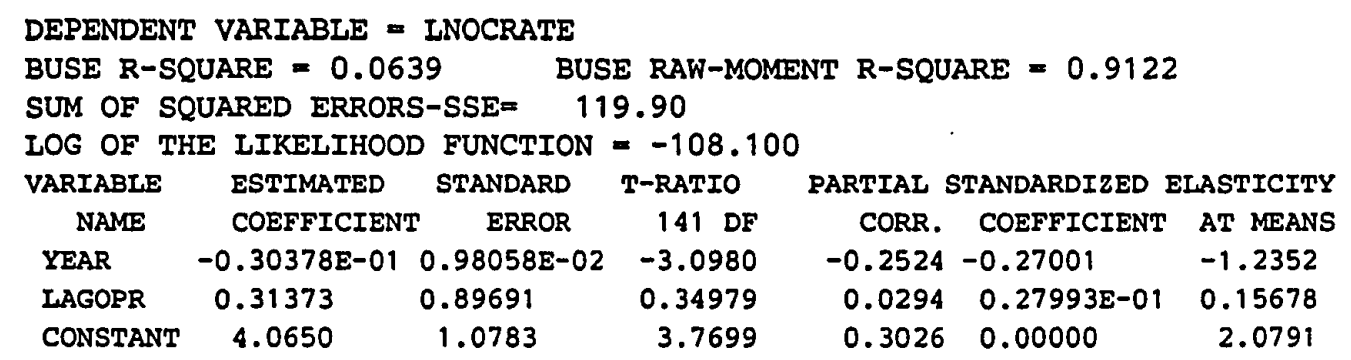

DEPENDENT VARIABLE = LNOCRATE

\begin{tabular}{|c|c|c|c|c|c|c|}
\hline $\begin{array}{l}\text { BUSE R-S } \\
\text { SUM OF } S\end{array}$ & $\begin{array}{l}\text { QUARE }=0.07 \\
\text { QUARED ERRORS }\end{array}$ & $\begin{array}{l}14 \\
S-S S E=\end{array}$ & $\begin{array}{l}\text { E RAW-MOMEN? } \\
1.88\end{array}$ & NT R-SQU & $R E=0$ & \\
\hline OG OF 1 & IE IIKELIHOOL & D FUNCTION & $=-107.777$ & & & \\
\hline JARIABLE & ESTIMATED & STANDARD & T-RATIO & PARTIAL & STANDARDIZED & ELASTICITY \\
\hline NAME & COEFFICIENT & ERROR & $140 \mathrm{DF}$ & CORR. & COEFFICIENT & AT MEANS \\
\hline YEAR & $-0.44329 E-01$ & $0.17929 \mathrm{E}-01$ & -2.4724 & -0.2045 & $5-0.39401$ & -1.8025 \\
\hline LAGOPR & $0.24078 E-01$ & 0.94346 & $0.25521 E-01$ & 10.0022 & $2 \quad 0.21484 \mathrm{E}-02$ & $0.12033 \mathrm{E}-01$ \\
\hline D & 0.17554 & 0.19009 & 0.92345 & 0.0778 & 0.15037 & $0.44892 \mathrm{E}-01$ \\
\hline CON & 5.3709 & 1.7510 & 3.0673 & 0.2509 & 0.00000 & 2.7470 \\
\hline
\end{tabular}

DEPENDENT VARIABLE = LNOCRATE

\begin{tabular}{|c|c|c|c|c|c|c|}
\hline \multirow{2}{*}{\multicolumn{7}{|c|}{$\begin{array}{l}\text { BUSE R-SQUARE }=0.2075 \quad \text { BUSE RAW-MOMENI } \\
\text { SUM OF SQUARED ERRORS-SSE= } 111.51 \\
\text { LOG OF THE LIKELIHOOD FUNCTION }=-99.4537\end{array}$}} \\
\hline & & & & & & \\
\hline VARIABLE & ESTIMATED & STANDARD & T-RATIO & PARTIAL & STANDARDIZED & ELASTICITY \\
\hline NAME & COEFFICIENT & ERROR & $140 \mathrm{DF}$ & CORR. & COEFFICIENT & AT MEANS \\
\hline YEAR & -0.10990 & $0.18670 \mathrm{E}-01$ & -5.8862 & -0.4454 & -0.97680 & -4.4686 \\
\hline LAGOPR & $0.56560 \mathrm{E}-01$ & 0.83008 & $0.68138 \mathrm{E}-01$ & 0.0058 & $0.50466 E-02$ & $0.28264 \mathrm{E}-01$ \\
\hline TIMEDUM & 0.14870 & $0.31214 E-01$ & 4.7639 & 0.3735 & 0.78865 & 0.19014 \\
\hline CONSTANT & 10.287 & 1.5870 & 6.4823 & 0.4805 & 0.00000 & 5.2616 \\
\hline
\end{tabular}

DEPENDENT VARIABLE = LNOCRATE

\begin{tabular}{|c|c|c|c|c|c|c|}
\hline \multicolumn{7}{|c|}{$\begin{array}{lc}\text { BUSE R-SQUARE }=0.2168 & \text { BUSE RAW-MOMEN } \\
\text { SUM OF SQUARED ERRORS-SSE }= & 103.50\end{array}$} \\
\hline & & & & & & \\
\hline VARIABLE & ESTIMATED & STANDARD & T-RATIO & PARTIAL & STANDARDIZED & ELASTICITY \\
\hline NAME & COEFFICIENT & ERROR & $139 \mathrm{DF}$ & CORR. & COEFFICIENT & AT MEANS \\
\hline YEAR & -0.12075 & $0.21893 E-01$ & -5.5157 & -0.4238 & -1.0733 & -4.9101 \\
\hline LAGOPR & -0.16927 & 0.87296 & -0.19390 & -0.0164 & $-0.15103 \mathrm{E}-01$ & $-0.84588 E-01$ \\
\hline D & 0.14440 & 0.16556 & 0.87222 & 0.0738 & 0.12370 & $0.36929 \mathrm{E}-01$ \\
\hline T & 0.14700 & $0.31103 E-01$ & 4.7263 & 0.3721 & 0.77963 & 0.18797 \\
\hline CON & 11.305 & 1.9267 & 5.8673 & 0.4455 & 0.00000 & 5.7820 \\
\hline
\end{tabular}




\section{APPENDIX J}

OPERATING RATIO WITH ZERO DUMMY 


\section{APPENDIX J \\ OPERATING RATIO WITH ZERO DUMMY \\ COMMAND FILE}

FILE 11 d: \shazam\d\f1\oprzd.doc

sample 195

read(11) airline year d totocc y $\mathrm{n}$ u hours opratio

* generate controlable rate

genr crate $=((1000000 * y)) /$ hours

*generate time since deregulation dummy

genr timedum $=d^{*}($ year -79$)$

* generate zero dummy for crate $=0$

genr zerodum $=\operatorname{dum}(.001$ - crate $)$

* generate modified rate with ones where there were zeroes genr modcrate $=$ crate + zerodum

* generate log of the modified rate

genr Inmodrat $=\log$ (modcrate)

print year crate zerodum modcrate Inmodrat d timedum opratio

pool Inmodrat year zerodum opratio pool Inmodrat year zerodum opratio pool Inmodrat year zerodum opratio pool Inmodrat year zerodum opratio

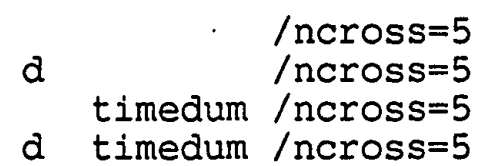

delete / all 


\section{APFENDIX J \\ OPERATING RATIO WITH ZERO DUMMY \\ (continued)}

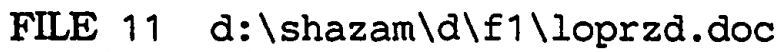

sample 190

read(11) airline year d totoce y $\mathrm{n} u$ hours lagopr

* generate controlable rate

genr crate $=((1000000 * y)) /$ hours

*generate time since deregulation dummy

genr timedum $=d *($ year -79$)$

* generate zero dummy for crate $=0$

genr zerodum $=\operatorname{dum}(.001$ - crate $)$

* generate modified rate with ones where there were zeroes genr modcrate $=$ crate + zerodum

* generate $\log$ of the modified rate genr Inmodrat $=\log$ (modcrate)

print year crate zerodum modcrate Inmodrat d timedum lagopr

pool Inmodrat year zerodum lagopr pool lnmodrat year zerodum lagopr pool Inmodrat year zerodum lagopr pool Inmodrat year zerodum lagopr

d $\quad \begin{aligned} & / \text { ncross }=5 \\ & / \text { ncross }=5\end{aligned}$

timedum /ncross $=5$

d timedum /ncross $=5$

delete / all 


\section{APPENDIX J \\ OPERATING RATIO WITH ZERO DUMMY (continued)}

\section{OUTPUT FILE}

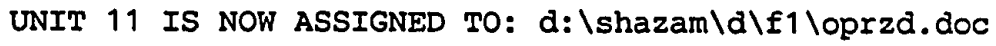

9 VARIABLES AND

95 OBSERVATIONS STARTING AT OBS
1

\begin{tabular}{|c|c|c|c|c|c|c|c|}
\hline YR & CRATE & ZERODUM & MODCRATE & LNMODRAT & - & TIMEDUM & OPRATIO \\
\hline 70 & 8.928877 & 0.00 & 8.928877 & 2.189291 & 0.00 & 0.00 & 1.013336 \\
\hline 1 & 15.18077 & .00 & 15.18077 & 20030 & .00 & 0.00 & 0.9769582 \\
\hline 72 & 6.225574 & 0.00 & 6.225574 & 1.828666 & .00 & 0.00 & 0.9695126 \\
\hline 73 & 10.58809 & 0.00 & 10.58809 & 2.359730 & 0.00 & 0.00 & 1.024519 \\
\hline 74 & 9.770125 & 0.00 & 9.770125 & 2.279329 & 0.00 & 0.00 & 0.9761608 \\
\hline 75 & 9.524959 & 0.00 & 9.524959 & 2.253916 & 0.00 & 0.00 & 1.015878 \\
\hline 76 & 4.572404 & 0.00 & 4.572404 & 1.520039 & 0.00 & 0.00 & 1233 \\
\hline 77 & 5.956458 & 0.00 & 5.956458 & 1.784476 & 0.00 & 0.00 & 0.9729827 \\
\hline 78 & 1799 & 0.00 & 1799 & 1.759890 & 0.00 & 0.00 & 0.9644798 \\
\hline 79 & 5.349396 & 0.00 & 396 & 84 & 0.00 & 0.00 & 0.9984729 \\
\hline 80 & 0.0000000 & 1.0 & 1.000000 & .0000000 & .0 & 1.0 & 1.030660 \\
\hline 81 & 4.914263 & 0.00 & 4.914263 & 1.592142 & 1.0 & 2.0 & 0.9889147 \\
\hline 82 & 4.844727 & 0.00 & 4.84 & 1.577891 & 1.0 & 3.0 & 1.004587 \\
\hline 83 & 9.1 & 0.00 & 9.1 & & 1.0 & 4.0 & 0.9449481 \\
\hline 84 & 6.6 & 0.00 & 6. & 1.8 & 1.0 & 5.0 & 3518 \\
\hline 85 & 10. & 0.00 & 10.47889 & 2.345 & 1.0 & 6.0 & 5595 \\
\hline 86 & 4.2 & 0.00 & 4.22 & 1.4 & 1.0 & 7.0 & 0558 \\
\hline 87 & 5.1 & 0.00 & & & 1.0 & 8.0 & 5834 \\
\hline 88 & 6.7 & 0.00 & 6.7 & 85 & 1.0 & 9.0 & 3228 \\
\hline 70 & 7.09 & 0.00 & 7.09 & 854 & 0.00 & 0.00 & 0282 \\
\hline 71 & 9.2 & 0.00 & 9.2 & 3464 & 0.00 & 0.00 & 0.9103325 \\
\hline 72 & & 0.00 & 16. & 73 & 0.00 & 0.00 & 0.8855433 \\
\hline 73 & 12. & 0.00 & & & 0.00 & 0.00 & 662 \\
\hline 74 & 13. & 0.00 & & & 0.00 & 0.00 & 7147 \\
\hline 75 & 11. & 0.00 & 89 & 349 & 0.00 & 0.00 & 0.9504106 \\
\hline 76 & 7.4 & 0.00 & 7.46 & 2.0 & 0.00 & 0.00 & 0.9215828 \\
\hline 77 & & & & & 0.00 & 0.00 & 0.9069057 \\
\hline 78 & 6.6 & 0.00 & 6. & 1.8 & 0.00 & 0.00 & 0.9 \\
\hline 79 & 1.557533 & 0.00 & 1.55 & 0.44 & 0.00 & 0.00 & 1052 \\
\hline 80 & 3.023125 & 0.00 & 3.0 & 91 & 1.0 & 1.0 & 0.95 \\
\hline 81 & 4.508349 & 0.00 & 4.508349 & 1.505931 & 1.0 & 2.0 & 0.9762623 \\
\hline 82 & 0.00 & & & 0.00 & 1.0 & 3.0 & 1.023665 \\
\hline 83 & 0.00 & 1.0 & 1. & 0.0 & 1.0 & 4.0 & 1649 \\
\hline 84 & 2.831169 & 0.00 & 2.8 & 690 & 1.0 & 5.0 & 0.9360994 \\
\hline 85 & 9.454515 & 0.00 & 9.454515 & 2.246492 & 1.0 & 6.0 & 0.9512033 \\
\hline 86 & 1.3 & 0.00 & 1.346910 & 0.2978132 & 1.0 & 7.0 & 0.9499553 \\
\hline 87 & 5.637069 & 0.00 & 5.637069 & & 1.0 & 8.0 & 0.9287347 \\
\hline 88 & 5.007695 & 0.00 & 5.007695 & 1.610976 & 1.0 & 9.0 & 0.9290386 \\
\hline
\end{tabular}


APPENDIX J

OPERATING RATIO WITH ZERO DUMMY

(continued)

\begin{tabular}{|c|c|c|c|c|c|c|c|}
\hline o & 8.001984 & 0.00 & 8.001984 & 2.079690 & 0.00 & 0.00 & 0.9548052 \\
\hline & 7.852388 & 0.00 & 7.852388 & 2.060818 & 0.00 & 0.00 & 0.9659982 \\
\hline 2 & 13.77653 & 0.00 & 13.77653 & 2.622966 & 0.00 & 0.00 & 0.9542277 \\
\hline 73 & 10.22931 & 0.00 & 10.22931 & 2.325257 & 0.00 & 0.00 & 1.015489 \\
\hline 74 & 8.323636 & 0.00 & 8.323636 & 2.119099 & 0.00 & 0.00 & 0.9537769 \\
\hline 75 & 10.91913 & 0.00 & 10.91913 & 2.390516 & 0.00 & 0.00 & 0.9960571 \\
\hline 76 & 4.512445 & 0.00 & 4.512445 & 1.506839 & 0.00 & 0.00 & 0.9565586 \\
\hline 77 & 5.874190 & 0.00 & 5.874190 & 1.770568 & 0.00 & 0.00 & 0.9830934 \\
\hline 78 & 4.334496 & 0.00 & 4.334496 & 1.466605 & 0.00 & 0.00 & 0.9593276 \\
\hline 79 & 2.754855 & 0.00 & 2.754855 & 1.013365 & 0.00 & 0.00 & 0.9614558 \\
\hline 80 & 2.711273 & 0.00 & 2.711273 & 0.9974181 & 1.0 & 1.0 & 0.9994623 \\
\hline 81 & 9.831668 & 0.00 & 9.831668 & 2.285609 & 1.0 & 2.0 & 1.013401 \\
\hline 82 & 4.402235 & 0.00 & 4.40 & 1.482112 & 1.0 & 3.0 & 1.004983 \\
\hline 83 & 025 & 0.00 & 5.6 & 1.72 & 1.0 & 4.0 & 1.025394 \\
\hline 84 & 5.193153 & 0.00 & 5.193153 & 1.647341 & 1.0 & 5.0 & 0.9565456 \\
\hline 85 & 5.076651 & 0.00 & 5.076651 & 1.624652 & 1.0 & 6.0 & 0.9539746 \\
\hline 86 & 9.830788 & 0.00 & 9.830788 & 2.28 & 1.0 & 7.0 & 0.9856234 \\
\hline 87 & 8 & 0. & 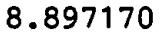 & &. & 3.0 & 959 \\
\hline 88 & 4.504444 & 0.00 & 4.504444 & 064 & 1.0 & 9.0 & 3866 \\
\hline 70 & 11.36593 & 0.00 & 11.36593 & 2.430620 & 0.00 & 0.00 & 1.073206 \\
\hline 71 & 7.411470 & 0.00 & 7.411470 & 2.003029 & 0.00 & 0.00 & 0.9880938 \\
\hline 2 & & & & & 0.00 & 0.00 & \\
\hline 73 & 3.266063 & 0.00 & 3.266063 & 1.18 & 0.00 & 0.00 & 0.9522793 \\
\hline 74 & 11.38284 & 0.00 & 11.38284 & 2.432107 & 0.00 & 0.00 & 1.010386 \\
\hline 75 & 11.71223 & 0.00 & 11.71223 & 2.460633 & 0.00 & 0.00 & 1.045252 \\
\hline 76 & 0.00 & 1.0 & 1. & 0 & 0.00 & 0.00 & 75 \\
\hline 77 & 3.2 & 0.00 & 3.2 & 1. & 0.00 & 0.00 & 97 \\
\hline 78 & 1.666647 & 0.00 & 1.666647 & 0.5108140 & 0.00 & 0.00 & 0.9801738 \\
\hline 79 & 3.337789 & 0.00 & 3.337789 & 1.205309 & 0.00 & 0.00 & 1.015234 \\
\hline 80 & 1.952096 & 0.00 & 1.952096 & 0.6689034 & 1.0 & 1.0 & 1.010865 \\
\hline 81 & & 0.0 & & & 1.0 & 2.0 & 42 \\
\hline 82 & 7.561989 & 0.00 & 7.5 & & 1.0 & 3.0 & 190 \\
\hline 83 & 12.13843 & 0.00 & 12.13843 & 2.496376 & 1.0 & 4.0 & 1.019582 \\
\hline 84 & 2.266885 & 0.00 & 2.266885 & 0.8184066 & 1.0 & 5.0 & 0.9793932 \\
\hline 85 & 2.144266 & 0.00 & 2.144266 & 0.7627974 & 1.0 & 6.0 & 1.016468 \\
\hline 86 & 6.2 & 0.0 & & & 1.0 & 7.0 & \\
\hline 87 & 3.506422 & 0.00 & 3.506422 & 1.254596 & 1.0 & 8.0 & 0.9407275 \\
\hline 88 & 1.645606 & 0.00 & 1.645606 & 0.4981085 & 1.0 & 9.0 & 0.9405159 \\
\hline
\end{tabular}


APPENDIX J

OPERATING RATIO WITH ZERO DUMMY (continued)

$\begin{array}{lrlrrrrr}70 & 11.15222 & 0.00 & 11.15222 & 2.411638 & 0.00 & 0.00 & 1.013977 \\ 71 & 10.91646 & 0.00 & 10.91646 & 2.390272 & 0.00 & 0.00 & 0.9772700 \\ 72 & 4.393113 & 0.00 & 4.393113 & 1.480038 & 0.00 & 0.00 & 0.9560165 \\ 73 & 3.302761 & 0.00 & 3.302761 & 1.194759 & 0.00 & 0.00 & 0.9226813 \\ 74 & 4.887436 & 0.00 & 4.887436 & 1.586668 & 0.00 & 0.00 & 0.9204581 \\ 75 & 6.506147 & 0.00 & 6.506147 & 1.872747 & 0.00 & 0.00 & 1.002413 \\ 76 & 1.231834 & 0.00 & 1.231834 & 0.2085037 & 0.00 & 0.00 & 0.9870916 \\ 77 & 4.708248 & 0.00 & 4.708248 & 1.549316 & 0.00 & 0.00 & 0.9728370 \\ 78 & 6.476209 & 0.00 & 6.476209 & 1.868135 & 0.00 & 0.00 & 0.9178491 \\ 79 & 1.227556 & 0.00 & 1.227556 & 0.2050249 & 0.00 & 0.00 & 1.073398 \\ 80 & 3.257690 & 0.00 & 3.257690 & 1.181018 & 1.0 & 1.0 & 1.015533 \\ 81 & 3.955837 & 0.00 & 3.955837 & 1.375192 & 1.0 & 2.0 & 1.032823 \\ 82 & 2.630862 & 0.00 & 2.630862 & 0.9673117 & 1.0 & 3.0 & 1.014857 \\ 83 & 9.602769 & 0.00 & 9.602769 & 2.262052 & 1.0 & 4.0 & 0.9711791 \\ 84 & 7.402707 & 0.00 & 7.402707 & 2.001846 & 1.0 & 5.0 & 0.9097885 \\ 85 & 2.419743 & 0.00 & 2.419743 & 0.8836614 & 1.0 & 6.0 & 1.066666 \\ 86 & 4.457436 & 0.00 & 4.457436 & 1.494574 & 1.0 & 7.0 & 1.001496 \\ 87 & 4.088518 & 0.00 & 4.088518 & 1.408183 & 1.0 & 8.0 & 0.9807680 \\ 88 & 2.496083 & 0.00 & 2.496083 & 0.9147228 & 1.0 & 9.0 & 0.9239948\end{array}$




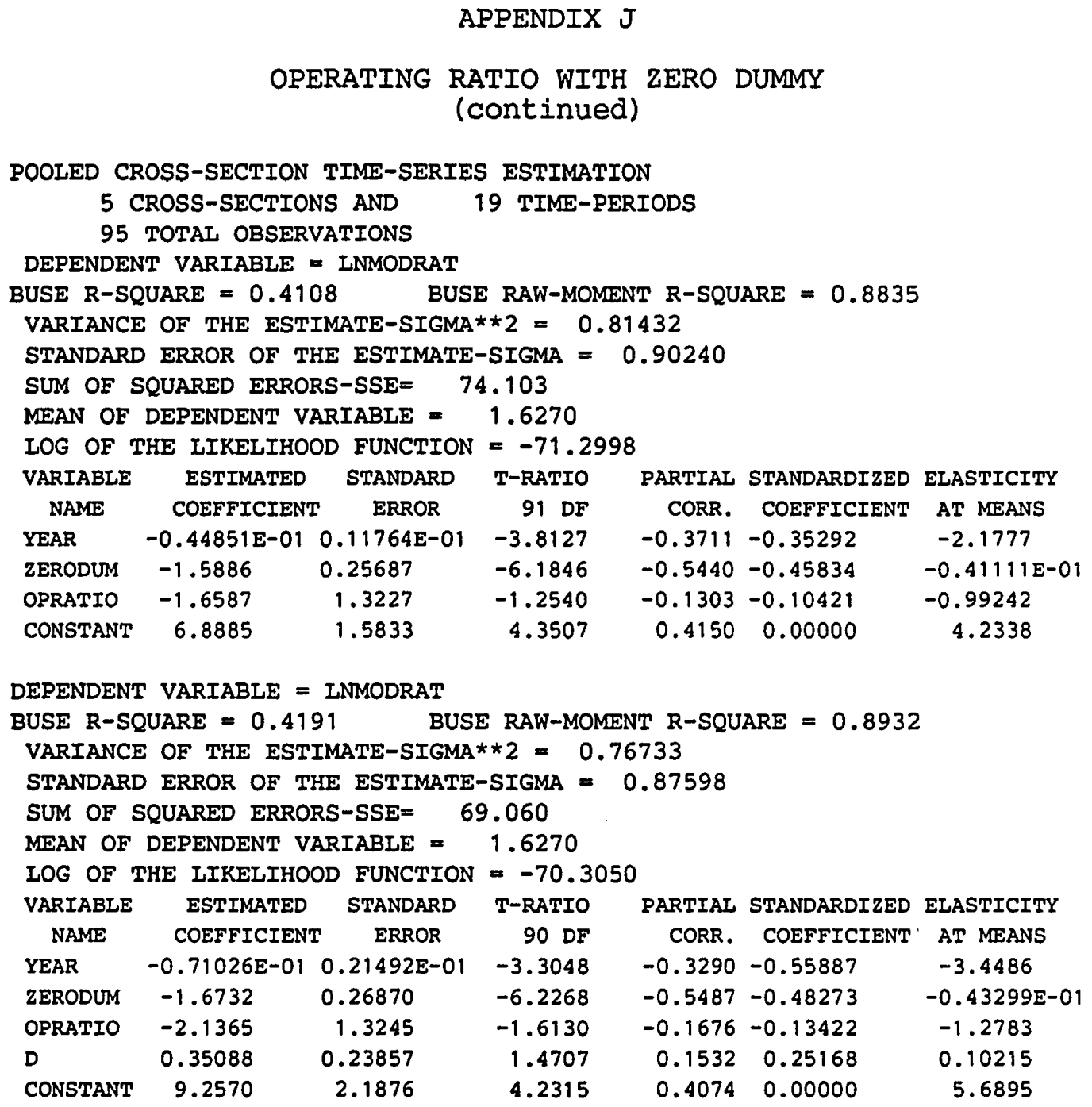




\section{APPENDIX J \\ OPERATING RATIO WITH ZERO DUMMY (continued)}

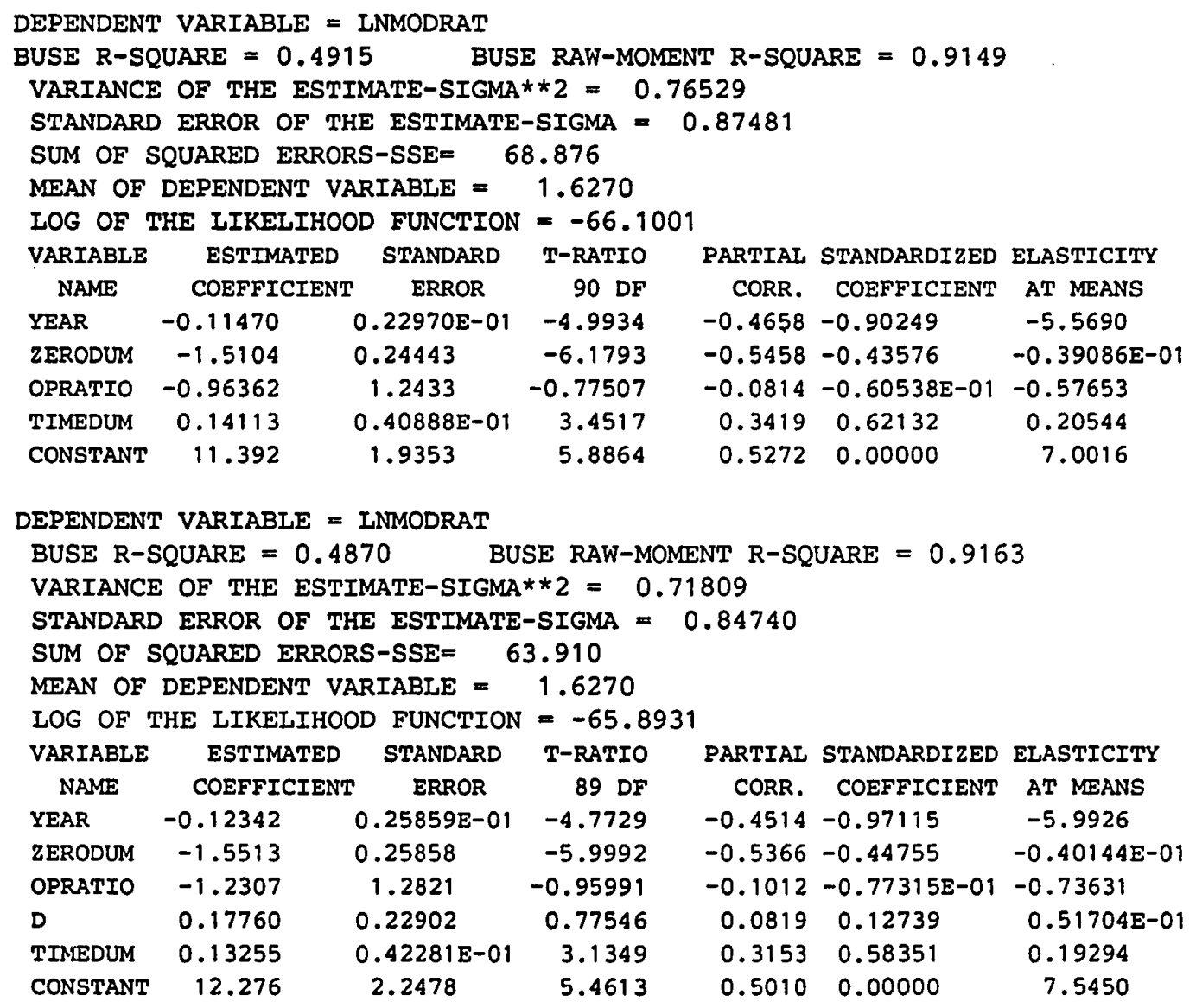

ALI VARIABLES HAVE BEEN DELETED 
APPENDIX J

OPERATING RATIO WITH ZERO DUMMY

(continued)

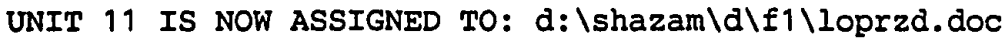

\begin{tabular}{|c|c|c|c|c|c|c|c|}
\hline & \multicolumn{2}{|c|}{9 VARIABLES AND } & \multicolumn{2}{|c|}{90 OBSERVATIONS } & \multicolumn{3}{|c|}{ STARTING AT OBS } \\
\hline & CRATE & BRODUM & MODCRATE & INMODRAT & D & TIMEDUM & AGO: \\
\hline & 5.18077 & & 15.18077 & 2.720030 & 0.00 & 0.00 & 1.013336 \\
\hline & 225574 & & 5574 & & & & כתעם \\
\hline & 10.58809 & 0.00 & 8809 & 2.359730 & 0 & 0.00 & .96 \\
\hline & 9.770125 & 0.00 & 9.770125 & 329 & 0.00 & 0.00 & 1.024519 \\
\hline & 9.524959 & 0.1 & 524959 & 916 & 0.00 & 0.00 & 608 \\
\hline & 4.572 & 0. & 4 & & & & 1.0 \\
\hline & 5.9 & 0.00 & & & & 0.00 & 233 \\
\hline 8 & 5.8 & 0.00 & 799 & & 0.00 & 0.00 & 0.97 \\
\hline & 5.3 & $0.1-1-10$ & 396 & & 10 & 0.00 & 798 \\
\hline & & & & & & 0 & \\
\hline 1 & 4.9 & 0.00 & $4 \cdot:$ & & 0 & 2.0 & 1. \\
\hline 2 & 4.8 & 0.00 & & & .0 & 3.0 & 0.5 \\
\hline 3 & & & & & .0 & 4.0 & \\
\hline & & & & & & & \\
\hline 5 & 10. & 0.1 & 10 & & .0 & 6.0 & 0. \\
\hline 6 & 4.2 & 0.0 & & & 1.0 & 7.0 & 0. \\
\hline & & & & & & 8.0 & \\
\hline 38 & 6 & & & & .0 & U & \\
\hline 71 & 9.2 & 0. & 0 & & 0.00 & 0.00 & 82 \\
\hline 72 & 16. & 0.0 & 5 & & 0.00 & 0.00 & 0.9 \\
\hline & & & & & 0 & 0 & \\
\hline & & & & & & & \\
\hline 15 & 11. & 0. & & & 00 & 0.00 & $0.8-1-1-1$ \\
\hline 6 & 7.46 & 0.0 & 7.4 & 2. & 0.00 & 0.00 & 0.9 \\
\hline 77 & 5.3 & 0.0 & & & .00 & 0.00 & 0. \\
\hline & 6 & & & & & & \\
\hline 19 & & 0 . & & & & 0.00 & \\
\hline 80 & 3.0 & 0.0 & 3.0 & & .0 & 1.0 & 0.5 \\
\hline 81 & 4.5 & 0.00 & 4.5 & 1 & .0 & 2.0 & 776 \\
\hline 32 & 0.00 & & & & 0 & .0 & 623 \\
\hline 3 & & & & & & & \\
\hline 84 & & 0. & & & 1.0 & 5.0 & \\
\hline 85 & 9.4 & 0. & 9. & $2 .:$ & 1.0 & 6.0 & 0.93 \\
\hline 86 & 1.3 & 0.0 & 1.346910 & 0.2978132 & 1.0 & 7.0 & 0.9512033 \\
\hline & & & & & 1.0 & 8.0 & \\
\hline & 5.0 & 0.00 & 95 & 1.610976 & 1.0 & 9.0 & 0.9287347 \\
\hline
\end{tabular}


APPENDIX J

OPERATING RATIO WITH ZERO DUMMY

(continued)

\begin{tabular}{|c|c|c|c|c|c|c|c|}
\hline 11 & 7.852388 & 0.00 & 7.852388 & 2.060818 & 0.00 & 0.00 & 0.9548052 \\
\hline & 13.77653 & 0.00 & 13.77653 & 2.622966 & 0.00 & 0.00 & .9659982 \\
\hline 73 & 10.22931 & 0.00 & 10.22931 & 2.325257 & 0.00 & 0.00 & .9542277 \\
\hline 74 & 8.323636 & 0.00 & 8.323636 & 2.119099 & 0.00 & 0.00 & 1.015489 \\
\hline 75 & 10.91913 & 0.00 & 10.91913 & 2.390516 & 0.00 & 0.00 & 0.9537769 \\
\hline 6 & 4.512445 & 0 & 4.512445 & 1.506839 & 0.00 & 0.00 & 0.9960571 \\
\hline 77 & 5.874190 & 0.00 & 5.874190 & 1.770568 & 0 & & 0.9565586 \\
\hline 78 & 4.334496 & 0.00 & 4.334496 & 1.466605 & 0.00 & 0.00 & 0.9830934 \\
\hline 79 & 2.754855 & 0.00 & 2.754855 & 1.013365 & 0.00 & 0.00 & 0.9593276 \\
\hline 80 & 2.711273 & 0.00 & 2.711273 & 0.9974 & 1.0 & 1.0 & 0.9614558 \\
\hline 81 & 9.831668 & 0.00 & 9.831668 & 2.285609 & 1.0 & 2.0 & 0.9994623 \\
\hline 82 & 4.402235 & 0.00 & 4.402235 & 1.482112 & 1.0 & 3.0 & 1.013401 \\
\hline 83 & 3025 & 0.00 & 5.618025 & 1.725980 & 1.0 & 4.0 & 1.004983 \\
\hline 4 & 53 & 0. & 3 & 1 & 1.0 & 5.0 & 394 \\
\hline 5 & 5.076651 & 0.0 & 51 & 1.62 & 1.0 & 6.0 & 0.95 \\
\hline 86 & 9.830788 & 0.00 & 9.830788 & 2.285519 & 1.0 & 7.0 & 0.9539746 \\
\hline 87 & 8.897170 & 0.00 & 8.897170 & 5733 & 1.0 & 8.0 & 0.9856234 \\
\hline 88 & 44 & 0. & & & 1.0 & 9.0 & 0.9869959 \\
\hline 71 & 7.411470 & 0.00 & .411470 & 2.0 & 0.00 & 0.00 & \\
\hline 72 & 11.86926 & 0.00 & 11.86926 & 2.473952 & 0.00 & 0.00 & 0.9880938 \\
\hline 73 & 3.2 & 0.00 & 3.266063 & 1.183585 & 0.00 & 0.00 & 0.9470673 \\
\hline 74 & & 0. & & & & 0.00 & 2793 \\
\hline 75 & 11.71223 & 0.00 & 11.7 & 2.460633 & 0.00 & & 1.0 \\
\hline 76 & 0.0000000 & 1.0 & 1.000000 & 0.0000000 & 0.00 & 0.00 & 1.045252 \\
\hline 77 & 3.240000 & 0.00 & 3.240000 & 1.175573 & 0.00 & 0.00 & 0.9738675 \\
\hline 78 & & 0 & & & 0.00 & 0.00 & 0.9816897 \\
\hline 79 & 3.33 & 0.00 & 3.3 & 1. & 0.00 & & \\
\hline 80 & 1.952096 & 0.00 & 1.952096 & 0.6689034 & 1.0 & 1.0 & 1.015234 \\
\hline 81 & 2.314531 & 0.00 & 2.314531 & 0.8392070 & 1.0 & 2.0 & 1.010865 \\
\hline 82 & 7.561989 & 0.00 & 7.561989 & 2.023134 & 1.0 & 3.0 & 0.9988842 \\
\hline 83 & & 0 & & & .0 & 4.0 & 1.032190 \\
\hline 84 & 2.26 & 0.0 & 2.2 & 0.8 & 1.0 & 5.0 & 1.019582 \\
\hline 85 & 2.144266 & 0.00 & 2.144266 & 0.7627974 & 1.0 & 6.0 & 0.9793932 \\
\hline 86 & 6.270326 & 0.00 & 6.270326 & 1.835828 & 1.0 & 7.0 & 1.016468 \\
\hline 87 & & & & & 1.0 & 8.0 & 1.023801 \\
\hline 88 & 1.645606 & 0.00 & 1.645606 & . 4981085 & 1.0 & 9.0 & 0.940727 \\
\hline
\end{tabular}


APPENDIX J

OPERATING RATIO WITH ZERO DUMMY

(continued)

$\begin{array}{lrllrllr}71 & 10.91646 & 0.00 & 10.91646 & 2.390272 & 0.00 & 0.00 & 1.013977 \\ 72 & 4.393113 & 0.00 & 4.393113 & 1.480038 & 0.00 & 0.00 & 0.9772700 \\ 73 & 3.302761 & 0.00 & 3.302761 & 1.194759 & 0.00 & 0.00 & 0.9560165 \\ 74 & 4.887436 & 0.00 & 4.887436 & 1.586668 & 0.00 & 0.00 & 0.9226813 \\ 75 & 6.506147 & 0.00 & 6.506147 & 1.872747 & 0.00 & 0.00 & 0.9204581 \\ 76 & 1.231834 & 0.00 & 1.231834 & 0.2085037 & 0.00 & 0.00 & 1.002413 \\ 77 & 4.708248 & 0.00 & 4.708248 & 1.549316 & 0.00 & 0.00 & 0.9870916 \\ 78 & 6.476209 & 0.00 & 6.476209 & 1.868135 & 0.00 & 0.00 & 0.9728370 \\ 79 & 1.227556 & 0.00 & 1.227556 & 0.2050249 & 0.00 & 0.00 & 0.9178491 \\ 80 & 3.257690 & 0.00 & 3.257690 & 1.181018 & 1.0 & 1.0 & 1.073398 \\ 81 & 3.955837 & 0.00 & 3.955837 & 1.375192 & 1.0 & 2.0 & 1.015533 \\ 82 & 2.630862 & 0.00 & 2.630862 & 0.9673117 & 1.0 & 3.0 & 1.032823 \\ 83 & 9.602769 & 0.00 & 9.602769 & 2.262052 & 1.0 & 4.0 & 1.014857 \\ 84 & 7.402707 & 0.00 & 7.402707 & 2.001846 & 1.0 & 5.0 & 0.9711791 \\ 85 & 2.419743 & 0.00 & 2.419743 & 0.8836614 & 1.0 & 6.0 & 0.9097885 \\ 86 & 4.457436 & 0.00 & 4.457436 & 1.494574 & 1.0 & 7.0 & 1.066666 \\ 87 & 4.088518 & 0.00 & 4.088518 & 1.408183 & 1.0 & 8.0 & 1.001496 \\ 88 & 2.496083 & 0.00 & 2.496083 & 0.9147228 & 1.0 & 9.0 & 0.9807680\end{array}$




\section{APPENDIX J}

\section{OPERATING RATIO WITH ZERO DUMMY (continued)}

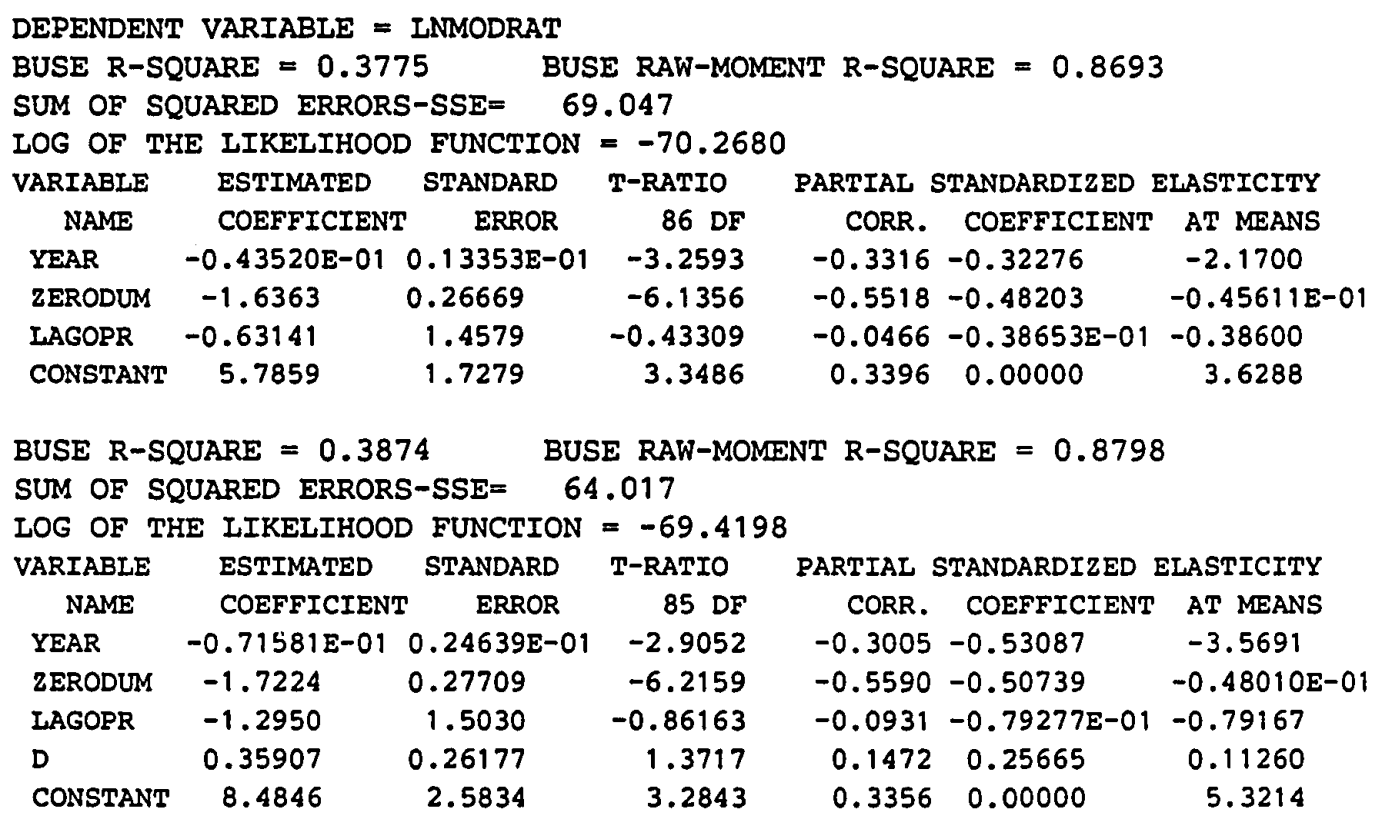


APPENDIX $\mathrm{K}$

CUSUM TEST 


\section{APPENDIX K \\ CUSUM TEST \\ COMMAND FILE}

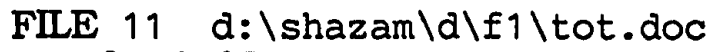

sample 125

read(11) year d totocc y $\mathrm{n} u$ hours

* generate controlable rate

genr crate $=((1000000 * y)) /$ hours

* generate log of the controlable rate genr Incrate $=\log$ (crate)

* generate time since deregulation dummy genr timedum $=d *$ (year - 79)

print $y$ hours crate Incrate year

ols lncrate year

lexactdw

diagnos / recur siglevel=1

ols Incrate year

lexactdw

diagnos / recur siglevel=5

ols Incrate year

lexactow

diagnos / recur siglevel=10

delete / all 
APPENDIX $\mathrm{K}$

CUSUM TEST

(continued)

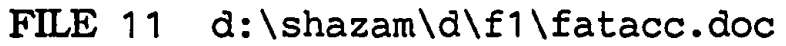
sample 127

read(11) year fatal acc hours

* generate accident rate

genr accrate $=(1000000 *$ acc $) /$ hours

* generate log of the accident rate

genr Inaccrat $=\log$ (accrate)

* generate deregulation dummy

genr $d=$ dum (year -79.9 )

genr timedum $=d^{*}($ year -79$)$

print year acc accrate Inaccrat hours

ols Inaccrat year

lexactdw

diagnos / recur siglevel=1

ols lnaccrat year

diagnos / recur siglevel=5

lexactdw

ols Inaccrat year

lexactdw

diagnos / recur siglevel=10

delete / all 


\section{APPENDIX $K$ \\ CUSUM TEST \\ (continued) \\ OUTPUT FILE}

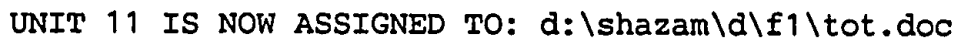

7 VARIABLES AND

$Y$

64.00000

45.00000

45.00000

48.00000

43.00000

44.00000

44.00000

48.00000

40.00000

30.00000

34.00000

36.00000

14.00000

20.00000

20.00000

14.00000

9.000000

27.00000

15.00000

32.00000

24.00000

25.00000

26.00000

36.00000

33.00000
25 OBSERVATIONS STARTING AT OBS

HOURS
2441185.
2691129.
2819170.
3507054.
4015838.
4336713.
4294706.
4224634
4204233
4346571
3997587
3936489.
4024069.
4135728.
4166439.
4329449.
4439343.
4049954.
4016962.
4197657.
4547810.
4744502.
5389885.
6921046.
7166746.

HOURS

CRATE

26.21678

16.72161

15.96214

13.68670

10.70760

10.14593

10.24517

11.36193

9.514221

6.901992

8.505131

9.145205

3.479066

4.835908

4.800262

3.233668

2.027327

6.666742

3.734165

7.623300

5.277265

5.269257

4.823851

5.201526

4.604600
1

YEAR

64.00000

65.00000

66.00000

67.00000

68.00000

69.00000

70.00000

71.00000

72.00000

73.00000

74.00000

75.00000

76.00000

77.00000

78.00000

79.00000

80.00000

81.00000

82.00000

83.00000

84.00000

85.00000

86.00000

87.00000

88.00000 


\section{APPENDIX $\mathrm{K}$}

CUSUM TEST

(continued)

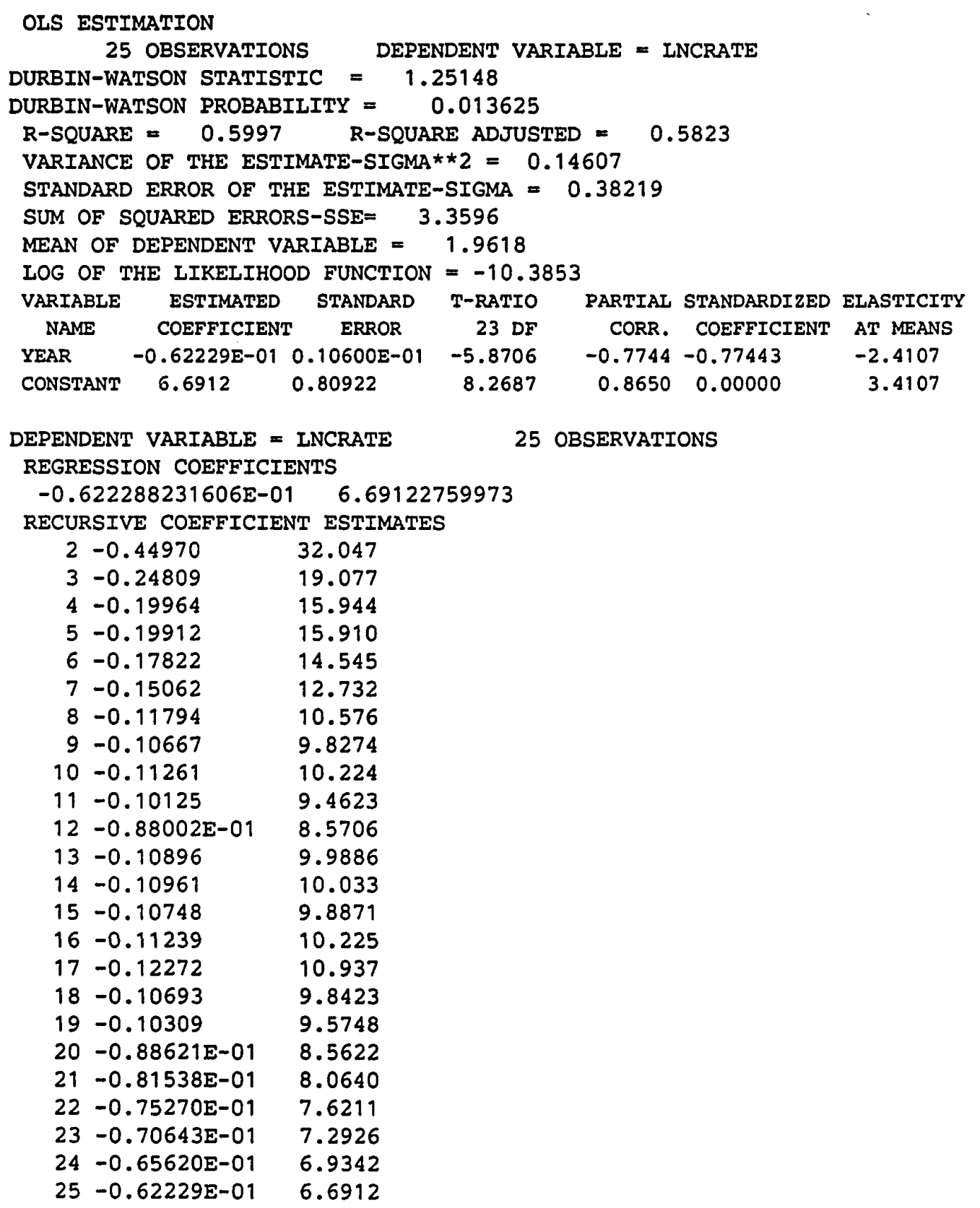




\section{APPENDIX K \\ CUSUM TEST \\ (continued)}

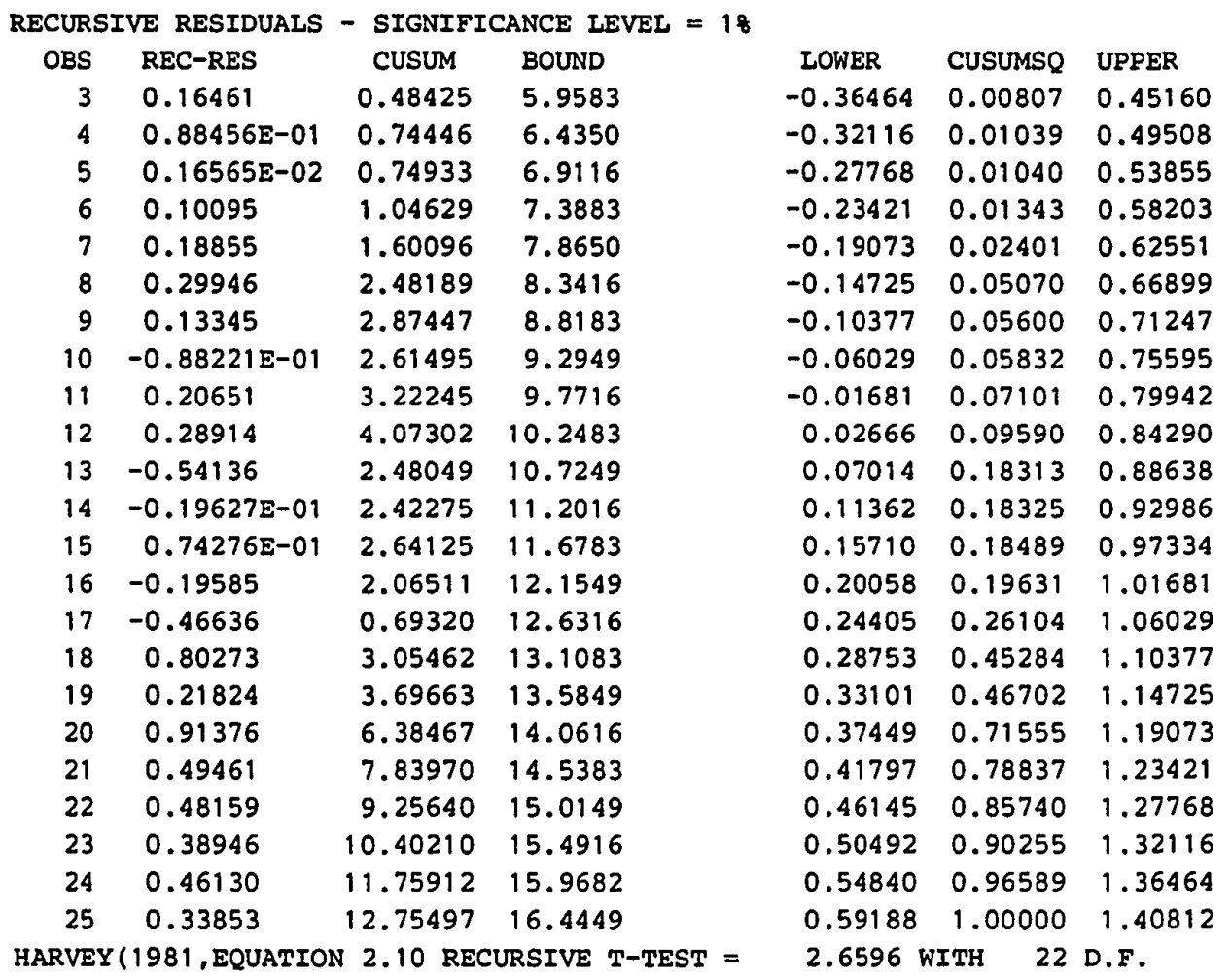

HARVEY $(1981$, EQUATION 2.12 HETEROSKEDASTICITY TEST $=9.7699$ WITH $\mathrm{M}=$ 


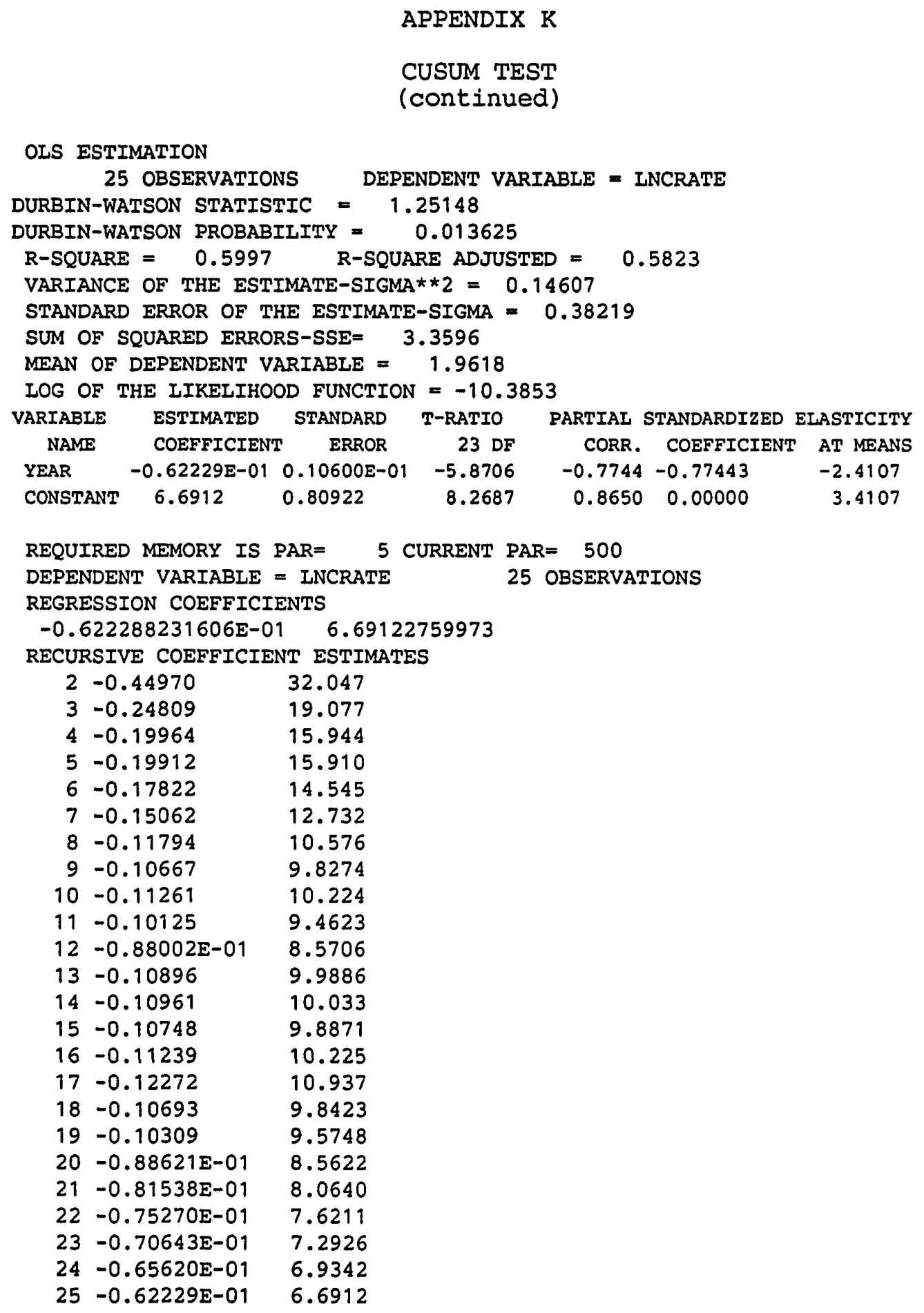


APPENDIX K

CUSUM TEST

(continued)

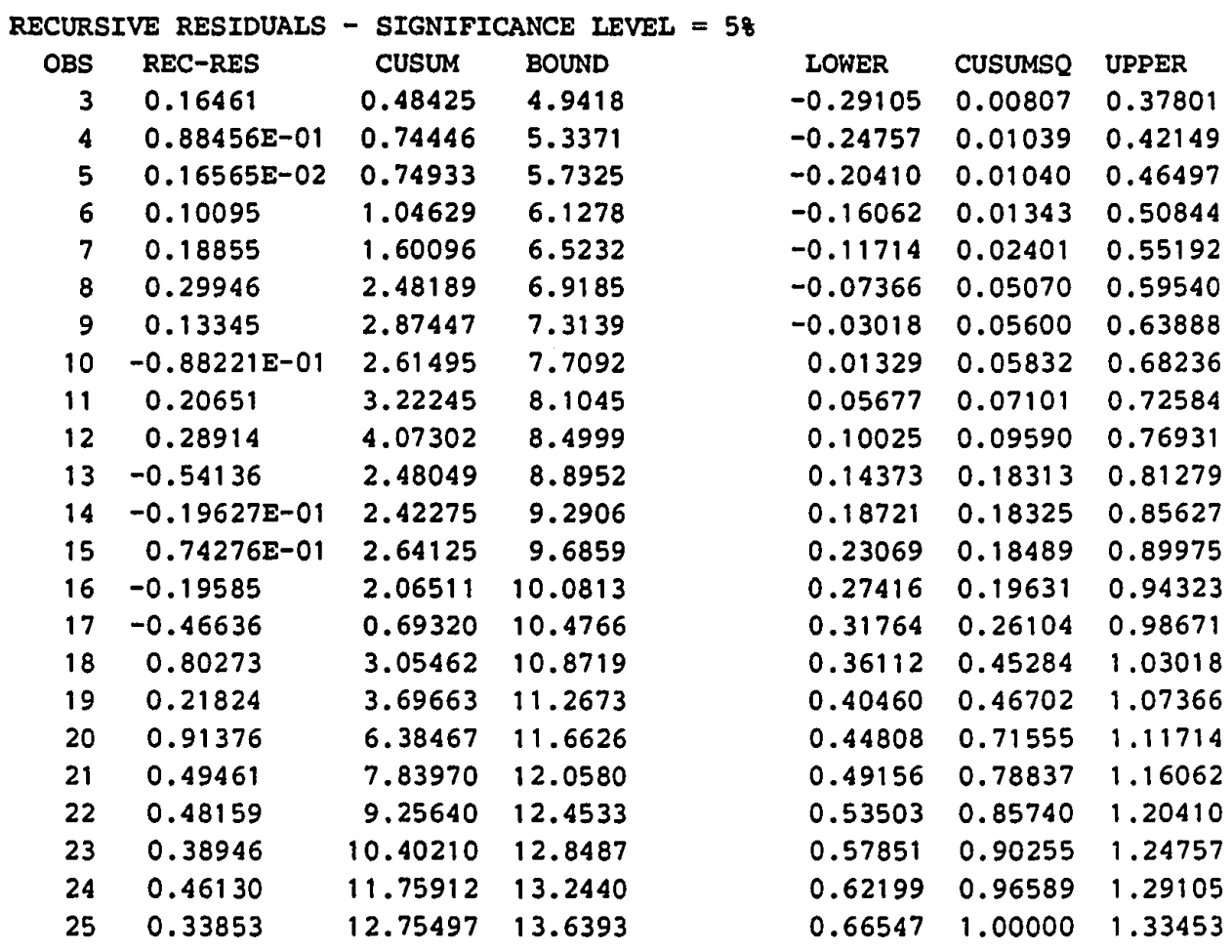

HARVEY (1981, EQUATION 2.10 RECURSIVE T-TEST $=2.6596$ WITH 22 D.F.

HARVEY $(1981$,EQUATION 2.12 HETEROSKEDASTICITY TEST $=9.7699$ WITH M $=7$ 


\section{APPENDIX $\mathrm{K}$ \\ CUSUM TEST \\ (continued)}

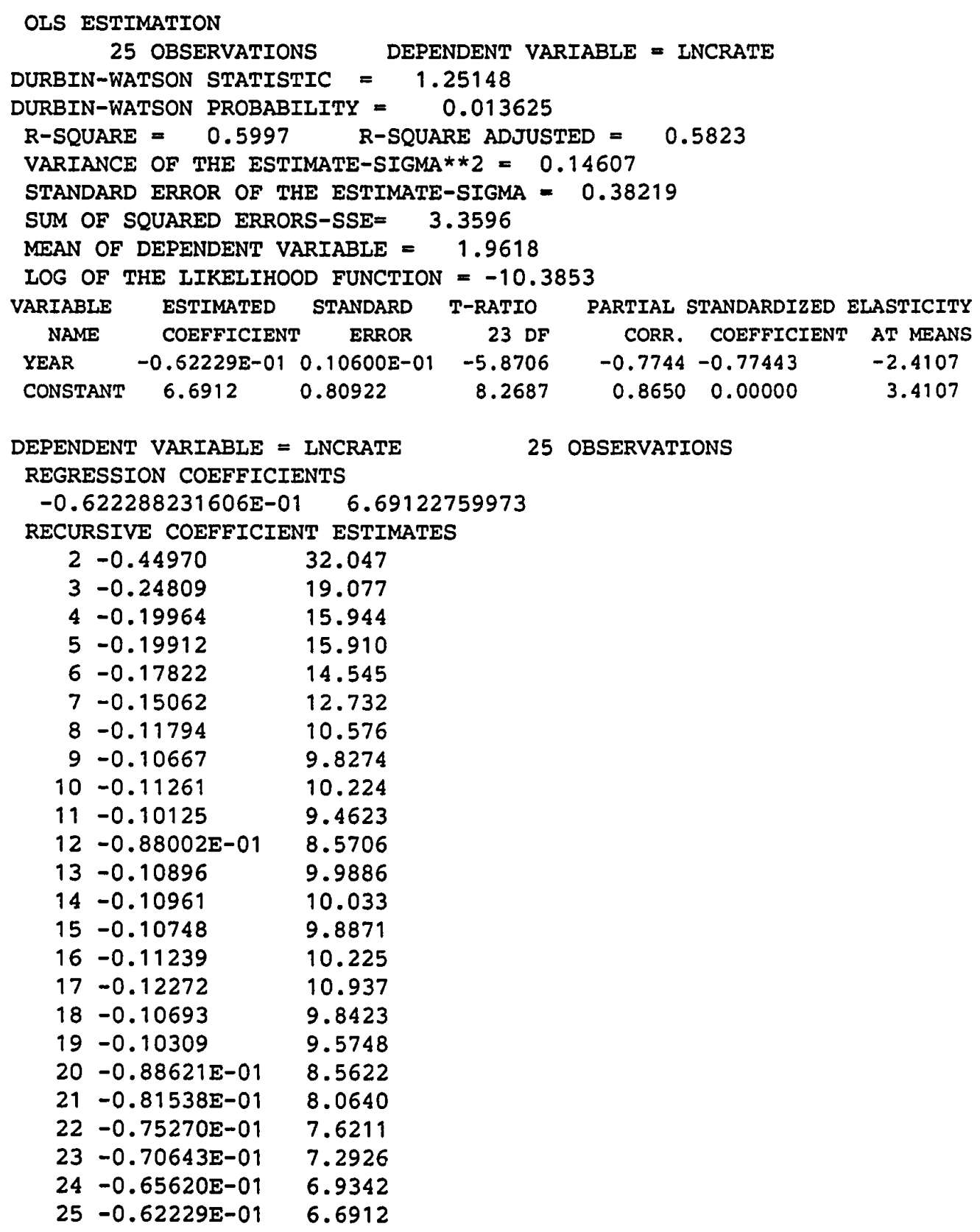




\section{APPENDIX $\mathrm{K}$}

CUSUM TEST

(continued)

RECURSIVE RESIDUALS - SIGNIFICANCE LEVEL $=10 \%$

$\begin{array}{rlllllll}\text { OBS } & \text { REC-RES } & \text { CUSUM } & \text { BOUND } & \text { LOWER } & \text { CUSUMSQ } & \text { UPPER } \\ 3 & 0.16461 & 0.48425 & 4.4309 & -0.25375 & 0.00807 & 0.34071 \\ 4 & 0.88456 E-01 & 0.74446 & 4.7854 & -0.21027 & 0.01039 & 0.38419 \\ 5 & 0.16565 E-02 & 0.74933 & 5.1399 & -0.16680 & 0.01040 & 0.42767 \\ 6 & 0.10095 & 1.04629 & 5.4944 & -0.12332 & 0.01343 & 0.47114 \\ 7 & 0.18855 & 1.60096 & 5.8488 & -0.07984 & 0.02401 & 0.51462 \\ 8 & 0.29946 & 2.48189 & 6.2033 & -0.03636 & 0.05070 & 0.55810 \\ 9 & 0.13345 & 2.87447 & 6.5578 & 0.00712 & 0.05600 & 0.60158 \\ 10 & -0.88221 E-01 & 2.61495 & 6.9123 & 0.05060 & 0.05832 & 0.64506 \\ 11 & 0.20651 & 3.22245 & 7.2667 & 0.09407 & 0.07101 & 0.68853 \\ 12 & 0.28914 & 4.07302 & 7.6212 & 0.13755 & 0.09590 & 0.73201 \\ 13 & -0.54136 & 2.48049 & 7.9757 & 0.18103 & 0.18313 & 0.77549 \\ 14 & -0.19627 E-01 & 2.42275 & 8.3302 & 0.22451 & 0.18325 & 0.81897 \\ 15 & 0.74276 E-01 & 2.64125 & 8.6846 & 0.26799 & 0.18489 & 0.86245 \\ 16 & -0.19585 & 2.06511 & 9.0391 & 0.31147 & 0.19631 & 0.90593 \\ 17 & -0.46636 & 0.69320 & 9.3936 & 0.35494 & 0.26104 & 0.94940 \\ 18 & 0.80273 & 3.05462 & 9.7480 & 0.39842 & 0.45284 & 0.99288 \\ 19 & 0.21824 & 3.69663 & 10.1025 & 0.44190 & 0.46702 & 1.03636 \\ 20 & 0.91376 & 6.38467 & 10.4570 & 0.48538 & 0.71555 & 1.07984 \\ 21 & 0.49461 & 7.83970 & 10.8115 & 0.52886 & 0.78837 & 1.12332 \\ 22 & 0.48159 & 9.25640 & 11.1659 & 0.57233 & 0.85740 & 1.16680 \\ 23 & 0.38946 & 10.40210 & 11.5204 & 0.61581 & 0.90255 & 1.21027 \\ 24 & 0.46130 & 11.75912 & 11.8749 & 0.65929 & 0.96589 & 1.25375 \\ 25 & 0.33853 & 12.75497 & 12.2294 & 0.70277 & 1.00000 & 1.29723 \\ \text { HARVEY } 1981 . E Q U A T I O N & 2.10 \mathrm{RECURSIVE} \mathrm{T-TEST}= & 2.6596 & \text { WITH } & 22 & D . F .\end{array}$

HARVEY (1981, EOUATION 2.12 HETEROSKEDASTICITY TEST $=9.7699$ WITH $M=$

ALI VARIABLES HAVE BEEN DELETED 


\section{APPENDIX K \\ CUSUM TEST \\ (continued)}

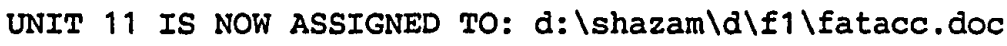

4 VARIABLES AND YEAR

61.00000

62.00000

63.00000

64.00000

65.00000

66.00000

67.00000

68.00000

69.00000

70.00000

71.00000

72.00000

73.00000

74.00000

75.00000

76.00000

77.00000

78.00000

79.00000

80.00000

81.00000

82.00000

83.00000

84.00000

85.00000

86.00000

87.00000
27 OBSERVATIONS STARTING AT OBS ACC ACCRATE INACCRAT
1

HOURS

$\begin{array}{llll}66.00000 & 18.05991 & 2.893695 & 3654503 . \\ 47.00000 & 13.46252 & 2.599910 & 3491174 . \\ 54.00000 & 14.98240 & 2.706876 & 3604228 . \\ 59.00000 & 15.63009 & 2.749198 & 3774771 . \\ 65.00000 & 15.96272 & 2.770256 & 4071987 . \\ 56.00000 & 13.22944 & 2.582445 & 4232982 . \\ 54.00000 & 10.96652 & 2.394847 & 4924080 . \\ 56.00000 & 10.14138 & 2.316624 & 5521931 . \\ 51.00000 & 8.655431 & 2.158187 & 5892254 . \\ 43.00000 & 7.438799 & 2.006709 & 5780503 . \\ 43.00000 & 7.535571 & 2.019635 & 5706270 . \\ 46.00000 & 8.127948 & 2.095308 & 5659485 . \\ 36.00000 & 6.103169 & 1.808808 & 5898575 . \\ 43.00000 & 7.854606 & 2.061100 & 5474495 . \\ 30.00000 & 5.532335 & 1.710610 & 5422665 . \\ 22.00000 & 3.937289 & 1.370492 & 5587601 . \\ 20.00000 & 3.447775 & 1.237729 & 5800843 . \\ 20.00000 & 3.315791 & 1.198696 & 6031743 . \\ 23.00000 & 3.432671 & 1.233339 & 6700322 . \\ 15.00000 & 2.206668 & 0.7914838 & 6797578 . \\ 25.00000 & 3.804429 & 1.336166 & 6571288 . \\ 15.00000 & 2.329134 & 0.8454964 & 6440163 . \\ 22.00000 & 3.308764 & 1.196575 & 6649009 . \\ 12.00000 & 1.613229 & 0.4782378 & 7438497 . \\ 17.00000 & 2.139055 & 0.7603641 & 7947435 . \\ 20.00000 & 2.137459 & 0.7596176 & 9356906 . \\ 30.00000 & 3.089280 & 1.127938 & 9711000 . \\ & & & \end{array}$




\section{APPENDIX $K$}

CUSUM TEST

(continued)

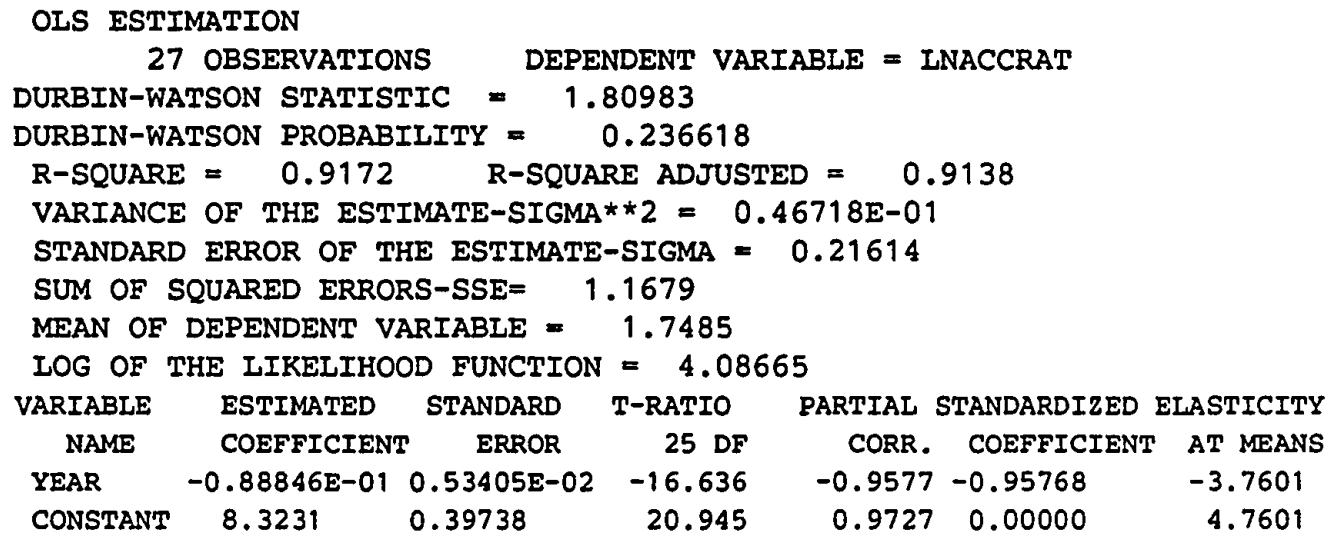


APPENDIX $\mathrm{K}$

CUSUM TEST

(continued)

\begin{tabular}{|c|c|c|c|c|c|c|}
\hline OBS & REC-RES & CUSUM & BOUND & LOWER & CUSUMSQ & UPPER \\
\hline 3 & 0.16361 & 0.74166 & 6.1722 & -0.35471 & 0.02292 & 0.43471 \\
\hline 4 & 0.11093 & 1.24450 & 6.6294 & -0.31471 & 0.03345 & 0.47471 \\
\hline 5 & $0.72396 \mathrm{E}-01$ & 1.57268 & 7.0866 & -0.27471 & 0.03794 & 0.51471 \\
\hline 6 & $-0.91272 E-01$ & 1.15893 & 7.5438 & -0.23471 & 0.04507 & 0.55471 \\
\hline 7 & -0.16243 & 0.42259 & 8.0010 & -0.19471 & 0.06766 & 0.59471 \\
\hline 8 & -0.11050 & -0.07833 & 8.4582 & -0.15471 & 0.07812 & 0.63471 \\
\hline 9 & -0.14068 & -0.71606 & 8.9154 & -0.11471 & 0.09506 & 0.67471 \\
\hline 10 & -0.15054 & -1.39848 & 9.3726 & -0.07471 & 0.11447 & 0.71471 \\
\hline 11 & $-0.18445 E-01$ & -1.48209 & 9.8298 & -0.03471 & 0.11476 & 0.75471 \\
\hline 12 & 0.12427 & -0.91877 & 10.2870 & 0.00529 & 0.12798 & 0.79471 \\
\hline 13 & $-0.85418 \mathrm{E}-01$ & -1.30599 & 10.7442 & 0.04529 & 0.13423 & 0.83471 \\
\hline 14 & 0.22815 & -0.27176 & 11.2014 & 0.08529 & 0.17879 & 0.87471 \\
\hline 15 & $-0.66407 E-01$ & -0.57279 & 11.6586 & 0.12529 & 0.18257 & 0.91471 \\
\hline 16 & -0.27981 & -1.84121 & 12.1158 & 0.16529 & 0.24960 & 0.95471 \\
\hline 17 & -0.25868 & -3.01387 & 12.5730 & 0.20529 & 0.30690 & 0.99471 \\
\hline 18 & -0.15685 & -3.72488 & 13.0302 & 0.24529 & 0.32796 & 1.03471 \\
\hline 19 & $-0.88801 E-02$ & -3.76514 & 13.4874 & 0.28529 & 0.32803 & 1.07471 \\
\hline 20 & -0.31974 & -5.21456 & 13.9446 & 0.32529 & 0.41556 & 1.11471 \\
\hline 21 & 0.32351 & -3.74803 & 14.4018 & 0.36529 & 0.50517 & 1.15471 \\
\hline 22 & $-0.92331 \mathrm{E}-01$ & -4.16658 & 14.8590 & 0.40529 & 0.51247 & 1.19471 \\
\hline 23 & 0.33308 & -2.65665 & 15.3162 & 0.44529 & 0.60746 & 1.23471 \\
\hline 24 & -0.29428 & -3.99065 & 15.7734 & 0.48529 & 0.68161 & 1.27471 \\
\hline 25 & $0.99762 \mathrm{E}-01$ & -3.53841 & 16.2306 & 0.52529 & 0.69013 & 1.31471 \\
\hline 26 & 0.17248 & -2.75655 & 16.6878 & 0.56529 & 0.71560 & 1.35471 \\
\hline 27 & 0.57633 & -0.14393 & 17.1450 & 0.60529 & 1.00000 & 1.39471 \\
\hline
\end{tabular}

HARVEY (1981, EQUATION 2.10 RECURSIVE T-TEST $=-0.0288 \mathrm{WITH} 24$ D.F.

HARVEY (1981, EQUATION 2.12 HETEROSKEDASTICITY TEST $=5.8704$ WITH M $=$ 


\section{APPENDIX $\mathrm{K}$}

CUSUM TEST

(continued)

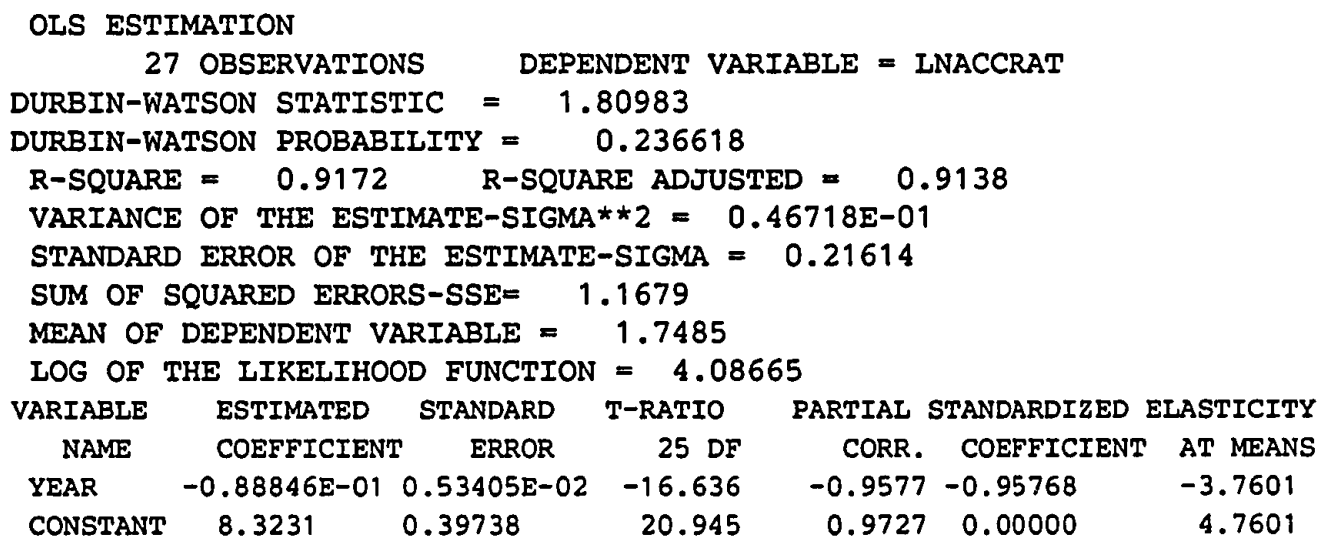


APPENDIX K

CUSUM TEST

(continued)

\begin{tabular}{|c|c|c|c|c|c|c|}
\hline OBS & REC-RES & CUSUM & BOUND & LOWER & CUSUMSQ & UPPER \\
\hline 3 & 0.16361 & 0.74166 & 5.1192 & -0.28368 & 0.02292 & 0.36368 \\
\hline 4 & 0.11093 & 1.24450 & 5.4984 & -0.24368 & 0.03345 & 0.40368 \\
\hline 5 & $0.72396 \mathrm{E}-01$ & 1.57268 & 5.8776 & -0.20368 & 0.03794 & 0.44368 \\
\hline 6 & $-0.91272 E-01$ & 1.15893 & 6.2568 & -0.16368 & 0.04507 & 0.48368 \\
\hline 7 & -0.16243 & 0.42259 & 6.6360 & -0.12368 & 0.06766 & 0.52368 \\
\hline 8 & -0.11050 & -0.07833 & 7.0152 & -0.08368 & 0.07812 & 0.56368 \\
\hline 9 & -0.14068 & -0.71606 & 7.3944 & -0.04368 & 0.09506 & 0.60368 \\
\hline 10 & -0.15054 & -1.39848 & 7.7736 & -0.00368 & 0.11447 & 0.64368 \\
\hline 11 & $-0.18445 \mathrm{E}-01$ & -1.48209 & 8.1528 & 0.03632 & 0.11476 & 0.68368 \\
\hline 12 & 0.12427 & -0.91877 & 8.5320 & 0.07632 & 0.12798 & 0.72368 \\
\hline 13 & $-0.85418 E-01$ & -1.30599 & 8.9112 & 0.11632 & 0.13423 & 0.76368 \\
\hline 14 & 0.22815 & -0.27176 & 9.2904 & 0.15632 & 0.17879 & 0.80368 \\
\hline 15 & $-0.66407 \mathrm{E}-01$ & -0.57279 & 9.6696 & 0.19632 & 0.18257 & 0.84368 \\
\hline 16 & -0.27981 & -1.84121 & 10.0488 & 0.23632 & 0.24960 & 0.88368 \\
\hline 17 & -0.25868 & -3.01387 & 10.4280 & 0.27632 & 0.30690 & 0.92368 \\
\hline 18 & -0.15685 & -3.72488 & 10.8072 & 0.31632 & 0.32796 & 0.96368 \\
\hline 19 & $-0.88801 \mathrm{E}-02$ & -3.76514 & 11.1864 & 0.35632 & 0.32803 & 1.00368 \\
\hline 20 & -0.31974 & -5.21456 & 11.5656 & 0.39632 & 0.41556 & 1.04368 \\
\hline 21 & 0.32351 & -3.74803 & 11.9448 & 0.43632 & 0.50517 & 1.08368 \\
\hline 22 & $-0.92331 E-01$ & -4.16658 & 12.3240 & 0.47632 & 0.51247 & 1.12368 \\
\hline 23 & 0.33308 & -2.65665 & 12.7032 & 0.51632 & 0.60746 & 1.16368 \\
\hline 24 & -0.29428 & -3.99065 & 13.0824 & 0.55632 & 0.68161 & 1.20368 \\
\hline 25 & $0.99762 \mathrm{E}-01$ & -3.53841 & 13.4616 & 0.59632 & 0.69013 & 1.24368 \\
\hline 26 & 0.17248 & -2.75655 & 13.8408 & 0.63632 & 0.71560 & 1.28368 \\
\hline 27 & 0.57633 & -0.14393 & 14.2200 & 0.67632 & 1.00000 & 1.32368 \\
\hline VEY & 981, EQUA & N $2.10 \mathrm{REC}$ & RSIVE T-TEST = & -0.0288 & 24 & .F. \\
\hline
\end{tabular}

HARVEY (1981, EOUATION 2.12 HETEROSKEDASTICITY TEST $=5.8704$ WITH M 
APPENDIX $K$

CUSUM TEST

(continued) .

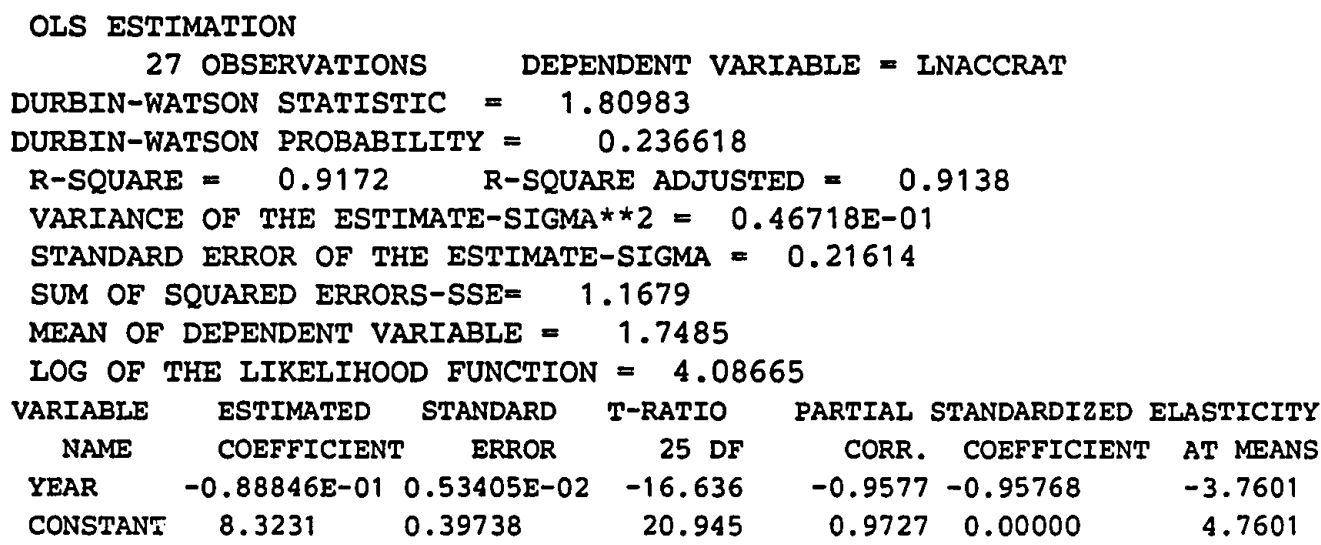

REQUIRED MEMORY IS PAR $=6$ CURRENT PAR $=500$

DEPENDENT VARIABLE = LNACCRAT 27 OBSERVATIONS

REGRESSION COEFFICIENTS

$-0.888459968996 \mathrm{E}-01 \quad 8.32313497880$

RECURSIVE COEFFICIENT ESTIMATES
$2-0.29379$
20.815
$3-0.93409 E-01$
8.5249
$4-0.32652 \mathrm{E}-01$
4.7782
$5-0.97589 E-02$
3.3588
$6-0.28654 \mathrm{E}-01$
4.5366
$7-0.52432 \mathrm{E}-01$
6.0267
$8-0.64489 \mathrm{E}-01$
6.7862
$9-0.76378 E-01$
7.5393
$10-0.86528 E-01$
8.1854
$11-0.87543 \mathrm{E}-01$
8.2504
$12-0.81851 \mathrm{E}-01$
7.8842
$13-0.85158 \mathrm{E}-01$
$14-0.77595 \mathrm{E}-01$
8.0981
7.6065
$15-0.79501 \mathrm{E}-01$
$16-0.86526 \mathrm{E}-01$
7.7310
$17-0.92253 \mathrm{E}-01$
8.1923
$18-0.95339 \mathrm{E}-01$
8.5703
$19-0.95495 \mathrm{E}-01$
8.7750
$20-0.10056$
8.7854
9.1245
$21-0.95924 \mathrm{E}-01$
8.8126
$22-0.97126 \mathrm{E}-01$
8.8939
8.6248
$24-0.96373 E-01$
8.8438
$25-0.95374 E-01$
8.7752
$26-0.93779 E-01$
8.6652
$27-0.88846 E-01$
8.3231 


\section{APPENDIX $\mathrm{K}$}

CUSUM TEST

(continued)

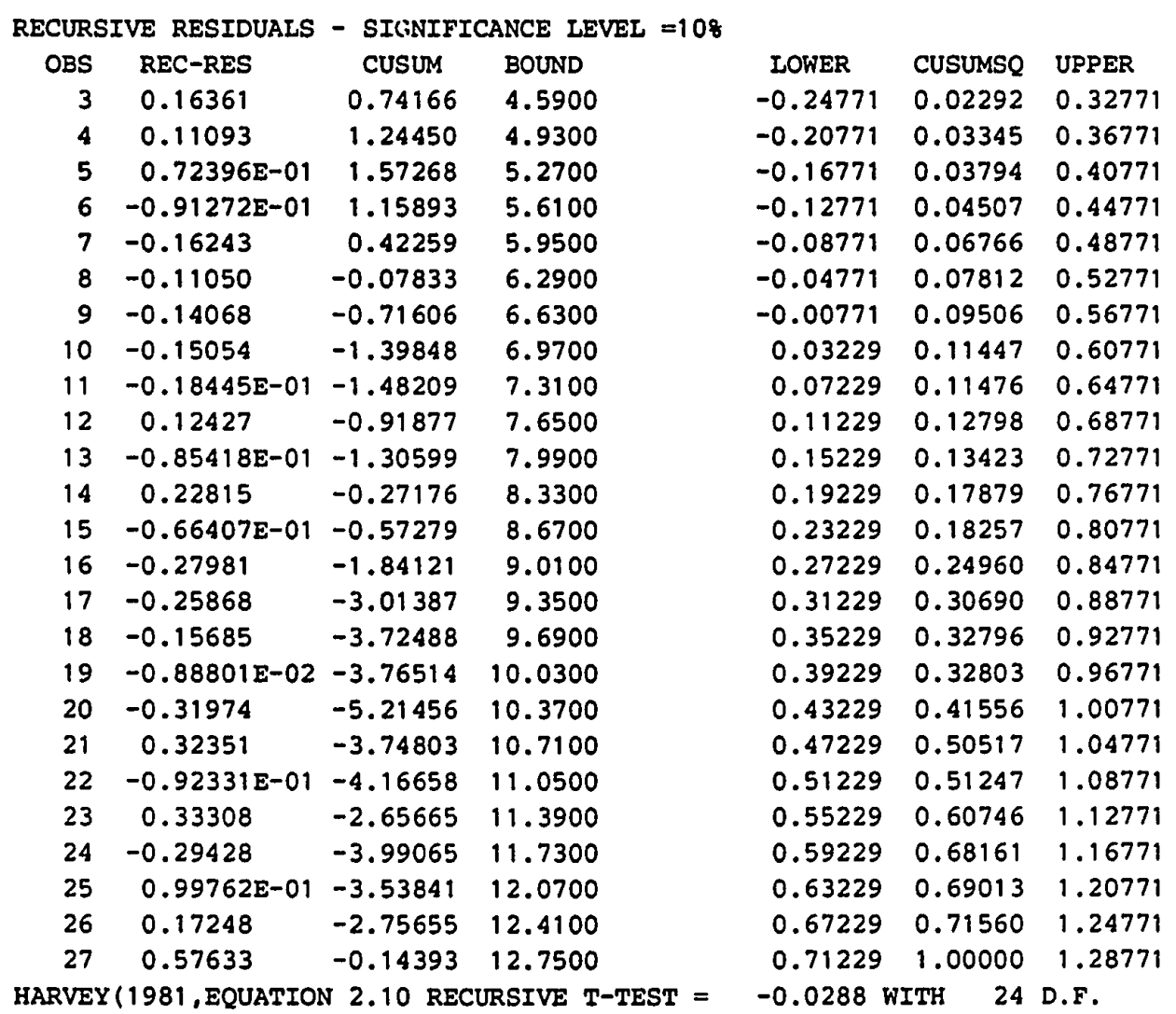

HARVEY (1981, EQUATION 2.12 HETEROSKEDASTICITY TEST $=5.8704$ WITH M 
APPENDIX I

RUNNING DEREGULATION DUMMY 
APPENDIX I

RUNNING DEREGULATION DUMMY

COMMAND FILE

FILE 11 d: \shazam\d\f1 \agr.doc sample 1200

read(11) airline year d totocc y $\mathrm{n} u$ hours

* generate controllable rate

genr ocrate $=(1000000 *(y+1)) /$ hours

* generate $\log$ of the controllable rate genr Inocrate = log (ocrate)

print year $Y$ hours ocrate Inocrate

*generate dummy for deregulation

genr $d \quad=$ dum (year - 74.9)

*generate time since deregulation dummy

genr timedum $=d^{*}$ (year -74$)$

print year d timedum

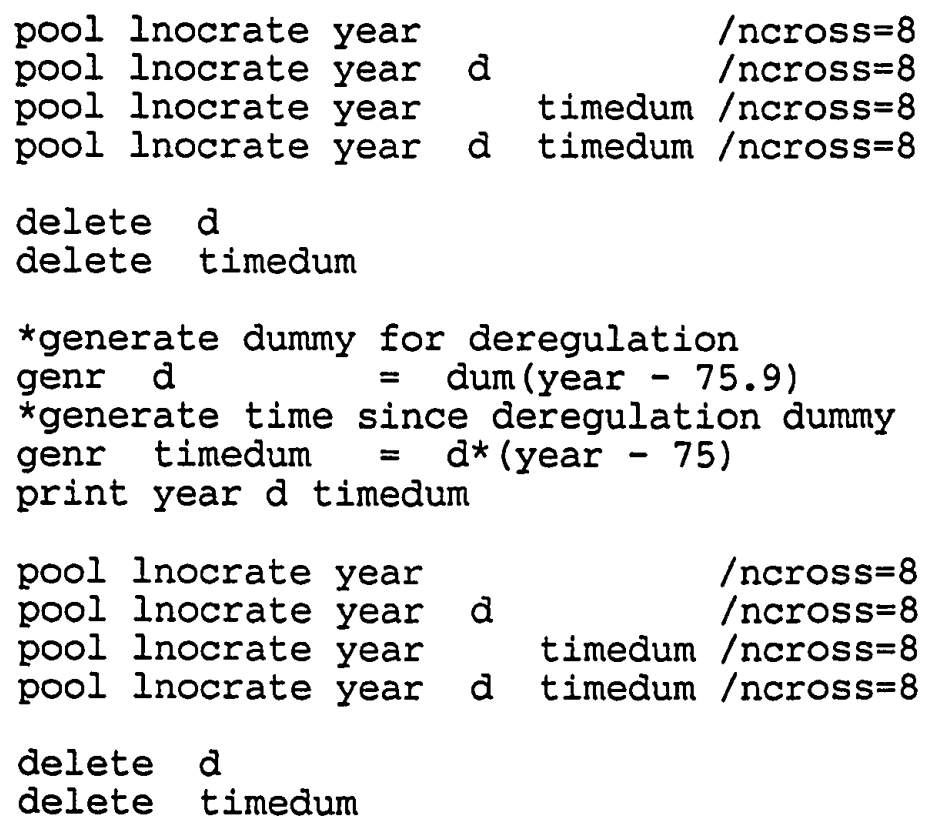


APPENDIX I

RUNNING DEREGULATION DUMMY

(continued)

*generate dummy for deregulation

genr $d=$ dum(year - 76.9)

*generate time since deregulation dummy

genr timedum $=d *($ year -76$)$

print year d timedum

pool Inocrate year
pool Inocrate year a $\begin{array}{r}\text { /ncross }=8 \\ \text { poross }=8 \\ \text { pool Inocrate year } \\ \text { pool Inocrate year a timedum } / \text { ncross }=8 \\ \text { timedum /ncross }=8\end{array}$

delete $d$

delete timedum

*generate dummy for deregulation

genr d = dum(year - 77.9)

*generate time since deregulation dummy genr timedum $=d *($ year -77$)$

print year d timedum

pool Inocrate year

pool Inocrate year

pool Inocrate year

pool lnocrate year a timedum /ncross $=8$

delete $d$

delete timedum

*generate dummy for deregulation

genr $d=\operatorname{dum}($ year -78.9 )

*generate time since deregulation dummy

genr timedum $=d *$ (year - 78)

print year d timedum

$\begin{array}{llr}\text { pool Inocrate year } & & \text { /ncross }=8 \\ \text { pool Inocrate year a } & \text { /ncross }=8 \\ \text { pool inocrate year } & & \text { timedum } / \text { ncross }=8 \\ \text { pool inocrate year d timedum /ncross }=8\end{array}$

delete $d$

delete timedum 
APPENDIX L

RUNNING DEREGULATION DUMMY (continued)

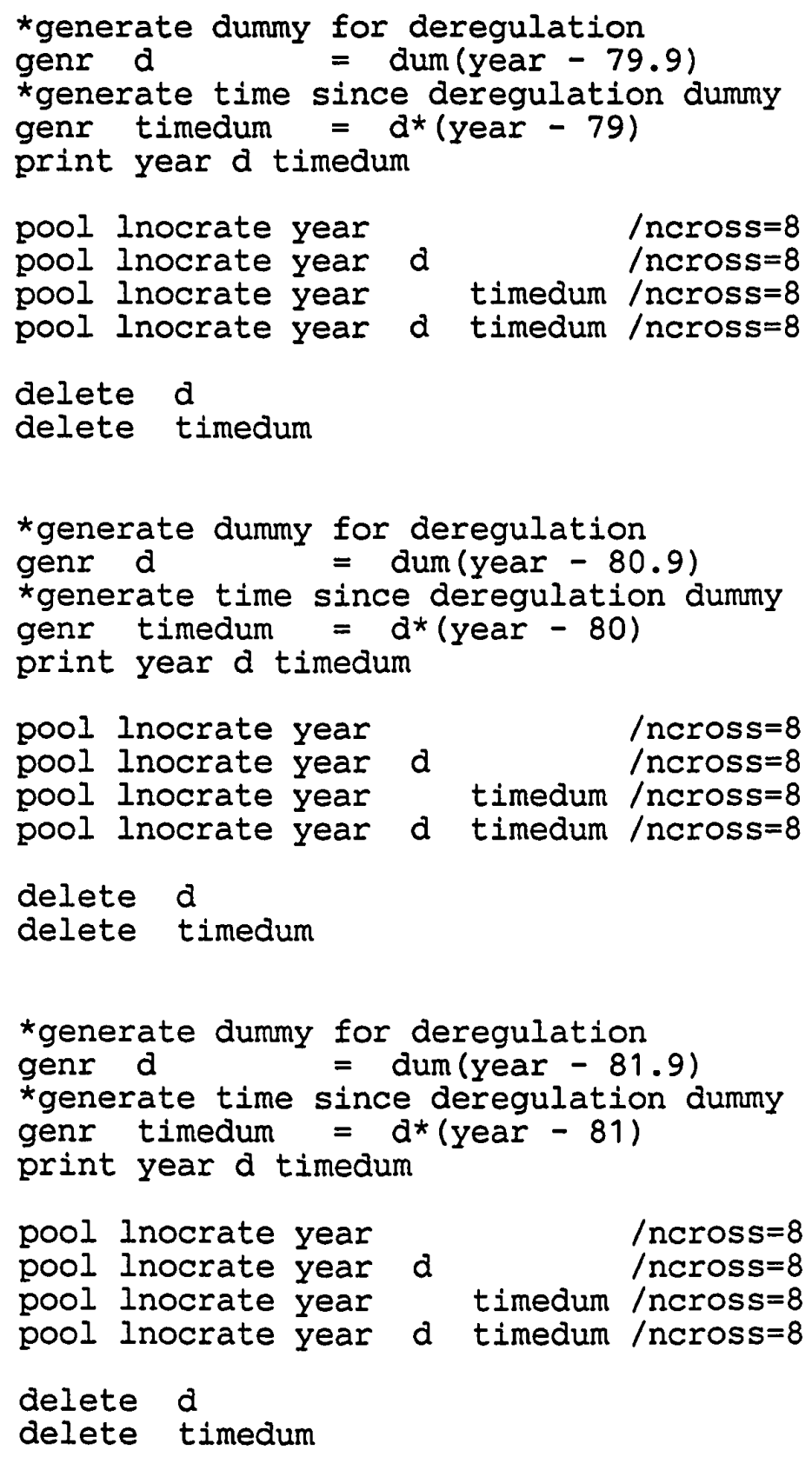




\section{APPENDIX I \\ RUNNING DEREGULATION DUMMY \\ (continued)}

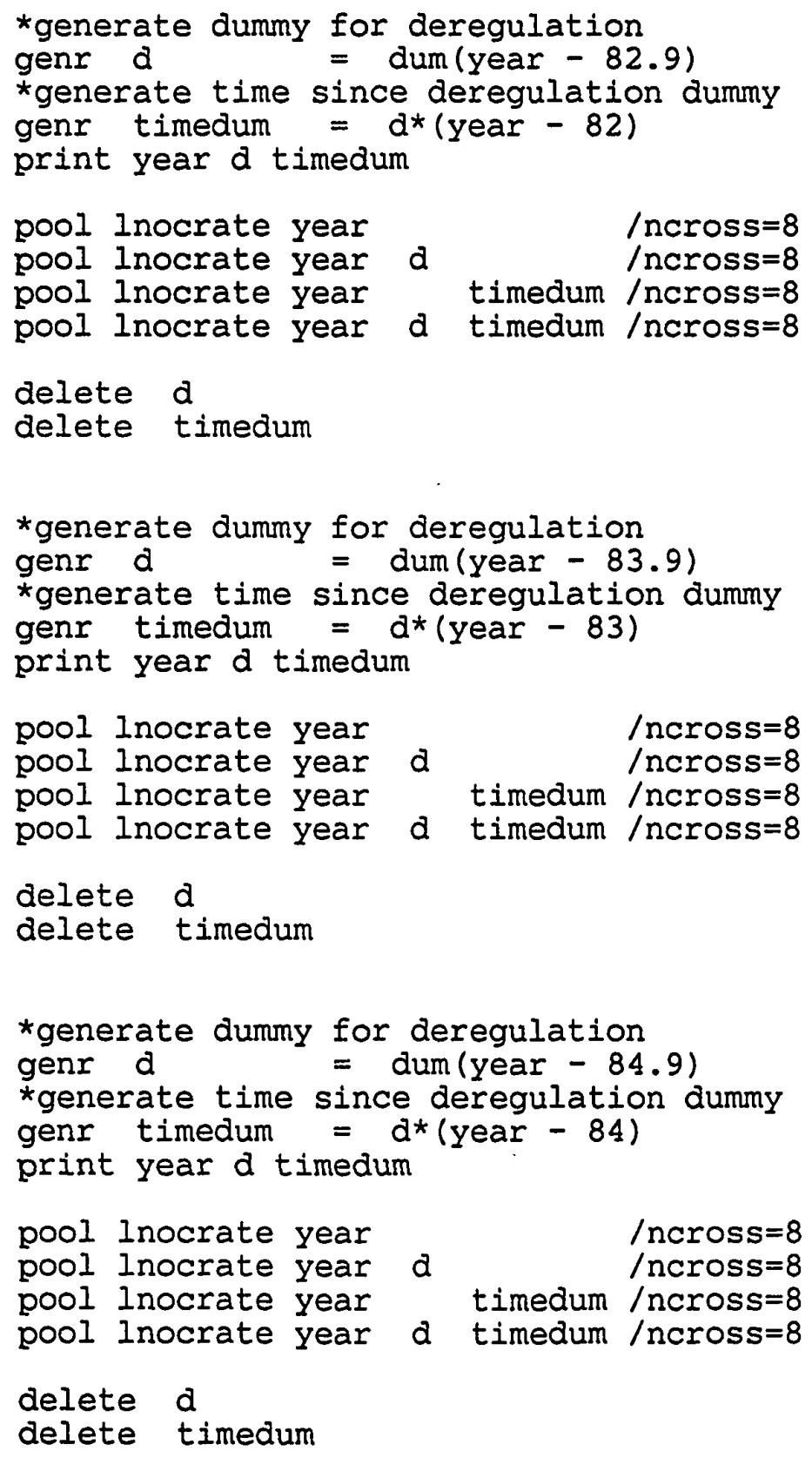


APPENDIX I

\section{RUNNING DEREGULATION DUMMY (continued)}

OUTPUT FILE

UNIT 11 IS NOW ASSIGNED TO: d:Ishazamld\filagr.doc

8 VARIABLES AND 200 OBSERVATIONS STARTING AT OBS 1

\begin{tabular}{|c|c|c|c|c|}
\hline YEAR & $\mathbf{Y}$ & HOURS & OCRATE & INOCRATE \\
\hline 64.00000 & 7.000000 & 363437.0 & 22.01207 & 3.091591 \\
\hline 65.00000 & 8.000000 & 391523.0 & 22.98716 & 3.134936 \\
\hline 66.00000 & 7.000000 & 453253.0 & 17.65019 & 2.870746 \\
\hline 67.00000 & 3.000000 & 541077.0 & 7.392663 & 2.000488 \\
\hline 68.00000 & 6.000000 & 618650.0 & 11.31496 & 2.426126 \\
\hline 69.00000 & 1.000000 & 637328.0 & 3.138102 & 1.143618 \\
\hline 70.00000 & 6.000000 & 671977.0 & 10.41702 & 2.343441 \\
\hline 71.00000 & 10.00000 & 658728.0 & 16.69885 & 2.815340 \\
\hline 72.00000 & 4.000000 & 642511.0 & 7.781968 & 2.051809 \\
\hline 73.00000 & 7.000000 & 661120.0 & 12.10068 & 2.493261 \\
\hline 74.00000 & 6.000000 & 614117.0 & 11.39848 & 2.433480 \\
\hline 75.00000 & 6.000000 & 629924.0 & 11.11245 & 2.408066 \\
\hline 76.00000 & 3.000000 & 656110.0 & 6.096539 & 1.807721 \\
\hline 77.00000 & 4.000000 & 671540.0 & 7.445573 & 2.007620 \\
\hline 78.00000 & 4.000000 & 688255.0 & 7.264749 & 1.983034 \\
\hline 79.00000 & 4.000000 & 747748.0 & 6.686745 & 1.900127 \\
\hline 80.00000 & 0.0000000 & 693604.0 & 1.441745 & 0.3658541 \\
\hline 81.00000 & 3.000000 & 610468.0 & 6.552350 & 1.879824 \\
\hline 82.00000 & 3.000000 & 619230.0 & 6.459635 & 1.865573 \\
\hline 83.00000 & 6.000000 & 658990.0 & 10.62232 & 2.362957 \\
\hline 84.00000 & 5.000000 & 749857.0 & 8.001526 & 2.079632 \\
\hline 85.00000 & 9.000000 & 858870.0 & 11.64321 & 2.454723 \\
\hline 86.00000 & 4.000000 & 946058.0 & 5.285088 & 1.664889 \\
\hline 87.00000 & 6.000000 & 1168616 & 5.989992 & 1.790090 \\
\hline 88.00000 & 9.000000 & 1337015 & 7.479348 & 2.012146 \\
\hline 64.00000 & 0.0000000 & 77582.00 & 12.88959 & 2.556420 \\
\hline 65.00000 & 2.000000 & 93043.00 & 32.24316 & 3.473306 \\
\hline 66.00000 & 2.000000 & 115295.0 & 26.02021 & 3.258874 \\
\hline 67.00000 & 1.000000 & 135369.0 & 14.77443 & 2.692898 \\
\hline 68.00000 & 0.0000000 & 167193.0 & 5.981112 & 1.788606 \\
\hline 69.00000 & 1.000000 & 194493.0 & 10.28315 & 2.330506 \\
\hline 70.00000 & 1.000000 & 194732.0 & 10.27053 & 2.329278 \\
\hline 71.00000 & 2.000000 & 199498.0 & 15.03774 & 2.710563 \\
\hline 72.00000 & 1.000000 & 195942.0 & 10.20710 & 2.323084 \\
\hline 73.00000 & 0.0000000 & 182774.0 & 5.471238 & 1.699505 \\
\hline 74.00000 & 0.0000000 & 168444.0 & 5.936691 & 1.781152 \\
\hline 75.00000 & 2.000000 & 175720.0 & 17.07262 & 2.837476 \\
\hline 76.00000 & 3.000000 & 163492.0 & 24.46603 & 3.197286 \\
\hline 77.00000 & 1.000000 & 186494.0 & 10.72421 & 2.372503 \\
\hline 78.00000 & 1.000000 & 210545.0 & 9.499157 & 2.251203 \\
\hline 79.00000 & 1.000000 & 240802.0 & 8.305579 & 2.116927 \\
\hline
\end{tabular}


APPENDIX L

RUNNING DEREGUIATION DUMMY (continued)

\begin{tabular}{|c|c|c|c|c|}
\hline 80.00000 & 1.000000 & 198611.0 & 10.06994 & 2.309554 \\
\hline 81.00000 & 2.000000 & 200482.0 & 14.96394 & 2.705643 \\
\hline 82.00000 & 2.000000 & 231456.0 & 12.96143 & 2.561978 \\
\hline 83.00000 & 6.000000 & 241362.0 & 29.00208 & 3.367368 \\
\hline 84.00000 & 1.000000 & 260119.0 & 7.688789 & 2.039763 \\
\hline 85.00000 & 0.0000000 & 375422.0 & 2.663669 & 0.9797046 \\
\hline 86.00000 & 2.000000 & 493447.0 & 6.079680 & 1.804952 \\
\hline 87.00000 & 5.000000 & 959845.0 & 6.251009 & 1.832743 \\
\hline 88.00000 & 2.000000 & 967692.0 & 3.100160 & 1.131454 \\
\hline 64.00000 & 5.000000 & 215521.0 & 27.83951 & 3.326456 \\
\hline 65.00000 & 1.000000 & 233057.0 & 8.581592 & 2.149619 \\
\hline 66.00000 & 7.000000 & 263519.0 & 30.35834 & 3.413071 \\
\hline 67.00000 & 3.000000 & 288875.0 & 13.84682 & 2.628056 \\
\hline 68.00000 & 2.000000 & 319499.0 & 9.389701 & 2.239613 \\
\hline 69.00000 & 9.000000 & 373621.0 & 26.76509 & 3.287098 \\
\hline 70.00000 & 3.000000 & 423060.0 & 9.454924 & 2.246536 \\
\hline 71.00000 & 4.000000 & 430775.0 & 11.60699 & 2.451607 \\
\hline 72.00000 & 8.000000 & 484794.0 & 18.56459 & 2.921256 \\
\hline 73.00000 & 7.000000 & 560178.0 & 14.28117 & 2.658942 \\
\hline 74.00000 & 7.000000 & 509258.0 & 15.70913 & 2.754242 \\
\hline 75.00000 & 6.000000 & 512431.0 & 13.66038 & 2.614499 \\
\hline 76.00000 & 4.000000 & 535971.0 & 9.328863 & 2.233113 \\
\hline 77.00000 & 3.000000 & 558720.0 & 7.159221 & 1.968401 \\
\hline 78.00000 & 4.000000 & 601411.0 & 8.313782 & 2.117915 \\
\hline 79.00000 & 1.000000 & 642041.0 & 3.115066 & 1.136250 \\
\hline 80.00000 & 2.000000 & 661567.0 & 4.534688 & 1.511756 \\
\hline 81.00000 & 3.000000 & 665432.0 & 6.011133 & 1.793613 \\
\hline 82.00000 & 0.0000000 & 649484.0 & 1.539684 & 0.4315771 \\
\hline 83.00000 & 0.0000000 & 666098.0 & 1.501281 & 0.4063185 \\
\hline 84.00000 & 2.000000 & 706422.0 & 4.246753 & 1.446155 \\
\hline 85.00000 & 7.000000 & 740387.0 & 10.80516 & 2.380024 \\
\hline 86.00000 & 1.000000 & 742440.0 & 2.693820 & 0.9909604 \\
\hline 87.00000 & 6.000000 & 1064383 & 6.576580 & 1.883515 \\
\hline 88.00000 & 0.000000 & 1198156. & 5.842311 & 1.765126 \\
\hline 64.00000 & 17.00000 & 402847.0 & 44.68198 & 3.799570 \\
\hline 65.00000 & 12.00000 & 417634.0 & 31.12773 & 3.438099 \\
\hline 66.00000 & 10.00000 & 365461.0 & 30.09897 & 3.404491 \\
\hline 67.00000 & 11.00000 & 486056.0 & 24.68851 & 3.206338 \\
\hline 68.00000 & 7.000000 & 545801.0 & 14.65736 & 2.684942 \\
\hline 69.00000 & 10.00000 & 612663.0 & 17.95441 & 2.887836 \\
\hline 70.00000 & 5.000000 & 624845.0 & 9.602381 & 2.262011 \\
\hline 71.00000 & 5.000000 & 636749.0 & 9.422865 & 2.243139 \\
\hline 72.00000 & 9.000000 & 653285.0 & 15.30725 & 2.728327 \\
\hline 73.00000 & 7.000000 & 684308.0 & 11.69064 & 2.458789 \\
\hline 74.00000 & 5.000000 & 600699.0 & 9.988364 & 2.301421 \\
\hline 75.00000 & 7.000000 & 641077.0 & 12.47900 & 2.524047 \\
\hline 76.00000 & 3.000000 & 664828.0 & 6.016594 & 1.794521 \\
\hline
\end{tabular}




\section{APPENDIX I}

RUNNING DEREGULATION DUMMY (continued)

\begin{tabular}{|c|c|c|c|c|}
\hline 77.00000 & 4.000000 & 680945.0 & 7.342737 & 1.993712 \\
\hline 78.00000 & 3.000000 & 692122.0 & 5.779328 & 1.754287 \\
\hline 79.00000 & 2.000000 & 725991.0 & 4.132283 & 1.418830 \\
\hline 80.00000 & 2.000000 & 737661.0 & 4.066909 & 1.402883 \\
\hline 81.00000 & 7.000000 & 711985.0 & 11.23619 & 2.419140 \\
\hline 82.00000 & 3.000000 & 681472.0 & 5.869647 & 1.769794 \\
\hline 83.00000 & 4.000000 & 711994.0 & 7.022531 & 1.949124 \\
\hline 84.00000 & 4.000000 & 770245.0 & 6.491441 & 1.870485 \\
\hline 85.00000 & 4.000000 & 787921.0 & 6.345814 & 1.847795 \\
\hline 86.00000 & 8.000000 & 813770.0 & 11.05964 & 2.403302 \\
\hline 87.00000 & 7.000000 & 786767.0 & 10.16819 & 2.319265 \\
\hline 88.00000 & 3.000000 & 666009.0 & 6.005925 & 1.792746 \\
\hline 64.00000 & 5.000000 & 147961.0 & 40.55123 & 3.702566 \\
\hline 65.00000 & 2.000000 & 170434.0 & 17.60212 & 2.868019 \\
\hline 66.00000 & 0.0000000 & 187125.0 & 5.344021 & 1.675978 \\
\hline 67.00000 & 1.000000 & 250665.0 & 7.978776 & 2.076785 \\
\hline 68.00000 & 4.000000 & 286372.0 & 17.45981 & 2.859902 \\
\hline 69.00000 & 0.0000000 & 319600.0 & 3.128911 & 1.140685 \\
\hline 70.00000 & 1.000000 & 204446.0 & 9.782534 & 2.280599 \\
\hline 71.00000 & 6.000000 & 250879.0 & 27.90190 & 3.328695 \\
\hline 72.00000 & 4.000000 & 195560.0 & 25.56760 & 3.241326 \\
\hline 73.00000 & 2.000000 & 266220.0 & 11.26888 & 2.422045 \\
\hline 74.00000 & 1.000000 & 254621.0 & 7.854812 & 2.061126 \\
\hline 75.00000 & 1.000000 & 247597.0 & 8.077642 & 2.089100 \\
\hline 76.00000 & 0.0000000 & 256599.0 & 3.897131 & 1.360241 \\
\hline 77.00000 & 1.000000 & 261980.0 & 7.634171 & 2.032634 \\
\hline 78.00000 & 0.0000000 & 154584.0 & 6.468975 & 1.867018 \\
\hline 79.00000 & 0.0000000 & 266743.0 & 3.748927 & 1.321470 \\
\hline 80.00000 & 0.0000000 & 275163.0 & 3.634210 & 1.290392 \\
\hline 81.00000 & 5.000000 & 272648.0 & 22.00640 & 3.091333 \\
\hline 82.00000 & 0.0000000 & 268219.0 & 3.728297 & 1.315951 \\
\hline 83.00000 & 1.000000 & 300621.0 & 6.652895 & 1.895052 \\
\hline 84.00000 & 3.000000 & 320482.0 & 12.48120 & 2.524224 \\
\hline 85.00000 & 2.000000 & 357120.0 & 8.400538 & 2.128296 \\
\hline 86.00000 & 1.000000 & 508201.0 & 3.935451 & 1.370025 \\
\hline 87.00000 & 3.000000 & 835486.0 & 4.787633 & 1.566036 \\
\hline 88.00000 & 7.000000 & 824055.0 & 9.708090 & 2.272960 \\
\hline 64.00000 & 8.000000 & 287792.0 & 31.27259 & 3.442742 \\
\hline 65.00000 & 5.000000 & 320997.0 & 18.69176 & 2.928083 \\
\hline 66.00000 & 4.000000 & 385718.0 & 12.96284 & 2.562087 \\
\hline 67.00000 & 6.000000 & 466942.0 & 14.99116 & 2.707460 \\
\hline 68.00000 & 6.000000 & 534702.0 & 13.09140 & 2.571956 \\
\hline 69.00000 & 7.000000 & 540925.0 & 14.78948 & 2.693916 \\
\hline 70.00000 & 9.000000 & 485437.0 & 20.60000 & 3.025291 \\
\hline 71.00000 & 6.000000 & 457327.0 & 15.30633 & 2.728267 \\
\hline 72.00000 & 2.000000 & 447615.0 & 6.702188 & 1.902434 \\
\hline 73.00000 & 2.000000 & 471282.0 & 6.365615 & 1.850911 \\
\hline
\end{tabular}


APPENDIX I

\section{RUNNING DEREGULATION DUMMY (continued)}

\begin{tabular}{|c|c|c|c|c|}
\hline 74.00000 & 4.000000 & 417062.0 & 11.98863 & 2.483958 \\
\hline 75.00000 & 2.000000 & 363570.0 & 8.251506 & 2.110396 \\
\hline 76.00000 & 0.0000000 & 327247.0 & 3.055796 & 1.117040 \\
\hline 77.00000 & 1.000000 & 309192.0 & 6.468473 & 1.866940 \\
\hline 78.00000 & 1.000000 & 293047.0 & 6.824844 & 1.920569 \\
\hline 79.00000 & 3.000000 & 292298.0 & 13.68466 & 2.616276 \\
\hline 80.00000 & 0.0000000 & 439569.0 & 2.274956 & 0.8219606 \\
\hline 81.00000 & 3.000000 & 398513.0 & 10.03731 & 2.306310 \\
\hline 82.00000 & 2.000000 & 410173.0 & 7.313987 & 1.989789 \\
\hline 83.00000 & 2.000000 & 373584.0 & 8.030322 & 2.083225 \\
\hline 84.00000 & 1.000000 & 353951.0 & 5.650500 & 1.731744 \\
\hline 85.00000 & 0.0000000 & 331888.0 & 3.013065 & 1.102958 \\
\hline 86.00000 & 2.000000 & 285804.0 & 10.49670 & 2.351061 \\
\hline 87.00000 & 2.000000 & 312630.0 & 9.596008 & 2.261347 \\
\hline 88.00000 & 2.000000 & 364257.0 & 8.235943 & 2.108508 \\
\hline 64.00000 & 8.000000 & 348781.0 & 25.80416 & 3.250536 \\
\hline 65.00000 & 6.000000 & 403289.0 & 17.35728 & 2.854012 \\
\hline 66.00000 & 4.000000 & 412011.0 & 12.13560 & 2.496143 \\
\hline 67.00000 & 6.000000 & 528992.0 & 13.23271 & 2.582692 \\
\hline 68.00000 & 5.000000 & 621522.0 & 9.653721 & 2.267343 \\
\hline 69.00000 & 7.000000 & 694349.0 & 11.52158 & 2.444222 \\
\hline 70.00000 & 8.000000 & 703858.0 & 12.78667 & 2.548403 \\
\hline 71.00000 & 5.000000 & 674630.0 & 8.893764 & 2.185350 \\
\hline 72.00000 & 8.000000 & 674010.0 & 13.35292 & 2.591735 \\
\hline 73.00000 & 2.000000 & 612358.0 & 4.899095 & 1.589050 \\
\hline 74.00000 & 7.000000 & 614961.0 & 13.00896 & 2.565638 \\
\hline 75.00000 & 7.000000 & 597666.0 & 13.38540 & 2.594165 \\
\hline 76.00000 & 0.0000000 & 608024.0 & 1.644672 & 0.4975409 \\
\hline 77.00000 & 2.000000 & 617284.0 & 4.860000 & 1.581038 \\
\hline 78.00000 & 1.000000 & 600007.0 & 3.333294 & 1.203961 \\
\hline 79.00000 & 2.000000 & 599199.0 & 5.006684 & 1.610774 \\
\hline 80.00000 & 1.000000 & 512270.0 & 3.904191 & 1.362051 \\
\hline 81.00000 & 1.000000 & 432053.0 & 4.629062 & 1.532354 \\
\hline 82.00000 & 3.000000 & 396721.0 & 10.08265 & 2.310816 \\
\hline 83.00000 & 5.000000 & 411915.0 & 14.56611 & 2.678698 \\
\hline 84.00000 & 1.000000 & 441134.0 & 4.533770 & 1.511554 \\
\hline 85.00000 & 1.000000 & 466360.0 & 4.288532 & 1.455945 \\
\hline 86.00000 & 3.000000 & 478444.0 & 8.360435 & 2.123510 \\
\hline 87.00000 & 2.000000 & 570382.0 & 5.259633 & 1.660061 \\
\hline 88.00000 & 1.000000 & 607679.0 & 3.291211 & 1.191256 \\
\hline 64.00000 & 14.00000 & 597264.0 & 25.11452 & 3.223446 \\
\hline 65.00000 & 9.000000 & 661152.0 & 15.12511 & 2.716357 \\
\hline 66.00000 & 11.00000 & 636788.0 & 18.84458 & 2.936225 \\
\hline 67.00000 & 17.00000 & 809078.0 & 22.24755 & 3.102232 \\
\hline 68.00000 & 13.00000 & 922099.0 & 15.18275 & 2.720160 \\
\hline 69.00000 & 9.000000 & 963734.0 & 10.37631 & 2.339525 \\
\hline 70.00000 & 11.00000 & 986351.0 & 12.16605 & 2.498650 \\
\hline
\end{tabular}


APPENDIX L

RUNNING DEREGULATION DUMMY (continued)

$\begin{array}{lllll}71.00000 & 10.00000 & 916048.0 & 12.00810 & 2.485582 \\ 72.00000 & 4.000000 & 910516.0 & 5.491392 & 1.703182 \\ 73.00000 & 3.000000 & 908331.0 & 4.403681 & 1.482441 \\ 74.00000 & 4.000000 & 818425.0 & 6.109295 & 1.809811 \\ 75.00000 & 5.000000 & 768504.0 & 7.807376 & 2.055069 \\ 76.00000 & 1.000000 & 811798.0 & 2.463667 & 0.9016509 \\ 77.00000 & 4.000000 & 849573.0 & 5.885309 & 1.772459 \\ 78.00000 & 6.000000 & 926468.0 & 7.555577 & 2.022286 \\ 79.00000 & 1.000000 & 814627.0 & 2.455111 & 0.8981721 \\ 80.00000 & 3.000000 & 920898.0 & 4.343586 & 1.468700 \\ 81.00000 & 3.000000 & 758373.0 & 5.274449 & 1.662874 \\ 82.00000 & 2.000000 & 760207.0 & 3.946294 & 1.372777 \\ 83.00000 & 8.000000 & 833093.0 & 10.80312 & 2.379835 \\ 84.00000 & 7.000000 & 945600.0 & 8.460237 & 2.135377 \\ 85.00000 & 2.000000 & 826534.0 & 3.629615 & 1.289127 \\ 86.00000 & 5.000000 & 1121721 . & 5.348924 & 1.676895 \\ 87.00000 & 5.000000 & 1222937 . & 4.906222 & 1.590504 \\ 88.00000 & 3.000000 & 1201883 . & 3.328111 & 1.202405\end{array}$


APPENDIX I

\section{RUNNING DEREGULATION DUMMY} (continued)

$\begin{array}{ccc}\text { YEAR } & \text { D } & \text { TIMEDUM } \\ 64.00000 & 0.0000000 & 0.0000000 \\ 65.00000 & 0.0000000 & 0.0000000 \\ 66.00000 & 0.0000000 & 0.0000000 \\ 67.00000 & 0.0000000 & 0.0000000 \\ 68.00000 & 0.0000000 & 0.0000000 \\ 69.00000 & 0.0000000 & 0.0000000 \\ 70.00000 & 0.0000000 & 0.0000000 \\ 71.00000 & 0.0000000 & 0.0000000 \\ 72.00000 & 0.0000000 & 0.0000000 \\ 73.00000 & 0.0000000 & 0.0000000 \\ 74.00000 & 0.0000000 & 0.0000000 \\ 75.00000 & 1.000000 & 1.000000 \\ 76.00000 & 1.000000 & 2.000000 \\ 77.00000 & 1.000000 & 3.000000 \\ 78.00000 & 1.000000 & 4.000000 \\ 79.00000 & 1.000000 & 5.000000 \\ 80.00000 & 1.000000 & 6.000000 \\ 81.00000 & 1.000000 & 7.000000 \\ 82.00000 & 1.000000 & 8.000000 \\ 83.00000 & 1.000000 & 9.000000 \\ 84.00000 & 1.000000 & 10.00000 \\ 85.00000 & 1.000000 & 11.00000 \\ 86.00000 & 1.000000 & 12.00000 \\ 87.00000 & 1.000000 & 13.00000 \\ 88.00000 & 1.000000 & 14.00000\end{array}$


APPENDIX I

\section{RUNNING DEREGULATION DUMMY (continued)}

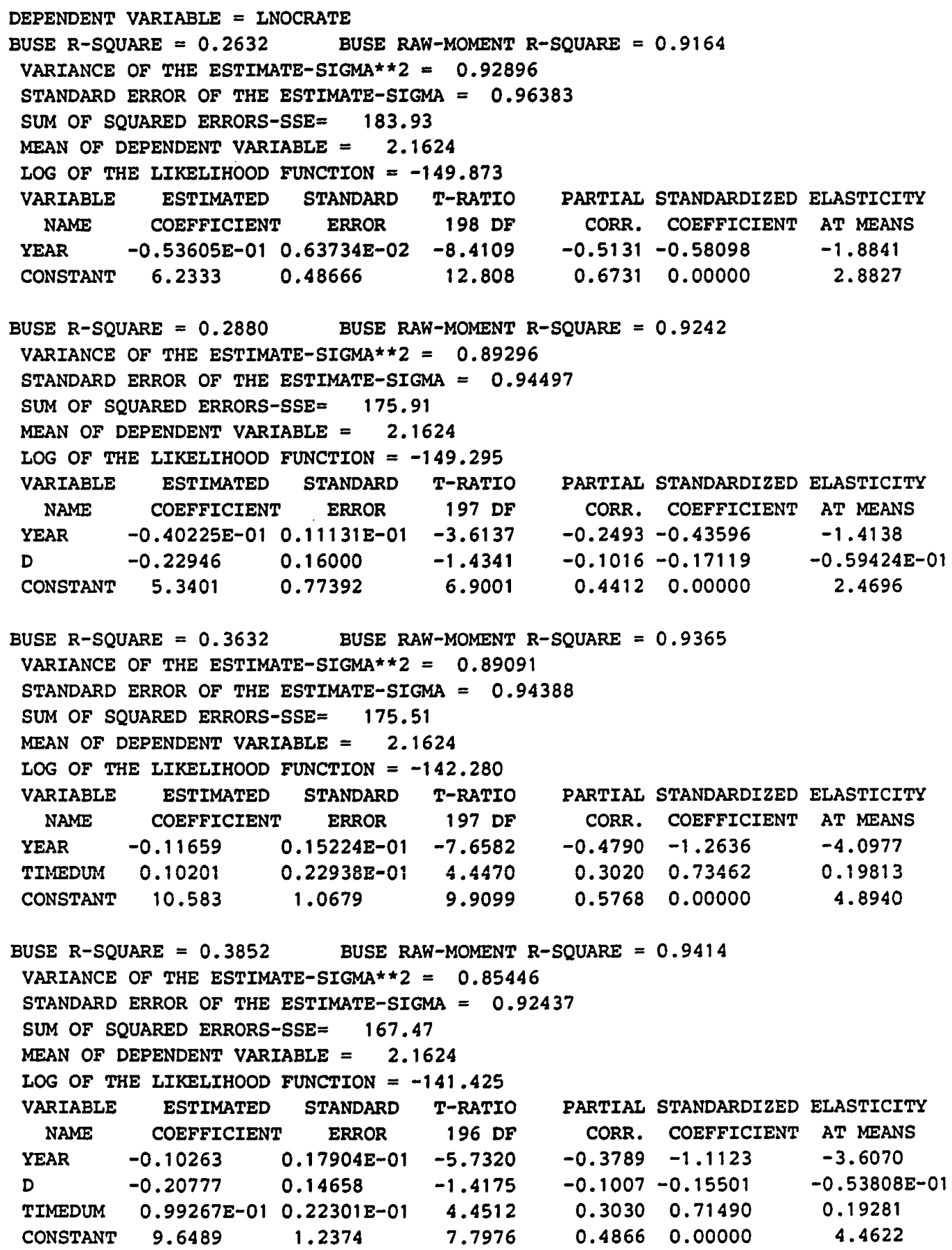

BUSE R-SQUARE $=0.3852$ BUSE RAW-MOMENT R-SQUARE $=0.9414$

VARIANCE OF THE ESTIMATE-SIGMA $\star 2=0.85446$

STANDARD ERROR OF THE ESTIMATE-SIGMA $=0.92437$

SUM OF SQUARED ERRORS-SSE $=167.47$

MEAN OF DEPENDENT VARIABLE $=2.1624$

LOG OF THE LIKELIHOOD FUNCTION $=-141.425$

VARIABLE ESTIMATED STANDARD T-RATIO

NAME COEFFICIENT ERROR 196 DF

YEAR $-0.10263 \quad 0.17904 \mathrm{E}-01 \quad-5.7320$

D $\quad-0.20777 \quad 0.14658 \quad-1.4175$

TIMEDUM $0.99267 \mathrm{E}-01 \quad 0.22301 \mathrm{E}-01 \quad 4.4512$

$\begin{array}{llll}\text { CONSTANT } & 9.6489 & 1.2374 & 7.7976\end{array}$

PARTIAL STANDARDIZED ELASTICITY

CORR. COEFFICIENT AT MEANS

$-0.3789-1.1123 \quad-3.6070$

$-0.1007-0.15501 \quad-0.53808 E-01$

$0.3030 \quad 0.71490 \quad 0.19281$

$\begin{array}{lll}0.4866 & 0.00000 & 4.4622\end{array}$ 
APPENDIX I

RUNNING DEREGULATION DUMMY

(continued)

$\begin{array}{ccc}\text { YEAR } & \text { D } & \text { TIMEDUM } \\ 64.00000 & 0.0000000 & 0.0000000 \\ 65.00000 & 0.0000000 & 0.0000000 \\ 66.00000 & 0.0000000 & 0.0000000 \\ 67.00000 & 0.0000000 & 0.0000000 \\ 68.00000 & 0.0000000 & 0.0000000 \\ 69.00000 & 0.0000000 & 0.0000000 \\ 70.00000 & 0.0000000 & 0.0000000 \\ 71.00000 & 0.0000000 & 0.0000000 \\ 72.00000 & 0.0000000 & 0.0000000 \\ 73.00000 & 0.0000000 & 0.0000000 \\ 74.00000 & 0.0000000 & 0.0000000 \\ 75.00000 & 0.0000000 & 0.0000000 \\ 76.00000 & 1.000000 & 1.000000 \\ 77.00000 & 1.000000 & 2.000000 \\ 78.00000 & 1.000000 & 3.000000 \\ 79.00000 & 1.000000 & 4.000000 \\ 80.00000 & 1.000000 & 5.000000 \\ 81.00000 & 1.000000 & 6.000000 \\ 82.00000 & 1.000000 & 7.000000 \\ 83.00000 & 1.000000 & 8.000000 \\ 84.00000 & 1.000000 & 9.000000 \\ 85.00000 & 1.000000 & 10.00000 \\ 86.00000 & 1.000000 & 11.00000 \\ 87.00000 & 1.000000 & 12.00000 \\ 88.00000 & 1.000000 & 13.00000\end{array}$




\section{APPENDIX I \\ RUNNING DEREGULATION DUMMY (continued)}

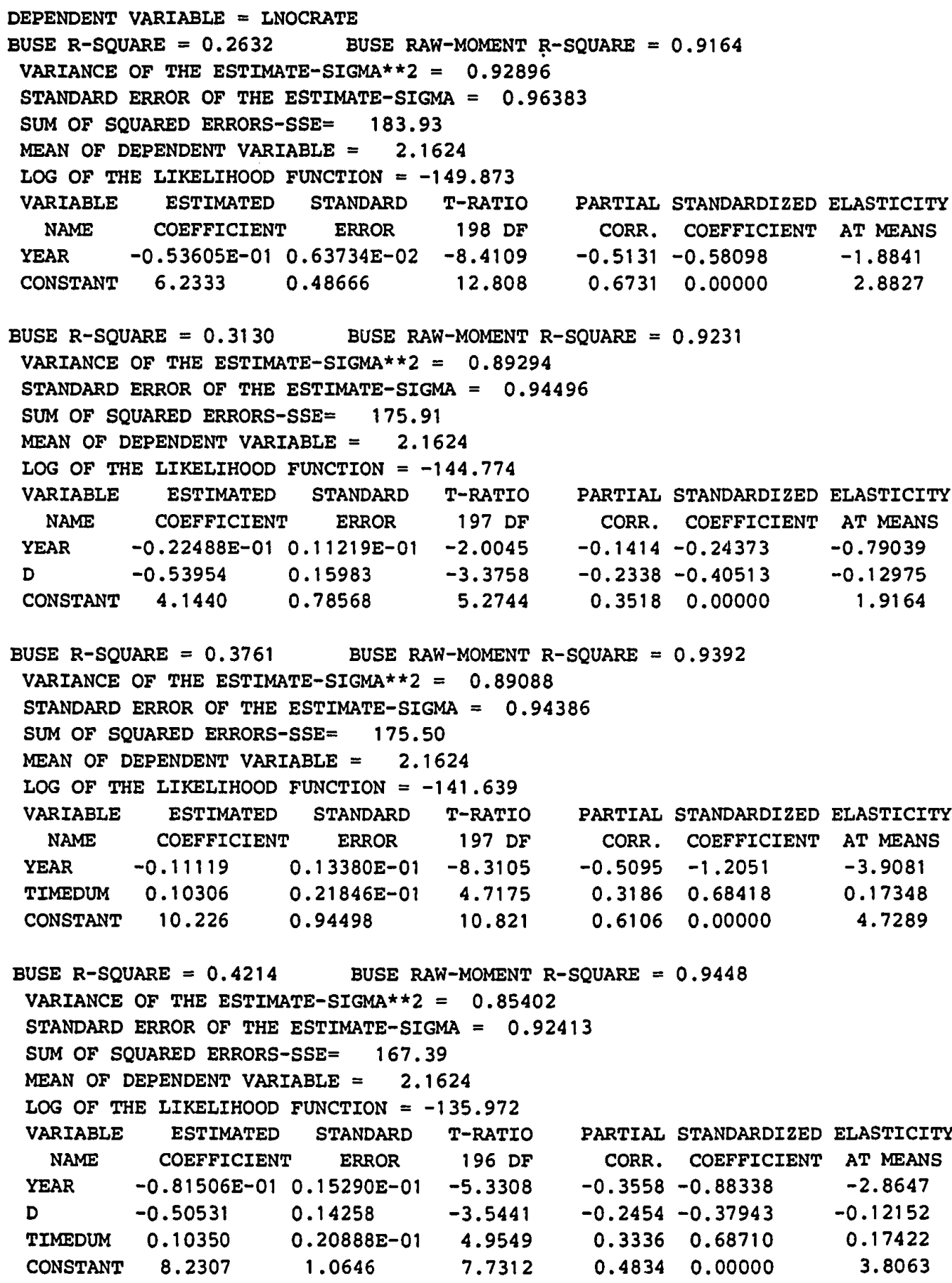


APPENDIX I

\section{RUNNING DEREGULATION DUMMY} (continued)

$\begin{array}{ccc}\text { YEAR } & \text { D } & \text { TIMEDUR } \\ 64.00000 & 0.0000000 & 0.0000000 \\ 65.00000 & 0.0000000 & 0.0000000 \\ 66.00000 & 0.0000000 & 0.0000000 \\ 67.00000 & 0.0000000 & 0.0000000 \\ 68.00000 & 0.0000000 & 0.0000000 \\ 69.00000 & 0.0000000 & 0.0000000 \\ 70.00000 & 0.0000000 & 0.0000000 \\ 71.00000 & 0.0000000 & 0.0000000 \\ 72.00000 & 0.0000000 & 0.0000000 \\ 73.00000 & 0.0000000 & 0.0000000 \\ 74.00000 & 0.0000000 & 0.0000000 \\ 75.00000 & 0.0000000 & 0.0000000 \\ 76.00000 & 0.0000000 & 0.0000000 \\ 77.00000 & 1.000000 & 1.000000 \\ 78.00000 & 1.000000 & 2.000000 \\ 79.00000 & 1.000000 & 3.000000 \\ 80.00000 & 1.000000 & 4.000000 \\ 81.00000 & 1.000000 & 5.000000 \\ 82.00000 & 1.000000 & 6.000000 \\ 83.00000 & 1.000000 & 7.000000 \\ 84.00000 & 1.000000 & 8.000000 \\ 85.00000 & 1.000000 & 9.000000 \\ 86.00000 & 1.000000 & 10.00000 \\ 87.00000 & 1.000000 & 11.00000 \\ 88.00000 & 1.000000 & 12.00000\end{array}$




\section{APPENDIX L \\ RUNNING DEREGULATION DUMMY (continued)}

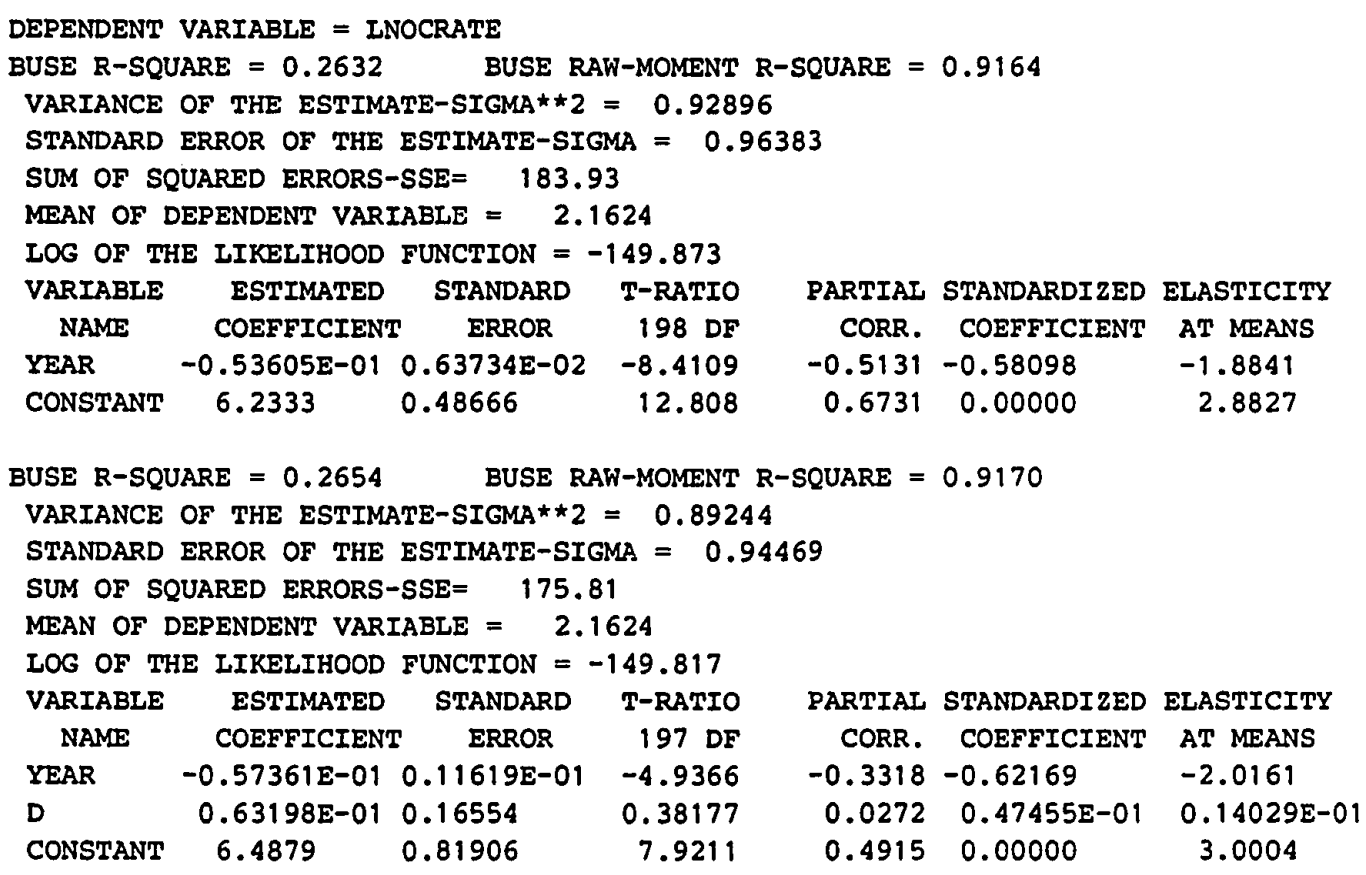

BUSE R-SQUARE $=0.3975$ BUSE RAW-MOMENT R-SQUARE $=0.9422$

VARIANCE OF THE ESTIMATE-SIGMA *2 $=0.89049$

STANDARD ERROR OF THE ESTIMATE-SIGMA $=0.94366$

SUM OF SQUARED ERRORS-SSE $=175.43$

MEAN OF DEPENDENT VARIABLE $=2.1624$

LOG OF THE LIKELIHOOD FUNCTION $=-139.473$

VARIABLE ESTIMATED STANDARD T-RATIO

NAME COEFFICIENT ERROR 197 DF

$\begin{array}{llll}\text { YEAR } & -0.10975 & 0.11817 E-01 & -9.2877\end{array}$

TIMEDUM $0.11231 \quad 0.21108 \mathrm{E}-01 \quad 5.3209$

$\begin{array}{llll}\text { CONSTANT } & 10.141 & 0.84013 & 12.071\end{array}$

PARTIAI STANDARDIZED ELASTICITY CORR. COEFFICIENT AT MEANS $\begin{array}{lll}-0.5518 & -1.1895 & -3.8575\end{array}$ $0.3545 \quad 0.68081 \quad 0.16206$

$\begin{array}{lll}0.6520 & 0.00000 & 4.6897\end{array}$

BUSE R-SQUARE $=0.4042$ BUSE RAW-MOMENT R-SQUARE $=0.9438$

VARIANCE OF THE ESTIMATE-SIGMA $* 2=0.85363$

STANDARD ERROR OF THE ESTIMATE-SIGMA $=0.92392$

SUM OF SQUARED ERRORS-SSE $=167.31$

MEAN OF DEPENDENT VARIABLE $=2.1624$

LOG OF THE LIKELIHOOD FUNCTION $=-139.439$

VARIABLE ESTIMATED STANDARD T-RATIO NAME COEFFICIENT ERROR $196 \mathrm{DF}$

YEAR $\quad-0.10622 \quad 0.13759 E-01 \quad-7.7205$

D $\quad-0.69645 E-010.14603 \quad-0.47692$

TIMEDUM $0.11343 \quad 0.21099 \mathrm{E}-01 \quad 5.3761$

$\begin{array}{llll}\text { CONSTANT } \quad 9.9030 & 0.96502 & 10.262\end{array}$

PARTIAL STANDARDIZED ELASTICITY CORR. COEFFICIENT AT MEANS $\begin{array}{lll}-0.4829 & -1.1513 & -3.7334\end{array}$

$-0.0340-0.52296 \mathrm{E}-01-0.15460 \mathrm{E}-01$

$0.3585 \quad 0.68757 \quad 0.16366$

$\begin{array}{lll}0.5912 & 0.00000 & 4.5797\end{array}$ 
APPENDIX I

\section{RUNNING DEREGULATION DUMMY (continued)}

$\begin{array}{ccc}\text { YEAR } & \text { D } & \text { TIMEDUM } \\ 64.00000 & 0.0000000 & 0.0000000 \\ 65.00000 & 0.0000000 & 0.0000000 \\ 66.00000 & 0.0000000 & 0.0000000 \\ 67.00000 & 0.0000000 & 0.0000000 \\ 68.00000 & 0.0000000 & 0.0000000 \\ 69.00000 & 0.0000000 & 0.0000000 \\ 70.00000 & 0.0000000 & 0.0000000 \\ 71.00000 & 0.0000000 & 0.0000000 \\ 72.00000 & 0.0000000 & 0.0000000 \\ 73.00000 & 0.0000000 & 0.0000000 \\ 74.00000 & 0.0000000 & 0.0000000 \\ 75.00000 & 0.0000000 & 0.0000000 \\ 76.00000 & 0.0000000 & 0.0000000 \\ 77.00000 & 0.0000000 & 0.0000000 \\ 78.00000 & 1.000000 & 1.000000 \\ 79.00000 & 1.000000 & 2.000000 \\ 80.00000 & 1.000000 & 3.000000 \\ 81.00000 & 1.000000 & 4.000000 \\ 82.00000 & 1.000000 & 5.000000 \\ 83.00000 & 1.000000 & 6.000000 \\ 84.00000 & 1.000000 & 7.000000 \\ 85.00000 & 1.000000 & 8.000000 \\ 86.00000 & 1.000000 & 9.000000 \\ 87.00000 & 1.000000 & 10.00000 \\ 88.00000 & 1.000000 & 11.000000\end{array}$




\section{APPENDIX L \\ RUNNING DEREGULATION DUMMY \\ (continued)}

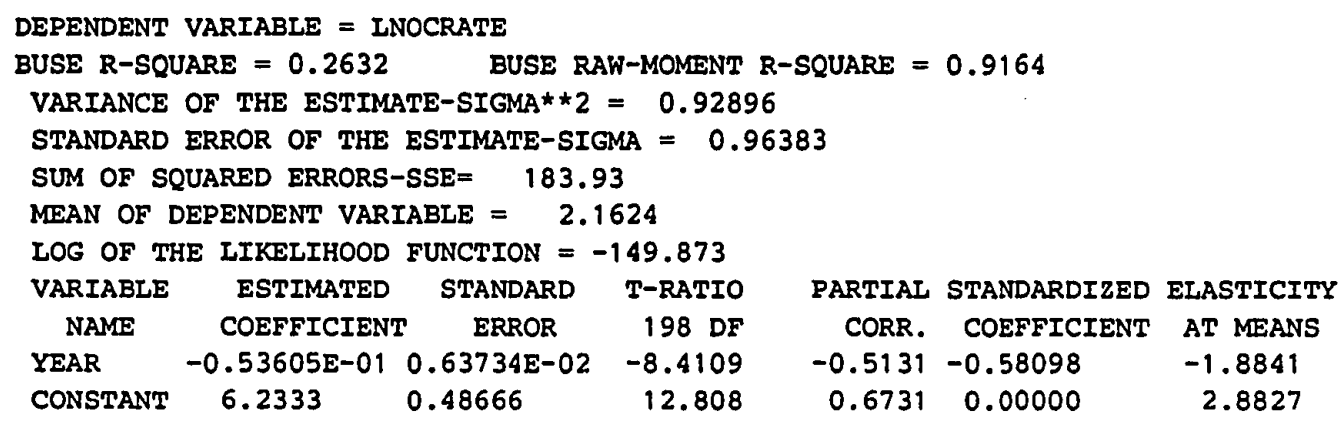

BUSE R-SQUARE $=0.2642$ BUSE RAW-MOMENT R-SQUARE $=0.9169$

VARIANCE OF THE ESTIMATE-SIGMA $* 2=0.89284$

STANDARD ERROR OF THE ESTIMATE-SIGMA $=0.94490$

SUM OF SQUARED ERRORS-SSE= 175.89

MEAN OF DEPENDENT VARIABLE $=2.1624$

LOG OF THE LIKELIHOOD FUNCTION $=-149.716$

VARIABLE ESTIMATED STANDARD T-RATIO

NAME COEFFICIENT ERROR 197 DF

YEAR $\quad-0.58939 E-010.11448 E-01 \quad-5.1485$

D $\quad 0.94393 E-010.16400 \quad 0.57556$

PARTIAL STANDARDIZED ELASTICITY

CORR. COEFFICIENT AT MEANS

$-0.3444-0.63879 \quad-2.0715$

$\begin{array}{llll}\text { CONSTANT } & 6.5970 & 0.81225 & 8.1219\end{array}$

$0.0410 \quad 0.70423 E-01 \quad 0.19207 E-01$

$\begin{array}{lll}0.5008 & 0.00000 & 3.0508\end{array}$

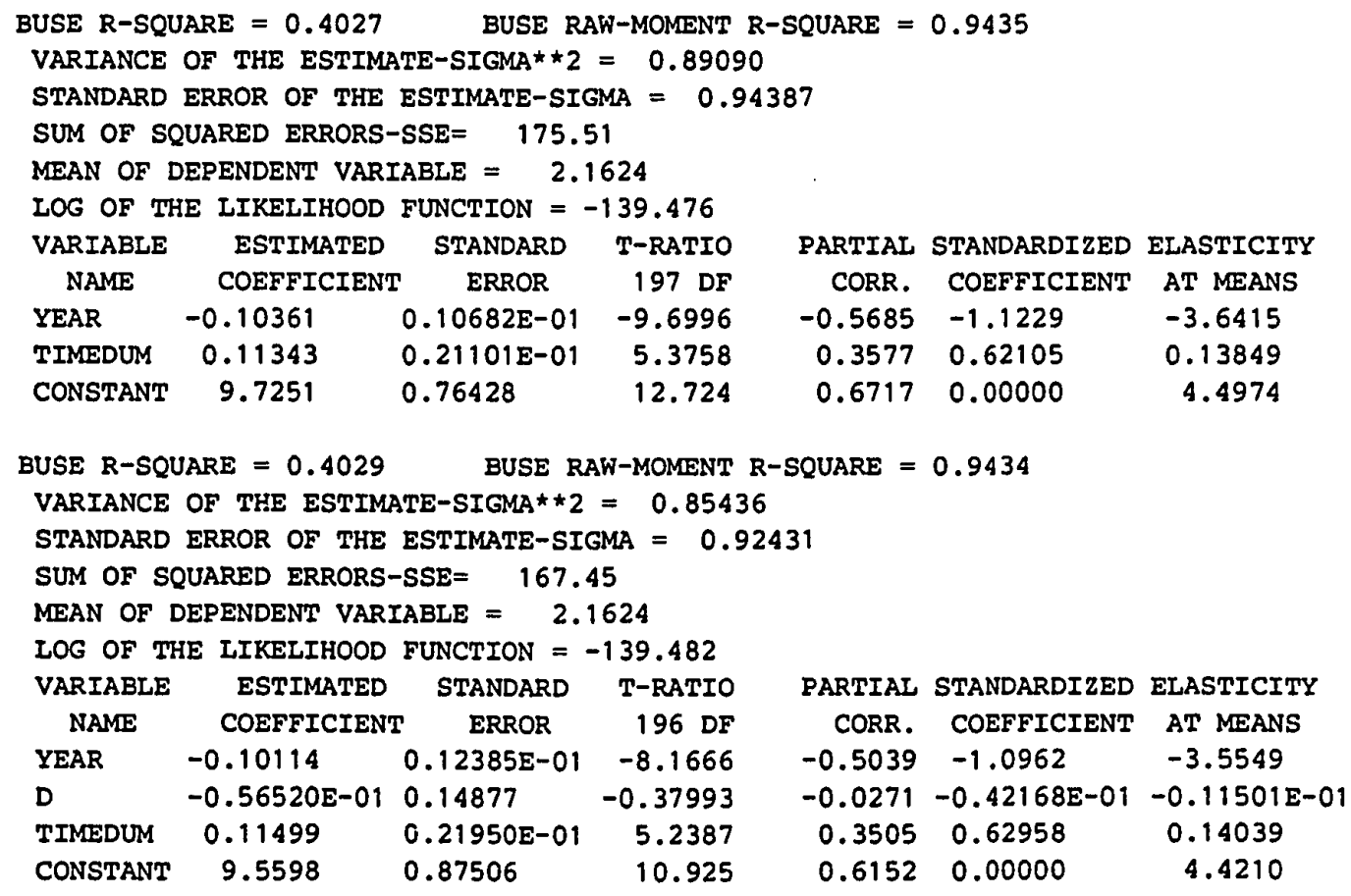


APPENDIX I

\section{RUNNING DEREGULATION DUMMY (continued)}

$\begin{array}{ccc}\text { YEAR } & \text { D } & \text { TIMEDUM } \\ 64.00000 & 0.0000000 & 0.0000000 \\ 65.00000 & 0.0000000 & 0.0000000 \\ 66.00000 & 0.0000000 & 0.0000000 \\ 67.00000 & 0.0000000 & 0.0000000 \\ 68.00000 & 0.0000000 & 0.0000000 \\ 69.00000 & 0.0000000 & 0.0000000 \\ 70.00000 & 0.0000000 & 0.0000000 \\ 71.00000 & 0.0000000 & 0.0000000 \\ 72.00000 & 0.0000000 & 0.0000000 \\ 73.00000 & 0.0000000 & 0.0000000 \\ 74.00000 & 0.0000000 & 0.0000000 \\ 75.00000 & 0.0000000 & 0.0000000 \\ 76.00000 & 0.0000000 & 0.0000000 \\ 77.00000 & 0.0000000 & 0.0000000 \\ 78.00000 & 0.0000000 & 0.0000000 \\ 79.00000 & 1.000000 & 1.000000 \\ 80.00000 & 1.000000 & 2.000000 \\ 81.00000 & 1.000000 & 3.000000 \\ 82.00000 & 1.000000 & 4.000000 \\ 83.00000 & 1.000000 & 5.000000 \\ 84.00000 & 1.000000 & 6.000000 \\ 85.00000 & 1.000000 & 7.000000 \\ 86.00000 & 1.000000 & 8.000000 \\ 87.00000 & 1.000000 & 9.000000 \\ 88.00000 & 1.000000 & 10.00000\end{array}$




\section{APPENDIX I \\ RUNNING DEREGULATION DUMMY (continued)}

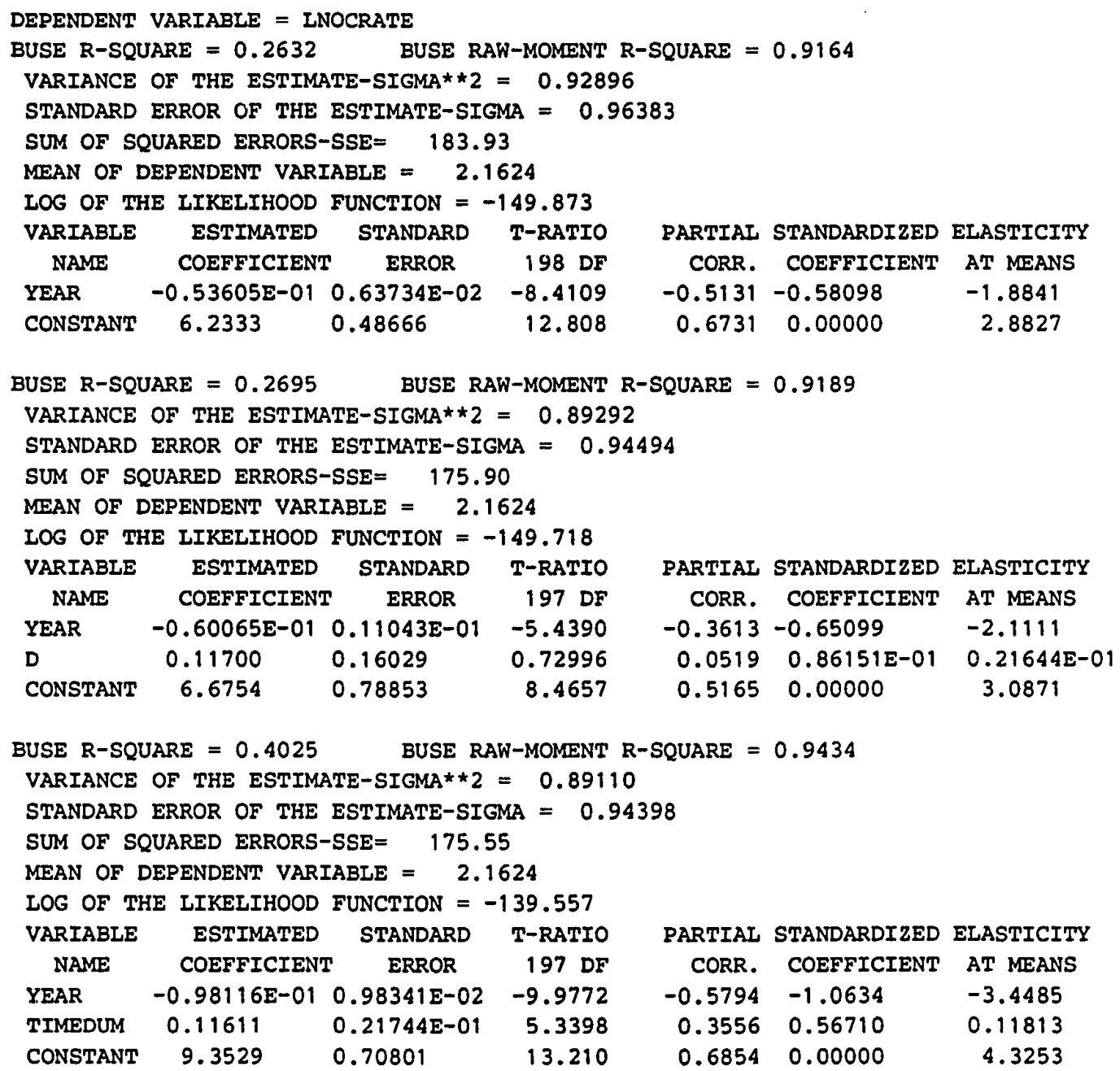

PARTIAL STANDARDIZED ELASTICITY CORR. COEFFICIENT AT MEANS $-0.5794-1.0634 \quad-3.4485$ $0.3556 \quad 0.56710 \quad 0.11813$ $0.6854 \quad 0.00000 \quad 4.3253$

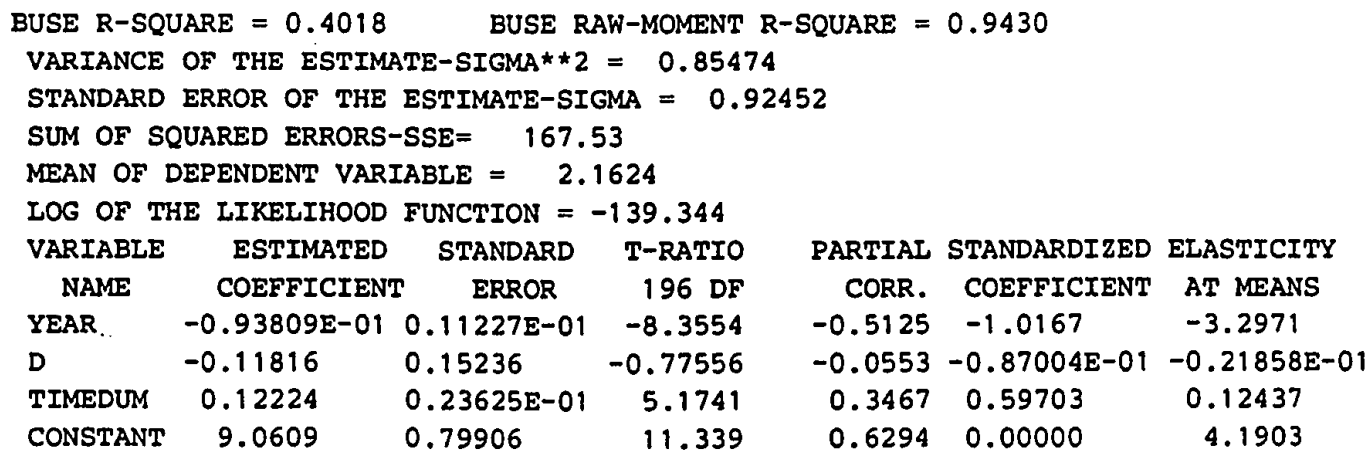


APPENDIX I

\section{RUNNING DEREGULATION DUMMY (continued)}

$\begin{array}{ccc}\text { YEAR } & \text { D } & \text { TIMEDUM } \\ 64.00000 & 0.0000000 & 0.0000000 \\ 65.00000 & 0.0000000 & 0.0000000 \\ 66.00000 & 0.0000000 & 0.0000000 \\ 67.00000 & 0.0000000 & 0.0000000 \\ 68.000000 & 0.0000000 & 0.0000000 \\ 69.00000 & 0.0000000 & 0.0000000 \\ 70.00000 & 0.0000000 & 0.0000000 \\ 71.000000 & 0.0000000 & 0.0000000 \\ 72.00000 & 0.0000000 & 0.0000000 \\ 73.00000 & 0.0000000 & 0.0000000 \\ 74.000000 & 0.0000000 & 0.0000000 \\ 75.00000 & 0.0000000 & 0.0000000 \\ 76.000000 & 0.0000000 & 0.0000000 \\ 77.00000 & 0.0000000 & 0.0000000 \\ 78.000000 & 0.0000000 & 0.0000000 \\ 79.00000 & 0.0000000 & 0.0000000 \\ 80.00000 & 1.000000 & 1.000000 \\ 81.00000 & 1.000000 & 2.000000 \\ 82.00000 & 1.000000 & 3.000000 \\ 83.00000 & 1.000000 & 4.000000 \\ 84.00000 & 1.000000 & 5.000000 \\ 85.00000 & 1.000000 & 6.000000 \\ 86.00000 & 1.000000 & 7.000000 \\ 87.000000 & 1.000000 & 8.000000 \\ 88.00000 & 1.000000 & 9.000000\end{array}$




\section{APPENDIX I \\ RUNNING DEREGULATION DUMMY (continued)}

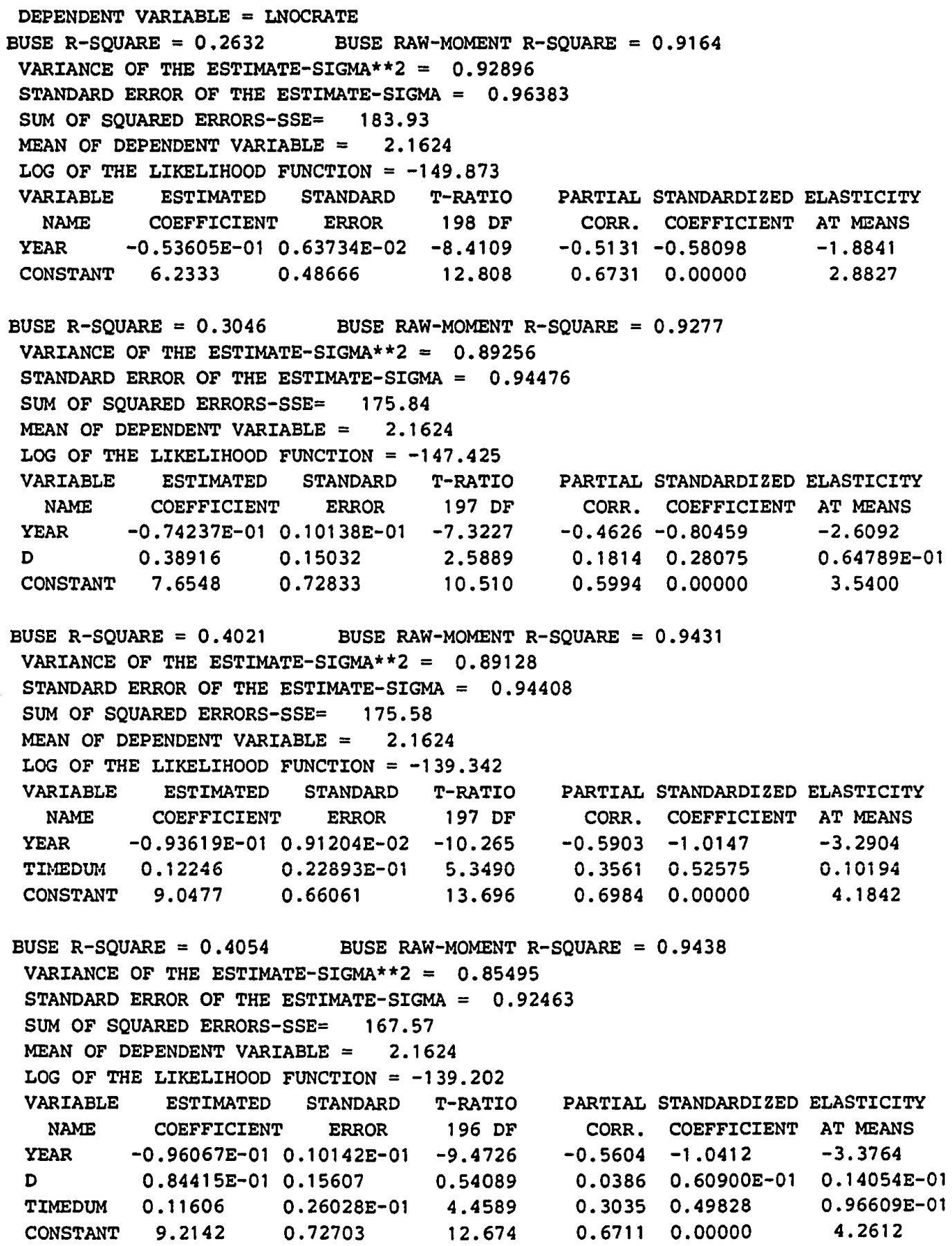

PARTIAL STANDARDIZED ELASTICITY CORR. COEFFICIENT AT MEANS $\begin{array}{lll}-0.5604 & -1.0412 & -3.3764\end{array}$ $0.0386 \quad 0.60900 \mathrm{E}-01 \quad 0.14054 \mathrm{E}-01$

$0.3035 \quad 0.49828 \quad 0.96609 \mathrm{E}-01$

$\begin{array}{lll}0.6711 & 0.00000 & 4.2612\end{array}$ 
APPENDIX I

\section{RUNNING DEREGULATION DUMMY (continued)}

$\begin{array}{ccc}\text { YEAR } & \text { D } & \text { TIMEDUM } \\ 64.00000 & 0.0000000 & 0.0000000 \\ 65.00000 & 0.0000000 & 0.0000000 \\ 66.00000 & 0.0000000 & 0.0000000 \\ 67.00000 & 0.0000000 & 0.0000000 \\ 68.00000 & 0.0000000 & 0.0000000 \\ 69.00000 & 0.0000000 & 0.0000000 \\ 70.00000 & 0.0000000 & 0.0000000 \\ 71.00000 & 0.0000000 & 0.0000000 \\ 72.00000 & 0.0000000 & 0.0000000 \\ 73.00000 & 0.0000000 & 0.0000000 \\ 74.00000 & 0.0000000 & 0.0000000 \\ 75.00000 & 0.0000000 & 0.0000000 \\ 76.00000 & 0.0000000 & 0.0000000 \\ 77.00000 & 0.0000000 & 0.0000000 \\ 78.00000 & 0.0000000 & 0.0000000 \\ 79.00000 & 0.0000000 & 0.0000000 \\ 80.00000 & 0.0000000 & 0.0000000 \\ 81.00000 & 1.000000 & 1.000000 \\ 82.00000 & 1.000000 & 2.000000 \\ 83.00000 & 1.000000 & 3.000000 \\ 84.00000 & 1.000000 & 4.000000 \\ 85.00000 & 1.000000 & 5.000000 \\ 86.00000 & 1.000000 & 6.000000 \\ 87.00000 & 1.000000 & 7.000000 \\ 88.00000 & 1.000000 & 8.000000\end{array}$




\section{APPENDIX I \\ RUNNING DEREGULATION DUMMY (continued)}

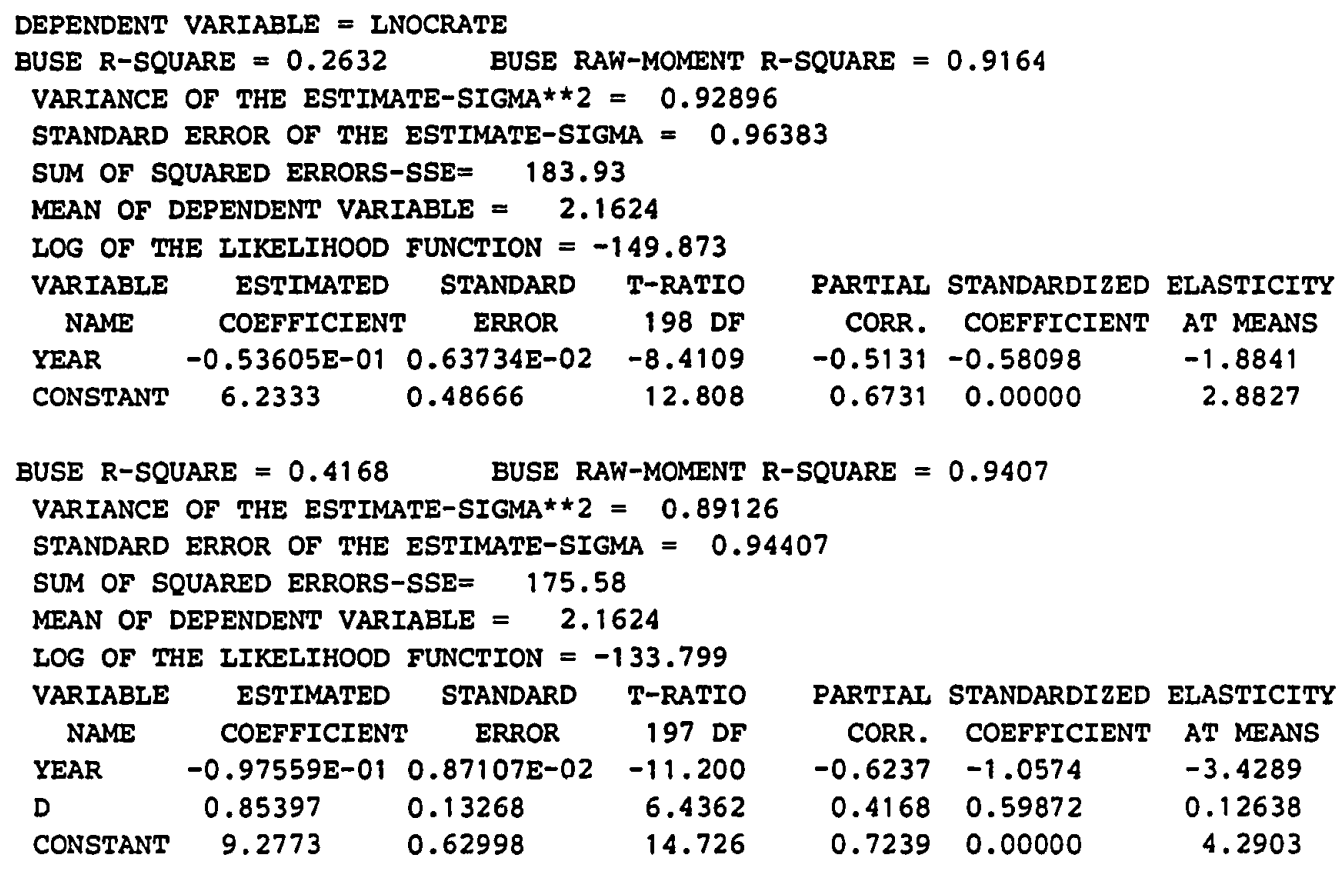

BUSE R-SQUARE $=0.3923$ BUSE RAW-MOMENT R-SQUARE $=0.9413$

VARIANCE OF THE ESTIMATE-SIGMA $\star 2=0.89154$

STANDARD ERROR OF THE ESTIMATE-SIGMA $=0.94421$

SUM OF SQUARED ERRORS-SSE $=175.63$

MEAN OF DEPENDENT VARIABLE $=2.1624$

LOG OF THE LIKELIHOOD FUNCTION $=-140.023$

VARIABLE ESTIMATED STANDARD T-RATIO NAME COEFFICIENT ERROR 197 DF

YEAR $\quad-0.88379 E-01 \quad 0.86145 E-02 \quad-10.259$

TIMEDUM $0.12745 \quad 0.24955 E-01 \quad 5.1074$

PARTIAL STANDARDIZED ELASTICITY CORR. COEFFICIENT AT MEANS

$\begin{array}{llll}\text { CONSTANT } & 8.6873 & 0.62767 & 13.841\end{array}$

$-0.5901-0.95787 \quad-3.1062$

$0.3419 \quad 0.47258 \quad 0.84875 \mathrm{E}-01$

$\begin{array}{lll}0.7021 & 0.00000 & 4.0175\end{array}$

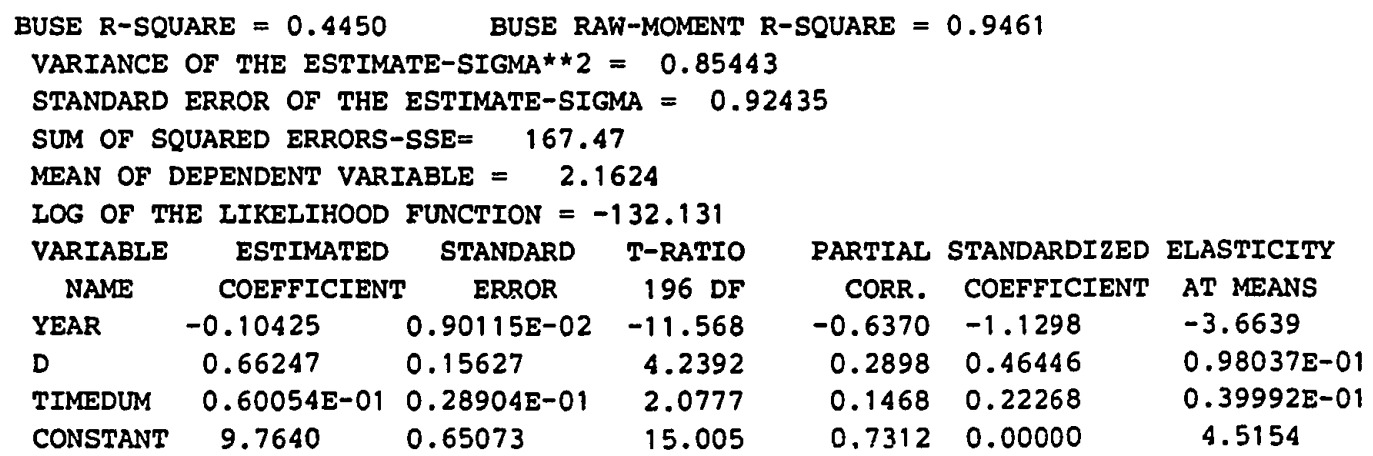


APPENDIX I

\section{RUNNING DEREGULATION DUMMY (continued)}

$\begin{array}{ccc}\text { YEAR } & \text { D } & \text { TIMEDUM } \\ 64.00000 & 0.0000000 & 0.0000000 \\ 65.00000 & 0.0000000 & 0.0000000 \\ 66.00000 & 0.0000000 & 0.0000000 \\ 67.00000 & 0.0000000 & 0.0000000 \\ 68.00000 & 0.0000000 & 0.0000000 \\ 69.00000 & 0.0000000 & 0.0000000 \\ 70.00000 & 0.0000000 & 0.0000000 \\ 71.00000 & 0.0000000 & 0.0000000 \\ 72.00000 & 0.0000000 & 0.0000000 \\ 73.00000 & 0.0000000 & 0.0000000 \\ 74.00000 & 0.0000000 & 0.0000000 \\ 75.00000 & 0.0000000 & 0.0000000 \\ 76.00000 & 0.0000000 & 0.0000000 \\ 77.00000 & 0.0000000 & 0.0000000 \\ 78.00000 & 0.0000000 & 0.0000000 \\ 79.00000 & 0.0000000 & 0.0000000 \\ 80.00000 & 0.0000000 & 0.0000000 \\ 81.00000 & 0.00000000 & 0.0000000 \\ 82.00000 & 1.000000 & 1.000000 \\ 83.00000 & 1.000000 & 2.000000 \\ 84.00000 & 1.000000 & 3.000000 \\ 85.00000 & 1.000000 & 4.000000 \\ 86.00000 & 1.000000 & 5.000000 \\ 87.00000 & 1.000000 & 6.000000 \\ 88.00000 & 1.000000 & 7.000000 \\ & & \end{array}$




\section{APPENDIX I \\ RUNNING DEREGULATION DUMMY (continued)}

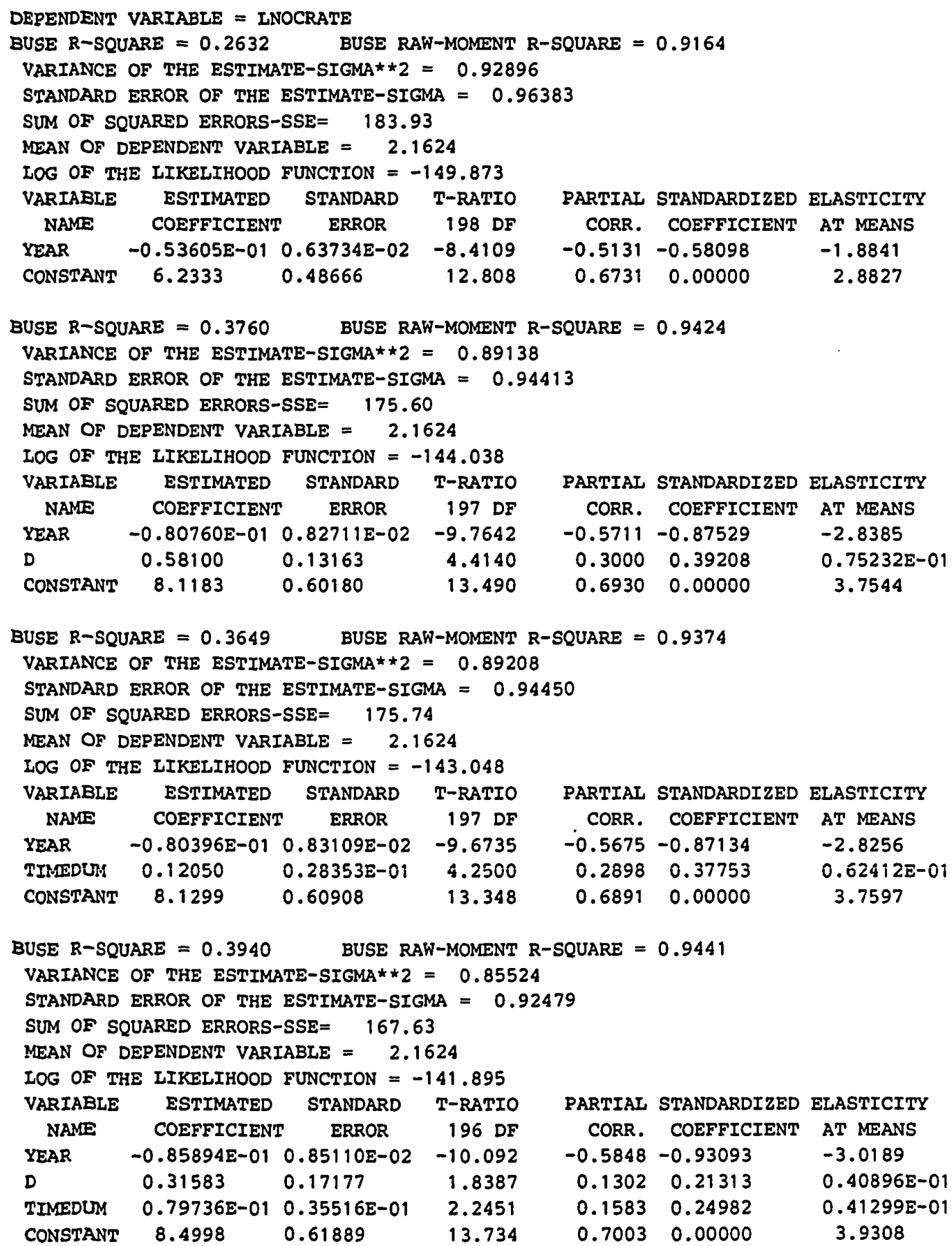

PARTIAL STANDARDIZED ELASTICITY CORR. COEFFICIENT AT MEANS $\begin{array}{lll}-0.5848 & -0.93093 & -3.0189\end{array}$ $\begin{array}{lll}0.1302 & 0.21313 & 0.40896 \mathrm{E}-01\end{array}$

$0.1583 \quad 0.24982$

$0.7003 \quad 0.00000$ 
APPENDIX L

\section{RUNNING DEREGULATION DUMMY} (continued)

$\begin{array}{ccr}\text { YEAR } & \text { D } & \text { TIMEDUA } \\ 64.00000 & 0.0000000 & 0.0000000 \\ 65.00000 & 0.0000000 & 0.0000000 \\ 66.00000 & 0.0000000 & 0.0000000 \\ 67.00000 & 0.0000000 & 0.0000000 \\ 68.00000 & 0.0000000 & 0.0000000 \\ 69.00000 & 0.0000000 & 0.0000000 \\ 70.00000 & 0.0000000 & 0.0000000 \\ 71.00000 & 0.0000000 & 0.0000000 \\ 72.00000 & 0.0000000 & 0.0000000 \\ 73.00000 & 0.0000000 & 0.0000000 \\ 74.00000 & 0.0000000 & 0.0000000 \\ 75.00000 & 0.0000000 & 0.0000000 \\ 76.00000 & 0.0000000 & 0.0000000 \\ 77.00000 & 0.0000000 & 0.0000000 \\ 78.00000 & 0.0000000 & 0.0000000 \\ 79.00000 & 0.0000000 & 0.0000000 \\ 80.00000 & 0.0000000 & 0.0000000 \\ 81.00000 & 0.0000000 & 0.0000000 \\ 82.00000 & 0.0000000 & 0.0000000 \\ 83.00000 & 1.000000 & 1.000000 \\ 84.00000 & 1.000000 & 2.000000 \\ 85.00000 & 1.000000 & 3.000000 \\ 86.00000 & 1.000000 & 4.000000 \\ 87.00000 & 1.000000 & 5.000000 \\ 88.00000 & 1.000000 & 6.000000\end{array}$




\section{APPENDIX I \\ RUNNING DEREGULATION DUMMY (continued)}

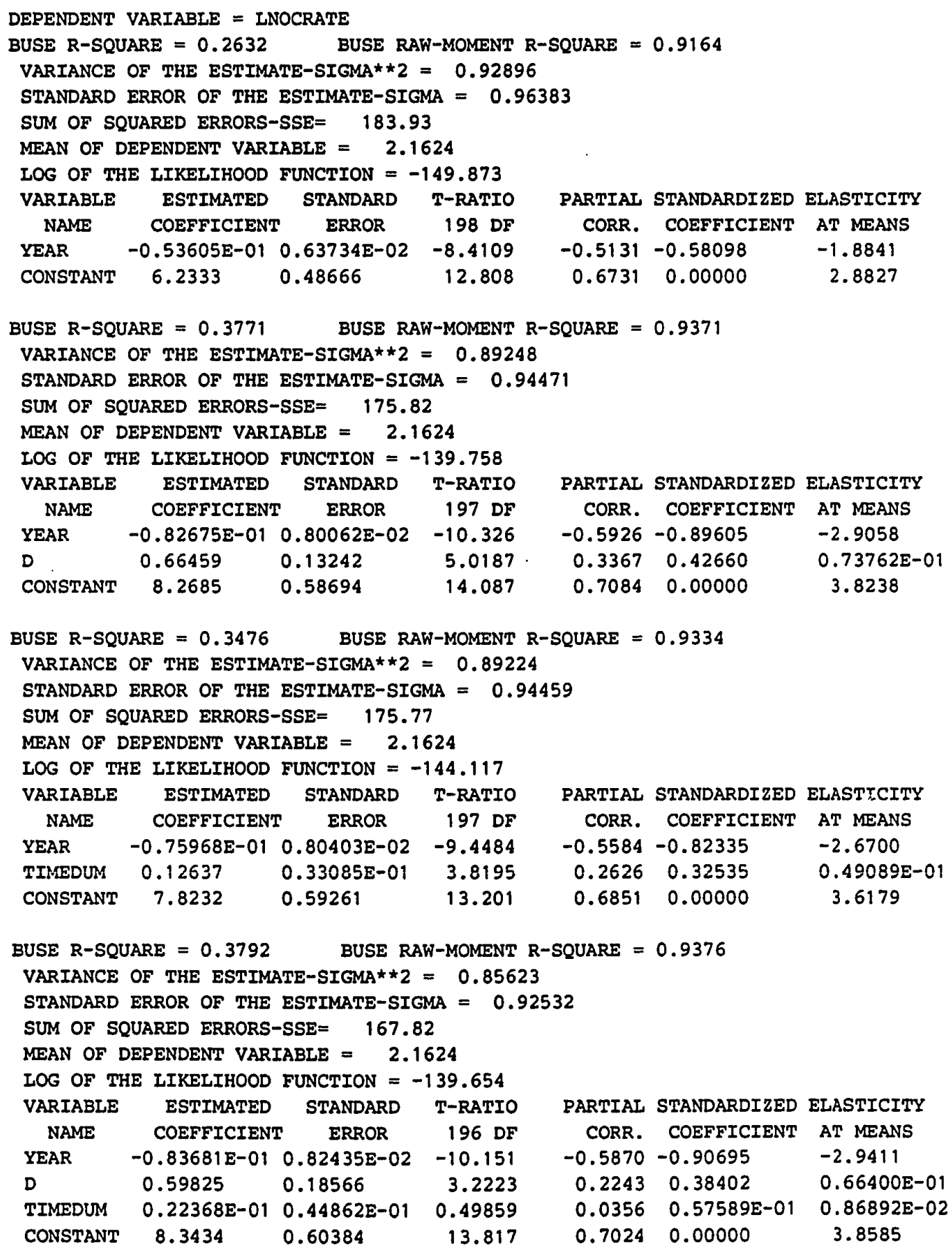


APPENDIX I

\section{RUNNING DEREGULATION DUMMY (continued)}

YEAR
64.00000
65.00000
66.00000
67.00000
68.00000
69.00000
70.00000
71.00000
72.00000
73.00000
74.00000
75.00000
76.00000
77.00000
78.00000
79.00000
80.00000
81.00000
82.00000
83.00000
84.00000
85.00000
86.00000
87.00000
88.00000

D TIMEDUM

$0.0000000 \quad 0.0000000$

0.0000000

0.0000000

0.0000000

0.0000000

0.0000000

0.0000000

0.0000000

0.0000000

0.0000000

0.0000000

0.0000000

0.0000000

0.0000000

0.0000000

0.0000000

0.0000000

0.0000000

0.0000000

0.0000000

0.0000000

0.0000000

1.000000

2.000000

3.000000

4.000000

5.000000 


\section{APPENDIX L \\ RUNNING DEREGULATION DUMMY (continued)}

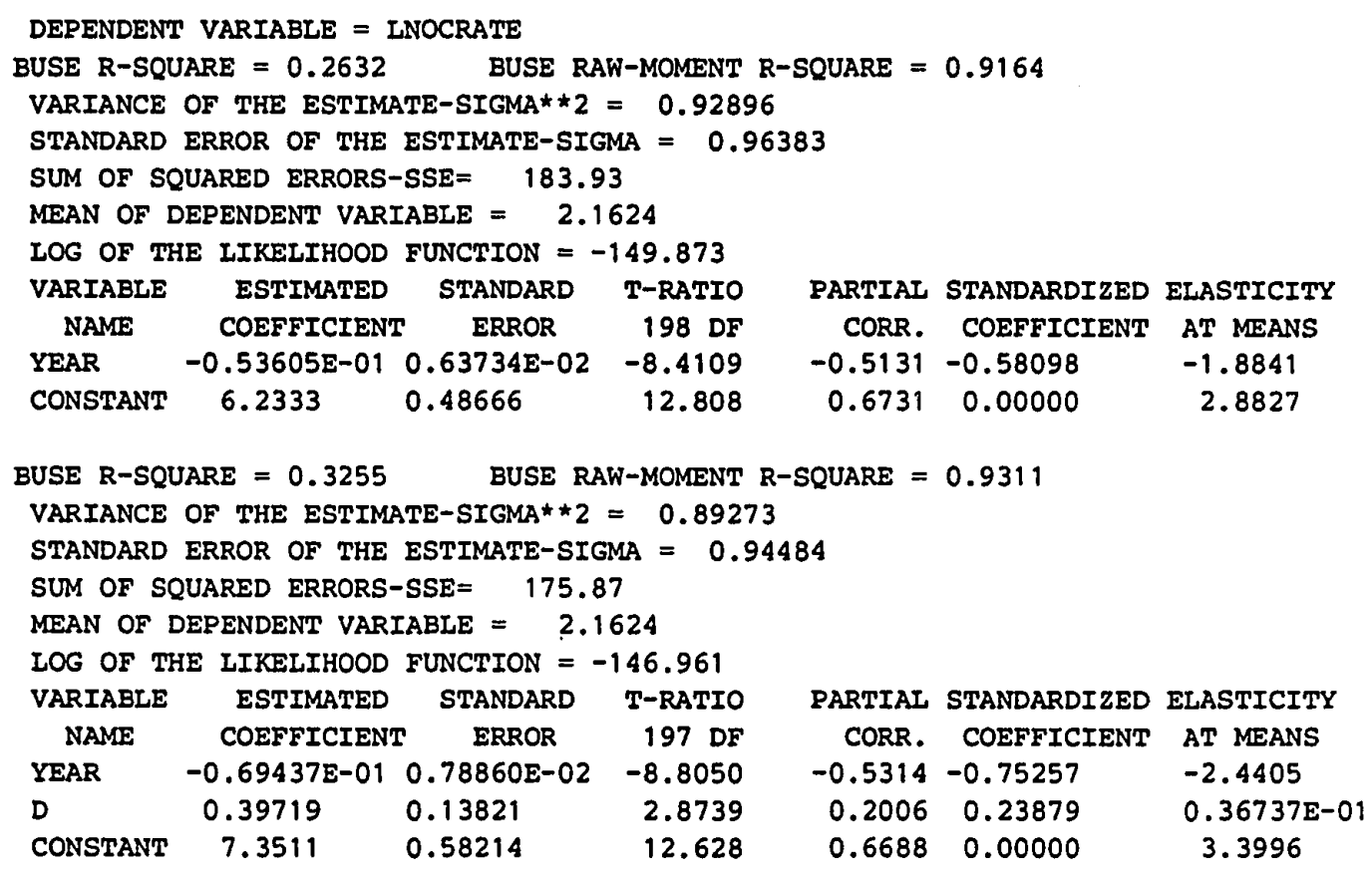

PARTIAL STANDARDIZED ELASTICITY CORR. COEFFICIENT AT MEANS $-0.5392-0.75680 \quad-2.4542$ $0.2114 \quad 0.24706 \quad 0.33625 E-01$ $0.6747 \quad 0.00000$

BUSE R-SQUARE $=0.3345 \quad$ BUSE RAW-MOMENT R-SQUARE $=0.9322$

VARIANCE OF THE ESTIMATE-SIGMA**2 $=0.85613$

STANDARD ERROR OF THE ESTIMATE-SIGMA $=0.92527$

SUM OF SQUARED ERRORS-SSE $=167.80$

MEAN OF DEPENDENT VARIABLE $=2.1624$

LOG OF THE IIKELIHOOD FUNCTION $=-146.031$

VARIABLE ESTIMATED STANDARD T-RATIO

NAME COEFFICIENT ERROR 196 DF

YEAR $-0.71826 E-01 \quad 0.79984 E-02 \quad-8.9800$

$\begin{array}{llll}D & 0.18253 & 0.20893 & 0.87366\end{array}$

TIMEDUM $\quad 0.82623 \mathrm{E}-01 \quad 0.59849 \mathrm{E}-01 \quad 1.3805$

$\begin{array}{llll}\text { CONSTANT } & 7.5273 & 0.59004 & 12.757\end{array}$

PARTIAL STANDARDIZED ELASTICITY CORR. COEFFICIENT AT MEANS

$\begin{array}{lll}-0.5399 & -0.77846 \quad-2.5244\end{array}$

$0.0623 \quad 0.10974 \quad 0.16883 \mathrm{E}-01$

$0.0981 \quad 0.16845 \quad 0.22926 \mathrm{E}-01$

$\begin{array}{lll}0.6735 & 0.00000 \quad 3.4810\end{array}$ 
APPENDIX I

\section{RUNNING DEREGULATION DUMMY (continued)}

$\begin{array}{ccc}\text { YEAR } & \text { D } & \text { TIMEDUM } \\ 64.00000 & 0.0000000 & 0.0000000 \\ 65.00000 & 0.0000000 & 0.0000000 \\ 66.00000 & 0.0000000 & 0.0000000 \\ 67.00000 & 0.0000000 & 0.0000000 \\ 68.00000 & 0.0000000 & 0.0000000 \\ 69.00000 & 0.0000000 & 0.0000000 \\ 70.00000 & 0.0000000 & 0.0000000 \\ 71.00000 & 0.0000000 & 0.0000000 \\ 72.00000 & 0.0000000 & 0.0000000 \\ 73.00000 & 0.0000000 & 0.0000000 \\ 74.00000 & 0.0000000 & 0.0000000 \\ 75.00000 & 0.0000000 & 0.0000000 \\ 76.00000 & 0.0000000 & 0.0000000 \\ 77.00000 & 0.0000000 & 0.0000000 \\ 78.00000 & 0.0000000 & 0.0000000 \\ 79.00000 & 0.0000000 & 0.0000000 \\ 80.00000 & 0.0000000 & 0.0000000 \\ 81.00000 & 0.0000000 & 0.0000000 \\ 82.00000 & 0.0000000 & 0.0000000 \\ 83.00000 & 0.0000000 & 0.0000000 \\ 84.00000 & 0.0000000 & 0.0000000 \\ 85.00000 & 1.000000 & 1.000000 \\ 86.00000 & 1.000000 & 2.000000 \\ 87.00000 & 1.000000 & 3.000000 \\ 88.00000 & 1.000000 & 4.000000\end{array}$




\section{APPENDIX I \\ RUNNING DEREGULATION DUMMY (continued)}

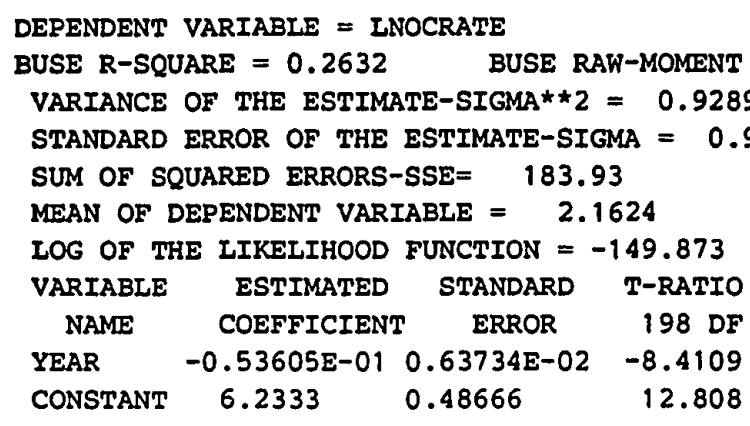
PARTIAL STANDARDIZED ELASTICITY CORR. COEFFICIENT AT MEANS $\begin{array}{lll}-0.5131 & -0.58098 & -1.8841\end{array}$ $\begin{array}{lll}0.6731 & 0.00000 & 2.8827\end{array}$
PARTIAL STANDARDIZED ELASTICITY CORR. COEFFICIENT AT MEANS $\begin{array}{lll}-0.5237 & -0.70839 & -2.2972\end{array}$ $0.1666 \quad 0.18613 \quad 0.24995 E-01$ $\begin{array}{lll}0.6668 & 0.00000 & 3.2699\end{array}$

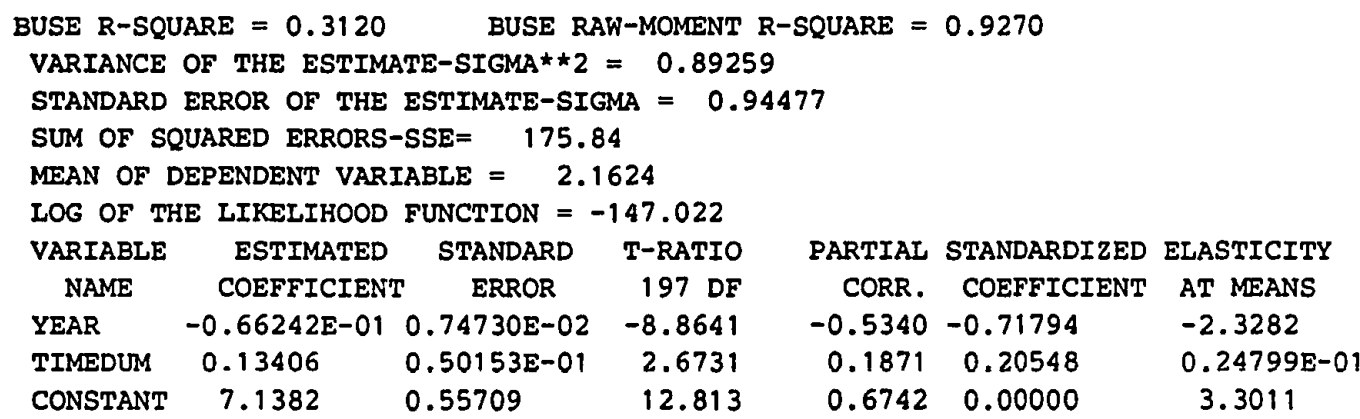

PARTIAL STANDARDIZED ELASTICITY CORR. COEFFICIENT AT MEANS $-0.5340-0.71794 \quad-2.3282$ $0.1871 \quad 0.20548 \quad 0.24799 \mathrm{E}-01$ $\begin{array}{lll}0.6742 & 0.00000 & 3.3011\end{array}$

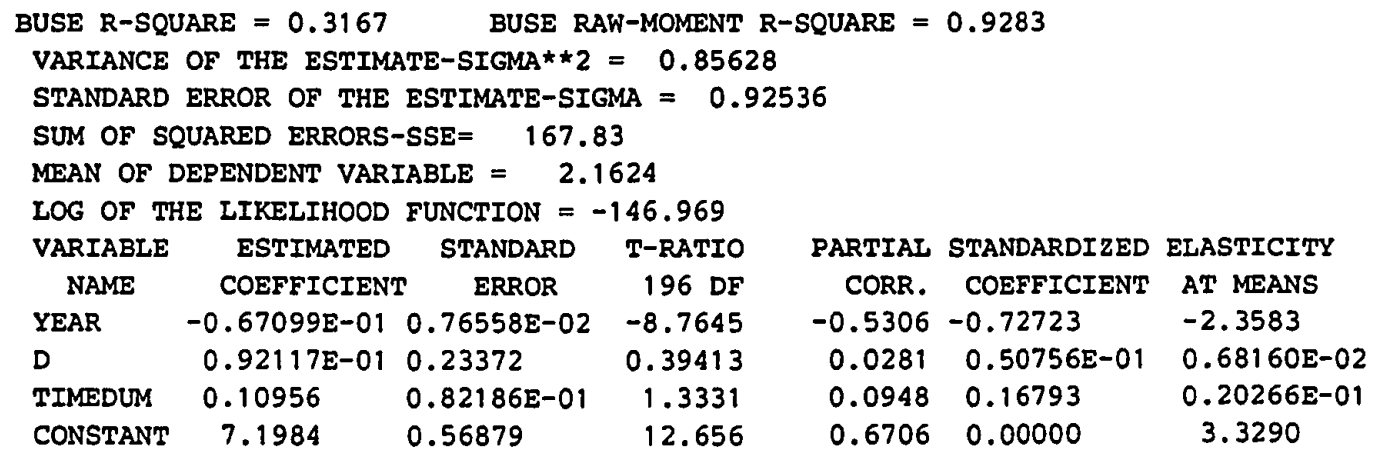


APPENDIX M

NOT CONTROLLABLE 
APPENDIX M

NOT CONTROLLABLE

COMMAND FILE

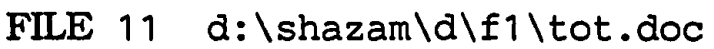

sample 125

read(11) year d totocc y n u hours

* generate controlable rate

genr ucrate $=((1000000 * n)) /$ hours

* generate log of the controlable rate genr Inucrate = log (ucrate)

* generate time since deregulation dummy

genr timedum $=d^{*}$ (year - 79)

print $n$ hours ucrate lnucrate year timedum

$\begin{array}{lllll}\text { ols Incrate year } & & \text { /exactdw } \\ \text { ols Incrate year d } & \text { lexactdw } \\ \text { ols incrate year } & \text { timedum } & \begin{array}{l}\text { /exactdw } \\ \text { ols incrate year d }\end{array} \text { timedum lexactdw }\end{array}$

delete / all 


\section{APPENDIX M \\ NOT CONTROLLABLE \\ (continued)}

\section{OUTPUT FILE}

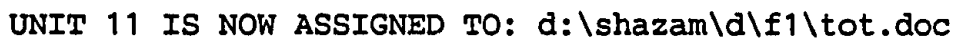

7 VARIABLES AND

$\begin{array}{ll}\text { N } & \text { HOURS } \\ 9 & 2441185 . \\ 11 & 2691129 . \\ 8 & 2819170 . \\ 10 & 3507054 . \\ 10 & 4015838 . \\ 10 & 4336713 . \\ 13 & 4294706 . \\ 14 & 4224634 . \\ 15 & 4204233 . \\ 8 & 4346571 . \\ 14 & 3997587 . \\ 10 & 3936489 . \\ 11 & 4024069 . \\ 6 & 4135728 . \\ 7 & 4166439 . \\ 5 & 4329449 . \\ 2 & 4439343 . \\ 4 & 4049954 . \\ 3 & 4016962 . \\ 6 & 4197657 . \\ 8 & 4547810 . \\ 6 & 4744502 . \\ 13 & 5389885 . \\ 21 & 6921046 . \\ 22 & 7166746 .\end{array}$

25 OBSERVATIONS STARTING AT OBS

$\begin{array}{rcrl}\text { UCRATE } & \text { LNUCRATE } & \text { YEAR } & \text { TIMEDUM } \\ 3.686734 & 1.304741 & 64 & 0.00 \\ 4.087504 & 1.407934 & 65 & 0.00 \\ 2.837715 & 1.042999 & 66 & 0.00 \\ 2.851396 & 1.047809 & 67 & 0.00 \\ 2.490140 & 0.9123391 & 68 & 0.00 \\ 2.305894 & 0.8354684 & 69 & 0.00 \\ 3.026983 & 1.107566 & 70 & 0.00 \\ 3.313897 & 1.198125 & 71 & 0.00 \\ 3.567833 & 1.271958 & 72 & 0.00 \\ 1.840531 & 0.6100543 & 73 & 0.00 \\ 3.502113 & 1.253366 & 74 & 0.00 \\ 2.540335 & 0.9322959 & 75 & 0.00 \\ 2.733552 & 1.005602 & 76 & 0.00 \\ 1.450772 & 0.3720961 & 77 & 0.00 \\ 1.680092 & 0.5188484 & 78 & 0.00 \\ 1.154881 & 0.1439976 & 79 & 0.00 \\ 0.4505171 & -0.7973592 & 80 & 1.0 \\ 0.9876655 & -0.1241116 E-01 & 81 & 2.0 \\ 0.7468331 & -0.2919136 & 82 & 3.0 \\ 1.429369 & 0.3572330 & 83 & 4.0 \\ 1.759088 & 0.5647957 & 84 & 5.0 \\ 1.264622 & 0.2347730 & 85 & 6.0 \\ 2.411925 & 0.8804253 & 86 & 7.0 \\ 3.034223 & 1.109956 & 87 & 8.0 \\ 3.069733 & 1.121591 & 88 & 9.0\end{array}$




\section{APPENDIX M \\ NOT CONTROLLABLE \\ (continued)}

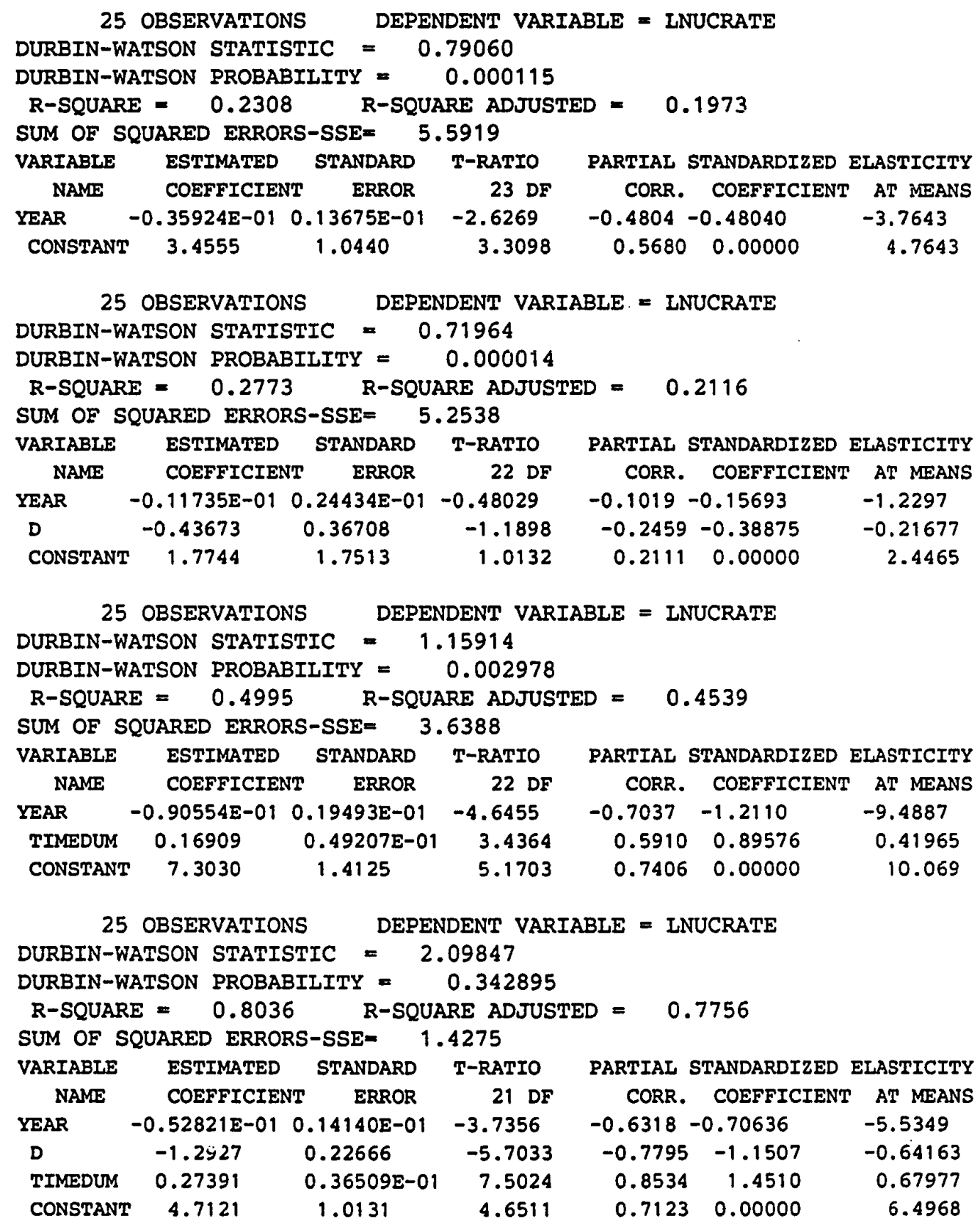


APPENDIX N

POOLED CROSS-SECTIONALLY HETEROSKEDASTIC AND TIME-WISE AUTOREGRESSIVE USING REVENUE PASSENGER MILES 
APPENDIX N

POOLED CROSS-SECTIONALLY HETEROSKEDASTIC AND TIME-WISE

AUTOREGRESSIVE USING REVENUE PASSENGER MILES

COMMAND FILE

FILE 11 d: \shazam\d\f1\agrrpm.doc

sample 1200

read(11) airline year d totocc $y \mathrm{n} u$ hours $\mathrm{rpm}$

* generate controllable rate

genr ocrate $=(1000000 *(y+1)) / \mathrm{rpm}$

* generate log of the controllable rate

genr Inocrate $=\log$ (ocrate)

* generate time since deregulation dummy

genr timedum $=d *$ (year - 79)

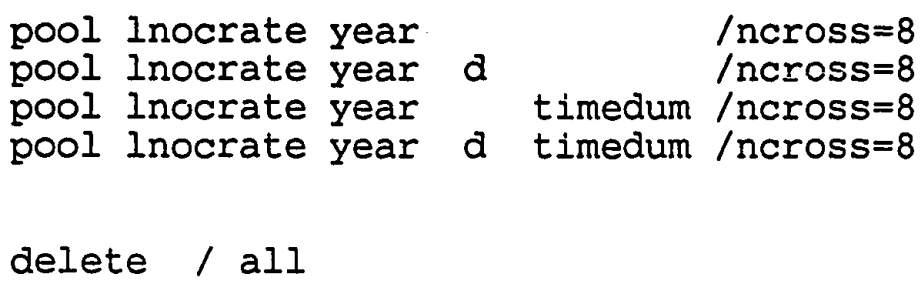

delete / all 
APPENDIX N

POOLED CROSS-SECTIONALLY HETEROSKEDASTIC AND TIME-WISE

AUTOREGRESSIVE USING REVENUE PASSENGER MILES

(continued)

OUTPUT FILE

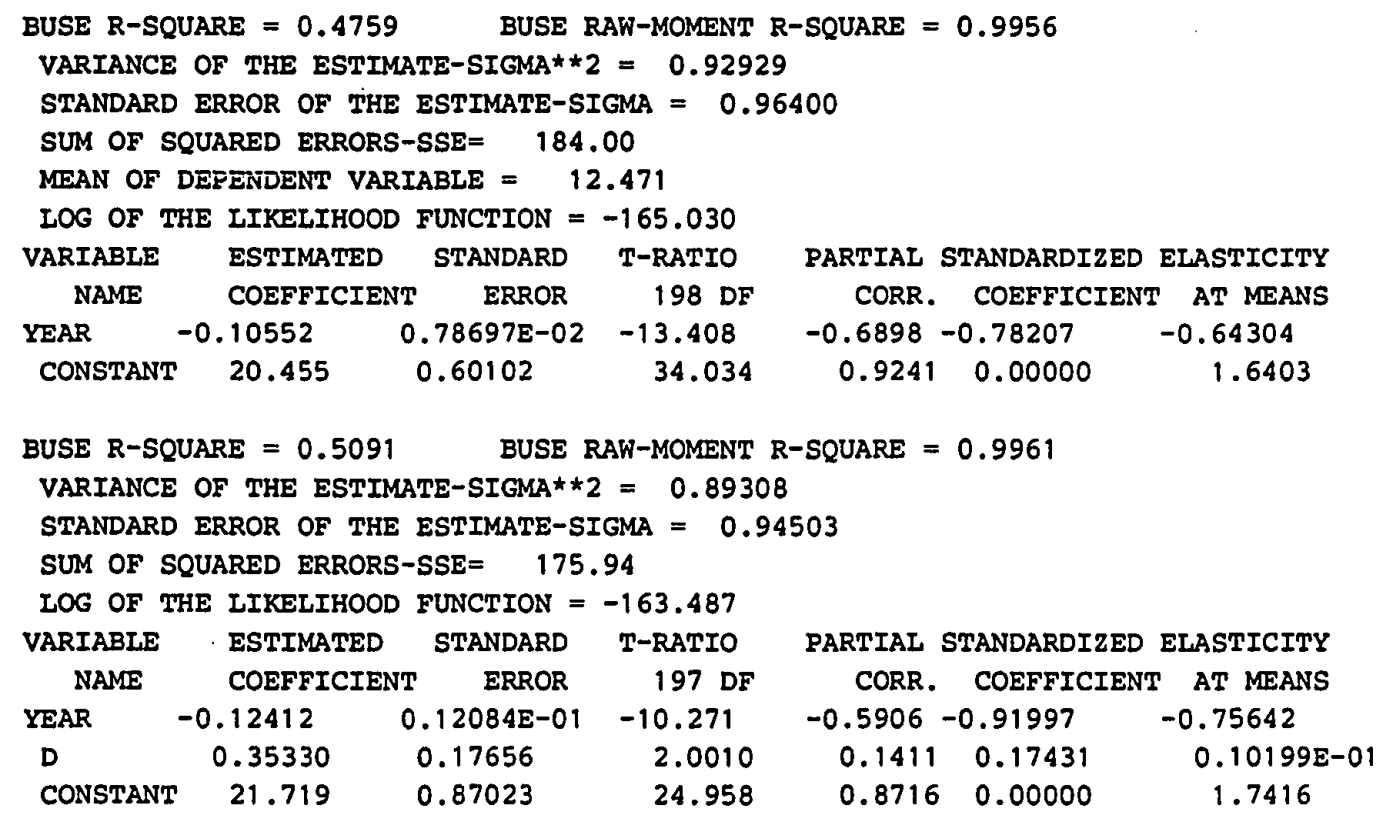

BUSE R-SQUARE $=0.6223$ BUSE RAW-MOMENT R-SQUARE $=0.9973$

VARIANCE OF THE ESTIMATE-SIGMA $* 2=0.89288$

STANDARD ERROR OF THE ESTIMATE-SIGMA $=0.94493$

SUM OF SQUARED ERRORS-SSE $=175.90$

LOG OF THE LIKELIHOOD FUNCTION $=-150.636$

VARIABLE ESTIMATED STANDARD T-RATIO

$\begin{array}{lllllll}\text { YEAR } & -0.15816 & 0.10717 E-01 & -14.758 & -0.7246 & -1.1723 & -0.96386\end{array}$

$\begin{array}{lllllll}\text { TIMEDUM } & 0.16144 & 0.26759 \mathrm{E}-01 & 6.0331 & 0.3949 & 0.47400 & 0.23302 \mathrm{E}-01\end{array}$

$\begin{array}{lllllll}\text { CONSTANT } & 24.117 & 0.77592 & 31.082 & 0.9114 & 0.00000 & 1.9339\end{array}$

BUSE R-SQUARE $=0.6221$ BUSE RAW-MOMENT R-SQUARE $=0.9973$

VARIANCE OF THE ESTIMATE-SIGMA $\star 2=0.85647$

STANDARD ERROR OF THE ESTIMATE-SIGMA $=0.92546$

SUM OF SQUARED ERRORS-SSE $=167.87$

LOG OF THE LIKELIHOOD FUNCTION $=-150.553$

VARIABLE ESTIMATED STANDARD T-RATIO

NAME COEFFICIENT ERROR 196 DF

YEAR $\quad-0.15617 \quad 0.11849 E-01 \quad-13.180$

PARTIAL STANDARDIZED ELASTICITY CORR. COEFFICIENT AT MEANS

$\begin{array}{lll}-0.6855 & -1.1576 & -0.95177\end{array}$

$D \quad-0.62189 E-010.17573 \quad-0.35389 \quad-0.0253-0.30682 E-01-0.17952 E-02$

$\begin{array}{lllllll}\text { TIMEDUM } & 0.16640 & 0.30232 \mathrm{E}-01 & 5.5041 & 0.3659 & 0.48857 & 0.24018 \mathrm{E}-01\end{array}$

$\begin{array}{lrlllll}\text { CONSTANT } & 23.979 & 0.84972 & 28.220 & 0.8958 & 0.00000 & 1.9228\end{array}$ 